UNIVERSIDAD POLITÉCNICA DE VALENCIA DEPARTAMENTO DE INGENIERÍA CARTOGRÁFICA GEODESIA Y FOTOGRAMETRÍA

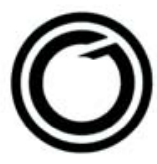

\title{
PROPUESTA DE NORMALIZACIÓN CARTOGRÁFICA PARA EL DESARROLLO TERRITORIAL
}

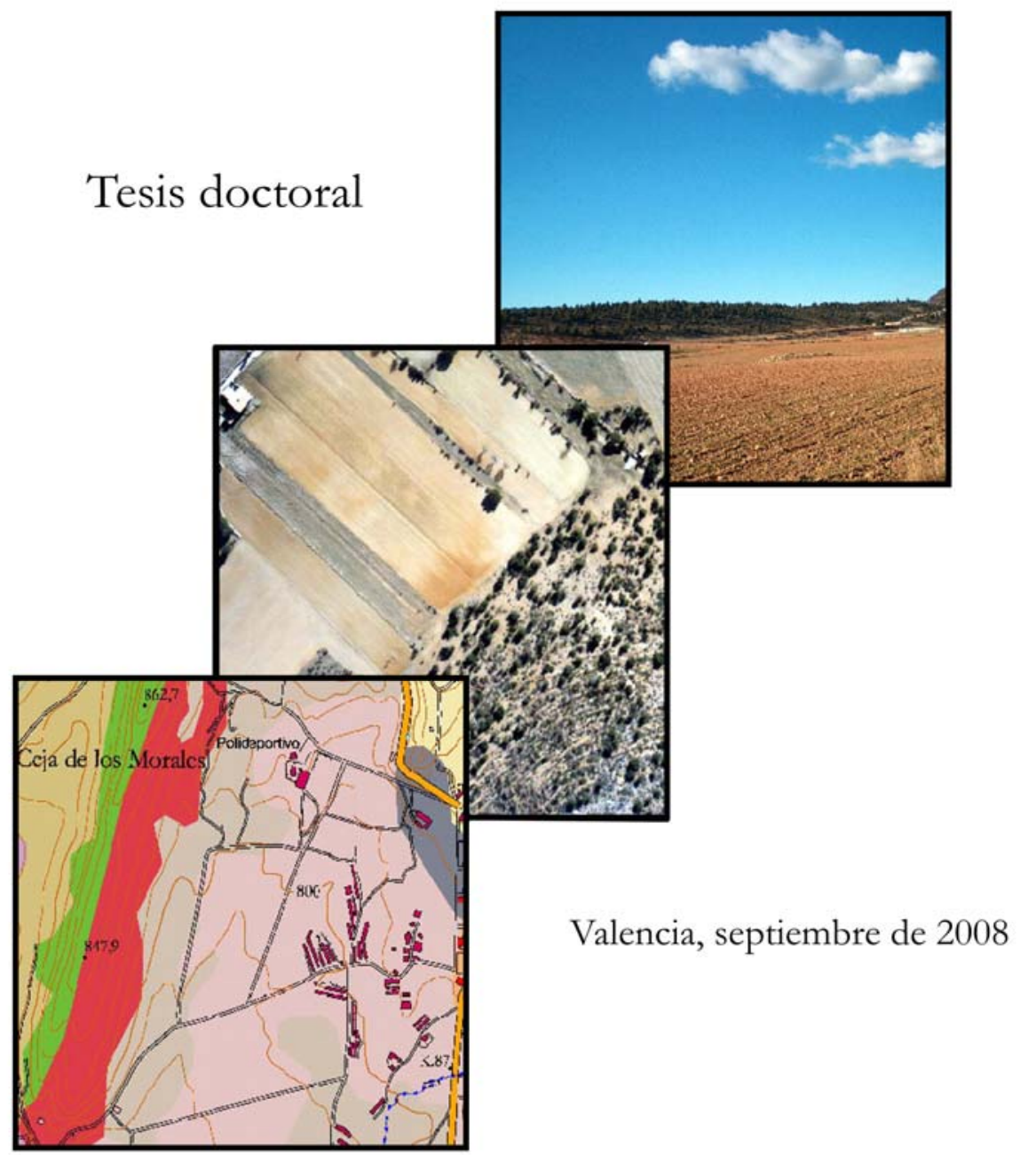

Autora: Natalia Garrido Villén

Director: Dr. D. José Luis Berné Valero 

Hazlo o no lo hagas, pero no lo intentes

Yoda 



\section{Agradecimientos}

En primer lugar gracias a Alberto, mi compañero de viaje, por su apoyo, ideas, criticas y su ayuda, sin la cual hubiese sido imposible terminar esta tesis.

Gracias a mis padres por aguantarme en los momentos de mayor agobio, por su apoyo incondicional y por conseguir que no fuese tan duro "abandonar" cada día a Joel un ratito para terminar la tesis.

Gracias a Joel e Isis, que han compartido a su madre con este trabajo aunque no hayan sido del todo conscientes.

Todo mi agradecimiento para mi director de Tesis, José Luis Berné, por sus ideas, consejos, y por presionarme lo justo para que por fin terminara el trabajo.

$Y$ por último gracias a todas las personas y entidades que me han facilitado la tarea y me han aportado ideas e información para llevarla a cabo; especialmente agradecer a Emilio Forcén la facilidad de acceso a todo el trabajo realizado por el Instituto Cartográfico Valenciano y gracias a Joan Romero por ofrecerme otro punto de vista. 



\section{Resumen}

El reciente interés mostrado por las administraciones públicas en lo que respecta al tema del estudio y protección del Paisaje, y su estrecha relación con la Ordenación del Territorio, nos ha llevado a examinar la participación que el cartógrafo pudiese tener tanto en la elaboración de documentos base, como de estudios previos o cartografía resultado de los mismos.

En este trabajo se ha tratado de sentar unas bases teóricas que nos permitan acercarnos al mundo de la Ordenación del Territorio y la Protección del Paisaje desde el punto de vista del cartógrafo; asimismo, a partir de la información analizada se ha elaborado una propuesta de normalización para la realización de cartografía relacionada con los temas en estudio.

Con el fin de elaborar la propuesta de normalización se ha estudiado con especial atención la cartografía oficial que existe en la actualidad en España, considerando especialmente la generada por el Instituto Geográfico Nacional, el Catastro y el Instituto Cartográfico Valenciano.

Para comprobar la utilidad del trabajo realizado se ha aplicado la normalización propuesta a un municipio de la provincia de Valencia, Titaguas, generando la cartografía que se ha considerado necesaria para el desarrollo de un proyecto del tipo que nos ocupa. 


\section{Resum}

El recent interés mostrat per les administracions públiques pel que fa al tema de l'estudi i protecció del Paisatge, i la seua estreta relació amb l'Ordenació del Territori, ens ha portat a examinar la participació que el cartògraf poguera tindre tant en l'elaboració de documents base, com d'estudis previs o en cartografia resultat.

En este treball s'ha tractat d'assentar unes bases teòriques que ens permeten acostar-nos al món de l'Ordenació del Territori i la Protecció del Paisatge des del punt de vista del cartògraf; així mateix, a partir de la informació analitzada s'ha elaborat una proposta de normalització per a la realització de cartografia relacionada amb els temes en estudi.

A fi d'elaborar la proposta de normalització s'ha estudiat amb especial atenció la cartografia oficial que existix en l'actualitat a Espanya, considerant especialment la generada per l'Institut Geogràfic Nacional, el Cadastre i l'Institut Cartogràfic Valencià.

Per a comprovar la utilitat del treball realitzat s'ha aplicat la normalització proposada a un municipi de la província de València, Titaguas, generant la cartografia que s'ha considerat necessària per al desenrotllament d'un projecte del tipus que ens ocupa. 


\begin{abstract}
The recent interest shown by the government in regard to the topic of the study and protection of the Landscape, and its close relationship with Land Use Planning, has led us to examine the involvement that the cartographer could have both on the development of basic documents, as previous studies or mapping the results.

This work has attempted to lay a theoretical foundation that will allow us to approach the world of the Land Use Planning and Landscape Protection from the point of view of the cartographer. Also, from the information analyzed a proposal for standardization for the conduct of mapping-related topics has been developed.

In order to develop the proposal for normalization, mapping official currently used in Spain have been studied with particular attention, especially considering the ones generated by the National Geographic Institute, Cadastre and Valenciano Cartographic Institute.

To test the usefulness of the work done, standardization proposal has been applied to a town in the province of Valencia, Titaguas, generating those maps that have been deemed necessary for the development of a project of the kind we are dealing with.
\end{abstract}





\section{ÍNDICE}

Página

1. OBJETIVO DE LA INVESTIGACIÓN

2. ANÁLISIS DEL ESCENARIO

2.1. Introducción a la Cartografía

2.1.1. Concepto

2.1.2. Historia

2.1.3. Situación actual

2.2. La representación cartográfica

2.2.1. El mapa como medio de comunicación. Semiología gráfica

2.2.2. Tipos de representación cartográfica.

2.2.3. Tipos de cartografía

2.2.4. La percepción visual humana

2.2.5. Las variables visuales 
2.2.7. El dato geográfico

2.2.8. Formatos de almacenamiento

2.2.9. Diseño del mapa

2.2.10. Tipos de símbolos

2.2.11. Tipografía y rotulación

2.2.12. Representación gráfica de la información.

2.3. E1 Territorio y el desarrollo sostenible

2.3.1. El Territorio

2.3.2. Desarrollo sostenible

2.3.3. Legislación aplicable

2.3.4. Previsiones de futuro

2.3.5. Políticas de desarrollo sostenible

2.3.6. Políticas relevantes en materia de conservación del Medio Ambiente

2.4. E1 Paisaje

2.4.1. Diferentes conceptos de paisaje 
2.4.3. Elementos que componen el paisaje

2.4.4. Elementos visuales del paisaje

2.4.5. Clasificación de los paisajes

2.4.6. Valoración del paisaje

2.4.7. Degradación y conservación del paisaje

2.4.8. Estudios de paisaje

2.4.9. Breve introducción a los indicadores de paisaje

2.4.10. Legislación aplicable

2.4.11. Cartografía del paisaje

2.5. La Cartografía en los Planes de Ordenación y Desarrollo Territorial

2.5.1. Estado actual

2.5.2. Cartografía del Instituto Cartográfico Valenciano para estudios de 169 paisaje 
2.6. Estudio de la información existente en materia de normalización cartográfica

2.6.1. Ley de Ordenación de la Cartografía

2.6.2. Situación en la Comunidad Valenciana

2.6.3. Plan cartográfico de Castilla y León

2.6.4. Normas cartográficas ambientales de Andalucía

2.6.5. Reglas de normalización cartográfica para Canarias

2.6.6. Comisión Cartográfica del Principado de Asturias

3.1. Principales variables cartográficas para la Ordenación del Territorio 
4.1. Elección del tipo de mapa en función de las necesidades 
4.1.2. Cartografía disponible

4.2. Datos a incluir

4.3. Normalización y maquetación

4.3.1. Diseño de la hoja

4.3.2. Estudio de la simbología a utilizar

4.4. Tratamiento de la información

4.4.1. Generalización cartográfica en los casos en los que resulte 233 necesario

4.4.2. Depuración y clasificación de los datos

4.5. Análisis de la simbología necesaria

4.6. Niveles de percepción, propiedades perceptivas y estudio de las variables visuales

4.7. Diseño de la simbología

4.7.1. Ríos y barrancos

4.7.2. Otros elementos hidrográficos

4.7.3. Curvas de nivel

4.7.4. Vías de comunicación 
4.7.15. EDAR (Estación de depuración de aguas residuales) 
4.7.21. Edificios singulares

4.7.22. Servicios

4.7.23. Mobiliario urbano

4.8. Tamaño de letra. Jerarquías 258

4.9. Evaluación de la simbología 259

5. PROPUESTA DE NORMALIZACIÓN 261

6. APLICACIÓN DE ESTA NORMALIZACIÓN AL MUNICIPIO DE 275 TITAGUAS

6.1. Realización de la cartografía en formato digital 275

6.2. Cartografía en formato papel 276

7. LÍNEAS FUTURAS 277

8. CARTOGRAFÍA RESULTANTE 279

9. BIBLIOGRAFÍA 


\section{OBJETIVO DE LA INVESTIGACIÓN}

La preocupación de las Administraciones Públicas por la Ordenación del Territorio y, por extensión, por la conservación del Paisaje, llevó en la Comunidad Valenciana a la publicación en junio de 2004 de la Ley 4/2004 de 30 de junio, de la Generalitat, de Ordenación del Territorio y Protección del Paisaje, que desarrolla el Reglamento de Paisaje de la Comunidad Valenciana, aprobado por el Consell en decreto 120/2006, de 11 de agosto de 2006.

Por otro lado, resulta patente la preocupación por el Desarrollo Sostenible y su promoción mediante la redacción de Planes de Ordenación que lo contemplen, así como por la adhesión por parte de un elevado número de municipios a la Agenda 21, cuyo fin último es conseguir el Desarrollo Sostenible de los municipios adheridos al sistema.

Partiendo de estas dos premisas y siempre desde el punto de vista cartográfico, se pensó que no existe ningún tipo de normalización para la producción de cartografía con fines de lo que llamamos en general "Desarrollo Territorial".

El objetivo de esta tesis consiste entonces en la realización de una propuesta de normalización cartográfica para Desarrollo Territorial, principalmente Ordenación del Territorio y Conservación del Paisaje. Para ello en primer lugar deberemos definir con claridad nuestros propósitos y necesidades y de este modo adaptar la cartografía a los mismos.

Una vez formulada la propuesta de normalización, la aplicaremos a un trabajo concreto, que consistirá en la realización de cartografía para la Auditoría Medioambiental de un municipio de la Comarca de los Serranos en Valencia, concretamente Titaguas.

Para conseguir esto, se realizará en primer lugar un análisis del escenario, que consistirá principalmente en una recopilación bibliográfica de los temas que consideramos necesario conocer para abordar el proyecto que tenemos entre manos. 
De este modo, se presenta en primer lugar una introducción a la Cartografía, que es la ciencia que nos permitirá elaborar nuestra propuesta de normalización, y seguidamente se estudia la representación cartográfica, que deberemos tener en consideración para la elección de la simbología a utilizar.

El siguiente paso será introducirnos en los conceptos de Territorio y Desarrollo Sostenible que deberemos comprender y contemplar para realizar cualquier estudio de Desarrollo Territorial. Igualmente se comentan los diferentes estudios que acerca de este tema se están llevando a cabo, como son el proyecto LUCDEME, el PAND, etc.

El concepto de Paisaje, extremadamente importante para el tema que nos ocupa y generalmente muy desconocido, se estudiará también en el primer punto como análisis del escenario.

A continuación veremos cómo está siendo tratada la Cartografía en los Planes de Ordenación y Desarrollo Territorial y del mismo modo estudiaremos la información existente en materia de normalización cartográfica, ampliando el ámbito hasta el nivel estatal.

Una vez sentadas las bases expuestas, se explicará la metodología aplicada, se realizará tomando ésta como base la propuesta de normalización y se aplicará al municipio de Titaguas.

Por último se expondrá la propuesta de normalización generada así como la cartografía resultante de su aplicación.

Los resultados se aportarán al Instituto Cartográfico Valenciano para que, tras su visto bueno, puedan ser aplicados a la cartografía territorial que por el citado Instituto se genere. 


\section{ANÁLISIS DEL ESCENARIO}

\subsection{Introducción a la Cartografía}

Siendo el objetivo de esta tesis el estudio de la Cartografía, resulta lógico comenzar introduciendo el concepto alrededor del cual se va a desarrollar el estudio.

La necesidad del ser humano de ubicarse o ubicar otros elementos y comunicar estas localizaciones a otros seres humanos puede decirse que dio lugar a la realización de los primeros mapas.

El hecho de organizar símbolos para representar elementos geográficos en un espacio reducido bidimensional, supuso un gran logro en el pensamiento abstracto. No se sabe con exactitud cuándo se elaboró el primer mapa, pero se supone que será contemporáneo de la comunicación mediante lenguaje escrito ${ }^{1}$.

\subsubsection{Concepto}

Podemos definir la Cartografía como la ciencia que estudia los mapas y su realización. No obstante, el concepto de Cartografía ha ido variando considerablemente a lo largo de la historia; la idea de mapa ha evolucionado al ritmo que lo ha ido haciendo la civilización humana, pasando de unas líneas y dibujos en una roca o arena, hasta una tarjeta de memoria que en la actualidad puede contener toda la cartografía de un país.

\footnotetext{
${ }^{1}$ Robinson A. et al., "Elementos de Cartografía", 1987.
} 


\subsubsection{Historia}

No conocemos el momento histórico en el que se elaboró el primer mapa, que seguramente sería una representación grosera de la ubicación de ciertos elementos en piedra o incluso en arena, pero parece muy probable que incluso en la prehistoria ya se utilizaran gráficos para representar lugares de caza, rutas, etc.

Ha llegado hasta nuestros días un antiguo mapa de Mesopotamia que cuenta con casi 5000 años de antigüedad, se trata de una tablilla de arcilla en la que se muestran montañas, masas de agua y otros elementos geográficos ${ }^{2}$.

Es un hecho comúnmente aceptado que la civilización egipcia realizaba mapas de las zonas inundables del Nilo para poder replantear de nuevo las parcelas tras las inundaciones, se han hallado varios planos, en su mayoría de tipo catastral o topográfico, pero no mapas de grandes zonas. Al igual que las civilizaciones antiguas, los pueblos que en la actualidad están tecnológicamente menos avanzados generan siempre un tipo u otro de mapas, que estarán lógicamente adaptados a sus necesidades: en ocasiones la escala está en función del tiempo de recorrido y no de la distancia; los soportes son de lo más variopinto, conchas, tablillas, roca, piel, etc. En lo que sí parece haber coincidencia es en la claridad de las relaciones topológicas, ya que lo realmente útil suele ser el conocimiento de las posiciones relativas de los elementos.

Como ejemplo de cartografía urbana tenemos el plano de Nippur, centro religioso de los Sumerios en Babilonia, que es quizá el plano de población más antiguo (1500 a. C.) y se conserva en la Universidad F. Shiller de Jena (Alemania).

\subsubsection{Cartografía en el mundo oriental ${ }^{3}$}

Aunque probablemente se creara cartografía con anterioridad, las piezas más antiguas que se conservan son tres mapas del siglo II antes de Cristo hallados en una tumba de la dinastía Han, se trata de manuscritos sobre seda, lo más relevante es que en uno de ellos se observa una cuadrícula, y aunque no se cree que se utilizaran ya proyecciones cartográficas parece que contaban con una escala bastante precisa que permitía un cálculo de distancias considerablemente exacto mediante el teorema de Pitágoras.

En lo que a Cartografía se refiere, China se encontraba mucho más avanzada que el mundo occidental; conocieron la brújula mucho antes, al igual que el papel, del cual fueron los inventores, la primera impresión de un mapa en China se realizó alrededor del año 1155 de nuestra era, 300 años antes que en Europa.

\subsubsection{Cartografía primitiva en occidente ${ }^{4}$}

Resulta un paso histórico en el pensamiento del ser humano el hecho de tener cierta inquietud por otros territorios y más aún, por la Tierra en su conjunto. Se sabe que en la época de Aristóteles (384-322 antes de Cristo) se tenía conocimiento de la esfericidad de la Tierra y

\footnotetext{
${ }^{2}$ Robinson A. et al., "Elementos de Cartografía", 1987.

${ }^{3}$ Robinson A. et al., "Elementos de Cartografía", 1987.

${ }^{4}$ Robinson A. et al., "Elementos de Cartografía”, 1987.
} 
durante el siglo II de nuestra era ya se había señalado el sistema de coordenadas geográficas, latitud y longitud.

En los tiempos en los que Alejandría era el centro intelectual de la civilización, Claudio Ptolomeo (90-160 antes de Cristo) escribió un tratado de Geografía en el que se describían los conocimientos que en ese momento se tenían de la Tierra y se incluía un tratado de Cartografía. En éste se trataba el problema de la representación de una Tierra esférica en un soporte plano, además se hacía referencia a varios lugares mediante sus coordenadas geográficas. Se supone que Ptolomeo generó cierto número de mapas, que aunque no han sido conservados se han reconstruido gracias a las descripciones dadas en el tratado de Cartografía.

\subsubsection{Cartografía medieval ${ }^{5}$}

La cultura clásica, tan elogiada en lo que se refiere a filosofía y letras, no aportó gran cosa en lo concerniente a tecnología y por lo tanto a Cartografía, la preocupación de griegos y romanos por estos temas no fue para nada significativa. Se sabe que los romanos tuvieron cierto control sobre la propiedad de la tierra y al parecer sí contaban con mapas administrativos y de ingeniería, pero con la caída del imperio se perdió totalmente el interés por la Cartografía.

Más tarde hubo un periodo en el que, en contraste con la sistemática de Ptolomeo de realizar mapas basados en estudios y observaciones de la realidad, los mapas se utilizaban para difundir una idea más bien religiosa de la forma y naturaleza de la Tierra, en los que la fantasía y la imaginación prevalecían totalmente sobre la rigurosidad métrica.

Durante la Alta Edad Media, se siguió la misma tónica, y deberemos esperar hasta después del primer milenio de la Era Cristiana para encontrar de nuevo documentos de Geografía y Cartografía con cierto rigor. Para ello fue fundamental la aportación de los árabes así como el interés que se iba generando por las tierras lejanas.

Fueron los árabes los que conservaron los escritos de Ptolomeo y los utilizaron para realizar mediciones de la Tierra en el siglo IX. Entre los años 1154 y 1161 un erudito árabe de la corte del rey Roger de Sicilia llamado Idrisi elaboró mapamundis que supusieron una revolución con respecto a la cartografía de la época.

Ya en el sigo XV, con la recuperación de los textos de Ptolomeo y dado el creciente interés por la mercadería y el descubrimiento de nuevas rutas, se produjo un cambio en la mentalidad y empezaron a realizarse avances en los campos de la Geografía y la Cartografía. Resulta significativa la exactitud con la que se representaron las costas y sus accidentes geográficos en las cartas de navegación que se denominaron portulanos, no así en lo que se refería a tierra firme.

\subsubsection{El Renacimiento en la Cartografía occidental ${ }^{6}$}

Como ya se ha comentado, el gran impulso que tuvieron en los siglos XV y XVI los viajes de ultramar, llevó a que la profesión de cartógrafo resultara muy lucrativa, lo que desembocó en un gran desarrollo de la misma.

\footnotetext{
${ }^{5}$ Robinson A. et al., "Elementos de Cartografía", 1987.

"Robinson A. et al., "Elementos de Cartografía", 1987.
} 
Otro hecho reseñable fue la invención en Europa de la imprenta y el grabado, poco después de 1450, que contribuyó enormemente a la difusión de la Cartografía, lo que supuso un gran avance de la misma.

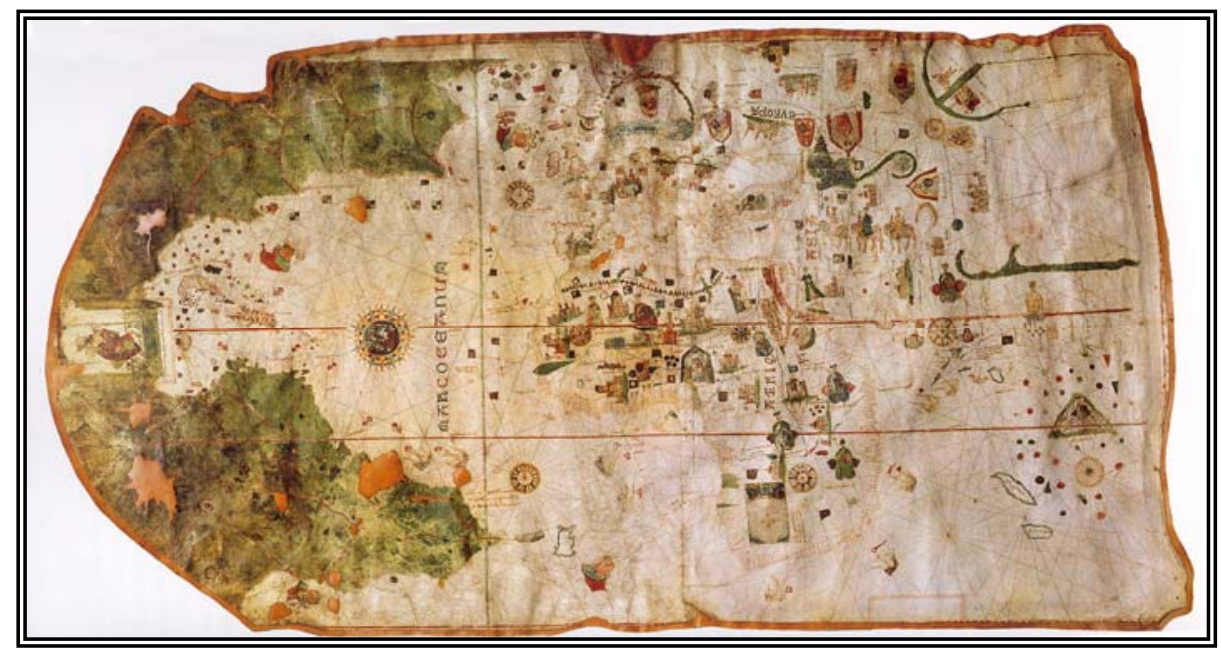

Figura 1.1. Carta de Juan de la Cosa. Año 1500.

El gran paso se produjo entre los años 1600 y 1650, cuando se cambió de nuevo el enfoque de la Cartografía, dejando atrás esa visión dogmática y pasándose a valorar de nuevo, tras 1500 años, la precisión y el método científico.

A principios del siglo XVI se establecieron en España y Portugal organizaciones oficiales para la supervisión de la elaboración de cartas náuticas, aunque no fue hasta el XIX cuando se crearon departamentos hidrográficos gubernamentales que editaron las cartas necesarias para la navegación segura.

La Academia Francesa de Ciencias, fundada en la segunda mitad del siglo XVII, supuso también un gran avance para la Cartografía, en cuanto que uno de sus cometidos era aumentar la precisión en la navegación y para ello resultaba imprescindible una buena cartografía, con la consiguiente investigación acerca de las dimensiones de la Tierra.

Y contando ya con unos perfiles costeros de considerable precisión, empezó a pensarse que el problema radicaba en la falta de exactitud de los mapas interiores, sin la cual resultaba muy difícil gobernar o incluso hacer la guerra. A raíz de esto aparecieron en Europa diferentes centros de generación de cartografía, primero en Francia y luego en Inglaterra, que hicieron posible que durante la última mitad del siglo XIX una gran parte de Europa hubiera sido cubierta por mapas topográficos.

\subsubsection{Situación actual}

Durante el siglo XX el avance de la Cartografía ha sido enorme comparado con la transformación que había sufrido a lo largo de la historia. Este gran desarrollo se ha debido a 
múltiples factores, entre los que se encuentran el avance de la aviación, que produjo por un lado un gran aumento de la demanda de cartografía, y por otro ofreció la oportunidad de generar mapas a partir de fotogrametría aérea, con el consiguiente abaratamiento de los costes en la toma de datos de campo.

Otra gran conquista para la ciencia cartográfica fue, y sigue siendo, el avance en materia de tecnología espacial. Esto ha permitido además de aplicar la teledetección a la generación de cartografía temática, el posicionamiento tanto relativo como absoluto y la toma de datos de campo mediante técnicas GPS.

Sin embargo, el verdadero cambio en el concepto de Cartografía se ha ido produciendo con la paulatina pero rápida introducción de los ordenadores en el proceso cartográfico. Actualmente no se puede concebir la elaboración de cartografía sin utilizar en prácticamente todas las partes del procedimiento algún recurso informático. Es más, la noción de Cartografía que nos hacía pensar en un mapa en formato papel, está complementándose con la posibilidad actual de disponer de los datos en formato digital.

Gracias a este gran avance tecnológico que ha supuesto el uso de la informática en el campo de la Cartografía, actualmente disponemos de uno de los productos cartográficos que están cobrando más auge, por la cantidad de información que ofrecen sin menoscabo alguno de su precisión, son las ortofotografías. Se trata de fotografías aéreas rectificadas de forma que el resultado sea una proyección ortogonal que permita la medición directa de distancias y superficies, esto es, cuya escala sea uniforme.

Una de las herramientas más útiles en lo que a gestión territorial se refiere, si no la más útil de ellas, es el Sistema de Información Geográfica (S.I.G.). Se trata de un sistema informático con una base cartográfica a la que se vincula una base de datos alfanuméricos, esto permite ver de forma fácil y clara la información tanto gráfica como alfanumérica, y además realizar análisis partiendo de ésta.

\subsubsection{Calidad en la producción cartográfica}

Precisamente debido a la relativa facilidad con la que actualmente se puede elaborar cartografía, en ocasiones se elaboran productos de dudosa calidad, debido sobre todo a que el proceso lo realiza personal sin la cualificación adecuada, situación que se ve agravada por el manifiesto retraso de la entrada de sistemas de gestión de calidad y normalización respecto a otros sectores productivos. 


\subsection{La representación cartográfica}

Dado que en esta tesis se pretende proponer una normalización que permita generar cartografía temática, resulta imprescindible estudiar cómo vamos a materializar todos los datos disponibles en la citada cartografía.

\subsubsection{E1 mapa como medio de comunicación. Semiología gráfica}

Puede entenderse el mapa como un "medio de comunicación” en el que la información se representa de forma gráfica. Uno de los mayores problemas de que adolece la cartografía en la actualidad es la mala codificación de los datos, de forma que la idea transmitida finalmente al lector del mapa no sea en absoluto la que se quería trasladar o sea insuficiente.

Entendiendo la cartografía como un "medio de comunicación" que nos permite transmitir cierta información, concretamente datos referidos a un territorio concreto, podemos decir que la semiología gráfica es la gramática del lenguaje cartográfico ${ }^{7}$.

Esta comunicación, que se produce entre el cartógrafo y el colectivo al que va dirigida la cartografía, para ser correcta debe cumplir las expectativas; esto se traduce en que el cartógrafo, tras estudiar la información, codifica los datos para generar una cartografía que el usuario deberá ser capaz de decodificar para poder entender. Es por ello de vital importancia tener una idea clara acerca de quién va a ser el usuario final y cuales son sus necesidades y su capacidad para entender la información que se le está intentando transmitir.

Del mismo modo, el cartógrafo debe ser capaz de enfatizar aquellos aspectos de la cartografía que considere más relevantes y para ello deberá utilizar las herramientas adecuadas, colores, grosores de línea, tamaño de los símbolos, etc. Teniendo en cuenta que existen ciertas reglas que el lector, independientemente de su cultura, aplicará intuitivamente a la hora de enfrentarse a un mapa, como son el hecho de que lo grande tiene mayor importancia que lo pequeño o lo oscuro es más pesado que lo claro; existen asimismo formalidades a observar que dependen de la cultura, como pueden ser "el pasado a la izquierda y el futuro a la derecha" en la cultura occidental (al contrario en la musulmana) o "lo blanco alegría y lo negro tristeza" (al contrario en la hindú $)^{8}$.

La eficacia de una imagen depende fundamentalmente de que posea dos cualidades: Ser estética y estar correctamente construida (Albert André. 1980. "L'expression graphique: Cartes et diagrammes". Masson.). Aunque se trata de un aspecto completamente subjetivo, existen ciertas reglas no escritas que hacen que un símbolo o una imagen sea estéticamente atractiva o no, en caso afirmativo atraerá más fácilmente la atención del observador y éste la retendra en su cerebro con menor esfuerzo y por lo tanto con mayor rapidez.

Desgraciadamente no contamos con unas reglas que nos permitan diseñar "el mapa perfecto", no existe una gramática cartográfica, pero deberemos dentro de lo posible intentar que la cartografía que generemos sea lo más clara y evocadora posible.

\footnotetext{
${ }^{7}$ Pérez, R. Propuesta de Normalización para la representación cartográfica en Internet. Tesis Doctoral. Madrid, 2003.

${ }^{8}$ Bernabé Poveda, M. A. Apuntes de la asignatura Diseño Cartográfico. http://nivel.topografia.upm.es/ mab, 10-0106.
} 
Es importante considerar la gran importancia que la simbología tiene a la hora de transmitir información por medio de la cartografía.

Si pensamos por ejemplo en un mapa en el que sólo se representen los límites de cada zona que tenga unas características determinadas, y un único símbolo o cifra que identifique esa cualidad, con ausencia total de color o tramado, y lo comparamos con la misma cartografía en la que sí se ha utilizado el color para distinguir las distintas clases, apreciaremos claramente que aquella no nos proporciona una información de conjunto clara y apreciable de forma intuitiva, efecto que se consigue con facilidad mediante el uso del color en la segunda cartografía. Un uso correcto de la simbología nos permitirá entonces transmitir diferentes aspectos como pueden ser distribuciones, comparaciones o interrelaciones.

Echando un vistazo a la figura 1.2. podemos ver claramente la confusión existente entre diferentes elementos como son curvas de nivel, ríos o caminos debido a la ausencia de color.

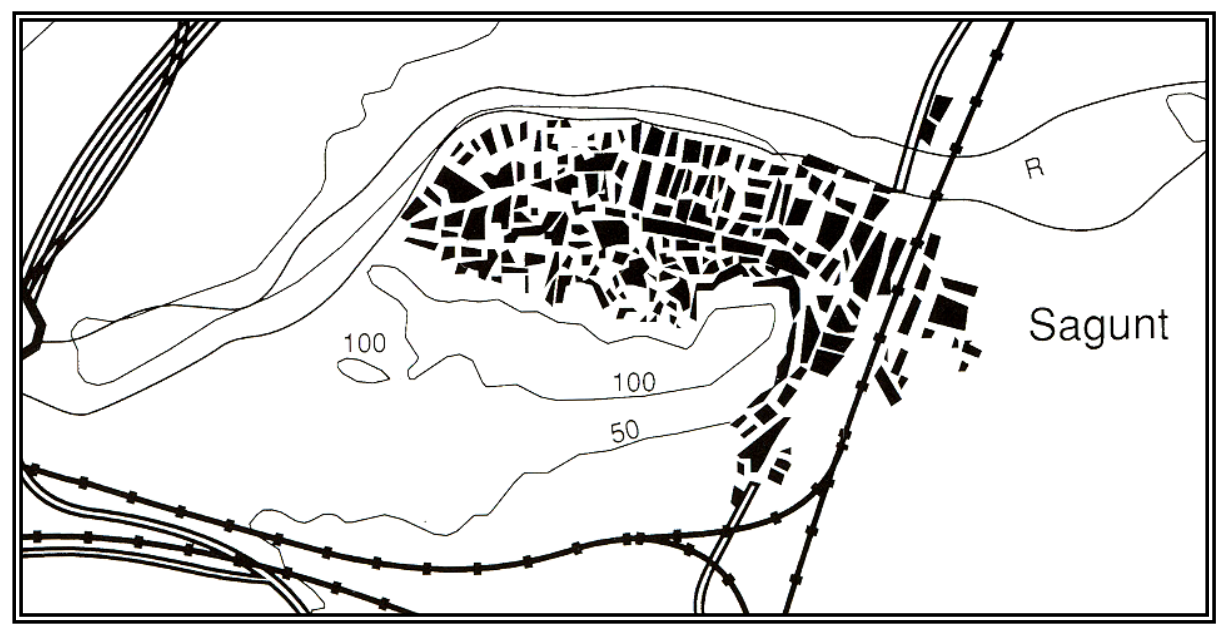

Figura 1.2. Fragmento de "Evaluación de impacto ambiental en el planeamiento urbanístico".

\subsubsection{Tipos de representación cartográfica.}

Hace muy poco tiempo, cuando se hablaba de Cartografía se pensaba automáticamente en un mapa en formato papel, en nuestros días esa idea supondría una visión extremadamente reducida de lo que podemos entender como Cartografía. Y este gran giro del concepto se debe a la introducción de la informática en la generación y uso de los mapas. Actualmente no sólo disponemos de mapas en formato papel, sino que contamos con cartografía en formato digital la cual puede estar integrada en un S.I.G. (Sistema de Información Geográfica) o no.

\subsubsection{Tipos de cartografía}

La clasificación más básica que podemos hacer de la Cartografía es la que la divide en Básica y Temática. 
La Cartografía Básica es aquella en la que se representan únicamente los elementos que encontramos en el terreno, es una representación a escala de la realidad. Si a esta información le agregamos cualquier otro tipo de datos climatológicos, de vegetación, de población, etc., obtendremos como resultado Cartografía Temática.

Puesto que el objetivo de esta tesis es la Normalización de Cartografía para Ordenación del Territorio y Conservación del Paisaje, los mapas que generaremos serán mapas temáticos, y lo haremos a partir de Cartografía Básica.

\subsubsection{Cartografía Temática}

En la segunda mitad del siglo XVII empezaron a utilizarse los mapas para ubicar otros datos además de los estrictamente físicos, así nació la Cartografía Temática. Aunque no cobraría verdadera relevancia hasta el siglo XIX, cuando se empezó a potenciar el estudio de los pueblos y sus instituciones?.

La Cartografía Temática se ocupa de reflejar cierto tipo de datos en una ubicación concreta, o bien de comparar conjuntos de datos referentes a lugares diferentes; la variedad de temas acerca de los que puede versar la Cartografía Temática es enorme. Como ejemplo podemos ver el mapa geológico del Instituto Geológico y Minero de España del cual tenemos una muestra en la figura 1.3..

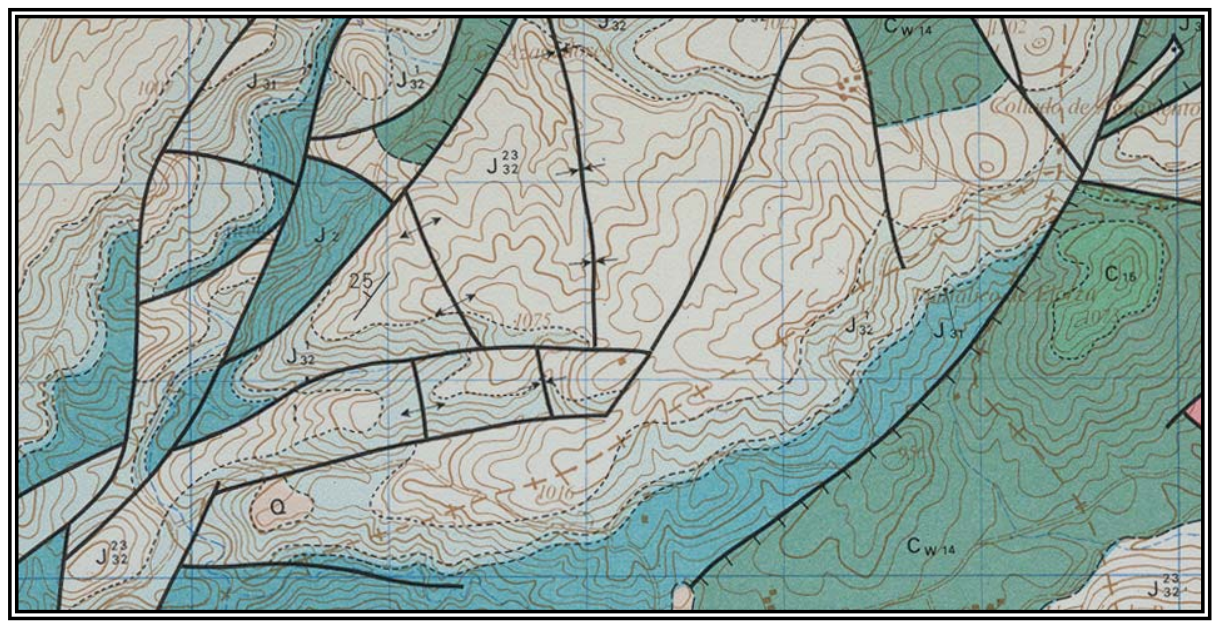

Figura 1.3. Mapa geológico escala 1:25.000. IGME

Como se ha comentado, la Cartografía Temática tiene un fin muy bien definido, y por eso es importante que cumpla una serie de condiciones:

\footnotetext{
${ }^{9}$ Robinson A. et al., "Elementos de Cartografía”, 1987.
} 
- Claridad. La información incluida debe ser clara y perfectamente comprensible, se evitará por ello introducir un exceso de información y los datos contenidos serán lo más esquemáticos posible.

- Exactitud. El hecho de que se intente simplificar al máximo los datos no debe hacer que estos pierdan rigurosidad, deberán ser por tanto tan precisos como pueda ser exigible.

- Poder de evocación. La Cartografía Temática está elaborada por expertos, pero generalmente está dirigida a un público que no lo es, por esta razón es muy importante que la simbología en ella utilizada sea clara y perfectamente comprensible para profanos en la materia.

Para la representación de un suceso en una cartografía tendremos siempre una variable, que tendrá un determinado valor y que se repetirá con una determinada frecuencia en un período determinado.

La componente temática es la variable a incluir en el mapa temático y se puede clasificar desde cuatro puntos de vista:

- Dependencia. El valor de la variable puede depender de otro o no.

- Continuidad. Hablamos de una variable discreta cuando podemos expresar sus valores concretos, sin embargo será continua cuando resulta imposible expresar todos los valores que adopta y deberemos por ejemplo discretizarlo en intervalos.

- Cualidad / cantidad. Las variables que vamos a tratar pueden expresar cualidades o características, en cuyo caso las denominaremos cualitativas y también pueden expresar cantidades, las denominaremos entonces cuantitativas.

\subsubsection{Tipos de cartografía temática en función de su contenido}

Podemos aceptar una clasificación de la Cartografía Temática en función de su contenido, de este modo nos podemos encontrar con mapas analíticos, complejos y sintéticos ${ }^{10}$.

Mapas analíticos. Serán aquellos en los que sólo venga representada una materia; en este tipo de mapas se presenta la distribución espacial de los datos referentes a esa materia.

Mapas complejos. En este tipo de mapas veremos representados varios temas, lo que permitirá hacer análisis de los datos estudiados.

Mapas sintéticos. Se trata de mapas más elaborados, a los que se incorporan datos que son el resultado de algún proceso; la manera más sencilla de generar este tipo de mapas es mediante un S.I.G., aunque no necesariamente deberemos disponer de esta herramienta.

\subsubsection{La percepción visual humana}

Cuando nos situamos en frente de un mapa y lo observamos, nuestros órganos sensoriales, en este caso nuestros ojos, envían unas señales al cerebro que éste procesa para que nosotros podamos "percibir" ese mapa y la información que contiene. Es importante que conozcamos este mecanismo de percepción puesto que deberemos tenerlo en cuenta a la hora

${ }^{10}$ Pérez, R. Propuesta de Normalización para la representación cartográfica en Internet. Tesis Doctoral. Madrid, 2003. 
de diseñar nuestra cartografía, para que el lector "perciba" lo que realmente queremos transmitirle. Aceptaremos pues que el proceso de percepción consiste no sólo en los estímulos que llegan al cerebro, sino en el proceso mental que ocasionan y los resultados que debido a estos estímulos se originan.

Por todo lo anterior, diremos que la percepción visual humana depende no sólo de los estímulos que en ese momento lleguen al cerebro, sino también de la información previa que éste tenga y que utilizará para procesar la información y percibirla de un modo u otro.

\subsubsection{Etapas de la visión ${ }^{11}$}

El proceso que conocemos como visión integra tres etapas fundamentales, la física, la fisiológica y la psicológica.

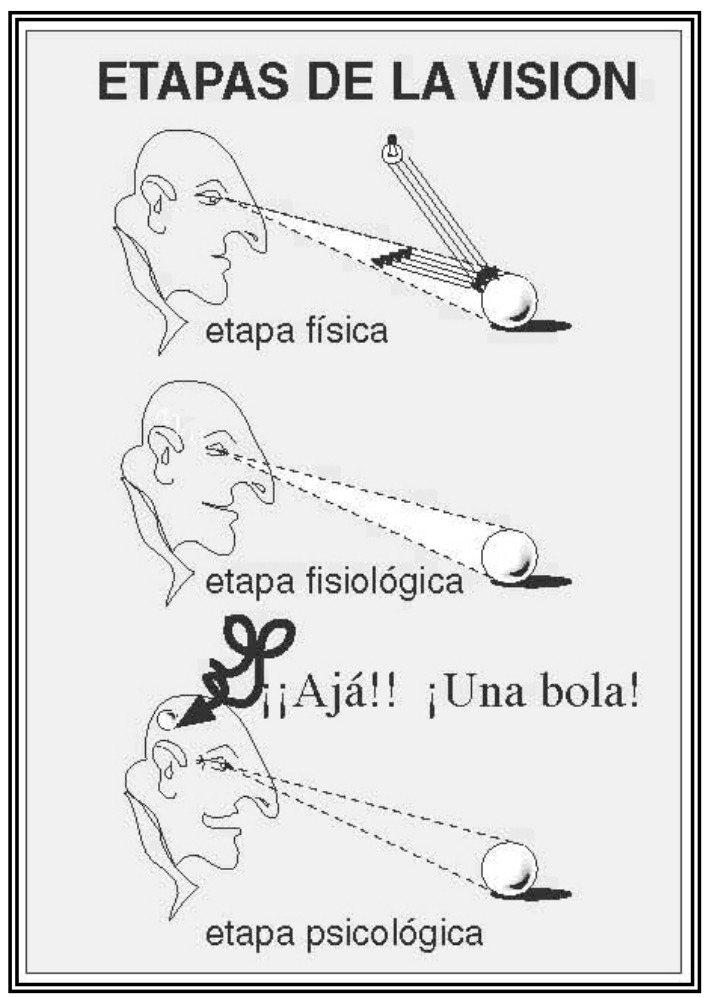

Figura 1.4. Etapas de la visión. Fuente: Apuntes de la asignatura "Diseño Cartográfico". Bernabé Poveda.

11 Bernabé Poveda, M. A. Apuntes de la asignatura Diseño Cartográfico. http://nivel.topografia.upm.es/ mab, 10-0106. 
Cuando hablamos de etapa física nos referimos al proceso consistente en la llegada de un haz luminoso al ojo, proveniente de un objeto. Este procedimiento puede verse modificado por:

- Las características de la fuente de luz, como el color de la misma, la lejanía del foco, la intensidad, etc.

- Las características del objeto: color, textura, etc.

- Duración del periodo de percepción, generalmente condicionado por el movimiento del objeto o del observador.

Trasladando esto al caso que nos ocupa, podemos decir que la información aportada por una cartografía puede ser percibida de forma diferente en función del tipo de luz con que se observe, del soporte cartográfico, de las tintas utilizadas o del tiempo de observación.

Una vez que el rayo luminoso ha alcanzado el ojo, comienza la etapa fisiológica, que comprende todos esos procesos que el haz incidente desencadena en nuestro ojo. El rayo alcanza la retina, que es el órgano fotosensible de nuestro sistema óptico, y genera ciertas reacciones en los bastones (células sensibles a los cambios de claridad) y en los conos (sensibles al cambio de color). Estas reacciones se traducen en cambios de potencial eléctrico, que será enviado al cerebro por el nervio óptico. El proceso de observación de la cartografía puede verse "distorsionado" por un incorrecto funcionamiento de cualquiera de los mecanismos de la visión.

Y por último la etapa psicológica, una vez que la señal eléctrica llega al cerebro, éste debe ser capaz de procesarla de manera que signifique algo para él. Pero para poder dar a la imagen un significado, el cerebro debe reconocerla, en caso contrario será incapaz de comprenderla. Sólo cuando el cerebro reconstruya convenientemente la información se podrá percibir correctamente el significado de la misma, por eso es de vital importancia conocer el proceso de percepción y las limitaciones de éste.

\subsubsection{Modificadores de la percepción}

El proceso de percepción se ve modificado por múltiples factores que hacen que existan diferentes percepciones de un mismo fenómeno dependiendo del punto de vista o de las condiciones de observación.

Por otro lado, somos capaces de reconocer un objeto aunque cambien las condiciones de observación. Veamos a continuación qué propiedades al ser modificadas no cambian nuestra percepción de los objetos y cuáles sí.

A esas propiedades de los objetos que permanecen invariables par nuestra percepción a pesar de que se dé un cambio en el estímulo que las hace presentes las denominaremos constancias perceptivas ${ }^{12}$.

Podemos considerar en primer lugar la constancia perceptiva de la forma, que hace que las propiedades intrínsecas de los objetos permanezcan constantes a pesar de que haya una modificación de los estímulos que los hacen visibles. Pensemos por ejemplo en cualquier objeto circular que no vemos exactamente de frente, aunque realmente estamos viendo una

12 Bernabé Poveda, M. A. Apuntes de la asignatura Diseño Cartográfico. http://nivel.topografia.upm.es/ mab, 10-0106. 
elipse, percibimos un círculo debido a que nuestro cerebro está acostumbrado a procesar objetos viéndolos desde una perspectiva cónica.

También existe la constancia del tamaño, por la misma razón que se ha citado anteriormente, nuestro cerebro no aprecia que los objetos sean más pequeños porque estén más alejados; del mismo modo, despreciaremos sistemáticamente la variable tamaño si observamos objetos genéricos no relacionados entre sí en los que lo que nos interesa diferenciar es la forma. Pensemos en un mapa turístico, para representar que hay animales salvajes podemos utilizar un símbolo del mismo tamaño que para comunicar la situación de un hotel sin que a nadie llamase la atención, aunque cualquier animal salvaje es mucho más pequeño que un hotel, nadie repararía en este hecho.

En lo que se refiere a la constancia de brillo y valor, diremos que el brillo de un objeto se refiere a la rugosidad de su superficie, no al color que tenga, ambas cualidades pueden ser apreciadas independientemente de la luminosidad del ambiente, ahora bien, lo que no resulta tan fácil es discernir entre dos colores parecidos o dos brillos similares si no tenemos la oportunidad de compararlos, en cuyo caso la capacidad de nuestro cerebro para distinguirlos sí es muy potente.

La constancia de tono también se da, independientemente de que se den cambios de valor o saturación en el color, nuestro cerebro será capaz de distinguir el tono principal. Al igual que con el brillo o el valor, somos capaces de distinguir pequeñas variaciones, pero siempre por comparación, no de manera absoluta.

Y del mismo modo que hemos visto las constancias perceptivas, podemos estudiar los contrastes perceptivos, que serán los cambios que ocurren aunque el estímulo no cambie.

El contraste perceptivo de la forma se refiere al cambio en la percepción de un objeto por la influencia de otro sobre él; generalmente se trata de ilusiones ópticas de las que hemos visto ejemplos en el colegio, como el de cruzar unas paralelas por otras haciendo que las primeras parezcan doblarse.

El caso del tamaño es similar, y generalmente se debe a que nuestro cerebro tiende a comparar cada objeto con los que le rodean o bien al hecho de que asumimos la perspectiva cónica y solemos pensar que los objetos lejanos tienen mayor tamaño.

$\mathrm{Y}$ en lo que al valor y al tono se refiere, el caso es el mismo, se aprecian valores mayores o menores según sean los objetos que rodean al que queremos percibir.

\subsubsection{Ayudas a la percepción ${ }^{13}$}

Una de las cuestiones que no podemos obviar, es el tema del fondo y la forma. Nuestro cerebro tiende a organizar la información de manera que reconoce un escenario y lo que sucede en él. Si queremos que nuestra cartografía sea rápidamente inteligible deberemos diferenciar claramente el fondo (escenario) de la forma (lo que sucede en él).

Así, en ocasiones el fondo del mapa es el mar, si utilizamos un azul extremadamente oscuro para el mismo, nuestra cartografía perderá claridad, es por lo que se utiliza habitualmente un tono claro, para dar más relevancia al contenido que realmente se está

13 Bernabé Poveda, M. A. Apuntes de la asignatura Diseño Cartográfico. http://nivel.topografia.upm.es/ mab, 10-0106. 
estudiando, la zona continental. Si se trata de mapas temáticos, el fondo será la cartografía base y la forma se corresponderá con la información temática, de ahí que si no existe una buena diferenciación entre fondo y forma la cartografía en cuestión adolecerá de falta de claridad.

Además, para que el cerebro reconozca con claridad la información, paso imprescindible para comprenderla, aquella debe estar correctamente estructurada, para ello el cartógrafo deberá intentar organizar los datos en niveles de información.

\subsection{Las leyes de la Gestalt}

A partir de los estudios del psicólogo alemán Von Ehrenfels (1856-1932) acerca de la Cualidad de la Forma (Gestalt-qualität), se originó la llamada Psicología de la Gestalt, una teoría que afirma que los procesos psíquicos son todos unificados y no una suma de actividades o elementos separados.

Los psicólogos alemanes de esta Escuela crearon, en el primer tercio de este siglo, unas directrices a través de profundos análisis acerca de la percepción de la forma. Gelstalt, en alemán, significa "forma" o "configuración”. Éstas se tradujeron en un aserie de leyes de las cuales citaremos aquellas que tienen relación con la Cartografía:

- Ley de la dimensión superficial: Cuanto más pequeña sea una superficie, más interés pone el ojo en verla. Dicho de otra manera: las pequeñas superficies tienen un mayor impacto visual.

- Ley de la proximidad: Los puntos y otros pequeños símbolos que estén cercanos unos a otros, tienden a formar grupos.

- Ley del cerramiento: Las áreas rodeadas por un contorno lineal se ven más fácilmente como "figuras" que las que no están completamente rodeadas.

- Ley de la simetría: Cuanto más simétrica sea una superficie cerrada, más fácilmente se la reconoce.

- Ley de la buena continuación o de la continuidad: Cuanto más continuo sea un objeto, más fácilmente se reconoce.

\subsection{El poder separador}

Con el término "poder separador" nos referimos a la capacidad de discriminar pequeños objetos y de distinguir entre objetos muy cercanos. Se trata pues de un concepto importante que condicionará la configuración de nuestro mapa final.

Existen diferentes factores que condicionan esta capacidad del ser humano de diferenciar unos objetos de otros, veamos una clasificación:

\section{Espaciales}

Se trata del factor más importante. La relación entre el tamaño de un objeto y su distancia al ojo puede expresarse por medio del ángulo visual, esto es, el ángulo que se forma en nuestro ojo entre los extremos del objeto observado. Una persona con visión normal puede ver objetos cuando el ángulo visual sea al menos de 1 minuto de arco. A la distancia de lectura normal (lo que conocemos como la distancia de la visión distinta, unos 25-30 cms), 1 minuto de arco corresponde a $0.09 \mathrm{~mm}$. Esto significa que para que un objeto sea visible debe medir al menos $0.09 \mathrm{~mm}$. El Profesor Bernabé considera que los umbrales para la percepción de un elemento aislado serán de: 
- $0.2 \mathrm{~mm}$ de diámetro para un punto

- $0.05 \mathrm{~mm}$, grosor de una línea negra

- $0.4 \mathrm{~mm}$ el lado de un cuadrado lleno

- $0.6 \mathrm{~mm}$ de lado si el cuadrado está vacío

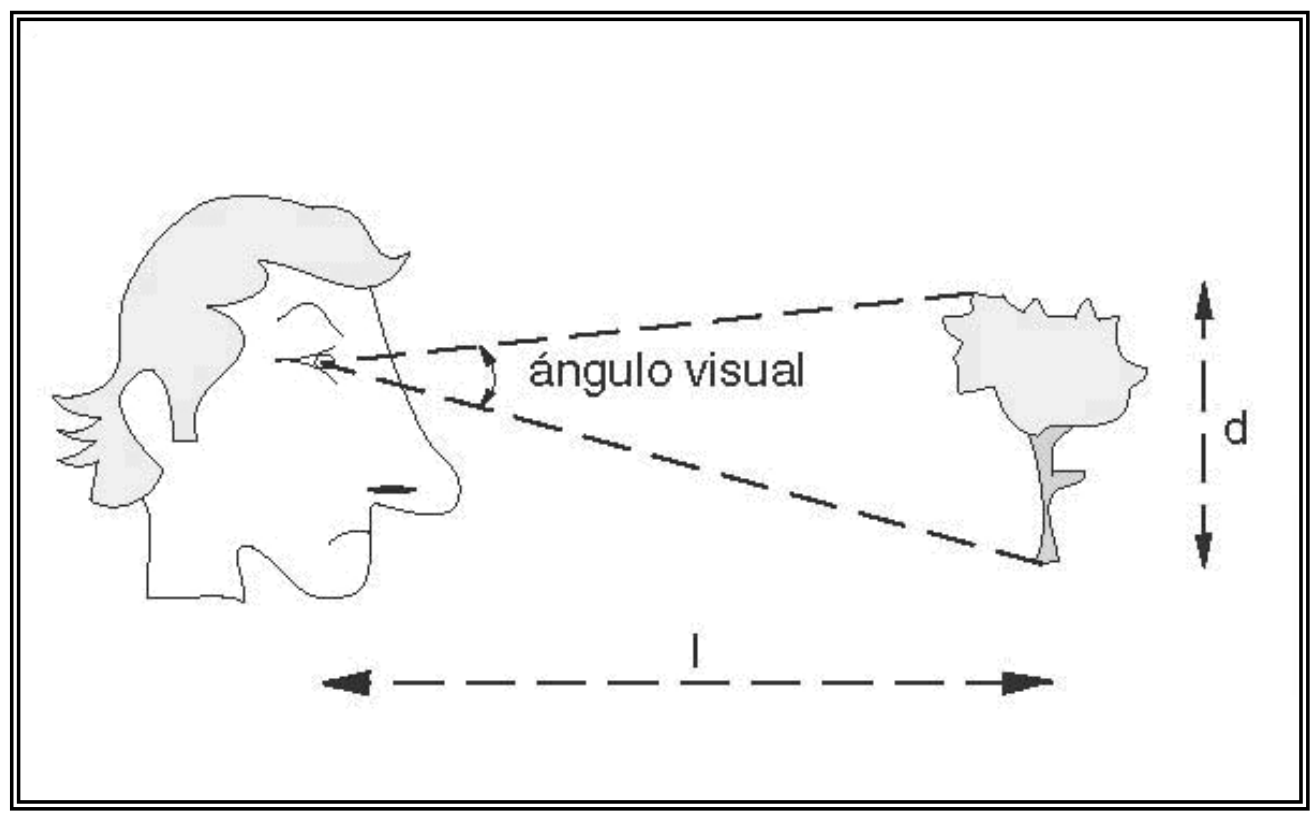

Figura 1.5. Ángulo visual. Fuente: Apuntes de la asignatura "Diseño Cartográfico". Bernabé Poveda.

Llamaremos poder de separación a la distancia mínima entre dos elementos gráficos que deben observarse a simple vista bajo circunstancias normales de iluminación. Esta distancia, en la práctica es de $0,2 \mathrm{~mm}$ como separación mínima entre dos líneas paralelas o entre los componentes de una trama cuya estructura deba aparecer como visible.

Asimismo denominaremos umbral de la diferenciación al condicionante mínimo que nos permite percibir las diferencias de forma entre dos elementos gráficos, o entre dos símbolos que tengan aproximadamente el mismo tamaño. Este umbral no tiene medidas mínimas estrictas y depende de:

El tipo de formas que deban diferenciarse. Es más fácil distinguir entre un triángulo y un cuadrado que entre un octógono y una circunferencia.

El número de grises que hemos elegido para diferenciar un elemento de otro con su misma forma. Cuanto más pequeño sea el elemento gráfico, menos variaciones de gris soporta.

La diferencia de tamaños aplicados a una misma forma: El ojo humano distingue con dificultad las pequeñas diferencias de tamaño si los elementos no están muy cercanos.

\section{Espectrales}

Hace referencia principalmente a:

- El grado de contraste entre el símbolo y el fondo en el que se encuentra 
- La longitud de onda (el color) de la radiación enviada por el objeto

La intensidad de luz

\section{Temporales}

La permanencia de un objeto hace que mejore su percepción. Por esta razón, los mapas que se muestran en medios como televisión, presentaciones, conferencias, etc, deben ser muy sencillos.

\subsubsection{La percepción de tamaño de los símbolos proporcionales}

Como venimos diciendo a lo largo del capítulo, la percepción humana no es una cuestión numérica, antes bien, investigaciones en este campo aseguran que los círculos de tamaños grandes son subestimados en tamaño, esto es, que se perciben menores de lo que realmente son. De esta forma el ser humano no es capaz de apreciar que un círculo con un tamaño dos veces mayor que otro es el doble de grande.

\subsubsection{La percepción de los valores de gris}

Las variaciones de los valores de gris no se perciben de acuerdo a su variación numérica, el valor de un color se verá afectado por el valor de los colores vecinos.

Pero incluso si se tratara de un mapa, poco usual, de tonos de gris, las investigaciones en este caso dicen que existen discontinuidades en la apreciación de los tonos. Las diferencias de valor entre dos tonos de grises del 10\% y del $20 \%$ no son las mismas (perceptivamente hablando) que entre el 80 y del $90 \%$.

\subsubsection{Las variables visuales}

Una vez procesada la información deberemos proceder a plasmarla en el mapa, para ello deberemos tener un total dominio del lenguaje gráfico.

Hay dos formas de representar la realidad, grafiándola simplemente como es o mediante símbolos. Los símbolos son representaciones icónicas de un fenómeno, no están a escala y deben ser lo más intuitivos posible.

Dos marcas dibujadas pueden diferir en múltiples aspectos, como son: posición, forma, tamaño, orientación, textura, estructura del relleno, color (tono, claridad y saturación) y foco ${ }^{14}$.

A estas propiedades es a lo que se conoce como Variables Visuales. Existe discrepancia entre los estudiosos del tema y aunque a grandes rasgos hay acuerdo, cada autor introduce sus propias variables.

J. Bertin ${ }^{15}$, el autor de la primera clasificación aplicada a la Cartografía aporta siete variables: Posición, Forma, Orientación, Color, Textura, Valor y Tamaño. Y afirma que seis de estas variables son capaces de proporcionar una tercera dimensión: Tamaño, Valor, Grano, Color, Orientación y Forma; entendiéndose tercera dimensión no estrictamente la cota.

\footnotetext{
${ }^{14}$ Bernabé Poveda, M. A. Apuntes de la asignatura Diseño Cartográfico. http://nivel.topografia.upm.es/ mab, 10-0106.

15 Bertin, J. "La graphique et le traitement graphique de l’information”. 1977.
} 
Robinson aporta en 1987 una pequeña variación, adoptando como elementos gráficos básicos: color, valor, tamaño, forma, espaciado, orientación y ubicación.

Border D. Dent ${ }^{16}$, basándose en un trabajo de Morrison, introduce otra clasificación, definiendo las siguientes variables: Forma, Tamaño, Tono del color, Valor del color, Intensidad (saturación) del color, Orientación de la trama, Disposición de la trama y Textura de la trama.

Al comienzo de la década de los 90 se aceptan nuevos conceptos, como el de estructura o disposición de los rellenos (Muehrke $\left.{ }^{17}, 1992\right)$ y aparece el concepto de "nivel de incertidumbre de los datos del mapa" (MacEachren ${ }^{18}$, 1993) y la necesidad de representarlo, considerándose entonces que la saturación sería la variable más adecuada para ello. A las 7 variables de Bertin se le añaden algunas nuevas.

Estudiemos a continuación las variables por separado.

\subsubsection{Posición}

Como intuitivamente podemos suponer, la variable posición hace referencia a la situación del elemento que en el mapa representa a otro existente en la realidad, generalmente definida por sus coordenadas $(\mathrm{x}, \mathrm{y})$.

Esta variable condiciona totalmente la simbología del mapa, sobre todo teniendo en cuenta que una de las cualidades que debe tener un mapa es la precisión y por lo tanto la posición es la variable más relevante; esto implica que la colocación de los símbolos se vea altamente constreñida por la ubicación del elemento al que representan. Por otro lado, en ocasiones es imposible representar todos los elementos en su posición real, para evitar la superposición de los símbolos y la falta de claridad del mapa, y se procede a un falseo sistemático de los datos para la mejor comprensión del mapa.

\subsubsection{Forma}

La forma es la figura que distingue un determinado evento o símbolo, se puede aplicar a símbolos puntuales, lineales o superficiales.

En lo que a símbolos puntuales se refiere, generalmente pensaremos en un punto como en el cruce de dos líneas. Los símbolos puntuales suelen utilizarse para representar un fenómeno que no tiene representación a la escala del mapa, pero que interesa reseñar.

Si hablamos de símbolos lineales, y concibiendo la línea como una sucesión de puntos infinitamente próximos, podemos decir que atendiendo a su forma las líneas pueden ser rectas, curvas, mixtas, onduladas o quebradas. Pero a la hora de su representación en un mapa, no podemos variar esta característica. Cuando hablemos de forma de una línea nos referiremos al grafismo que la representa.

Y por último veremos qué ocurre con los símbolos superficiales, que son los que se refieren a un evento que afecta a una porción de territorio. El caso es similar al de la línea, no podemos variar la forma, es decir el contorno, pero sí la simbología de la línea que lo delimita.

\footnotetext{
16 Dent B.D. “Thematic Map Design”. 1990.

${ }^{17}$ Muehrcke, P.C. et al. "Map use”. 1992

18 MacEachren et al. "Geographic visualization”, 1993
} 


\subsubsection{Orientación}

Otra de las variables que podemos utilizar para indicar variaciones de un fenómeno es la orientación del elemento o símbolo que lo representa en el mapa. Al igual que en el punto anterior, distinguiremos entre los diferentes tipos de elementos.

Un elemento puntual propiamente dicho, un punto, no puede simbolizar nada con un cambio de orientación, ya que éste no es apreciable; pero sí lo es en un símbolo que utilicemos para representar un elemento puntual.

En los elementos lineales es de difícil aplicación, ya que un elemento lineal tiene su propia orientación y esto puede llevarnos a error. Esto no quiere decir que no se utilice en ocasiones puntuales.

Por el contrario se utiliza con frecuencia la orientación para distinguir simbologías de elementos superficiales, generalmente rellenos.

\subsubsection{Color}

El color resulta ser la variable más significativa ya que es la que intuitivamente permite distinguir más rápidamente entre dos símbolos.

La sensación de color resulta de las diferencias de percepción del ojo a las distintas longitudes de onda que recibe de la luz reflejada en los objetos. El ojo humano es capaz de distinguir entre 10.000 colores.

Esta variable, al ser fácil de diferenciar, no hace necesario un gran tamaño de símbolo, aunque los símbolos puntuales deben tener al menos 1,5 $\mathrm{mm}$ de diámetro porque al disminuir el diámetro se hace mucho más difícil la discriminación.

En los símbolos lineales, podremos utilizar un grosor menor que el diámetro del punto mencionado anteriormente, ya que la longitud del elemento permitirá en general distinguir el tono.

Y por último hablaremos de los símbolos superficiales, tradicionalmente se solía exponer en los textos de Cartografía que el tono debía aplicarse cuando los datos representados fueran cualitativos y se debería utilizar el valor cuando hubiera que mostrar diferencias de orden o cantidad.

Veamos unas pinceladas acerca de la teoría del color. 


\subsection{Naturaleza del color ${ }^{19}$}

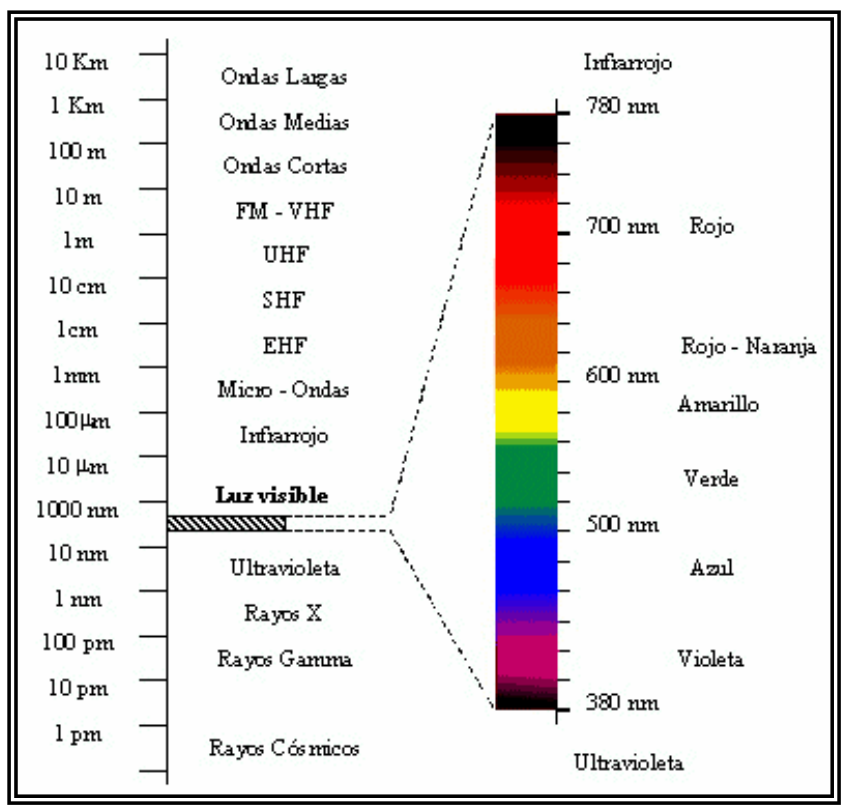

Figura 1.6. Espectro luminoso. Fuente: www.desarrolloweb.com.

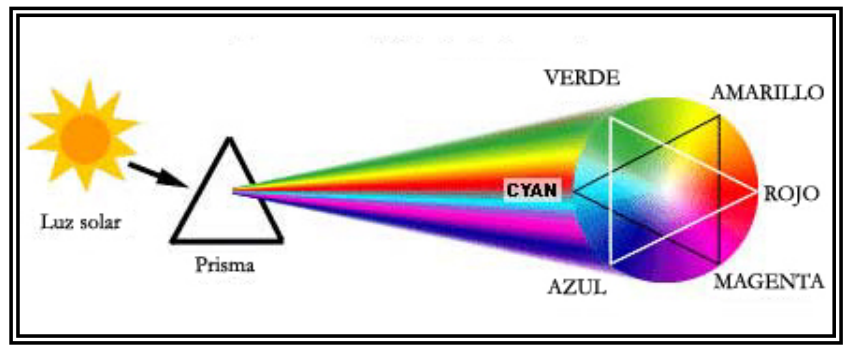

Figura 1.7. Descomposición de la luz.

Fuente: www.desarrolloweb.com.
La luz que procede del Sol está formada por un amplio espectro de radiaciones electromagnéticas de diferentes longitudes de onda, formando un espectro continuo que comprende desde longitudes de onda muy pequeñas, de menos de 1 picómetro (rayos cósmicos), hasta longitudes de onda muy grandes, de más de 1 kilómetro.

El ser humano tan solo es capaz de visualizar un subconjunto de ellas, las que van desde 380 (violeta) a 780 nanómetros (rojo), como podemos apreciar claramente si la hacemos pasar por un prisma, efecto descubierto por Newton.

Cada longitud de onda define un color diferente (colores de emisión). La suma de todos los colores (longitudes de onda) da como resultado la luz blanca, siendo el color negro u oscuridad la ausencia de colores.

Si una vez descompuesta la luz solar en sus longitudes de onda constituyentes volvemos a juntarlas con otro prisma, volveremos a obtener la luz blanca.

\footnotetext{
19 www.desarrolloweb.com. 30/07/07
} 


\subsection{Clasificación de los colores}

Podemos hacer varias clasificaciones de los colores, pero vamos a intentar sintetizar los sistemas de clasificación más empleados.

En primer lugar diremos que partiendo de los colores primarios, que son colores que se consideran absolutos y que no pueden crearse mediante la mezcla de otros colores, podremos obtener los colores a los que denominaremos secundarios, que obtendremos al mezclar a partes iguales colores primarios. Estos dos grupos de colores serán los más relevantes en las clasificaciones habituales, pero reseñaremos también los colores a los que denominaremos terciarios, que obtendremos al mezclar partes iguales de un tono primario y de un secundario adyacente. No podemos olvidar el resto de los colores, que serán fruto de la mezcla de los mencionados.

En general podemos encontrar tres conjuntos de colores primarios.

\section{- Primarios aditivos.}

No es necesaria la unión de todas las longitudes del espectro visible para obtener el blanco, ya que si mezclamos sólo rojo, verde y azul obtendremos el mismo resultado. Es por esto por lo que estos colores son denominados colores primarios aditivos, porque la suma de los tres produce el blanco. Además, todos los colores del espectro pueden ser obtenidos a partir de ellos ${ }^{20}$.

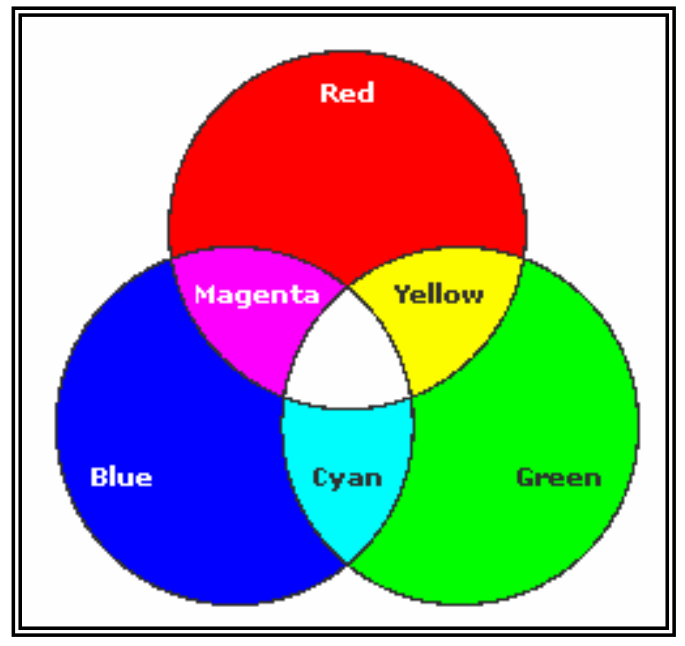

Figura 1.8. Primarios aditivos.

Fuente: www.desarrolloweb.com.
Los colores aditivos se utilizan en ocasiones en trabajo gráfico con monitores de ordenador, ya que los monitores antiguos producen los puntos de luz partiendo de tres tubos de rayos catódicos, uno rojo, otro verde y otro azul. Es lo que se llama modelo RGB (Red, Green, Blue).

Para representar un color en el sistema RGB se le asigna un valor entre 0 y 255 (notación decimal) o entre 00 y FF (notación hexadecimal) para cada uno de los componentes rojo, verde y azul que lo forman. Los valores más altos de RGB corresponden a una cantidad mayor de luz blanca. Por consiguiente, cuanto más altos son los valores RGB, más claros son los colores.

De esta forma, un color cualquiera vendrá representado en el sistema RGB mediante la sintaxis decimal $(R, G, B)$ o mediante la sintaxis hexadecimal \#RRGGBB.

\footnotetext{
${ }^{20}$ www.desarrolloweb.com. 30/07/07
} 


\section{- Primarios sustractivos.}

Aceptar esta clasificación supone adoptar una forma diferente de percibir el color.

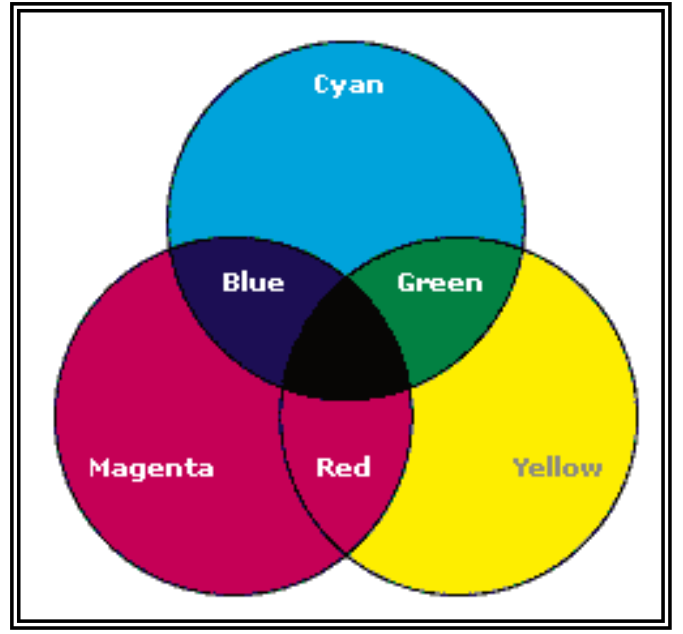

Figura 1.9. Primarios sustractivos.

Fuente: www.desarrolloweb.com.
Cuando la luz solar choca contra la superficie de un objeto, éste absorbe diferentes longitudes de onda de su espectro total, mientras que refleja otras. Estas longitudes de onda reflejadas son precisamente las causantes de los colores de los objetos, colores que por ser producidos por filtrado de longitudes de onda se denominan colores sustractivos ${ }^{21}$.

Aunque actualmente su empleo es más generalizado, en principio eran los empleados por los impresores. En imprenta, la separación de colores se realiza utilizando filtros para restar luz de los primarios aditivos, con lo que se obtienen los colores de impresión por proceso sustractivo.

Un coche es de color azul porque absorbe todas las longitudes de onda que forman la luz solar, excepto la correspondiente al color azul, que refleja, mientras que un objeto es blanco porque refleja todo el espectro de ondas que forman la luz, es decir, refleja todos los colores, y el resultado de la mezcla de todos ellos da como resultado el blanco. Por su parte, un objeto es negro porque absorbe todas las longitudes de onda del espectro: el negro es la ausencia de luz y de color.

En esta concepción sustractiva, los colores primarios son otros, concretamente el cian, el magenta y el amarillo. A partir de estos tres colores podemos obtener casi todos los demás, salvo el blanco y el negro.

Efectivamente, la mezcla de pigmentos cian, magenta y amarillo no produce el color blanco, sino un color gris sucio, neutro. En cuanto al negro, tampoco es posible obtenerlo a partir de los primarios, siendo necesario incluirlo en el conjunto de colores básicos sustractivos, obteniéndose el modelo CMYK (Cyan, Magenta, Yellow, Black).

El sistema CMYK, define los colores de forma similar a como funciona una impresora de inyección de tinta o una imprenta comercial de cuatricromía. El color resulta de la superposición o de colocar juntas gotas de tinta semitransparente, de los colores cian (un azul brillante), magenta (un color rosa intenso), amarillo y negro, y su notación se corresponde con el valor en tanto por ciento de cada uno de estos colores.

21 www.desarrolloweb.com. 30/07/07 
De esta forma, un color cualquiera vendrá expresado en el sistema CMYK mediante la expresión $(\mathrm{C}, \mathrm{M}, \mathrm{Y}, \mathrm{K})$, en la que figuran los tantos por ciento que el color posee de los componentes básicos del sistema. Por ejemplo, $(0,0,0,0)$ es blanco puro (el blanco del papel), mientras que $(100,0,100,0)$ corresponde al color verde.

Los sistemas RGB, CMYK se encuentran relacionados, ya que los colores primarios de uno son los secundarios del otro (los colores secundarios son los obtenidos por mezcla directa de los primarios).

\section{- Otro sistema}

Los artistas y diseñadores parten de un juego formado por el rojo, el amarillo y el azul. Mezclando pigmentos de estos colores pueden obtenerse todos los demás tonos.

\subsection{Componentes del color}

El color tiene tres componentes, tono, valor y saturación. De éstas, el tono es la más significativa, por ser la más fácilmente apreciable por el ojo humano.

\section{El tono (Hue)}

El tono viene dado por la longitud de onda, nos permite distinguir el rojo del azul, y se refiere al recorrido que hace un tono hacia uno u otro lado del círculo cromático, por lo que el verde

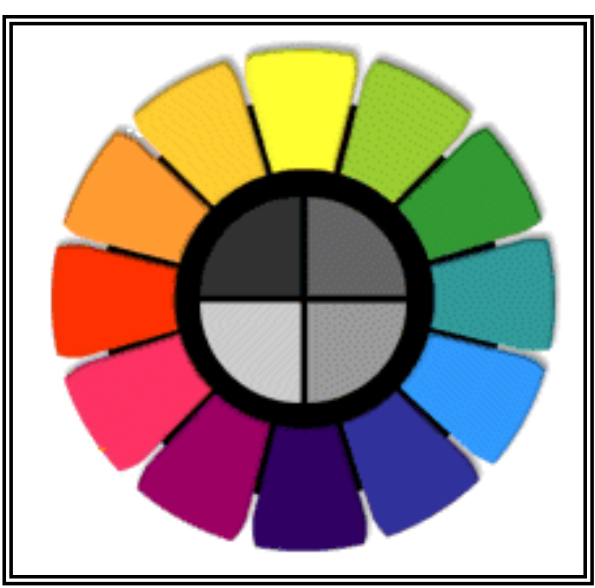

Figura 1.10. Círculo cromático.

Fuente: www.desarrolloweb.com. amarillento y el verde azulado serán tonos diferentes del verde.

En la figura 1.10. podemos apreciar los tonos en el círculo cromático.

Los 3 colores primarios representan los 3 matices primarios, y mezclando estos podemos obtener los demás matices o colores. Dos colores son complementarios cuando están uno frente a otro en el círculo de cromático.

Podemos hacer una división entre:

- Tonos cálidos (rojo, amarillo y anaranjados). Aquellos que asociamos con la luz solar, el fuego...

- Tonos fríos (azul y verde). Los colores fríos son aquellos que asociamos con el agua, la luz de la luna ...

\section{E1 valor o brillo (Value)}

El valor es la cantidad de luz reflejada, alude a la claridad u oscuridad de un tono. Es una condición variable, que puede alterar fundamentalmente la apariencia de un color. La luminosidad puede variar añadiendo negro o blanco a un tono. Dos colores diferentes (como 
el rojo y el azul) pueden llegar a tener el mismo tono, si consideramos el concepto como el mismo grado de claridad u oscuridad con relación a la misma cantidad de blanco o negro que contengan, según cada caso. La descripción clásica de los valores corresponde a claro (cuando contiene cantidades de blanco), medio (cuando contiene cantidades de gris) y oscuro (cuando contiene cantidades de negro).

La manera más fácil de apreciar estas diferencias de tono es con un esquema, fijémonos en la figura 1.11. que representa variaciones de tono del color rojo.

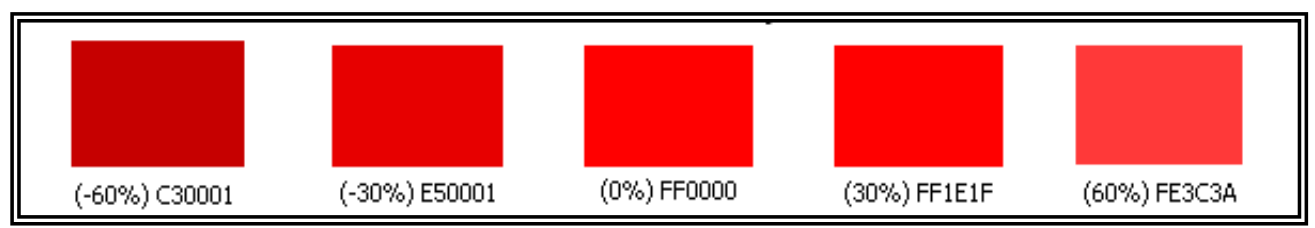

Figura 1.11. Diferencias de brillo en el color rojo. Fuente: www.desarrolloweb.com.

\section{La saturación (Saturation)}

La saturación es la pureza o la intensidad de un color, la viveza o palidez del mismo, y puede relacionarse con el ancho de banda de la luz que estamos visualizando. Los colores puros del espectro están completamente saturados. Un color intenso es muy vivo.

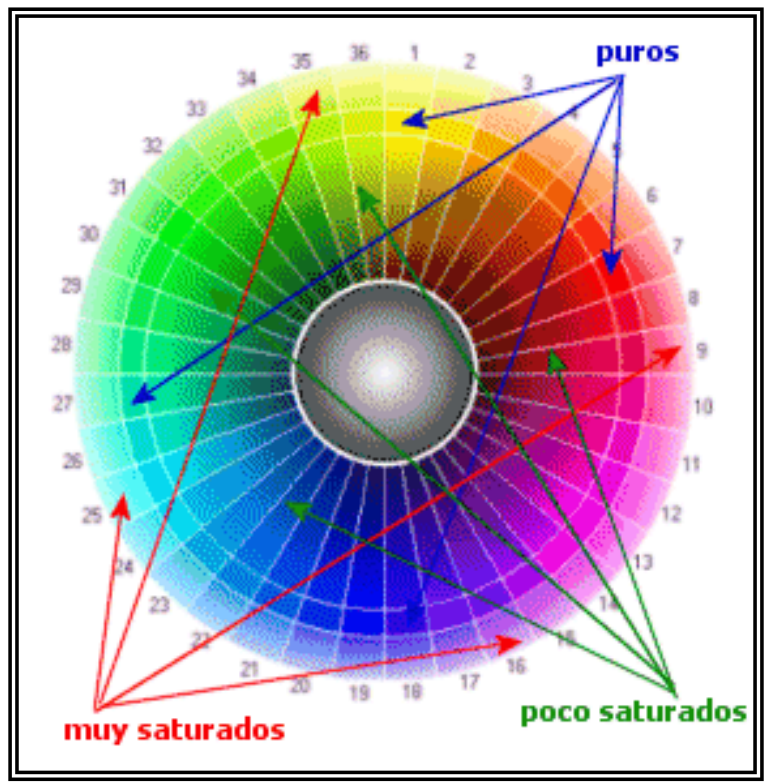

Figura 1.12. Saturación de los colores.

Fuente: www.desarrolloweb.com.

se le añada blanco y se convierta en celeste.
También puede ser definida por la cantidad de gris que contiene un color: cuanto más gris o más neutro es, menos brillante $\mathrm{o}$ menos "saturado" es. Igualmente, cualquier cambio hecho a un color puro automáticamente baja su saturación. Por ejemplo, decimos "un rojo muy saturado" cuando nos referimos a un rojo puro. Pero cuando nos referimos a los tonos de un color que tiene algún valor de gris, los llamamos menos saturados. La saturación del color se dice que es más baja cuando se le añade su opuesto (llamado complementario) en el círculo cromático.

Para restar saturación a un color sin que varíe su valor, hay que mezclarlo con un gris de blanco y negro de su mismo valor.

Un color intenso como el azul perderá su saturación a medida que 
Esta propiedad es siempre comparativa, ya que relacionamos la intensidad en comparación con otras cosas. Lo importante es aprender a distinguir las relaciones de intensidad, ya que ésta muchas veces cambia cuando un color está rodeado por otro.

Como en el ejemplo anterior, vamos a ilustrar la definición con un ejemplo donde se muestran diferentes saturaciones del color rojo.

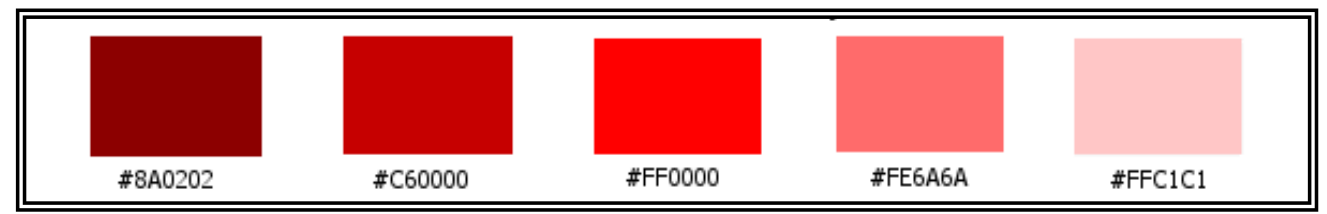

Figura 1.13. Diferencias de saturación en el color rojo. Fuente: www.desarrolloweb.com.

\section{El modelo HSV}

A partir de estas propiedades se ha establecido un modelo de definición del color, se trata del modelo HSV (Hue, Saturation, Value), que define los colores en función de los valores de los atributos estudiados anteriormente, tono, saturación y valor.

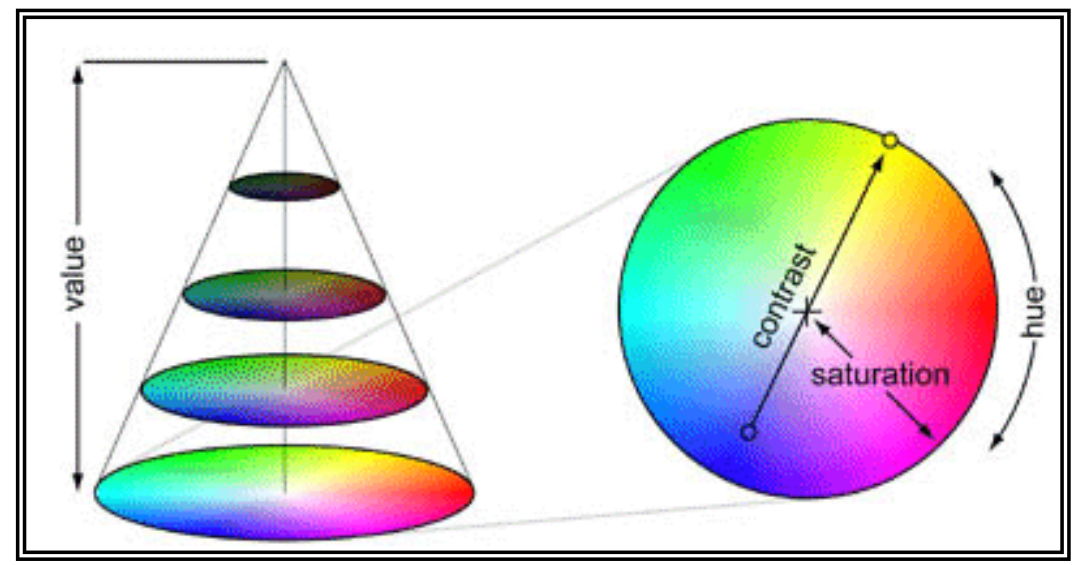

Figura 1.14. Sistema HSV. Fuente: www.desarrolloweb.com. 


\subsection{Propiedades perceptivas del color}

Los colores menos saturados transmiten sensaciones tranquilas y suaves, por el contrario los colores más saturados transmiten tensión.

La propiedad más determinante del color tal vez sea su carácter relativo. Ningún color puede ser evaluado al margen de su entorno. En el libro "Interacción del color" Josef Albers afirma que "un mismo color permite innumerables lecturas". Un mismo tono puede parecer diferente cuando se coloca sobre diferentes fondos, y diferentes colores pueden parecer casi el mismo cuando se asocian a distintos fondos.

Existen dos formas básicas compositivas del color que son ${ }^{22}$ :

\section{Armonía}

Armonizar significa coordinar los diferentes valores que el color adquiere en una composición, es decir, cuando en una composición todos los colores poseen una parte común al resto de los colores componentes. Armónicas son las combinaciones en las que se utilizan modulaciones de un mismo tono, o también de diferentes tonos, pero que en su mezcla mantienen los unos parte de los mismos pigmentos de los restantes.

En todas las armonías cromáticas, se pueden observar tres colores: uno dominante, otro tónico y otro de mediación. El tono dominante, que es el más neutro y de mayor extensión (su función es destacar los otros colores que conforman nuestra composición). El color tónico, normalmente en la gama del complementario del dominante, es el más potente en color y valor, y el de mediación, que su función es actuar como conciliador y modo de transición de los anteriores y suele tener una situación en el círculo cromático próxima a la del color tónico.

La armonía más sencilla es aquella en la que se conjugan tonos de la misma gama o de una misma parte del círculo, aunque puede resultar un tanto carente de vivacidad. Según diversas teorías la sensación de armonía o concordancia suscitada por una composición gráfica tiene su origen exclusivamente en las relaciones y en las proporciones de sus componentes cromáticos. Sería el resultado de yuxtaponer colores equidistantes en el círculo cromático o colores afines entre sí, o de tonos de la misma gama representados en gradaciones constantes, o del fuerte contraste entre tonos complementarios, o de los contrastes más suavizados entre un color saturado y otro no saturado y también de las relaciones entre las superficies que se asignen a cada valor tonal de nuestra composición.

\section{Contraste ${ }^{23}$}

Cuando dos colores diferentes entran en contraste directo, el contraste intensifica las diferencias entre ambos. El contraste aumenta cuanto mayor sea el grado de diferencia y mayor sea el grado de contacto, llegando a su máximo contraste cuando un color está rodeado por otro.

El efecto de contraste es recíproco, ya que afecta a los dos colores que intervienen. Todos los colores de una composición sufren la influencia de los colores con los que entran en

22 www.artesvisuales.com, 30/07/07

23 www.desarrolloweb.com. 30/07/07 
contacto. Existen diferentes tipos de contraste en función de si lo que diferencia los colores es la luminosidad, el color de fondo sobre el que se proyectan...

\section{Contraste de luminosidad}

También denominado contraste claro-oscuro, se produce al confrontar un color claro o

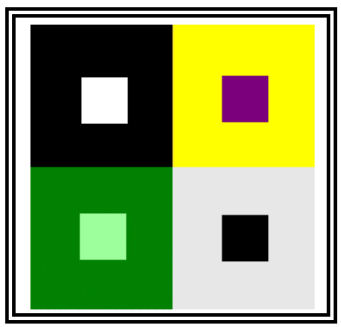
saturado con blanco y un color oscuro o saturado de negro.

Es uno de los más efectivos, siendo muy recomendable para contenidos textuales, que deben destacar con claridad sobre el fondo.

Figura 1.15. Contraste de luminosidad.

Fuente: www.desarrolloweb.com.

\section{Contraste de valor}

Cuando se presentan dos valores diferentes en contraste simultáneo, el más claro parecerá más alto y el más oscuro, mas bajo.

Por ejemplo, al colocar dos rectángulos granates, uno sobre fondo verdoso y el otro

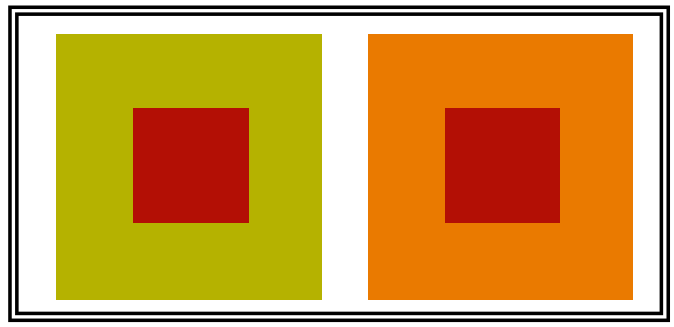
sobre fondo naranja, veremos más claro el situado sobre fondo verdoso.

La yuxtaposición de colores primarios exalta el valor de cada uno.

Figura 1.16. Contraste de valor. Fuente: www.desarrolloweb.com.

\section{Contraste de saturación}

Se origina de la modulación de un tono puro, saturándolo con blanco, negro o gris. El contraste puede darse entre colores puros o bien por la confrontación de éstos con otros no puros.

Los colores puros pierden luminosidad cuando se les añade negro, y varían su saturación mediante la adicción del blanco, modificando los atributos de calidez y frialdad. El verde es el color que menos cambia mezclado tanto con blanco como con negro.

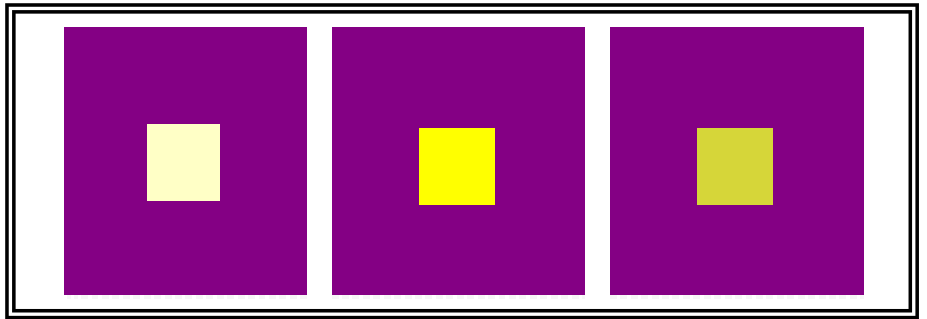

Figura 1.17. Contraste de saturación. Fuente: www.desarrolloweb.com. ejemplo, si situamos sobre un mismo fondo tres rectángulos con diferentes saturaciones de amarillo, contrastará más el más puro. 


\section{Contraste de temperatura}

Es el contraste producido al confrontar un color cálido con otro frío.

La calidez o frialdad de un color es relativa, ya que el color es modificado por los

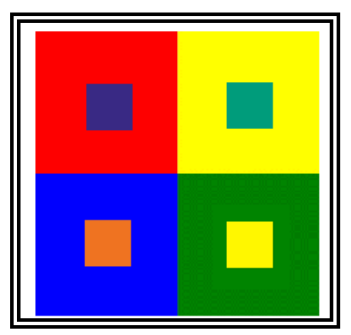

colores que lo rodean. Así un amarillo puede ser cálido con respecto a un azul y frío con respecto a un rojo. Y también un mismo amarillo puede ser más cálido si está rodeado de colores fríos y menos cálido si lo rodean con rojo, naranja, etc.

Figura 1.18. Contraste de temperatura.

Fuente: www.desarrolloweb.com.

\section{Otros contrastes}
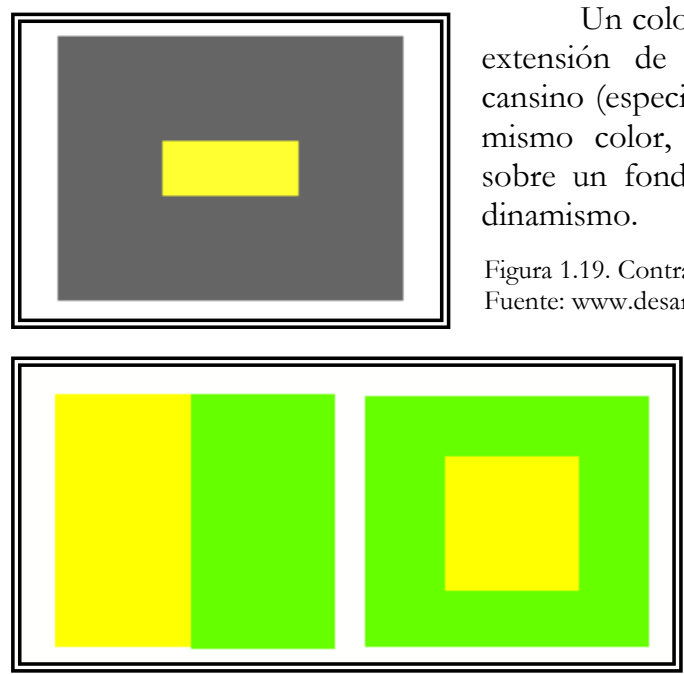

Un color puro y brillante aplicado en una gran extensión de la página suele resultar irritante y cansino (especialmente, el amarillo), mientras que ese mismo color, usado en pequeñas proporciones $\mathrm{y}$ sobre un fondo apagado puede crear sensación de dinamismo.

Figura 1.19. Contraste de color brillante. Fuente: www.desarrolloweb.com.

Dos colores claros brillantes puestos uno al lado de otro impactan en nuestra vista, produciendo un efecto de rechazo, mientras que si esos dos mismos colores los situamos uno dentro del otro el efecto cambia por completo, resultando agradable.

Figura 1.20. Contraste de dos colores brillantes. Fuente: www.desarrolloweb.com.

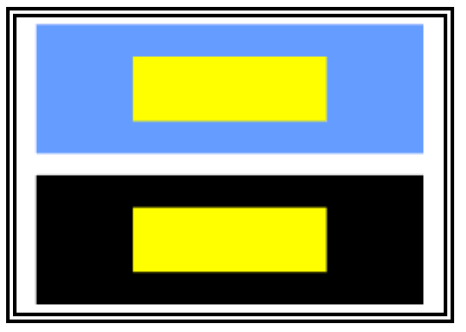

Figura 1.21. Metamerismo.

Fuente: www.desarrolloweb.com.
Un mismo color puede cambiar mucho su aspecto visual dependiendo del color en el que se encuentre embutido. Este efecto del cambio de apariencia de un color dependiendo de la luz incidente sobre él, del material de que esta formado o del diferente color que le sirva de fondo recibe el nombre de Metamerismo.

En este ejemplo vemos dos cuadrados, uno de color de fondo azul, y otro negro, ambos con un cuadrado amarillo dentro. Los dos cuadrados interiores son del mismo amarillo, pero parecen 
diferentes: en fondo azul se enmascara la pureza del amarillo, mientras que en fondo negro el amarillo muestra toda su pureza y frescura.

\subsubsection{Textura}

La textura hace referencia al relleno, a la trama que éste tenga. Con la misma proporción de blanco/negro, la trama será diferente en la medida en que varíe al hacer ampliaciones. No debemos confundir la variación de textura con la variación de tamaño, en este último sí se producen variaciones de la proporción de blanco/negro. Es importante tener en cuenta los efectos vibratorio y sombra que puede producir la utilización de tramas.

En los símbolos puntuales sólo será apreciable un cambio de textura cuando el símbolo sea considerablemente grande. Por otro lado el caso de los elementos lineales resulta confuso, porque no hay consenso acerca de qué es realmente un cambio de textura en un elemento lineal, suele confundirse con el tamaño o la estructura de lo línea. El uso ideal de la textura reside en los elementos superficiales, aquellos que pueden rellenarse.

\subsubsection{Valor}

Cuando hablamos de valor nos referimos a la oscuridad relativa del relleno, la cantidad de luz que refleja; diremos que tenemos un alto valor cuando encontremos claridad y un valor bajo para la oscuridad, aunque generalmente en la cartografía en formato papel suele asociarse la oscuridad a un mayor valor que la claridad.

\subsubsection{Tamaño}

Como se puede suponer, esta variable se refiere a la dimensión del símbolo.

Huelgan explicaciones en lo que a elementos puntuales se refiere.

Si nos ocupamos de elementos lineales, existen tamaños normalizados de línea que permiten diferenciar claramente una de otra sin que exista ambigüedad en su identificación, siempre que el número de líneas no sea grande. Cuando el número de grosores es mayor que 4, comienza a aparecer la ambigüedad, pues no parece adecuado sobrepasar el límite de $1 \mathrm{~mm}$ en características lineales. Para que dos líneas de distinto grosor se diferencien sin ambigüedad y sin estar próximas, cada una debe diferenciarse de la superior al menos en un $80 \%$ de su grosor. De esa forma, si se comienza en $0.06 \mathrm{~mm}$-un tamaño en el límite de ser percibido por el ojo humano- la serie máxima estará compuesta por 6 grosores diferentes: 0.06, 0.10, 0.18, $0.32,0.58$ y $1.0 \mathrm{~mm}$. (con algunos redondeos).

$\mathrm{Y}$ en lo que a superficie se refiere, lo relacionaremos con el tamaño del símbolo utilizado en la trama.

La variación de tamaño tiene una relevancia especial cuando estamos trabajando con información cuantitativa, ya que resulta la única manera de cuantificar variables por medio de símbolos. 


\subsubsection{Tipos de datos}

Partiendo de este concepto de Cartografía podemos encontrar dos tipos de datos muy diferentes: los datos topográficos, que definen la forma y dimensiones del terreno; y los datos temáticos, que aportan una información extra que se localiza en un lugar de ese terreno, y que puede versar sobre los aspectos más variopintos, tanto del terreno como de la sociedad que los habita.

\subsubsection{Tipos de datos temáticos}

Vamos a establecer una clasificación de los datos temáticos según tengan una componente principalmente cuantitativa o cualitativa, siendo para cada caso diferente la forma en la que los trataremos.

Datos Cualitativos

Cuando tratemos datos cualitativos obtendremos como resultado una codificación en la que todos los símbolos tendrán el mismo peso, enlazando esto con el escalado de los datos podemos decir que se tratará de una escala nominal.

Para la representación de datos puntuales utilizaremos símbolos pictóricos, geométricos, números o letras (plano municipal de lugares de interés); para el caso de símbolos lineales, se suelen utilizar cambios de color, aunque también es posible el uso de cambio de tipo de línea (mapa de senderos de una zona turística); por último para el caso de datos superficiales se suele utilizar el cambio de color, aunque sería también posible el uso del cambio de tramado (mapa de cultivos).

\section{Datos Cuantitativos}

En este caso la variedad de mapas así como las opciones de representación son mucho mayores.

\subsubsection{El dato geográfico ${ }^{24}$}

La labor del cartógrafo consiste en transmitir de una forma clara un conjunto de "eventos" que se producen en una ubicación determinada, las variables geográficas son múltiples y de diferentes tipos. Es el dato geográfico lo que en última instancia queremos que llegue al usuario de la cartografía, pero para que este proceso se produzca correctamente deberemos analizar ese dato, para poder elegir correctamente los símbolos que utilizaremos a la hora de representarlo.

\subsubsection{Tipos según su dimensión}

Debemos señalar que la dimensionalidad de un dato puede variar en función de la escala de la cartografía en la que queramos representarlo, de este modo un elemento puede ser puntual a una escala pequeña como 1:25000, piénsese por ejemplo en un edificio singular, y sin embargo tener entidad superficial en un plano a gran escala como pudiera ser un 1:500; de la

${ }^{24}$ Robinson A. et al., "Elementos de Cartografía", 1987. 
misma forma el cauce de un río será lineal o superficial también dependiendo de la escala. Dicho esto, y teniendo en cuenta las dimensiones de los datos, podemos establecer la siguiente clasificación:

- Datos puntuales (adimensionales). Son datos que tienen una localización individual, se asocia cada dato con un único punto. Son datos de este tipo elementos como Fuente, Mina, o bien datos estadísticos como Cantidad de Población.

- Datos lineales (unidimensionales). Son todos aquellos cuya característica principal es su unidimensionalidad. Como suelen ser los Límites Administrativos, Cursos Fluviales, Vías de Comunicación..., o también datos estadísticos como Flujos Migratorios.

- Datos superficiales (bidimensionales). Que tienen una representación superficial, como por ejemplo el tipo de cultivo dominante, el idioma principal...

- Datos volumétricos (tridimensionales). Es importante aclarar que cuando hablamos de datos volumétricos no nos referimos exclusivamente a aquellos que se refieren a elementos con volumen, de la misma forma que cuando hablamos de "Modelos Digitales del Terreno" no nos referimos estrictamente a "Modelos Digitales de Elevaciones", puesto que lo que utilizamos como coordenada Z, la tercera dimensión, puede ser cualquier otro tipo de dato; pensemos por ejemplo en los mapas isobáricos que cada día vemos en las informaciones meteorológicas, donde el tercer dato es la presión atmosférica.

- Datos espacio-temporales (cuatro dimensiones)

Serán estos últimos datos los más problemáticos a la hora de representarlos en la cartografía, para clarificar esta cuestión consideraremos cuatro tipos de medidas: nominales, ordinales, intervalos y ratios, para cuya representación se utilizará una simbología diferente.

\subsubsection{Tipos según su continuidad}

El tratamiento que demos a los datos cartográficos será diferente según estén distribuidos de forma discreta, o lo que es lo mismo discontinua, o su distribución sea continua; la diferencia radica principalmente en el hecho de que si los datos con los que debemos trabajar se distribuyen de una manera discreta, sólo tendremos datos para ciertas zonas del mapa, por el contrario si la distribución es continua no existirá ninguna zona del mapa que carezca de datos. Pensemos por ejemplo en un mapa de servicios en el que figuren gasolineras, centros de salud, etc., en un trabajo de estas características sólo tendríamos datos para localizaciones puntuales, se trata de una distribución discreta; sin embargo en un mapa por ejemplo de cultivos, encontraremos datos para el conjunto del mapa, teniendo un distribución continua.

Gran cantidad de los datos discretos pueden transformarse en continuos con una variación del concepto, como puede ser por ejemplo convertir los datos puntuales en intervalos y vincular una simbología a esos intervalos o relacionar el dato con una superficie determinada, véase por ejemplo la población total o la densidad de población. 


\subsubsection{Tipos según su uniformidad}

Hablaremos de datos uniformes cuando entre dos zonas próximas existe una diferencia progresiva en el valor de los datos, como puede ser la altitud sobre el nivel del mar. Por el contrario diremos que la distribución de los datos no es uniforme cuando entre dos zonas próximas el valor de los datos varía bruscamente, como sucede por ejemplo con los niveles de renta o escolarización.

\subsubsection{Escalado de los datos}

A la hora de abordar un proyecto de Cartografía, nos encontraremos con que debemos reflejar uno conjunto de datos en un mapa y que esto resulta imposible si no procesamos esos datos de algún modo. Para ello generalmente se recurre al escalado de las variables. Este escalado lo podemos realizar de cuatro formas:

\section{Escalas nominales}

Son las que utilizaremos cuando hagamos la distinción entre los elementos según consideraciones cualitativas y no cuantitativas, por ejemplo cuando hacemos uso de la toponimia. Dado que un mapa es bidimensional no se puede tratar un volumen como tal si no se utiliza un atributo, en consecuencia, podremos utilizar este tipo de escalas para elementos puntuales, lineales o superficiales, pero no volumétricos, para ello será preciso el uso de escalas superiores como las ordinales, de intervalo o de índices.

Escalas ordinales

Pueden entenderse como una ampliación de las escalas nominales, ya que se basan en éstas, pero introducen una clasificación por rango según un criterio cuantitativo; en esta clasificación no se especifica valor alguno, hablaremos únicamente de rangos. Este tipo de clasificación facilita en ocasiones la comprensión de los datos, pero no aporta datos concretos.

Escalas de intervalo

Resultan ser una ampliación de las escalas ordinales, con la diferencia de que en este caso se dota de un valor numérico a cada intervalo, para ello se deberá utilizar una unidad de medida convencional y se especificará en la leyenda.

Escalas de índices

Desde el punto de vista cartográfico esta escala es la misma que la de intervalo, la única diferencia reside en el hecho de que en este caso el punto de partida de las escalas no es arbitrario. Se trata pues de un caso concreto de escala de intervalo en el que la información tiene un mayor significado, sobre todo para ciertos colectivos. Fijémonos por ejemplo en la representación del relieve mediante curvas de nivel, podemos tomar (y es la forma habitual de hacerlo) como punto de partida el nivel medio del mar, en ese caso tendríamos una escala de índices, si tomásemos cualquier otro valor seguiríamos teniendo la misma información acerca del relieve de forma relativa, pero no en el sistema absoluto que generalmente se utiliza, se trataría de una escala de intervalo.

\subsubsection{Formatos de almacenamiento}

Debido al auge que la informática ha tenido en los últimos años, el método utilizado para almacenar los datos ha variado considerablemente, mientras hace no demasiado tiempo 
los datos se almacenaban en montones de papel, actualmente podemos tener toda esa información en un soporte digital que llevamos en el bolsillo.

\subsubsection{Formato analógico}

Hablando de Cartografía, cuando nos referimos al formato analógico estamos pensando en datos o mapas en papel. La introducción de la informática en todos los ámbitos de la vida, ha tenido como consecuencia que el uso de este formato haya quedado obsoleto en muchos terrenos y, cómo no, también en el campo de la Cartografía.

Este destierro del formato analógico frente al digital se debe a varios motivos, el más importante de ellos es la facilidad que nos ofrece la informática para reutilizar los datos, modificarlos y generar nueva cartografía o actualizar la existente; por otro lado eliminamos el problema del almacenamiento masivo de papel, que además de incómodo es más frágil y de más difícil acceso.

\subsubsection{Formato digital}

Ni que decir tiene que ante el actual panorama tecnológico resultaría absurdo afrontar cualquier proyecto sin disponer de los datos necesarios en formato digital. A la hora de abordar el tema de la elaboración de cartografía, podemos disponer de dos tipos de información: datos que tienen una representación espacial que se puede asimilar a un elemento geométrico simple; o datos que asimilamos a un mapa de bits, se trata de lo que conocemos como información vectorial o ráster.

Formato vectorial

Como acabamos de introducir, podemos disponer de los datos de tal manera que la información se almacene como un conjunto de entidades puntuales, lineales o de superficie (polígonos) definidos por sus vértices. De este modo, cada elemento con representación cartográfica se asimila a una forma geométrica simple que se almacena como un conjunto de coordenadas, que corresponden a las coordenadas de sus vértices.

Por supuesto que siempre dependeremos de la escala de trabajo, pero en principio este método ofrece una mayor precisión espacial.

Información geográfica en formato ráster

En este caso la información se almacena en un mapa de bits, supondremos el territorio dividido por una malla en la que cada cuadrado será lo que llamaremos píxel, y su tamaño dependerá de la resolución de la imagen, no refiriéndonos cuando hablamos de imagen a una imagen real. A cada uno de estos píxeles se le asignarán los valores correspondientes.

Información geográfica alfanumérica

Se trata de datos no estrictamente cartográficos, pero que generalmente constituirán la información central que deberá aportar en último término la cartografía generada. Estos datos se almacenan generalmente en bases de datos.

\subsubsection{Diseño del mapa}

Entendiendo, como ya hemos comentado, el mapa como un medio de comunicación, deberemos definir correctamente el que será nuestro "lenguaje", éste debe ser claro y permitir 
una correcta distinción entre los diferentes símbolos que corresponden a eventos diferentes, de la misma forma, resultará útil que se puedan relacionar datos similares con símbolos parecidos.

El primer paso para conseguir un diseño correcto del mapa radicará en la elección de la simbología que consideremos correcta teniendo en cuenta qué información queremos transmitir y a quién. Esto implica tener en cuenta el tipo de mapa a generar, su escala, quienes serán lo usuarios, etc.

El segundo paso consistirá en la correcta disposición de los símbolos, de manera que el conjunto aporte una visión al usuario que se asemeje lo más posible a aquella que queremos transmitir.

Es lógico pensar que estos procesos no siguen un orden estricto, para elegir los símbolos a utilizar deberemos tener en cuenta dónde los tendremos que colocar y el tamaño final que queremos que tengan, lo cual dependerá de la escala, el tamaño del papel, el tipo de mapa..., como puede deducirse se trata de un proceso conjunto en el que no puede tomarse una decisión sin tener en cuenta todos los factores implicados.

El diseño del mapa tiene unos componentes gráficos, que son los atributos de los signos utilizados en la representación de los fenómenos y que poseen un significado relevante para el conjunto total del mapa. Estos componentes se comentan brevemente a continuación ${ }^{25}$.

\subsubsection{Claridad y legibilidad}

Serán dos cualidades imprescindibles a exigir a toda cartografía y que conseguiremos mediante la correcta elección de símbolos, grosores, colores, etc. Las líneas deberán distinguirse con claridad, al igual que los colores o tramados y la simbología utilizada no deberá prestarse a confusión.

Para conseguir este objetivo será imprescindible tener en cuenta el tamaño, que está íntimamente relacionado con la escala. Todas las decisiones que tomemos con respecto al diseño de la simbología deberán tener en cuenta el tamaño final que ésta tendrá en nuestro mapa. Se acepta normalmente que el cerebro humano no es capaz de distinguir un símbolo menor que aquel que forma un ángulo de 1' con respecto al ojo humano en condiciones ideales, como generalmente no se darán esas condiciones ideales de luz, claridad, etc., consideraremos ese ángulo como 2', que en la práctica supone fijar un límite de 0,3 mm, suponiendo que observaremos el papel desde unos $50 \mathrm{~cm}$ de distancia.

Para que un mapa pueda ser comprendido por la mayoría de los usuarios debe seguir una serie de reglas que J. Bertin relaciona en su obra "Sémiologie graphique".

Diremos en primer lugar que existe una cantidad óptima de símbolos por centímetro cuadrado, concepto que se conoce como densidad gráfica, que permitirán el correcto entendimiento del mapa; del mismo modo, es imprescindible que los símbolos incluidos en ese mapa sean fácilmente identificables entre ellos, que no se solapen. Por otro lado, será imprescindible la separación de fondo y mapa, de objetos significativos o menos significativos, etc. Para poder abordar con éxito esta cuestión haremos uso de las variables retinianas ${ }^{26}$, señaladas anteriormente como variables visuales.

25 Robinson A. et al., "Elementos de Cartografía", 1987.

26 Bertin J., "Sémiologie graphique”, 1967. 
Se he llegado a la conclusión de que la legibilidad de un documento cartográfico se degrada considerablemente a causa de una densidad de signos excesiva. Experimentalmente se ha determinado que diez signos por centímetro cuadrado representa un límite a no superar.

Si pensamos en dos elementos lineales iguales, pero que deben ser distinguidos con facilidad, la lógica nos hace pensar que si los citados elementos forman un ángulo cercano a $0^{\circ}$ o $180^{\circ}$, será mucho más difícil discernir cuál es cuál.

\subsubsection{Contraste visual}

La existencia de contraste es una condición de especial relevancia, puesto que no importa lo intuitivos que sean los símbolos, lo adecuada que sea su escala o la pertinencia de sus colores, si no existe un contraste entre ellos o entre ellos y el fondo. Cuando hablamos de contraste no sólo nos referimos al contraste de tono o color, también podemos utilizar un "contraste" de tamaño para discriminar unos datos de otros. Por el contrario, un contraste excesivo puede hacer que la visión del mapa resulte desagradable, produciendo un efecto indeseable que deberemos tratar de evitar.

\subsubsection{Equilibrio visual}

Consiste en conseguir que cuando el usuario final observe la cartografía que vamos a generar, no tenga la impresión de que existen elementos "fuera de lugar", es decir, que todos los elementos que componen nuestro mapa guarden cierta armonía.

Para conseguir este efecto no existe una receta única, pero se supone que el equilibrio visual se consigue situando correctamente cada elemento con respecto al centro visual de la hoja, siempre teniendo en cuenta la importancia de aquel y su peso visual. El centro visual que hemos mencionado se encuentra situado ligeramente por encima del centro del formato.

\subsubsection{Figura-Fondo}

El cerebro humano está acostumbrado a distinguir figuras que capta claramente sobre un fondo al que presta una menor atención. Nuestro deber es explotar esta cualidad, intentando ayudar al cerebro a discernir entre lo que nosotros consideramos que debe ser figura y lo que será el fondo. Esto lo conseguiremos mediante la utilización de diferentes colores, tonos, grosores, sombras, etc.

\subsubsection{Organización jerárquica}

Este punto se refiere al hecho de que dentro de nuestra cartografía habrá elementos que consideraremos más relevantes que otros y así deberá percibirlo el usuario final, para lograr este efecto deberemos hacer una combinación correcta de los elementos gráficos.

Distinguiremos tres tipos de organización:

Organización de extensión, con la que se expresa la importancia relativa de los objetos mediante cambios en el color, grosor, etc. Como ejemplo podemos pensar en la red de carreteras, donde encontramos viales de diferente importancia representados por líneas diferentes. 
Organización de subdivisión, que se utiliza para representar diferentes niveles de un mismo atributo, como por ejemplo haríamos en un mapa de cultivos, geológico, etc. En general se utilizan diferencias de diseño o color.

Organización estereográmica, donde se intenta que el usuario perciba diferencias de nivel entre varios componentes de un mapa, es decir, conseguir que cierto conjunto de datos adquiera más relevancia que el resto.

\subsubsection{Tipos de símbolos.}

Del mismo modo que, como ya hemos comentado, los datos pueden ser de varios tipos, también los símbolos que los representen serán de distinto tipo; vamos a establecer una sencilla clasificación en: símbolos puntuales, símbolos lineales y símbolos zonales. (Robinson, 1987).

$\underline{\text { Símbolos puntuales }}$

Son aquellos que se utilizan para representar un dato que se produce en una ubicación determinada, y aunque realmente el dato se refiera a una zona se aportará el dato en un punto concreto de la citada área. Se excluye entonces cualquier concepto de dimensión, aunque en la realidad el elemento sí ocupe un espacio determinado. Se pueden considerar como puntos los círculos cuyo diámetro es menor de $2 \mathrm{~mm}$. Suelen aparecer muy asociados a la variable color. Como puntuales podemos utilizar símbolos pictóricos, geométricos, letras o números, etc.

\section{$\underline{\text { Símbolos lineales }}$}

No se hace necesario explicar en qué consiste un símbolo lineal, lo que sí vamos a reseñar es que un símbolo lineal no tiene necesariamente que representar a un dato lineal, véanse por ejemplo las curvas de nivel, que representan el nivel de una superficie, se trata entonces de un dato volumétrico. A las líneas que no representan un elemento real del terreno sino cierta cualidad asociada a éste, se les denomina isolíneas, líneas isométricas o isopletas.

$\underline{\text { Símbolos zonales }}$

Como su nombre indica se trata de símbolos que cubren una determinada superficie del mapa y que representan zonas con un mismo valor o característica.

Dentro de esta clasificación básica, podemos en Cartografía encontrar varios tipos de símbolos puntuales, como son: signos, cartodiagramas y figuras geométricas, veamos a continuación una breve descripción de los mismos.

Signos. Denominamos así a figuras más o menos esquemáticas, a las que se les asigna un significado en principio aleatorio, pero de tal modo que su valor sea fácil de averiguar de forma intuitiva. Encontraremos signos convencionales, que aparecen generalmente en todos los mapas con simbologías similares y que suelen apoyarse en una leyenda y también signos pictóricos, que son una representación lo más fidedigna posible, pero a la vez esquemática, del elemento a representar.

Cartodiagramas. Son mapas que contienen gráficas que representan los valores de un fenómeno en un periodo de tiempo, generalmente en el punto en el que se encuentra la gráfica.

Figuras geométricas. Que se utilizan como símbolos arbitrarios para representar los valores que toma una variable. 


\subsubsection{Tipografía y rotulación}

Entendemos como rotulación del mapa todos aquellos nombres que incluimos en el mismo. La función de toda cartografía es comunicar algún tipo de información, resulta obvio que un mapa "mudo" no aporta excesiva información a la mayoría de los usuarios, de ahí la importancia de la rotulación del mapa.

Se trata de un proceso muy laborioso, ya que el procedimiento no está automatizado y no siempre resulta fácil situar todos los nombres que deseamos incluir en nuestra cartografía. Es por ello de vital importancia la correcta elección de la tipografía que utilizaremos para cada tipo de elemento, de esto dependerá en gran medida la inteligibilidad del mapa; una correcta elección de la tipografía (tipo de letra, color, grosor, tamaño, inclinación, etc.) tendrá como resultado un más fácil acceso a la información, con el consiguiente incremento de la funcionalidad del documento cartográfico.

Son varios los elementos a tener en cuenta a la hora de elegir la tipografía:

Estilo de letra. Actualmente existe una gran variedad de tipos de letra que además son de fácil acceso y uso gracias a la informática. A la hora de elegir el tipo o tipos de letra a utilizar deberemos tener en cuenta no sólo cuántas clases de elementos debemos diferenciar, sino también si vamos a utilizar mayúsculas, negrita, cursiva o versalitas, lo que puede reducir bastante el número de estilos a utilizar y contribuir a la armonía del mapa.

Forma. Cuando hablamos de forma nos referimos al uso de mayúsculas, negrita, cursiva o versalitas. No existe una norma general que oriente al cartógrafo acerca del uso de diferentes formas, pero sí hay unas pautas generalmente seguidas, como son: el hecho de utilizar mayúsculas para nombres cuya separación entre las letras sea amplia; el uso de cursiva para accidentes geográficos, o normal para denominaciones antrópicas.

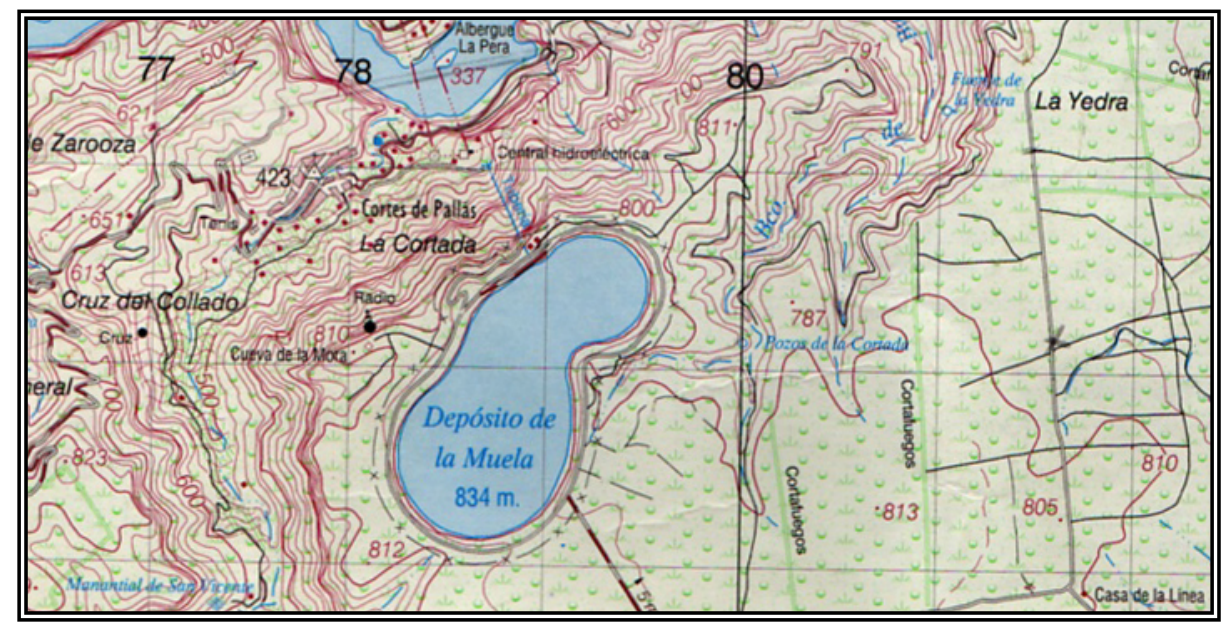

Figura 1.22. Mapa donde se utilizan diferentes tipos, tamaños y colores de letra. Fuente: Ejército serie L. 
Tamaño. No es una tarea sencilla la elección del tamaño de letra de cada texto según la importancia que se quiere dar al elemento que denomina, ya que este tamaño depende del tipo de letra utilizado y también del uso de mayúsculas o cursiva.

Podemos encontrar dos formas de designar el tamaño de la letra, por puntos o por tamaño en milímetros. Si se utiliza el sistema de medición por puntos, se pueden encontrar grandes variaciones de tamaño entre dos tipos de letra con cierto número de puntos si hablamos de minúsculas, con las mayúsculas la diferencia no es tan acusada.

No podemos jugar con el tamaño de forma ilimitada, ya que el ser humano no es capaz de distinguir sutiles cambios de tamaño si los textos no están situados uno al lado de otro. Hay estudios $^{27}$, que aconsejan no utilizar más de tres tamaños para diferenciar categorías del mismo dato.

Color. En cartografía, al contrario que para la representación de la cartografía propiamente dicha, no se suele utilizar gran variedad de colores para la tipografía, antes bien, generalmente se usa el color negro para todos los elementos (por su contraste con los elementos representados) excepto para la hidrografía, donde se utiliza el azul.

\subsubsection{Representación gráfica de la información.}

En ocasiones la solución óptima para la representación de la información pasa por la utilización de gráficos, cuyo objetivo es mostrar las relaciones entre las diferentes magnitudes, así como el valor y la representatividad de cada dato con respecto al total.

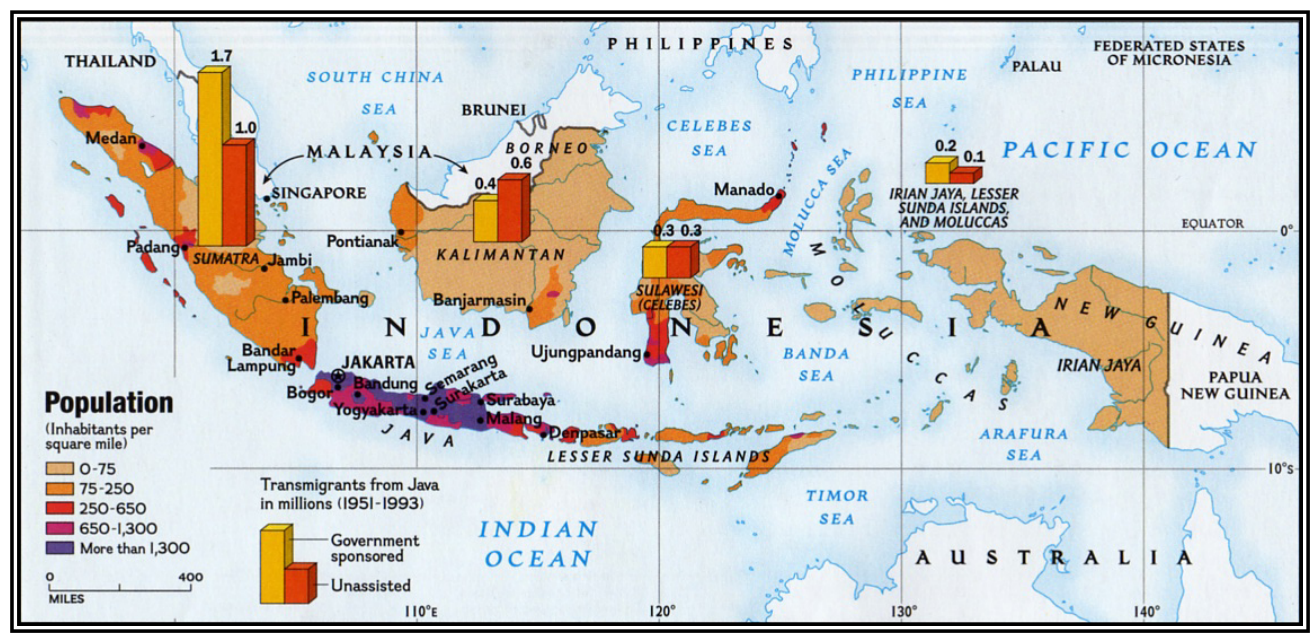

Figura 1.23. Mapa donde se utilizan gráficos de barras. Fuente: National Geographic Society.

${ }^{27}$ Robinson A. et al., "Elementos de Cartografía", 1987. 
Podemos servirnos de diferentes tipos de gráficos:

- Gráficos lineales. Que nos resultarán útiles para relacionar varios elementos, estudiar la variación temporal de un fenómeno, etc. Generalmente la variable independiente se representa en el eje de abscisas y la dependiente en el de ordenadas.

- Gráficos de barras. Se utilizan para representar información acerca de fenómenos muy variables. Como muestra la figura 1.23.

- Gráficos sectoriales. Permiten representar dos informaciones al mismo tiempo. Por un lado el tamaño del círculo nos indica el peso total del fenómeno y por otro, según el área de cada sector sabremos el peso de cada variable respecto al fenómeno global.

- Diagramas triangulares. Se usan para representar una cantidad constante en tres elementos variables.

- Gráficos de escala semilogarítmica. Permiten relacionar un elemento constante a lo largo del eje horizontal con un elemento variable que cambia proporcionalmente en el eje vertical. Se utiliza cuando queremos representar características muy dispares. 


\subsection{E1 Territorio y el desarrollo sostenible}

El creciente desarrollo de nuestra civilización y su influencia en el medio natural han hecho que resulte imprescindible lo que hoy se conoce en términos generales como "Ordenación del Territorio". Esto viene en realidad a suponer una ordenación de las actividades que los ciudadanos de un territorio desarrollan y que pueden tener cierta influencia en el medio ambiente. El concepto de Ordenación del Territorio está hoy en día fuertemente ligado al de "Desarrollo Sostenible".

\subsection{1. $\quad$ E1 Territorio}

\subsubsection{Concepto}

Cuando hablamos de territorio nos referimos generalmente a una porción concreta del medio físico en el que se llevan a cabo las actividades del ser humano. La primera definición de la palabra territorio que ofrece el diccionario de la Real Academia de la Lengua es: "Porción de la superficie terrestre perteneciente a una nación, región, provincia, etc." Ateniéndonos a esta definición, podríamos estudiar la Ordenación del Territorio a diferentes niveles, pero en este caso nos centraremos en el ámbito de la Provincia. Cada Comunidad Autónoma debe definir las directrices de ordenación que posteriormente deberán desarrollar las administraciones de menor entidad, para que exista una uniformidad de criterios y no se desarrollen Planes de Ordenación que resulten ser incompatibles entre ellos.

\subsubsection{Ordenación del territorio}

\subsection{Antecedentes}

La idea de Ordenación del Territorio surge de la necesidad de resolución de ciertos problemas que se plantean a causa de la ocupación aleatoria de algunos territorios por actividades muy variopintas. El cuerpo doctrinal de la ordenación del territorio recoge todos los problemas que a lo largo de la historia han ido surgiendo con el territorio como protagonista, intentando también adelantarse a los conflictos futuros y dando una posible solución a priori.

\subsection{Concepto}

La primera definición de este concepto que hemos encontrado en bibliografía de España es la dada en 1969 por G. Saenz de Buruaga 28: "es el estudio interdisciplinario y prospectivo de la transformación óptima del espacio regional, y de la distribución de esta transformación y de la población total entre los núcleos urbanos con funciones y jerarquías diferentes, con vistas a su integración en áreas supranacionales"

28 Pujadas, R. et al, “Ordenación y planificación territorial”, 1998. 
De manera más sencilla podríamos explicar la Ordenación del Territorio con la definición que se dio en la Conferencia Europea de Ministros Responsables de Ordenación del Territorio de 1983 y que forma parte de la Carta Europea de Ordenación de Territorio, de este modo se define la Ordenación Territorial: "la expresión espacial de las políticas económicas, sociales, culturales y ecológicas de la sociedad. Es a la vez una disciplina científica, una técnica administrativa y una política concebida como un enfoque interdisciplinario y global, cuyo objetivo es un desarrollo equilibrado de las regiones y la organización física del espacio según un concepto rector"'29.

La Ordenación del Territorio no resulta ser una tarea fácil, ya que para llevarla a cabo se hace necesario tener en cuenta una gran cantidad de factores, todos aquellos que puedan tener alguna influencia tanto en el medio físico, como en el correcto desarrollo de las actividades del ser humano. Y lo más difícil resulta ser la resolución de los conflictos de intereses; la Ordenación del Territorio media entre desarrollo y conservación del medio, entre interés público y privado, etc.

Para desempeñar esta empresa resulta imprescindible tener en cuenta las características físicas del territorio objeto del trabajo, ya que éstas serán determinantes. Es por esto que al margen de otros estudios que es imprescindible realizar, se debe contar con una buena cartografía base, a partir de la cual se van a realizar los trabajos y en la cual se van a plasmar las propuestas.

\subsection{Necesidad}

La necesidad de ordenar el territorio surge ante la aleatoria y por tanto caótica localización de actividades desarrolladas por el ser humano. Poco a poco se va tomando conciencia de que el medio ambiente no es capaz de asimilar todas las agresiones de las que está siendo objeto y de que esto va en detrimento de la calidad de vida de los seres humanos que habitan en ese determinado medio. Asimismo, existen actividades cuya proximidad con los núcleos de población resulta como mínimo poco recomendable, y sobre todo se trata de lograr un territorio en el que la población pueda vivir con las mejores condiciones ambientales, aunque también con los mejores servicios.

Así pues, la ordenación del territorio, consistente en planificar el modelo idóneo de espacio y tomar las medidas adecuadas para lograrlo a medio plazo, es ya una práctica necesaria en la sociedad actual

\subsection{El carácter interdisciplinar de la Ordenación del Territorio}

Diversos autores han puesto de manifiesto el carácter evidentemente interdisciplinar de la Ordenación de Territorio. Hildenbrand destaca el carácter horizontal de la Ordenación del Territorio, con un enfoque interdisciplinario y sistémico-integral, que supera la aproximación fragmentada e incompleta de los enfoques estrictamente sectoriales ${ }^{30}$.

\footnotetext{
${ }^{29}$ Pujadas, R. et al, “Ordenación y planificación territorial”, 1998.

${ }^{30}$ Pujadas, R. et al, “Ordenación y planificación territorial”, 1998.
} 
El primer paso para abordar el proceso de Ordenación del Territorio consiste en un análisis exhaustivo de la situación actual que permita tanto detectar los problema existentes como hacer previsiones de futuro, para la correcta realización de este análisis se habrá de contar con expertos en las distintas materias a estudiar. Son muy diversos pues los profesionales que intervienen en los procesos de Ordenación del Territorio: ingenieros, arquitectos, abogados, economistas, biólogos, geólogos, geógrafos y todos aquellos profesionales que tengan algo que aportar al complicado proceso de elaboración de los planes de Ordenación.

\subsection{Etapas básicas de la Ordenación del Territorio}

A la hora de ordenar el territorio se nos plantean tres interrogantes ${ }^{31}$ :

- Qué debemos ordenar. Los usos del suelo, los usos a los que el ser humano va a destinar una determinada parte del territorio, residencial, industrial, forestal...

- Con qué fin lo vamos a ordenar. Deberemos tener una idea clara del tipo de territorio que queremos conseguir, definir un modelo territorial.

- Cómo lo vamos a conseguir. Una vez tengamos unos objetivos bien definidos, plantearemos una estrategia a seguir para alcanzarlos.

Esto nos define las tres etapas de la Ordenación del Territorio.

\subsection{Legislación}

El primer paso consiste en determinar las políticas territoriales a adoptar, éstas pueden tener mayor o menor concreción dependiendo del organismo responsable y se deberán plasmar en una o varias leyes, ya que lo preceptivo es que las leyes promulgadas por organismos inferiores desarrollen y concreten las leyes aprobadas por organismos de mayor entidad.

\subsection{Planificación}

Consistente en adaptar esa legislación a un territorio concreto, se trata de la Ordenación del Territorio propiamente dicha, este proceso suele tener a su vez varias fases.

- Análisis territorial.

Como en todo trabajo que abordemos, el primer paso consistirá en realizar un análisis de la situación. Para efectuar este examen nos valdremos de todos los instrumentos a nuestro alcance, puesto que cuantos más sean los factores estudiados, más completo será el diagnóstico. Para ello nos valdremos tanto de los conocimientos teóricos que puedan aportar los diferentes profesionales implicados en el proceso, como de los instrumentos de análisis que tengamos a nuestra disposición.

Dado el carácter interdisciplinar de la Ordenación del Territorio, son muy numerosos los profesionales que tienen algo que aportar a un trabajo de este tipo, estos profesionales deben dominar los instrumentos de análisis territorial relacionados con la materia que les

31 Pujadas, R. et al, “Ordenación y planificación territorial”, 1998. 
compete y además tener los conceptos generales necesarios para poder aportar una visión integradora.

\section{- Diagnóstico territorial}

En esta fase se trata de, a partir del análisis territorial realizado, hacer un diagnóstico de la situación actual del territorio en estudio, esto es, identificar los problemas existentes. Estos problemas lo serán en la medida en que no se adapten a la legislación vigente $\mathrm{o}$ al planteamiento territorial que se haya adoptado. Una vez identificadas las deficiencias existentes, se utilizarán las técnicas más adecuadas para que el planeamiento pueda darles solución.

- Pronóstico territorial

Este pronóstico debe coincidir en último término con el modelo territorial planteado y deseable para la zona en estudio. El resultado de aplicar el planeamiento propuesto deberá coincidir en la medida de lo posible con el modelo territorial teórico.

\subsection{Ejecución}

Donde se trata de materializar en el terreno lo expuesto en el Plan de Ordenación.

\subsection{Técnicas utilizadas para la ordenación del territorio}

\subsection{Técnicas prospectivas}

Conocemos como técnicas prospectivas a aquellas que realizan un análisis científico de los problemas futuros y las opciones que tenemos para afrontarlos. Es pues lógico que la ordenación del territorio recurra a técnicas de este tipo, ya que con ella se pretende alcanzar un modelo territorial, teniendo en cuenta el estado actual y las tendencias previstas.

La prospectiva puede entenderse como una combinación de la profecía, que intenta averiguar el futuro sin base científica alguna; la utopía, que propone un futuro ideal y previsiblemente irreal; y la previsión, que realiza predicciones basándose en datos reales y por procedimientos científicos.

- Técnicas de simulación.

Estas técnicas consideran la realidad como un conjunto de elementos que se encuentran interrelacionados. Para generar un modelo sólo tendremos que representar los principales elementos y sus principales interrelaciones.

Para el desarrollo de esta técnica la informática ha sido de gran ayuda en cuanto que permite plantear ecuaciones matemáticas y resolverlas con gran facilidad.

J. Brian McLoughlin (1971), distinguía entre cuatro tipos de simulación ${ }^{32}$ :

o Informal / manual. Se proyectan de manera independiente las diferentes variables.

o Formal / manual. Representa un primer paso en la dirección de la elaboración de modelos, estableciendo unas interrelaciones relativamente simples entre diferentes variables.

32 Pujadas, R. et al, “Ordenación y planificación territorial”, 1998. 
o Parcialmente mecánica. Se intenta un modelado más complejo del sistema, de manera que la escala de cálculos necesarios obliga a la utilización de ordenadores.

o Totalmente mecánica. Prácticamente todo el proceso de simulación se hace a través de ordenador.

El fin último de los modelos de simulación será determinar el comportamiento de los elementos en estudio a lo largo del tiempo. Estos modelos pueden ser de gran utilidad a la hora de evaluar los planes de ordenación y en su caso modificarlos.

B. Reif (1978), distingue entre los siguientes tipos de modelos utilizables en el planeamiento territorial y urbano ${ }^{33}$ :

o Modelos descriptivos. Comprensión de los mecanismos que determinan la estructura de ciudades y regiones. La elaboración de un modelo descriptivo tiene como objetivo reproducir las características relevantes de un sistema urbano o regional. No plantean situaciones futuras, por lo que serán de un interés limitado para los planificadores.

o Modelos predictivos. Se diseñan para definir los estados futuros de los sistemas urbanos y regionales. Se subdividen en modelos de extrapolación, que presuponen la continuidad de las tendencias actuales y modelos condicionales, en los que se especifican los mecanismos de causa-efecto que interrelacionan las variables.

o Modelos de exploración. Descubrimiento de otras realidades lógicamente posibles.

o Modelos de planeamiento o de toma de decisiones. Se introducen la evaluación y medida de los resultados y se trata de encontrar la solución óptima.

- El método de los escenarios.

Otra técnica prospectiva es la que se conoce como método de los escenarios. Empezó a gestarse en el aménagement du territoire francés, aunque fue con la publicación de la DATAR: Une image de la France en l'an 2000: scénario de l'inacceptable (1971) cuando cobró mayor relevancia.

Este método se basa, como su nombre indica, en el planteamiento de escenarios, que nos permitirán simular el proceso que previsiblemente se va a producir y a partir de esto podremos deducir el resultado final. Para ello resulta imprescindible un correcto conocimiento del estado actual y una previsión de los acontecimientos que van a afectar al proceso en estudio.

Podemos distinguir dos tipos de escenarios:

o Exploratorios. Estos escenarios se plantean a partir de la situación existente, teniendo en cuenta las variaciones previsibles de acuerdo con la tendencia actual, de este modo, cambiando las hipótesis se pueden obtener varios escenarios posibles. Este tipo de escenarios resulta muy útil como herramienta para prever el resultado en el caso de no actuación.

o De anticipación. Al contrario que en el caso anterior, aquí se parte de la situación a la que se desea llegar y se proponen medidas para alcanzarla.

33 Pujadas, R. et al, “Ordenación y planificación territorial”, 1998. 


\subsection{Marco general de la Ordenación del Territorio ${ }^{34}$}

\subsection{Carácter público}

Es obvio que la Ordenación del Territorio debe ser competencia de las Administraciones Públicas, ya que son éstas las que tienen que velar por una correcta planificación territorial. Sin embargo, el sector público ordena el territorio principalmente para que el sector privado se instale en él, luego tendrá que tener muy en cuenta las necesidades de aquél.

Por este motivo, los procesos de aceptación de un planeamiento por parte de una administración, sobre todo local, se realizan de forma pública, para facilitar la participación de todas las partes interesadas, aunque es siempre la administración competente la que tiene la última palabra.

\subsection{Escala de actuación}

En Ordenación del Territorio se suele trabajar a tres escalas: nacional, regional y municipal. Podemos hacer una distinción entre planificación económica, que se haría a escala nacional y planificación física, a escalas regional y local. Y del mismo modo se puede discriminar la Ordenación del Territorio propiamente dicha, generalmente a escala regional, del urbanismo que se lleva a cabo a escala municipal.

La planificación económica tiene generalmente un carácter indicativo, esbozando las actuaciones que se deben llevar a cabo, planteando unas estrategias que en la actualidad estarán en consonancia con la Estrategia Española de Desarrollo Sostenible. Esto es, corregir los desequilibrios económicos interregionales y potenciar el desarrollo de las regiones más atrasadas.

En lo que a planificación física se refiere, se suele entender como la planificación de los usos del suelo de un determinado territorio. Esta labor ha sido tradicionalmente competencia de las administraciones locales, aunque la tendencia actual es a la redacción de planes territoriales, que den lugar a una ordenación global regional, a la que deban adaptarse las administraciones locales.

\subsection{Carácter científico, técnico y político}

La Carta Europea de Ordenación del Territorio de 1983 califica la ordenación del territorio a la vez como disciplina científica, técnica administrativa y actividad política.

$\mathrm{Y}$ es que no debemos olvidar que aunque sean científicos y técnicos los que realicen los proyectos de ordenación, éstos no dejan de ser procesos administrativos condicionados por decisiones políticas.

En el ámbito de la ordenación del territorio podemos contemplar tres grandes apartados:

34 Pujadas, R. et al, “Ordenación y planificación territorial”, 1998. 
- Un cuerpo doctrinal. Constituido por un conjunto de creencias y principios que deberían integrar lo que la sociedad en general piensa que debe ser un territorio ordenado; esto no es del todo cierto, ya que son los políticos los que tienen la última palabra y no siempre los Planes de Ordenación resultan ser el reflejo del pensamiento de la ciudadanía.

- Un cuerpo procedimental. Que no son más que los instrumentos y métodos que permiten a los técnicos la ordenación del territorio. Estos instrumentos serán diferentes según la escala a la que se deba trabajar y según el organismo responsable de llevarlos a cabo.

- Una práctica. Es lógico suponer que toda la teoría desarrollada en los planes de ordenación no tiene sentido si no se materializa en un terreno concreto y deben ser las administraciones las garantes de controlar el proceso.

\subsection{Diferentes modalidades de planificación ${ }^{35}$}

\subsection{Planificación vinculante y planificación indicativa}

Ya hemos comentado la diferencia entre planificación económica y planificación física, estos dos tipos de planificación pueden diferenciarse también según R. Pujadas por la naturaleza básica de sus determinaciones; bien de carácter vinculante o bien de carácter indicativo ${ }^{36}$.

La diferencia entre estos dos caracteres radica en la obligatoriedad o no de su cumplimiento.

Por lo general la planificación económica suele ser indicativa para el sector privado, es decir, se trata de marcar unas pautas de comportamiento, unas recomendaciones que generalmente no son de obligado cumplimiento; en ocasiones resulta ser vinculante para la administración porque se trata de condiciones que le impone una administración superior. De otro lado tenemos la planificación física que por el contrario es de obligado cumplimiento para todos los estamentos, es pues de carácter vinculante.

\subsection{Diferentes modalidades de planificación física}

Ya se ha comentado que la planificación física consiste en establecer las zonas en las que se permitirá un determinado uso del suelo. Esta planificación física puede ser:

- Planificación general. La planificación general se centra en el territorio de una manera global. Se trata de una aproximación horizontal, lo que se intenta es hacer una división de las zonas en las que se ubican o se ubicarán los diferentes usos del suelo. Este tipo de planificación engloba a otras dos:

o Planificación territorial. Destinada a ordenar ámbitos regionales o subregionales

o Planificación urbanística. Que se centra en los ámbitos municipales.

35 Pujadas, R. et al, “Ordenación y planificación territorial”, 1998.

36 Pujadas, R. et al, “Ordenación y planificación territorial”, 1998. 
- Planificación sectorial. Que se centra en la distribución territorial de una determinada variable, no en el territorio en general. Se trata pues de una aproximación vertical. En este tipo de planificación puede encontrarse una enorme diversidad temática, que podrían ser: planificación de infraestructuras, planificación de equipamientos colectivos, gestión medioambiental y planificación de sectores económicos.

- Planificación normativa. Llamamos así a la planificación que se ve plasmada en unas normas de obligado cumplimiento, leyes, ordenanzas... Su nivel de concreción puede variar desde el nivel máximo de la ordenación urbanística al mínimo de la territorial.

- Planificación no normativa. Actualmente son varios los organismos que ofrecen las directrices de ordenación que consideran deseables, se trata de describir a grandes rasgos el modelo territorial esperado y esbozar el camino para alcanzarlo, es pues una ordenación poco concreta que deberá complementarse con planificaciones normativas por los organismos competentes. Por supuesto estas directrices no son vinculantes, aunque suelen aceptarse generalmente.

- Planificación integrada. Se trata de un intento de unificación de: la ordenación del territorio, el desarrollo socioeconómico y la protección del medio ambiente en un mismo cuerpo de planificación.

\subsubsection{Desarrollo sostenible}

Aunque el concepto de Desarrollo Sostenible es bastante reciente, la idea de Conservación del Medio Ambiente, a la que está íntimamente ligado ya aparece en nuestra Constitución. El Artículo 45.1. de la Constitución Española de 1978 dice: "Todos tienen derecho a disfrutar de un medio ambiente adecuado para el desarrollo de la persona así como el deber de conservarlo". Y en el Artículo 45.2. podemos leer: "Los poderes públicos velarán por la utilización racional de todos los recursos naturales, con el fin de proteger y mejorar la calidad de vida y defender y restaurar el medio ambiente, apoyándose en la indispensable solidaridad colectiva”.

Es un hecho por todos conocido que la acción del ser humano sobre el planeta está ocasionando un deterioro ambiental que de seguir a este ritmo podría llegar a ser irreversible. Hechos como la destrucción de la capa de ozono, el cambio climático, la pérdida de biodiversidad, la deforestación, la contaminación, la sobreexplotación de recursos naturales, etc., nos colocan ante una situación realmente preocupante.

Puede considerarse que el medio ambiente está integrado por múltiples elementos, como son: el relieve, los suelos, la atmósfera, el agua, los asentamientos, la agricultura, la silvicultura, la hidroeconomía, la industria, el transporte, la recreación y la población.

El concepto de Desarrollo Sostenible aparece por primera vez en el informe que la doctora Gro Harlem Brundtland remitió a la Comisión Mundial de las Naciones Unidas sobre Medio Ambiente y Desarrollo en 1987 que llevaba por título "Nuestro Futuro Común”; en él se define como el "desarrollo que satisface las necesidades del presente sin comprometer la habilidad de generaciones futuras de satisfacer sus propias necesidades". Para llevar a cabo este desarrollo de nuestra sociedad resulta imprescindible la Ordenación del Territorio.

El primer principio de la Declaración de Río sobre el Medio Ambiente y el Desarrollo de 1992, adoptada por las Naciones Unidas dice: "Los seres bumanos constituyen el centro de las preocupaciones relacionadas con el desarrollo sostenible. Tienen derecho a una vida saludable y productiva en armonía con la naturaleza." Esta declaración es el documento base de la estrategia global que 
contempla, por primera vez y con rango internacional, una política ambiental integrada y de desarrollo, teniendo presentes no sólo los habitantes actuales del planeta sino también las generaciones futuras ${ }^{37}$.

A partir del Tratado de Ámsterdam, en 1997, se introduce el término de Desarrollo Sostenible en los tratados comunitarios. El artículo 2 del Tratado establece que la Unión tendrá como objetivos promover el progreso económico y social y un alto nivel de empleo y conseguir un desarrollo equilibrado y sostenible, "principalmente mediante la creación de un espacio sin fronteras interiores, el fortalecimiento de la cohesión económica y social y el establecimiento de una unión económica y monetaria, que implicará en su momento una moneda única"

En el Consejo Europeo de Helsinki de 1999, se invita a la Comisión Europea a elaborar una propuesta de estrategia a largo plazo que integre políticas de desarrollo sostenible. El Consejo Europeo de Estocolmo de 2001, acordó que la estrategia a presentar por la Unión debía reforzar el compromiso político incluyendo la dimensión ambiental.

Otros documentos de la Comisión Europea, en este caso comunicaciones, relacionados con el tema que nos ocupa son:

- Diez años después de Río: preparación de la Cumbre Mundial sobre Desarrollo Sostenible de 2002.

- Una Europa Sostenible para un Mundo Mejor. Que contiene la Propuesta de la Comisión de una Estrategia de la Unión Europea de Desarrollo Sostenible, de mayo de 2001.

También la Organización para la Cooperación y el Desarrollo Económico (OCDE) en 1998 aprobó una estrategia que tiene el doble propósito de "proporcionar orientaciones claras para políticas ambientales sostenibles a los Estados y guiar el futuro trabajo de la OCDE en materia ambiental".

Tras esta introducción histórica del concepto, resulta también imprescindible introducir el término sostenibilidad que por sí solo hace referencia a la integración de las dimensiones económica, social y medioambiental del desarrollo.

De todos es sabido que la primera Ley de la Termodinámica dice que "la energía ni se crea ni se destruye", aunque es menos común conocer la Segunda Ley o Ley de la Entropía que, siendo un corolario de la primera, dice: "pero se degrada" hacia formas que no nos resultan útiles. El ser humano es incapaz de utilizar la energía exosomática, la que no metabolizamos nosotros mismos, por lo que resulta imprescindible, si el objetivo es alcanzar la sostenibilidad, utilizar formas de energía de baja entropía. Asimismo, es fundamental utilizar los recursos en función de su capacidad de renovación, generar una cantidad de residuos que el medio pueda absorber, y mantener la biodiversidad.

Pero ¿cuál es el límite de la insostenibilidad?. Si la biosfera no es capaz de absorber nuestros residuos y sobrepasamos la tasa de reposición de los recursos renovables habremos llegado a una situación de insostenibilidad.

Como conclusión podemos decir que el Desarrollo Sostenible se sustenta en dos ideas principales:

${ }^{37}$ Comisión Interministerial de Coordinación de la Estrategia Española de Desarrollo Sostenible. "Estrategia Española de Desarrollo Sostenible. Documento de consulta”, 2001. 
- El desarrollo tiene una dimensión económica, social y ambiental y sólo será sostenible si se logra el equilibrio entre los distintos factores que influyen en la calidad de vida.

- La generación actual tiene la obligación, frente a las generaciones futuras, de dejar suficientes recursos sociales, ambientales y económicos para que aquellas puedan disfrutar, al menos, del mismo grado de bienestar que ella.

\subsubsection{Objetivos del Desarrollo Sostenible ${ }^{38}$}

\section{- Progreso social}

Entendido como la dimensión cualitativa del desarrollo y con dos aspiraciones, la erradicación de la pobreza y la calidad de vida, ambos entendidos desde el punto de vista de la salud, la seguridad y la equidad, con el objetivo de reducir las diferencias entre los individuos.

El concepto de calidad de vida está constituido por varios elementos, entre los que destacan el bienestar social, la calidad ambiental y la identidad cultural.

- Uso racional de los recursos

De manera que el medio ambiente sea capaz de regenerar los recursos consumidos por el ser humano. Actualmente, debido al hecho de que hay zonas en las que ya se ha ocasionado la degradación del medio, el objetivo no es sólo conservar los recursos sino regenerar en lo posible los medios degradados.

- Desarrollo económico

Como su nombre indica hablamos de desarrollo sostenible, por lo tanto se supone que uno de los objetivos que se persigue es el desarrollo económico, teniendo en cuenta que este desarrollo sea compatible con la conservación del medio ambiente, no sólo del más próximo a nosotros, hablamos del medio ambiente a escala global, teniendo en cuenta la totalidad del planeta.

Para conseguir este objetivo se deberá modificar la forma de entender los gastos de producción, incorporando a éstos los gastos de regeneración del medio si fuese necesario, también deberá aumentarse la eficiencia en la producción y fomentar un cambio social hacia otras formas de consumo.

\subsubsection{Dimensiones del desarrollo sostenible}

No se puede concebir el desarrollo sostenible si no es desde una perspectiva global, aunque las actuaciones se llevarán a cabo desde distintas instancia a varias escalas, internacional, territorial y urbana.

- Internacional

Las relaciones internacionales resultan básicas para la economía mundial; en este planeta en el que la globalización es un hecho, se deben tener en cuenta las consecuencias medioambientales a nivel planetario de las decisiones que se adoptan. Las políticas ambientales de un país no afectan solamente a ese país, sino también a

\footnotetext{
38 Comisión Interministerial de Coordinación de la Estrategia Española de Desarrollo Sostenible. "Estrategia Española de Desarrollo Sostenible. Documento de consulta", 2001.
} 
los que le rodean e incluso al resto del planeta. En esta línea, son los países en vías de desarrollo los que presentan actualmente una menor concienciación en lo que a sostenibilidad se refiere, pero son los países más desarrollados los que invierten en aquellos. Se hace necesaria una política de concienciación común a escala internacional.

- Territorial

Por mucho que adoptemos políticas generales en pro del desarrollo sostenible, es en un territorio concreto donde se ocasiona la degradación o conservación del medio, es por esto que las políticas se deberán aplicar también a nivel territorial, con el control pertinente de las autoridades competentes.

- Urbana

En lo que a la dimensión local del tema que nos ocupa se refiere, su importancia radica en la sostenibilidad de las ciudades, que actualmente se comportan en su mayoría de manera del todo insostenible. En España es de los gestores locales de los que se espera que den solución a este creciente problema mediante la aplicación de las Agendas 21 Locales, de las que hablaremos con posterioridad.

\subsubsection{Indicadores}

Para abordar el análisis ambiental se hace necesaria la identificación de los elementos que deben ser tomados en cuenta, definir los indicadores que los representarán, así como los índices que los cuantifiquen.

Vamos a denominar indicador a una observación empírica que sintetiza aspectos de un fenómeno que resulten importantes para uno o más propósitos analíticos y prácticos. Si bien el término indicador puede aludir a cualquier característica observable de un fenómeno, suele aplicarse a aquéllas que son susceptibles de expresión numérica. Los indicadores pueden ser expresados en términos absolutos. Los indicadores ambientales son pues un sistema de parámetros que reflejan las características cualitativas de los impactos, cambios y consecuencias, así como su distribución y magnitud y variarán según el objetivo que se persiga $^{39}$.

Una posible clasificación es la que propone Novúa, que se extrajo del coloquio celebrado en 1995 en Santiago de Chile, donde se contemplan cinco grupos:

- Recursos naturales: balances físicos

o Recursos hídricos. Agua

o Suelos. Desertificación, acidificación, salinización, pérdida de suelos

o Ecosistemas. Recursos forestales, deforestación, extinción de especies

- Impacto ambiental

o Energía. Consumo

o Industrias en general

o Agroindustrias

o Agropecuario

39 Novúa, O. et al., Sistema de Información Geográfica para el análisis ambiental documentación metodológica y funcional. Mapping, 2004. 
o Comercio internacional. Exportación de recursos naturales

o Turismo

- Calidad de los elementos

o Contaminación de aguas. Tipo de contaminantes, fuentes, cuerpos de agua

o Contaminación atmosférica. Urbana. Tipo de emisiones

- Factores socio ambientales

o Población y asentamientos humanos

o Contaminación atmosférica urbana

o Residuos sólidos domiciliarios

- Política ambiental

o Educación ambiental

o Legislación

\subsubsection{Legislación aplicable}

La Ley 4/2004 de 30 de junio, de la Generalitat, de Ordenación del Territorio y Protección del Paisaje tiene como objetivo, según se expresa en su Artículo 2, la mejora de la calidad de vida de los ciudadanos y el desarrollo sostenible ${ }^{40}$.

Ya en su preámbulo, la citada ley habla de desarrollo sostenible y se plantea como objetivo la protección y mejora de la calidad de vida de las personas, mediante el desarrollo equilibrado y sostenible basado en las características del territorio y en la gestión racional de los recursos naturales.

Asimismo se habla de la Estrategia Territorial de la Comunidad Valenciana, como un instrumento de ordenación del territorio, que contiene las directrices, orientaciones y criterios que, junto con la ley, constituyen un referente de las decisiones públicas de incidencia territorial contenidas en los distintos instrumentos de planeamiento, estableciendo las pautas de armonización y de coordinación de las distintas políticas sectoriales y proyecciones económicas y sociales. ${ }^{41}$

\subsubsection{Previsiones de futuro}

\subsubsection{Modelo territorial de la Comunidad Valenciana}

Una de las ponencias del Seminario "Modelos Territoriales sostenibles en espacios litorales mediterráneos" exponía este modelo como se describe a continuación.

El instrumento de planificación territorial más importante que se está elaborando (y que seguramente se va a elaborar en muchos años) es el denominado Modelo Territorial de Futuro de la Comunidad Valenciana. El Modelo Territorial establece los objetivos globales, los criterios y los proyectos fundamentales de referencia para el desarrollo territorial de la Comunidad Valenciana. Conceptualmente es equivalente a lo que serían unas Directrices o un Plan Territorial de ámbito regional.

\footnotetext{
${ }^{40}$ Ley 4/2004 de 30 de junio, de la Generalitat, de Ordenación del Territorio y Protección del Paisaje

${ }^{41}$ Ley 4/2004 de 30 de junio, de la Generalitat, de Ordenación del Territorio y Protección del Paisaje
} 
El Modelo Territorial se expresará mediante propuestas estratégicas, de carácter orientador y dinamizador, y mediante determinaciones normativas con diferente nivel de vinculación. Aunque su ámbito de actuación es toda la Comunidad Valenciana, podrá proponer estrategias específicas para ámbitos territoriales menores cuando sean necesarias para el logro de los objetivos globales perseguidos por el Modelo.

Estos ámbitos territoriales menores surgen del convencimiento de la imposibilidad de dar respuesta a todos los problemas territoriales desde el planeamiento municipal. Planeamiento que, por otra parte, tampoco permite obtener la máxima rentabilidad de nuestras oportunidades territoriales ${ }^{42}$.

Según este modelo, la Comunidad Valenciana se dividirá en quince Áreas Funcionales que serán ámbitos para el desarrollo de planes de escala intermedia.

\subsubsection{Políticas de desarrollo sostenible}

\subsubsection{Estrategia Europea de Desarrollo Sostenible}

En su reunión de Helsinki de diciembre de 1999, el Consejo Europeo invitó a la Comisión Europea a "elaborar una propuesta de estrategia a largo plazo que integre politicas de desarrollo sostenible desde el punto de vista económico, social y ecológico, y que deberá presentarse al Consejo Europeo en junio de 2001"'.

El primer paso consistió en la preparación de un "Documento de consulta sobre la preparación de una estrategia comunitaria para el desarrollo sostenible" 43 .

El objetivo del documento era apuntar los conceptos básicos que permitirían formular dicha estrategia. Se trata de un documento en el que además de presentar las ideas de partida para la consecución del desarrollo sostenible, se exponían las principales amenazas a la sostenibilidad y se proponían soluciones.

Se analizan en el anterior documento seis temas que se consideran prioritarios para la estrategia europea de desarrollo sostenible, que son: el cambio climático y energías limpias, la salud pública, la gestión de los recursos naturales, la pobreza y exclusión social, el envejecimiento y demografía, y la movilidad, usos del suelo y desarrollo territorial.

Todos estos datos fueron expuestos al público con el fin de que todos los ciudadanos pudieran comunicar sus puntos de vista al respecto y con ello ser capaces de elaborar una estrategia europea con el mayor consenso posible, el plazo para enviar comentarios finalizó el 30 de abril de 2001 y con los datos disponibles se elaboró el documento de la Estrategia Europea de Desarrollo Sostenible.

La Estrategia Europea de Desarrollo Sostenible fue aprobada por el Consejo Europeo de Gotemburgo de junio de $2001^{44}$.

Se acepta que existen las siguientes amenazas al desarrollo sostenible:

\footnotetext{
42 Benlliure Moreno, J.M., “Grandes Retos para la ordenación del litoral valenciano”, 2000

43 Comisión Europea, "Documento de consulta sobre la preparación de una estrategia comunitaria para el Desarrollo Sostenible", 2000

44 Comisión Europea, "Desarrollo Sostenible en Europa para un mundo mejor: Estrategia de la Unión Europea para un Desarrollo Sostenible”, 2001
} 
- Calentamiento global

- Inseguridad alimentaria

- Pobreza

- Envejecimiento de la población

- Pérdida de biodiversidad

- Desequilibrios territoriales

Y se plantean unas necesidades:

- Actuación urgente

- Liderazgo político

- Nuevo enfoque en la formulación de políticas

- Actuaciones de todos a todos los niveles

- Responsabilidad internacional

Para ello se conciben varias propuestas para dar respuesta a los diferentes retos:

- Con el fin de mejorar la coherencia de la actuación política, se adoptará el desarrollo sostenible como objetivo central, se potenciará la agricultura de calidad frente a la cantidad, se gestionará de manera sostenible la pesca protegiendo los ecosistema marinos, se fomentará el uso de transportes menos perjudiciales para el medio ambiente y se llevarán a cabo políticas de cohesión que potencien las regiones desfavorecidas y disminuyan la exclusión social.

- Para fijar unos precios de mercado reales, se dará prioridad a planteamientos de mercado que supongan incentivos en materia de precios, siempre que permitan alcanzar los objetivos sociales y ambientales de forma flexible y rentable.

- En lo que respecta a inversiones en ciencia y tecnología, se potenciarán las inversiones relacionadas con el desarrollo sostenible, se potenciarán productos y servicios poco contaminantes, se fomentarán iniciativas privadas que incorporen factores ambientales a sus especificaciones de compra, se creará una competencia en materia de vigilancia global del medio ambiente.

- Para mejorar la comunicación y movilizar a ciudadanos y empresas, se potenciará la consulta de los ciudadanos, se instará a las empresas a publicar ciertos datos, se implantará la idea de desarrollo sostenible en la educación pública.

- En aras a tener en cuenta la ampliación y la dimensión mundial, se publicará la posible contribución de la Unión al desarrollo sostenible mundial.

Se establecen unas metas a largo plazo:

- Actuar en una amplia gama de políticas

- Limitar el cambio climático e incrementar el uso de energías limpias

- Responder a las amenazas a la salud pública

- Gestión más responsable de los recursos naturales

- Mejora del sistema de transportes y la ordenación territorial

Una vez adoptada la estrategia, se evaluarán los progresos, los pasos serán los siguientes:

- Balance anual para evaluar los avances

- Necesidad de cambiar los métodos de trabajo

- Revisiones a largo plazo para estudiar la conveniencia de modificar la estrategia 


\subsection{Estrategia temática sobre medio ambiente urbano ${ }^{45}$}

La sociedad actual tiende a desplazar su lugar de residencia hacia zonas urbanas y actualmente cerca de un $80 \%$ de los ciudadanos europeos vive en estas zonas, con el consiguiente problema medioambiental que esta aglomeración de habitantes genera, contaminación acústica, del aire, del agua, hacen que la calidad de vida disminuya considerablemente.

La planificación en pro de un alto nivel de protección medioambiental es una condición sine qua non para fomentar el desarrollo sostenible de las ciudades y garantizar un alto nivel de calidad de vida a los ciudadanos urbanos europeos.

La estrategia que nos ocupa se enmarca dentro del Sexto Programa de Acción de la Comunidad Europea en materia de Medio Ambiente denominado "Medio Ambiente 2010: el futuro está en nuestras manos". Es una de las siete estrategias temáticas del Programa, que fueron incluidas con el fin de simplificar los principales problemas medioambientales, desde un punto de vista más global, intentando aportar soluciones a estos problemas. El citado Sexto Programa de Acción en materia de Medio Ambiente dice que, debe establecerse una estrategia temática "... que fomente un enfoque integrado horizontal de las políticas comunitarias y que mejore la calidad del medio ambiente urbano, que tenga en cuenta los avances realizados en la aplicación del actual marco de cooperación, lo revise cuando sea necesario, y trate sobre:

- el fomento del Programa 21 Local,

- la disminución de los vínculos entre el crecimiento económico y la demanda de transporte de pasajeros,

- la necesidad de un mayor peso del transporte público, del ferrocarril, de la navegación interior, y de los modos de desplazamiento a pie y en bicicleta,

- la necesidad de hacer frente a un volumen de tráfico en aumento y de disociar de manera significativa el crecimiento del transporte y el crecimiento del PIB,

- la necesidad de fomentar el uso de vebiculos con bajos niveles de emisiones en el transporte público,

- la toma en consideración de indicadores medioambientales urbanos."

El objetivo de esta estrategia temática sobre el medio ambiente urbano es "Mejorar los resultados medioambientales y la calidad del entorno en las zonas urbanas, y garantizar un medio de vida sano para los ciudadanos urbanos europeos, reforzando la contribución del medio ambiente al desarrollo urbano sostenible."

Aunque no olvidemos que no hay dos ciudades iguales, todas las ciudades europeas tienen aproximadamente los mismos problemas, y sería deseable dar a la actuación política un enfoque que mediante el uso de los medios existentes permita una cooperación total y sobre todo coordinación entre los diferentes niveles de gobierno.

La comunicación "Hacia una estrategia temática sobre el medio ambiente urbano" fue la primera fase de la preparación de la Estrategia final, que sería lanzada en el verano de 2005. El objetivo de la Comisión era conseguir un máximo de reacciones a las propuestas que se plantean en la Comunicación, para ello, a lo largo de 2004 se llevaron a cabo una serie consultas y reuniones técnicas de grupos de trabajo para estudiar con atención las propuestas de actuación, su viabilidad y cómo contribuirían a la mejora del entorno urbano. El concepto

\footnotetext{
45 Comisión de las Comunidades Europeas. "Comunicación de la Comisión al Consejo, al Parlamento Europeo, al Comité Económico y Social Europeo y al Comité de las Regiones. Estrategia para un medio ambiente urbano”, 2004.
} 
es que la estrategia debe conseguir el mayor consenso posible, y para ello se intentaría que tomasen parte en el proceso el mayor número de grupos, representantes de los Estados miembros, países adherentes y candidatos, regiones, ciudades, empresas, ONGs y entidades docentes. Las partes interesadas pudieron presentar sus observaciones de forma directa hasta el 1 de abril de 2004. A mediados de 2005 se presentaría la estrategia temática definitiva para la que se tendrían en cuenta las consultas de las partes interesadas y los resultados de los grupos de trabajo.

Los temas prioritarios son:

- La gestión urbana sostenible.

Para gestionar correctamente este tema son necesarias una visión clara y una estrategia global que permita la adopción de medidas que no contemplen fronteras entre municipios, aunque no deja de ser una acción local que deberá considerarse fundamental. Es ésta una tarea que deberán realizar de forma conjunta las administraciones, con la colaboración de ciudadanos, empresas y otras partes interesadas.

Las acciones propuestas en lo que a gestión urbana sostenible se refiere son ${ }^{46}$ :

o Cada capital o ciudad de más de 100000 habitantes debería adoptar un plan de gestión medioambiental para la zona urbana en su conjunto, y fijar objetivos para cada impacto medioambiental importante. Asimismo, debería establecer un sistema de gestión medioambiental para ejecutar el proceso y dar cumplimiento a los objetivos. La Comisión considera que, a tal efecto, podrían establecerse unas obligaciones a nivel comunitario. Este punto será objeto de nuevas consultas en 2004, por ejemplo con ocasión de la reunión de un grupo de trabajo específico de expertos y partes interesadas.

o La Comisión elaborará unas orientaciones para la puesta en práctica de tales sistemas de gestión por parte de las autoridades locales. Se instará a los Estados miembros a proporcionar a dichas autoridades el respaldo necesario, por ejemplo en forma de formación y de asesoramiento para la ejecución del sistema de gestión medioambiental.

o La Comisión analizará las posibilidades que existen de formación, investigación e intercambio de experiencias en el ámbito de la gestión urbana sostenible.

- El transporte urbano sostenible.

El tráfico es un factor determinante a la hora de valorar la contaminación tanto ambiental como acústica, y afectan considerablemente la salud de los ciudadanos así como la calidad de vida. Las previsiones son que, de no poner freno a la situación actual de aumento progresivo del tráfico, las emisiones de $\mathrm{CO}_{2}$ derivadas del transporte habrán aumentado en un 40\% para 2010 en comparación con 1990. El tráfico urbano es responsable de un $40 \%$ de las emisiones de $\mathrm{CO}_{2}$ derivadas del transporte.

\footnotetext{
46 Comisión de las Comunidades Europeas. "Comunicación de la Comisión al Consejo, al Parlamento Europeo, al Comité Económico y Social Europeo y al Comité de las Regiones. Estrategia para un medio ambiente urbano”, 2004.
} 
Además de ser el principal responsable de la contaminación urbana, el uso del automóvil está fomentando el sedentarismo, que está ocasionando graves problemas de salud, principalmente cardiovasculares, y acortando por ello la esperanza de vida. Además, el número de muertes y lesiones que producen anualmente los accidentes de tráfico en las ciudades es alarmante, dos tercios de los accidentes de tráfico con resultado de lesiones que se produjeron en la UE en 2000 se dieron en zonas urbanas, así como un accidente de cada dos.

Otro problema, que ya hemos mencionado, es la contaminación acústica producida por el tráfico, un $80 \%$ de la contaminación acústica urbana está producida por éste. Y todavía podemos mencionar un efecto indirecto del alto volumen de tráfico, los ciudadanos consideran incómodo pasear por las calles y peligroso dejar que sus hijos jueguen en ellas, lo que contribuye a que se debilite el sentimiento de pertenencia a un barrio o a una comunidad local.

La movilidad urbana es también un elemento importante para la equidad social, ya que puede suceder que ciertos sectores de la sociedad no tengan acceso a los servicios, la educación, el empleo, el ocio y los bienes por el hecho de no poseer un vehículo propio.

Se están desarrollando actualmente planes de transportes urbanos sostenibles que tendrán en consideración la totalidad de las zonas urbanas y cuyo objetivo será reducir el impacto negativo de los transportes, teniendo en consideración la actual tendencia de aumento e intentando coordinar las acciones a todos los niveles.

Ya hemos mencionado que cada ciudad es única y cuenta con particularidades que hacen que sea imposible establecer metas, objetivos, soluciones y paquetes de medidas a nivel comunitario; asimismo es importante intentar conseguir en la medida de lo posible un consenso entre los ciudadanos, los agentes económicos y otras partes interesadas. Obviamente el plan tendría que ser puesto en consonancia con los planes y objetivos de desarrollo económico y social globales de la ciudad.

El propósito de los planes es que las 500 ciudades más importantes de la UE de los veinticinco cumplan los requisitos de las Directivas en materia de evaluación y gestión de la calidad del aire y del ruido, así como los objetivos del acuerdo de Kioto.

Las acciones propuestas en lo que a transporte urbano sostenible se refiere son ${ }^{47}$ :

o Todas las capitales y las ciudades de más de 100000 habitantes deberían elaborar, adoptar, ejecutar y revisar de forma regular un plan de transporte urbano sostenible dotado de objetivos a corto, medio y largo plazo. La Comisión es de la opinión de que se podría imponer una obligación a nivel comunitario en este sentido. Este aspecto será objeto de nuevos debates en 2004, en particular en el contexto de un grupo de trabajo específico de expertos y partes interesadas.

o Se pedirá a todos los Estados miembros

47 Comisión de las Comunidades Europeas. "Comunicación de la Comisión al Consejo, al Parlamento Europeo, al Comité Económico y Social Europeo y al Comité de las Regiones. Estrategia para un medio ambiente urbano”, 2004. 
- que establezcan una política marco clara en el ámbito del transporte urbano sostenible;

- que evalúen la incidencia de los nuevos proyectos infraestructurales de transporte urbano en la sostenibilidad del sistema de transportes de la ciudad;

- que sigan fielmente las orientaciones sobre la utilización de los Fondos Estructurales.

o En el marco del Libro Blanco sobre la política europea de transportes, la Comisión está preparando una directiva que se centra en la adquisición de vehículos de bajo nivel de consumo y emisiones por parte de las autoridades públicas. El objetivo perseguido es el de fomentar la compra de vehículos más limpios y eficientes, pero no se van a fijar unas normas técnicas ni se va a recurrir a los incentivos fiscales existentes en el ámbito de los vehículos.

o En el marco de la Estrategia de combustibles alternativos, la Comisión propondrá un Plan de acción que promueva el desarrollo del mercado de los combustibles alternativos, en particular del gas natural y del hidrógeno.

o La Comisión seguirá desarrollando y ampliando el programa CIVITAS, las iniciativas de investigación urbana y el intercambio de experiencias y buenas prácticas.

o Asimismo, desarrollará la capacidad, en el ámbito del transporte, de los $250 \mathrm{o}$ más departamentos regionales o locales de energía o de otro tipo que existen en Europa, con el fin de respaldar la instauración del transporte urbano sostenible y promover las buenas prácticas.

o Por otra parte, determinará unos indicadores básicos en materia de transporte urbano sostenible sobre la base del trabajo de la Conferencia Europea de Ministros de Transporte.

o La Comisión continuará realizando actividades promocionales tales como el día europeo sin coches o la semana de la movilidad. Se evaluará la necesidad de establecer acciones de orientación o de formación en materia de transporte urbano sostenible, así como la contribución de nuevos métodos de trabajo, tales como el teletrabajo.

- La construcción sostenible.

La conservación del paisaje urbano constituye un tema de interés creciente, la tipología de la construcción y en general el entorno construido, determinan el entorno urbano; este entorno se tiende a que además de que sea funcional e identificativo de la ciudad, tenga un marcado carácter atractivo, que resulte agradable para vivir y trabajar. La calidad del entorno construido resulta determinante a la hora de valorar la calidad del medio ambiente urbano, que se traduce en una mejor calidad de vida.

Se estima que un $42 \%$ del consumo de energía se debe al calentamiento e iluminación de los edificios, del cual un $70 \%$ corresponde a la calefacción. Además se producen un 35\% de las emisiones de gases efecto invernadero. En lo que a la construcción se refiere, la mitad de los materiales de que están hechos los edificios y construcciones proceden de la corteza terrestre, y producen anualmente 450 MT de residuos de construcción y demolición (más de la cuarta parte de todos los residuos generados). Modificar la manera en que se conciben, construyen, renuevan y derriban los edificios 
podría redundar en una importante mejora de los resultados económicos y medioambientales de las ciudades y de la calidad de vida de los ciudadanos urbanos.

Las construcciones existentes deben hacerse más sostenibles modernizándolas o asegurándose de que al ser renovadas se tenga en cuenta de forma prioritaria su sostenibilidad. Modernizar el rendimiento energético de los edificios existentes es una de las formas más económicas de dar cumplimiento a los compromisos de Kioto en materia de cambio climático. La renovación es algo más complejo que la construcción, sin embargo, la renovación tiene varias ventajas desde el punto de vista medioambiental sobre el derribo o la reconstrucción, por ejemplo la conservación de los materiales y de la energía contenida en ellos. Por otro lado, la renovación y la rehabilitación de zonas y edificios históricos contribuyen a conservar el patrimonio y la identidad de las comunidades locales.

Tras la ampliación, resulta prioritaria la conservación y restauración de las construcciones existentes, con el objetivo de no tolerar la degradación de algunas zonas. Se estima que una quinta parte de los apartamentos necesitan una ligera renovación, tres quintas partes una renovación importante y una quinta parte una reconstrucción completa. Los conjuntos en sí necesitan también una reestructuración que arroje una mejor combinación de las instalaciones con fines residenciales, económicos y sociales para crear unas comunidades más sostenibles y evitar la situación actual, en la que son necesarios largos desplazamientos para acceder a los servicios.

La Comisión ha adoptado un proyecto de Directiva sobre la eficiencia energética del usuario final y sobre los servicios del ámbito de la energía, cuyo objetivo es promover de forma generalizada la eficiencia energética y la prestación de servicios de carácter energético que no se limiten a suministrar energía, sino que asesoren a sus clientes sobre cómo conseguir una mayor eficiencia y cómo gestionar sus necesidades energéticas. A largo plazo esta Directiva deberá modificar de forma radical la forma en que se comercializa la energía, logrando grandes ahorros de consumo.

Las acciones propuestas en lo que a construcción sostenible se refiere son ${ }^{48}$ :

o La Comisión desarrollará una metodología común para evaluar la sostenibilidad global de los edificios y del entorno construido, que incluirá indicadores de costes durante el ciclo de vida útil. Ésta se aplicará también a los proyectos de edificios nuevos y a las renovaciones importantes. Se alentará a todos los Estados miembros a adoptar esta metodología y a utilizarla como soporte de las mejores prácticas. La Comisión propondrá entonces nuevos requisitos de eficiencia medioambiental de carácter no energético que complementen la Directiva 2002/91, relativa a la eficiencia energética de los edificios, teniendo en cuenta la metodología propuesta por esta Directiva.

o Como se señalaba en la Directiva 2002/91, la Comisión, con la asistencia del Comité establecido por la propia Directiva, examinará posibles posibilidades de

48 Comisión de las Comunidades Europeas. "Comunicación de la Comisión al Consejo, al Parlamento Europeo, al Comité Económico y Social Europeo y al Comité de las Regiones. Estrategia para un medio ambiente urbano”, 2004. 
renovación de edificios más pequeños, así como incentivos generales de eficiencia energética.

o Se alentará a todos los Estados miembros a desarrollar y poner en práctica un programa nacional de construcción sostenible y a fijar unas exigencias de eficiencia medioambiental rigurosas utilizando normas europeas y el Eurocódigo. Se alentará asimismo a las autoridades locales a promover la construcción sostenible.

o Se instará a todos los Estados miembros, autoridades locales y organismos públicos contratantes a utilizar requisitos de sostenibilidad en sus procedimientos de licitación de edificios y obras de construcción, así como en la utilización de fondos públicos para dichos edificios y obras. Asimismo, se les pedirá que creen incentivos fiscales en pro de unos edificios más sostenibles.

o La Comisión analizará posibilidades de formación, orientación e intercambio de experiencias, así como de investigación, acerca de la construcción sostenible.

o Por otro lado, y como parte de la Estrategia temática para la prevención y el reciclado de residuos, estudiará medidas para atender al problema del volumen creciente de residuos de construcción y demolición.

o La Comisión desarrollará el etiquetado medioambiental de los materiales de construcción (mediante declaraciones medioambientales o etiquetas ecológicas de la UE) y propondrá una etiqueta ecológica o una declaración medioambiental armonizada para la construcción o los servicios de construcción.

- El urbanismo sostenible.

Dada la constante expansión de las ciudades, una de las competencias de la administración local que resultan determinantes a la hora de alcanzar un desarrollo sostenible es la planificación urbanística. Los usos del suelo son un factor decisivo para la conservación del medio ambiente, y definen el modelo de ciudad. Una mala gestión puede llevar a ciudades insostenibles y además poco atractivas, lo que termina generando una merma en la calidad de vida de los ciudadanos. Actualmente la tendencia es el desplazamiento hacia la periferia, hacia zonas de baja densidad de vivienda, esto ocasiona problemas añadidos de desplazamiento, aumento del tráfico y con ello de la contaminación.

Este problema resulta más acuciante en los países adherentes y candidatos, que se encuentran todavía en vías de desarrollo, en los que todavía se está produciendo un trasvase de población del campo a las ciudades; es en estos países en los que resulta imprescindible la aplicación de una Estrategia de Desarrollo Sostenible.

Otro de los retos que se plantean si el objetivo es el desarrollo sostenible es la conservación de las zonas verdes existentes o bien la implantación de zonas nuevas; estas zonas son cruciales para la calidad de vida de los habitantes de las zonas contiguas, permiten a los ciudadanos relajarse, hacer deporte, e incluso entrar en contacto con la flora y la fauna existentes.

La expansión urbanística es un hecho, incluso considerando que la población disminuye, los nuevos hábitos de vida hacen que las nuevas familias, menos numerosas e incluso con un solo miembro, tengan o quieran tener su propia vivienda. Otro problema acuciante es el abandono de las viviendas que se está produciendo en los centros de las ciudades, debido al mal estado de las mismas, al alto coste de la 
restauración... Por esta razón, si queremos una ciudad sostenible deberemos conservar el centro histórico de la misma.

La Perspectiva Europea de Ordenación Territorial (PEOT), elaborada en 1999 por el Comité de Desarrollo Territorial ha sido adoptada por todos los Estados miembros con carácter voluntario. En ella se establecen los objetivos y orientaciones para un desarrollo territorial equilibrado y sostenible; un tercio de las 60 opciones políticas acordadas abordan directamente la cuestión de cómo controlar la expansión física de las ciudades.

Existen varias directivas que ejercen su influencia en el terreno del uso del suelo urbano, entre ellas las Directivas sobre la evaluación de impacto medioambiental y sobre la evaluación medioambiental estratégica, así como la Directiva marco del agua. Las normas que rigen los Fondos Estructurales y las Directrices para el período 20002006 establecen la necesidad de adoptar enfoques sostenibles para el uso del suelo urbano, y afirman que deberá darse prioridad a la rehabilitación de emplazamientos industriales abandonados por encima de la creación de polos industriales nuevos. La iniciativa URBAN II sostiene una utilización mixta y no perjudicial para el medio ambiente a la hora de reutilizar emplazamientos industriales abandonados, disminuyendo la presión ejercida por la creación de polos industriales nuevos y la expansión urbana. Entre las posibles medidas indicativas está la recuperación de emplazamientos abandonados y tierras contaminadas; rehabilitación de espacios públicos, incluidos espacios verdes; y renovación de edificios para acoger actividades económicas y sociales de una manera sostenible y no perjudicial para el medio ambiente. INTERREG ha ofrecido oportunidades similares.

Las acciones propuestas en lo que a urbanismo sostenible se refiere son ${ }^{49}$ :

o Se animará a los todos los Estados miembros a:

- velar porque sus sistemas de planificación urbanística consigan modelos de asentamiento urbano sostenible y tengan en cuenta los riesgos medioambientales, y a emprender un estudio a tal efecto;

- crear incentivos para fomentar el aprovechamiento de las instalaciones industriales abandonadas en vez de la ocupación de terrenos vírgenes, crear bases de datos nacionales sobre instalaciones industriales abandonadas y fijar objetivos ambiciosos para su aprovechamiento, y proporcionar ayudas para el aprovechamiento de edificios vacíos en las zonas urbanas;

- fijar densidades mínimas para las zonas residenciales, que permitan fomentar una mayor densificación y frenar la expansión urbana;

- evaluar las consecuencias del cambio climático para sus ciudades, a fin de que no se inicien proyectos urbanísticos inadecuados y que las adaptaciones a las nuevas condiciones climáticas puedan integrarse en el proceso de planificación urbanística.

49 Comisión de las Comunidades Europeas. "Comunicación de la Comisión al Consejo, al Parlamento Europeo, al Comité Económico y Social Europeo y al Comité de las Regiones. Estrategia para un medio ambiente urbano”, 2004. 
o La Comisión elaborará Directrices para una ordenación del territorio orientada a la alta densidad y la multifuncionalidad, y propondrá definiciones de instalaciones industriales abandonadas y terrenos vírgenes. Estudiará también la posibilidad de definir otras orientaciones sobre cuestiones particulares de urbanismo.

o Asimismo, examinará las posibilidades de formación, investigación e intercambio de experiencias sobre el urbanismo sostenible.

o La Agencia Europea de Medio Ambiente (AEMA) seguirá supervisando prioritariamente las modificaciones del uso y la cobertura del suelo. La expansión urbana incontrolada y el uso del suelo serán objeto de un informe especial de la AEMA.

\subsubsection{Estrategia Española de Desarrollo Sostenible ${ }^{50}$}

Debido a la herencia política que se ha tenido que superar en España, se centraron los esfuerzos en conseguir unas condiciones básicas de bienestar que no se poseían y no es hasta principios de los noventa cuando se empieza a acoger una nueva cultura encaminada a la consecución del desarrollo sostenible.

Para cumplir el compromiso adquirido en la Asamblea General (Río +5) celebrada en Nueva York, España elaboró la Estrategia Española de Desarrollo Sostenible (EEDS), con el objeto de presentarla en la cumbre de Johannesburgo en 2002.

Dado el fuerte impulso que está cobrando el desarrollo sostenible en la política de la Unión Europea, España también está desarrollando su Estrategia de Desarrollo Sostenible para los próximos 25 años. Este proceso se llevará a cabo en varias fases:

- Coordinación entre Ministerios y preparación del Documento de Consulta. Para la elaboración de este documento la Comisión Delegada del Gobierno para Asuntos Económicos ha constituido una Comisión Interministerial de Coordinación de la Estrategia de Desarrollo Sostenible.

- La segunda fase es una fase de consulta con las Administraciones Territoriales y el Consejo Económico y Social, y contempla la participación pública. Esta participación tiene un doble objetivo, conocer la opinión de los ciudadanos e impulsar una toma de conciencia del objetivo perseguido de Desarrollo Sostenible.

- A continuación, teniendo en cuenta la información recopilada, el Gobierno elaborará la Estrategia Española de Desarrollo Sostenible y pondrá en marcha los instrumentos necesarios para conseguir los objetivos fijados.

- La Estrategia se concibe como un proceso de evolución continua. Los progresos serán medidos mediante un conjunto de indicadores y la Estrategia sometida a evaluaciones y revisiones constantes.

\footnotetext{
${ }^{50}$ Comisión Interministerial de Coordinación de la Estrategia Española de Desarrollo Sostenible. "Estrategia Española de Desarrollo Sostenible. Documento de consulta", 2001.
} 


\subsection{Marco de referencia}

Tomando como base la declaración de Río, y teniendo en cuenta las directivas comunitarias mencionadas, se parte para la elaboración del Documento de Consulta de dos ideas básicas:

- El desarrollo tiene una dimensión económica, social y ambiental y sólo será sostenible si se logra el equilibrio entre los distintos factores que influyen en la calidad de vida.

- La generación actual tiene la obligación, frente a las generaciones futuras, de dejar suficientes recursos sociales, ambientales y económicos para que puedan disfrutar, al menos, del mismo grado de bienestar que ella.

El objetivo es conseguir una sociedad más justa, más solidaria, más próspera, más segura, más sana y que ofrezca una calidad de vida duradera intra e inter generaciones.

Esto no significa que solamente se tenga en cuenta el factor ambiental, si hablamos de "Desarrollo Sostenible" hablamos de desarrollo, y habrá que tener en cuenta el desarrollo económico, sin olvidarnos de potenciar la cohesión social.

Podría entenderse el "Desarrollo Sostenible" como la conjunción de tres objetivos:

- CRECIMIENTO ECONÓMICO. Que para conseguir un "Desarrollo Sostenible" deberá ser equilibrado y estable a largo plazo. Para ello se deben: reducir y eliminar sistemas de producción y consumo insostenibles, potenciando: la progresiva utilización de costes reales que incorporen los costes de consumo de recursos naturales, el establecimiento de nuevos requisitos que garanticen la calidad ambiental y permitan la capacidad de elección de los consumidores, la eficiencia en la producción y la información y la formación para nuevas formas de consumo.

- PROGRESO SOCIAL. Esto es, erradicación de la pobreza y calidad de vida, entendida esta última como la consecución de bienestar social, calidad ambiental e identidad cultural.

- RESPETO AL MEDIO AMBIENTE. Que se traduce en un uso racional de los recursos de manera que el medio sea capaz de regenerar lo que consumimos y asimilar los residuos que generamos, con el objetivo de que las generaciones futuras puedan seguir disfrutando de estos recursos.

\subsection{Principios inspiradores}

Para la elaboración de la Estrategia Española de Desarrollo Sostenible y con el fin de enfocar el progreso de nuestro país hacia la sostenibilidad, se adoptan los siguientes principios:

- Deberá adoptarse un enfoque integrado, para contribuir a la sostenibilidad tanto local como global.

- Se hace necesario un compromiso institucional ya que serán las instituciones en último término las que garanticen el cumplimiento de los compromisos aceptados.

- Será imprescindible alcanzar el mayor consenso social posible, porque es la actitud de los ciudadanos la que hace sostenible el sistema y son ellos los destinatarios de las mejoras de la calidad de vida. 


\subsection{Principios Generales}

Se apoya la Estrategia Española en los 27 principios contemplados en la declaración de Río, de los que destaca:

- Derecho a una vida saludable y en armonía con la naturaleza.

- Equidad intra e inter generacional del derecho al desarrollo.

- Integración del medio ambiente en los procesos de desarrollo.

- Incorporación del principio de precaución.

- Internalización de los costes y beneficios ambientales.

- Garantía de acceso a la información y a la participación.

- Promoción de sistemas de producción y consumo sostenibles.

- Corresponsabilidad de los diferentes agentes

- Coherencia y equilibrio en el desarrollo territorial.

\subsection{Cuerpo de la EEDS}

Para la confección de la EEDS, se hizo necesario el proceso que se describe a continuación.

\subsection{Diagnóstico}

El objetivo que tiene la realización de un diagnóstico es el de tener una base para poder valorar las políticas a adoptar y las medidas concretas a tomar, en definitiva, la Estrategia de Desarrollo Sostenible. Como se ha comentado la sostenibilidad se sustenta en tres pilares:

Dimensión social. Que contempla factores como son: la dimensión social de la sostenibilidad en España, la estructura demográfica y el sistema territorial, empleo e integración social, educación formación y cultura, salud pública y prevención de riesgos.

Dimensión económica. Donde se evalúan los parámetros: crecimiento de la economía, evolución, el empleo en la economía, implicación de las actividades productivas sobre la sostenibilidad y factores de futuro.

Dimensión ambiental. En pro de la conservación del medio ambiente, se analizan: la naturaleza y el patrimonio cultural, la atmósfera, el agua, el suelo, las costas y el medio marino, los recursos forestales y agropecuarios y los residuos.

Y se realiza una evaluación general a partir de la cual se concluye: "El estado de la sostenibilidad en España es el resultado de un complejo entramado de interrelaciones entre múltiples esferas de actividad, sobre las que hasta ahora se ha estado actuando en gran medida como si fueran completamente independientes. De ahí deriva la gran dificultad que presenta invertir algunas de las tendencias más negativas para la sostenibilidad, fuertemente enraizadas en el modelo productivo, en el sistema de ocupación y uso del territorio, y en las propias pautas de comportamiento individual y social".

A partir de los resultados de esta evaluación, se obtienen los principales desafíos de la sostenibilidad en España: hacer el sistema productivo más competitivo y eficiente, asegurar y reforzar la cohesión social, desvincular la mejora de la calidad de vida de la sobreexplotación de los recursos naturales y el medio ambiente, reequilibrar el modelo territorial y potenciar la sensibilidad de la población hacia la sostenibilidad. 


\subsection{Bases}

Se considera que el desarrollo sostenible tiene tres dimensiones.

- La cohesión y el progreso social. Con dos áreas de actuación, una estructura y una dinámica socioeconómica más equilibradas, y el refuerzo de los mecanismos de integración social y la mejora general del bienestar social.

- Una economía para un desarrollo sostenible. Con la que se pretende conseguir un crecimiento económico equilibrado, dotación y mejora en el uso de factores productivos, una producción y un consumo sostenibles y la contribución de los sectores productivos al desarrollo sostenible.

- El uso responsable de los recursos naturales y la conservación del medio. Es el campo clave cuando se habla de sostenibilidad y las áreas a tratar serán: la conservación del patrimonio natural y cultural, y la calidad y salud ambientales.

- Estructura y dinámica territorial. Este concepto se refiere a la interacción entre el territorio y la población que lo habita y transforma, buscando el equilibrio que proporcione la sostenibilidad y calidad de vida deseables. Estas soluciones pasan por establecer nuevos planteamientos frente al riesgo de despoblación de los espacios rurales y la implantación de una estrategia de desarrollo urbano sostenible.

- Contribuciones de España al Desarrollo Sostenible Global. Como se ha comentado, la globalización hace que las políticas que se adopten en nuestro país influyan en otros, es importante por lo tanto estudiar: las relaciones de flujos con el exterior y la proyección de España en el mundo.

\subsection{Instrumentación}

Los instrumentos de aplicación de la EEDS son la introducción de políticas o la participación en la toma de decisiones, pero la EEDS no puede empezar a aplicarse en todos los ámbitos, sino que se establecen unas áreas clave:

- Crecimiento económico, empleo y competitividad.

- Gestión de los Recursos Naturales y Conservación de la Biodiversidad.

- Formación, Investigación e Innovación Tecnológica.

- Cohesión Social y Territorial.

- Lucha contra el cambio climático y la contaminación atmosférica.

- Turismo sostenible.

- Gestión y reducción de residuos.

\subsection{Aplicación y gestión de la estrategia}

La EEDS es un documento base que guía las políticas a seguir, pero para conseguir la sostenibilidad es necesaria la cooperación entre las diferentes administraciones, así como el sector privado.

Se definen algunos principios generales que deben guiar la orientación de la EEDS:

- La función del Estado como principal articulador e impulsor de los objetivos del desarrollo sostenible. 
- La cooperación y armonización de actuaciones entre las diferentes instituciones públicas que forman el Estado.

Si se llevan a cabo las acciones propuestas en la EEDS, se deduce de lo anteriormente comentado que se conseguirá:

- Disminuir la contaminación asociada a las actividades productivas.

- Favorecer la formación y la educación

- Establecer incentivos a los procesos más respetuosos con la naturaleza y el medio ambiente.

- Establecer relaciones y sinergias entre diferentes políticas sectoriales y ejes de actuación.

- El tratamiento integrado de varias políticas, que puede evitar superposiciones y conflictos de carácter material, temporal o territorial de diferentes medidas puestas en marcha desde ópticas sectoriales y con objetivos distintos.

Por todo lo visto, se establecen en el Documento Base los compromisos de:

- Cooperación institucional

- Distribución de competencias entre instituciones

- Cooperación interterritorial

- Cultura de evaluación continua

\subsubsection{Estrategia para el desarrollo sostenible de la Comunidad Valenciana ${ }^{51}$}

Este documento base fue adoptado por el Gobierno Valenciano por Acuerdo de 16 de

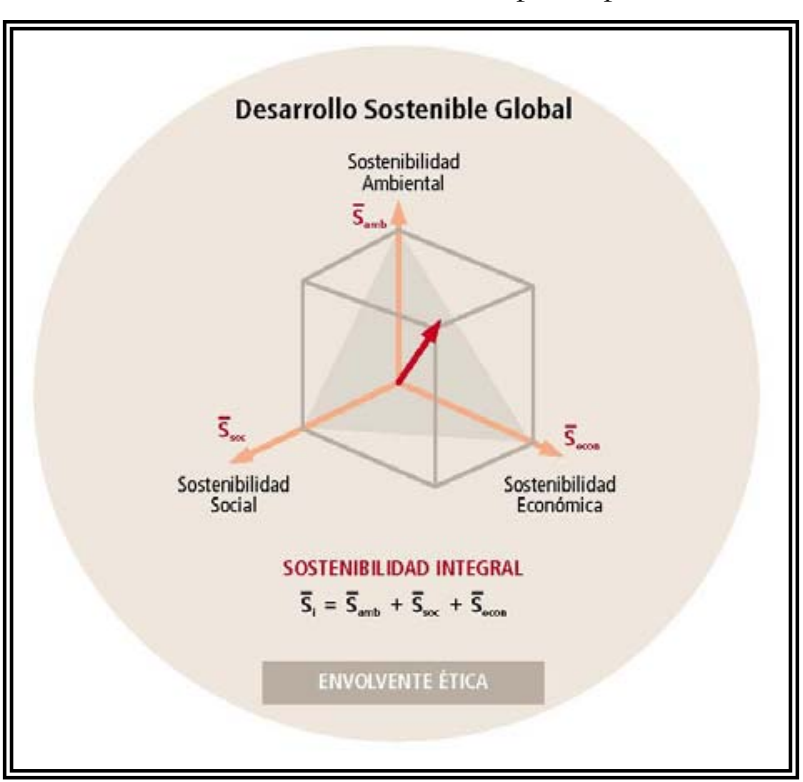
julio de 2002 y como ya hemos apreciado en los documentos elaborados por otras administraciones, y según se dice en el propio documento, constituye el primer paso en la adopción de una estrategia integral de desarrollo que asegure, desde una situación y características propias, el progreso y bienestar futuro de la Comunidad Valenciana.

Anteriormente hemos definido la sostenibilidad como la integración de las dimensiones económica, social y medioambiental del desarrollo; este término está muy relacionado

Figura 1.24. Fuente: Generalitat Valenciana

51 Generalitat Valenciana. "Estrategia para el desarrollo sostenible de la Comunidad Valenciana”. 2002. 
con la solidaridad entre generaciones, que viene a hacer referencia al hecho de que una generación tenga en cuenta la limitación de recursos existentes y sea solidaria con las generaciones futuras.

Esta concepción del desarrollo, controlando la influencia que el ser humano está ejerciendo sobre el medio, nos llevaría lógicamente a una globalización de las políticas de desarrollo. Pero teniendo en cuenta que estas políticas se llevan a la práctica a escala regional o incluso municipal, debe proponerse una estrategia que permita que la sostenibilidad en este caso de la Comunidad Valenciana contribuya a la sostenibilidad europea.

Esta Estrategia para el Desarrollo Sostenible tiene la aspiración de ser un referente no sólo para la acción política, sino también para el conjunto de la sociedad, aunque es cierto que son en última instancia las administraciones públicas las que materializarán estas propuestas en acciones concretas.

\subsection{Desarrollo}

El crecimiento económico de la Comunidad Valenciana se ha visto incrementado notablemente en los últimos años y se prevé que esta tendencia seguirá en el futuro. Se ha acelerado con ello la convergencia con Europa.

Parece que las perspectivas a medio-largo plazo son favorables, sobre todo en lo que a la primera industria valenciana se refiere, el turismo.

Con la ampliación de la Unión Europea se abren nuevos mercados, nuevos demandantes de los productos de la Comunidad Valenciana.

Desde el punto de vista territorial, se dispone de una situación estratégica en el eje mediterráneo, que deberá explotarse adecuadamente potenciando infraestructuras como el Puerto de Valencia.

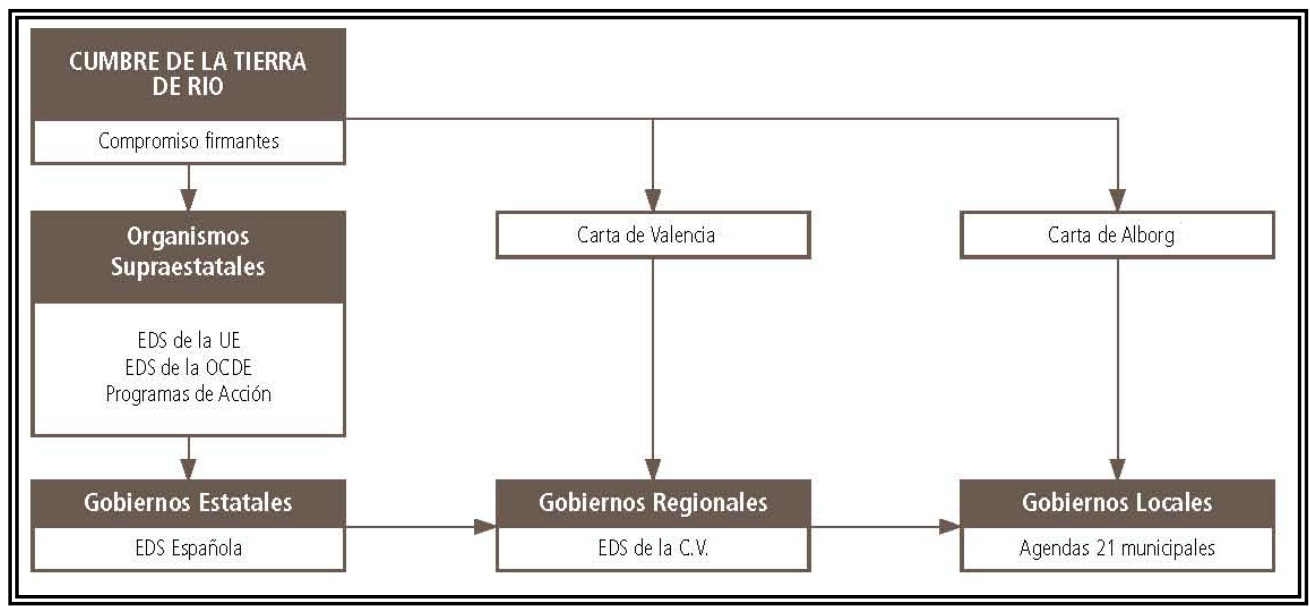

Figura 1.25. Fuente: Generalitat Valenciana 
En lo que a valores medioambientales se refiere, esta Comunidad tiene también grandes activos reconocidos a nivel europeo.

Pasando a revisar el crecimiento demográfico, uno de los mayores problemas de Europa, vemos que en la Comunidad Valenciana ha sido del 1\% en el último decenio, esta población es sobre todo población emigrante joven, que contribuye al rejuvenecimiento de la pirámide poblacional.

Todos estos datos que se aportan, parecen bastante esperanzadores, pero existen temas susceptibles de mejora como son la eficiencia energética, la racionalización de los usos del suelo, la resolución del déficit hídrico, la gestión de los residuos, la mejora de la calidad de vida en las ciudades, la extinción de la marginación social, la seguridad ciudadana, el envejecimiento de la población o la despoblación de las zonas más desfavorecidas.

Parece necesario un cambio estructural en la Comunidad Valenciana, un modelo más acorde con los que están vigentes en la Comunidad Europea. Se ha ido reduciendo el peso de subsectores tradicionales industriales y también el de la agricultura, al tiempo que aumentaba el peso del sector servicios. Este cambio de tendencia ha redundado en un aumento significativo del consumo energético que se va traduciendo en un incremento del sector de producción de energía, alcanzando al sector agrícola.

El cambio estructural al que se alude, no sólo afecta a los sectores productivos, sino también a los sectores sociales, a los ciudadanos en general. El desarrollo económico se tiende a enfocar hacia el bienestar social, uso racional de los recursos, correcta gestión de los residuos, lo que hace que aumente considerablemente el gasto social y en la misma línea el gasto ambiental.

\subsection{Estrategia}

Como cada administración, el Gobierno de la Comunidad Valenciana se ve obligado a emprender el camino hacia el desarrollo sostenible, lo que le lleva a plantear su estrategia. Esta estrategia será un referente para las actuaciones públicas.

La sostenibilidad es actualmente, o debe serlo, uno de los principales objetivos políticos. Entendida como un concepto general, que incluye a la sostenibilidad social, ambiental, etc.

\subsection{Formulación}

Se llevará a cabo según un proceso establecido que consistirá en, partiendo de la optimización de recursos tanto materiales como humanos, estudiar las estrategias ya existentes; se creará una Comisión Delegada de Gobierno para el Desarrollo Sostenible que encomendará la elaboración de la Estrategia a una Comisión Interdepartamental que contará con un Comisión Técnica que será apoyada por consultores y expertos externos a la Administración.

Una vez se cuente con un primer documento, documento de Avance, será sometido a información pública, para que pueda ser discutido por ciudadanos y agentes sociales. Cuando se hayan incorporado las sugerencias pertinentes al documento de Avance, la Comisión Delegada de Gobierno para el Desarrollo Sostenible, tras la comunicación al Pleno, a menos que los cambios fuesen considerables y fuese necesario exponerlo de nuevo a la opinión pública, lo aprobará definitivamente. 
Será también la Comisión Delegada de Gobierno, la Comisión Técnica de Seguimiento a través del "Observatorio de Desarrollo Sostenible", con la ayuda de una auditoría externa, la encargada del seguimiento y evaluación de la Estrategia.

Debemos tener en cuenta que la Estrategia no es un documento cerrado, sino que estará en constante evolución, adaptándose a las necesidades de cada momento y según los resultados obtenidos.

Partiendo de la idea de que el Desarrollo Sostenible es el objetivo en todas las zonas, existen unas "áreas clave" que serán merecedoras de una espacial atención. Estas áreas son ${ }^{52}$ :

- Producción, distribución y consumo en sectores estratégicos: energía, agricultura, transportes, industria, construcción, turismo...

- Gestión del Patrimonio Natural: recursos, riesgos, calidad ambiental...

- Gestión de residuos: urbanos, industriales, agrícolas, construcción...

- Gestión de recursos culturales y educativos: patrimonio, formación, investigación...

- Cohesión e inclusión social: pobreza, exclusión, empleo e inmigración...

- Previsión y protección social: envejecimiento, dependencia, recursos del bienestar, calidad de vida.

- Estructura y dinámica territorial: movilidad, usos del suelo, infraestructuras, equipamientos...

- Relaciones externas: comercio, cooperación, ayuda al desarrollo...

El desarrollo sostenible debe ser objetivo para todas las políticas que se desarrollen en la Comunidad Valenciana, tanto medioambientales como económicas y sociales, de este modo, los principios y criterios de sostenibilidad deberán ser tenidos en cuenta por todos los sectores de la administración. Estos principios, planteados en un marco europeo, deben ser adaptados a la realidad de la Comunidad Valenciana y concretados. "Así el objetivo genérico de reducción de la contaminación atmosférica, se concretará por ejemplo, en el de la reducción de las emisiones de gases que provocan el efecto invernadero, que a su vez se concreta en el de la reducción de las emisiones de $\mathrm{CO}_{2}$ como uno de sus componentes más relevantes. Esta concreción del primer objetivo general debe permitir su transposición a una política sectorial específica, como por ejemplo la de la producción de energía en centrales térmicas, mediante la posterior formulación de objetivos particulares" 53 .

Estos objetivos deberán tener una finalidad concreta que deberá también estar perfectamente definida, con el paso del tiempo se podrá evaluar si se han conseguido los objetivos propuestos. Esta evaluación servirá para corregir la Estrategia en caso de que sea necesario.

Para la consecución de los objetivos será necesario emplear unos instrumentos de acción pública que se definirán también en el documento de la Estrategia. Estos instrumentos pueden ser de tres tipos ${ }^{54}$ :

- Acciones o medidas directamente ejecutadas por la Administración: Planes, Programas, Proyectos etc...

- Medidas de regulación y control: normas, leyes, inspecciones, sanciones, etc.

\footnotetext{
52 Generalitat Valenciana. "Estrategia para el desarrollo sostenible de la Comunidad Valenciana”. 2002

53 Generalitat Valenciana. "Estrategia para el desarrollo sostenible de la Comunidad Valenciana". 2002

54 Generalitat Valenciana. "Estrategia para el desarrollo sostenible de la Comunidad Valenciana”. 2002
} 
- Medidas de promoción o disuasión: campañas de sensibilización, fiscalidad, ayudas, subvenciones etc.

\subsubsection{Agenda 21 Local}

La primera propuesta de desarrollo sostenible a nivel local corrió a cargo del Consejo Internacional de Iniciativas Locales para el Medio Ambiente (ICLEI), que organizó la Conferencia Europea sobre ciudades sostenibles en 1994 en Aalborg (Dinamarca). Fueron ochenta autoridades locales europeas las que firmaron la Carta de las Ciudades y Pueblos Europeos hacia la Sostenibilidad (la carta de Aalborg). Esta carta, a la que se puede sumar cualquier autoridad local, inició la Campaña Europea de Ciudades y Poblaciones Sostenibles. El hecho de firmar la carta de Aalborg compromete a la autoridad local a involucrarse en el proceso de la Agenda 21 Local, que supone la redacción y ejecución de un plan que les conduzca a la sostenibilidad.

En 1995 tuvo lugar en Valencia la II Conferencia de Ministros y Responsables de Medio Ambiente de las Regiones de la Unión Europea en materia de Medio Ambiente, de la que emana la Carta de las Nacionalidades y Regiones Europeas para el Medio Ambiente (Carta de Valencia).

Dada la gran aceptación de la carta de Aalborg y con las aportaciones de más de 600 participantes, se decidió revisarla y mejorarla en una posterior reunión en Lisboa, en septiembre de 1996. Allí se decidió el Plan de Acción (Carta de Lisboa), concretando en once puntos el trabajo teórico y de principios elaborado en Aalborg. Actualmente son más de 500 ciudades europeas las adheridas a la Campaña Europea de Ciudades sostenibles y firmantes de la Carta de Aalborg.

La Diputación de Barcelona impulsó la creación de la Red Catalana de Ciudades y Pueblos sostenibles, iniciativa a la que posteriormente se sumó la Generalitat de Cataluña. Esta Red fue ratificada en Asamblea constitutiva en Manresa, el día 16 de julio de 1997, con la participación de 118 municipios y situó a la provincia de Barcelona a la cabeza de Europa en lo que a desarrollo sostenible local se refiere. Actualmente formada por 150 pueblos y ciudades de todos los tamaños y colores políticos y de características sociales muy diferentes, la Red está elaborando las auditorías ambientales para confeccionar los Planes de acción de las Agendas 21, una colección de una cincuentena de indicadores de estado, presión y respuesta y unos trabajos sectoriales sobre flujos de energía, del ciclo de agua, de los transportes y de los residuos, que son considerados ejemplares por la comunidad científica y por las instituciones europeas responsables del medio ambiente.

En lo que a la Comunidad Valenciana se refiere, el responsable de la Consellería de Medio Ambiente ha declarado recientemente ante las Cortes Valencianas que el diseño y la aplicación de la Agenda 21 Local constituye el primer eje de la política ambiental del Gobierno Valenciano. La Diputación de Valencia, Ayuntamiento de los Ayuntamientos de la provincia, coordina este proceso y se fijó como uno de sus objetivos crear una Red de municipios valencianos hacia la sostenibilidad, que se tradujo en la firma el 30 de mayo de 2000 de la "Declaración de Xátiva".

En esta declaración, los firmantes se comprometen a adherirse a la Carta de Aalborg y a integrarse en el Consorcio-Red de Municipios Valencianos hacia la sostenibilidad cuyo objetivo es servir de instrumento para que los municipios evolucionen hacia situaciones de mayor 
sostenibilidad económica, ambiental y social, mediante la transmisión de información, la aportación de medios técnicos, la promoción de acciones conjuntas con la red europea de ciudades sostenibles, el intercambio de experiencias, la búsqueda de financiación externa, y cualquier otro que persiga la consecución de un Desarrollo Sostenible en los municipios valencianos ${ }^{55}$.

En la Cumbre Mundial sobre el Desarrollo Sostenible (CMDS) celebrada en Johannesburgo entre agosto y septiembre de 2002, los Alcaldes, Líderes y representantes de las ciudades y de los gobiernos locales del mundo, así como de sus asociaciones internacionales y nacionales acordaron la "Declaración del gobierno local ante la cumbre mundial sobre Desarrollo Sostenible". Que parte de las siguientes premisas:

- Celebran la convocatoria de la Cumbre Mundial sobre Desarrollo Sostenible

- Se comprometen a cumplir los objetivos de la Agenda Local 21, de la Agenda Hábitat y de la Declaración del Milenio de Naciones Unidas.

- Reafirman su compromiso con los objetivos del desarrollo sostenible.

- Son conscientes de que a pesar de haber conseguido muchos éxitos y de disponer de un gran compromiso (en especial por parte de los gobiernos locales) con respecto a la Agenda Local 21, falta mucho para conseguir un futuro sostenible para la especie humana.

- Están Convencidos de que es esencial desarrollar una colaboración entre todas las esferas de gobierno.

- Se muestran preocupados por el proceso de depredación actual de los recursos del planeta y por la degradación generalizada del medio ambiente.

- Recuerdan el importante papel que juegan los representantes de los gobiernos locales, que más de 6000 gobiernos locales han puesto en marcha un proceso de Agenda Local 21 y las conclusiones, iniciativas y solicitudes recogidas en la Declaración Final de la Segunda Asamblea de Ciudades y Gobiernos Locales en Río de Janeiro del 6 de mayo del 2001.

- Adoptan las conclusiones y las futuras estrategias expuestas en el Documento de Discusión de los Gobiernos Locales, preparado para la CMDS.

- Celebran la creciente colaboración entre los gobiernos locales, las Naciones Unidas y otras organizaciones.

Y establecen cuatro principios:

- El Desarrollo Sostenible

- Eficiente descentralización democrática

- Buen Gobierno

- Cooperación y Solidaridad

Llegando a los siguientes compromisos:

- Intentar reducir a la mitad, en el 2015 el porcentaje de quienes viven en la pobreza extrema y conseguir una drástica mejora en la calidad de vida de los indigentes hasta el 2020.

- Fortalecer las capacidades de los gobiernos locales con respecto al desarrollo sostenible.

55 Diputación de Valencia. www.dva.gva.es/medioambiente/agenda_21.htm 
- Desarrollar estrategias de ciudades y de gobiernos locales para integrar las dimensiones económicas, sociales, ambientales y culturales del desarrollo.

- Fomentar la Agenda Local 21.

- Iniciar Cooperación de Ciudad a Ciudad y Cooperación Internacional Municipal.

- Desarrollar una cultura de la sostenibilidad.

- Desarrollar un gobierno transparente y con participación de las distintas agrupaciones cívicas y con el sector privado.

- Gestionar los gobiernos públicos de forma integral.

Asimismo, animarán tanto a gobiernos locales como nacionales a colaborar en pro de un desarrollo sostenible, por medio de la aplicación de la Agenda 21 Local.

Como hemos comentado, la preocupación por el desarrollo sostenible está presente en los órganos de gobierno a todos los niveles, pero dado que en Europa un 80\% de la población vive en ciudades, es lógico que se plantee un plan de acción de ámbito municipal, este plan es la Agenda 21 Local. Como expone Espinoza ${ }^{56}$, se trata de pensar globalmente y actuar localmente.

Podemos concebir las ciudades como organismos vivos, que consumen recursos y producen residuos, la clave reside en que el medio sea capaz de regenerar esos recursos y asimilar esos residuos. Generalmente no es así y cada vez son mayores las zonas de afección de las ciudades, la huella ecológica que éstas van dejando debido a su creciente demanda de servicios. Por otro lado, la contaminación puntual que las ciudades generan, va en detrimento de la calidad de vida de los ciudadanos que en ellas habitan.

La adopción de la Agenda 21 Local supone un cambio total de la política local, así como del modelo económico. Tradicionalmente se tendía a modelos desarrollistas, que no tenían en cuenta el deterioro que este desarrollo producía en el medio ambiente. En la actualidad se tiende a valorar el coste ambiental de cualquier acción, en función del beneficio que ésta reporta.

En la ya citada Conferencia de Naciones Unidas sobre Medio Ambiente y Desarrollo de 1992 se animaba a las autoridades locales a "iniciar un diálogo con sus ciudadanos, organizaciones sociales y empresas privadas para adoptar una Agenda Local 21. Mediante consultas y procesos consensuados, las autoridades locales deben dirigirse a las organizaciones cívicas, vecinales, empresariales locales, y adquirir la información adecuada para diseñar la mejor estrategia. El proceso participativo debe reforzar en cada casa y cada vecino la consciencia de los problemas que implica el desarrollo sostenible"

Las ciudades están creciendo de forma desmesurada en buena parte debido a la escasa o nula preocupación que ha habido con respecto a este tema. Actualmente se tiende a fomentar políticas de rehabilitación, para evitar el deterioro de algunos barrios, así como a una ordenación que favorezca el desarrollo sostenible. De todos modos, el modelo de ciudad está cambiando, se tiende a distribuir las actividades por zonas, esto es, a adoptar el modelo "americano".

Tratándose de un compromiso que afecta a la práctica totalidad de las políticas municipales, deberá tenerse en cuenta sobre todo a la hora de elaborar o modificar el Plan

56 Martín, J. et al, “Agenda Local 21”, 2003. 
General de Ordenación Urbana (PGOU), ya que en éste se definen los usos del suelo, su calificación y clasificación, la ubicación de los sistemas generales, etc., es decir, el modelo de ciudad; y este modelo debe adecuarse a las decisiones tomadas a la hora de elaborar la Agenda 21 Local.

El compromiso con el medio ambiente implica, no sólo cumplir unos requisitos de minimización de la contaminación, reciclaje de residuos, potenciación del uso de energías renovables, creación de reservas de espacios verdes, etc.; sino también una forma diferente de edificar, impulsando la eficiencia energética, empleando otro tipo de materiales..., es lo que se viene denominando como arquitectura bioclimática. Es por esto que resulta vital el compromiso del Ayuntamiento que debe intentar controlar al máximo el proceso de urbanización, no dejando en manos de promotores privados la toma de decisiones tan importantes.

La Guía Europea para la Planificación de las Agendas 21 locales, promovida por el Consejo Internacional de Iniciativas Locales para el Medio Ambiente (ICLEI), pretende ser una ayuda para los municipios participantes en la campaña y tiene como objetivos:

- Reforzar la capacidad del gobierno local para hacer frente a problemas ambientales, en particular a ciudades pequeñas y medianas.

- Despertar una comprensión adecuada sobre los problemas del medio ambiente.

- Desarrollar procedimientos políticos y administrativos adecuados, así como la participación ciudadana.

- Aplicar de manera eficiente los instrumentos y las herramientas para la gestión ambiental.

- Hacer del municipio un ejemplo de práctica ambiental adecuada para sus ciudadanos y otros municipios de la zona ${ }^{57}$.

Las acciones prioritarias a abordar según la Federación Española de Municipios y provincias (FEMP), son las siguientes ${ }^{58}$ :

- El mundo próspero: revitalización del desarrollo con criterios sostenibles.

- El mundo justo: una vida sostenible.

- El mundo habitable: núcleos de población.

- El mundo fértil: uso eficiente de los recursos.

- El mundo compartido: recursos globales y regionales.

- El mundo limpio: gestión de productos químicos y residuos.

- El mundo de las personas: participación y responsabilidad de las personas.

\subsection{Metodología}

Una vez adoptada la decisión por parte de la autoridad local competente de elaborar la Agenda 21 Local, los pasos a seguir deberían ser a grandes rasgos los siguientes:

- Creación de un Foro Ambiental en el que participen el mayor número de organizaciones ciudadanas, agente sociales, etc. Este foro debe elaborar un documento que recoja la filosofía del proyecto.

\footnotetext{
${ }^{57}$ Diputación de Valencia. www.dva.gva.es/medioambiente/agenda_21.htm.
}

58 FEMP. “Código de Buenas Prácticas Ambientales”. 2004. www.femp.es/life. 
- Formación de un grupo de trabajo en el que se integren tanto técnicos municipales como ajenos, de modo que ningún área de conocimiento a tratar quede sin técnico competente.

- Divulgación del proceso, para poder recoger el mayor número de opiniones e intentar que todos los grupos puedan realizar sus aportaciones.

- Definición por parte del Foro Ambiental de unos objetivos y la metodología de trabajo para conseguirlos.

- Propuesta del los Indicadores de Sostenibilidad que se utilizarán a lo largo del proceso.

- Elaboración de un informe inicial que recoja el estado actual del municipio en lo que a Sostenibilidad se refiere.

- Estudio pormenorizado del comportamiento de cada Indicador.

- Elaboración de un plan de acción que lleve a la consecución de los resultados deseables.

- Control del proceso y los resultados obtenidos y, en su caso, modificación de la estrategia.

Para poder resolver los problemas medioambientales de cada municipio, objetivo de la Agenda 21 Local, es imprescindible en primer lugar identificarlos y descubrir sus causas, es para lo que se utilizan las ecoauditorías o auditorías medioambientales.

\subsection{Auditorías Medioambientales}

La finalidad de las auditorías medioambientales (AM) no es sólo la de realizar un diagnóstico de la situación medioambiental de un municipio, sino además, plantear soluciones tanto a corto como a largo plazo para proponer políticas que permitan alcanzar el objetivo último, la sostenibilidad.

Así pues, las auditorías medioambientales pueden considerarse como el inicio del proceso de las Agendas 21 Locales. Dado que la sostenibilidad es un tema que debe preocupar a toda la sociedad, es importante que en el proceso de las auditorías medioambientales colaboren y participen todos los colectivos municipales (empresas, sindicatos, asociaciones vecinales, ONG, etc.), así como todas las administraciones que intervienen en el territorio: locales, autonómicas y estatales.

Una vez realizado el diagnóstico, tomadas las decisiones acerca de las políticas a adoptar e impuesto un calendario de actuación, es importante diseñar mecanismos e indicadores que permitan evaluar los avances obtenidos y en caso de que los resultados no sean los deseados, modificar las estrategias a seguir.

A la hora de abordar un proyecto de este calibre, se deberá tener en cuenta que vamos a trabajar en un territorio concreto, con unas particularidades físicas concretas; por esto resultará imprescindible el uso de una cartografía adecuada a las necesidades de cada tarea. 


\subsection{Auditorías Medioambientales según la Federación Española de Municipios y Provincias (FEMP)}

Para poder llevar a cabo una AM, es necesario un amplio consenso político, una fuerte inversión económica y sobre todo la disposición de la Corporación Local a trabajar en el tema, ya que puede suponer un considerable aumento del volumen de trabajo.

Según este organismo, la realización de una Auditoría Medioambiental ofrece ${ }^{59}$ :

- El conocimiento del estado medioambiental del territorio municipal a partir del cual podemos definir una correcta política ambiental que haga posible el desarrollo sostenible de los recursos.

- La identificación de aquellas incidencias medioambientales que afectan a la Entidad Local, con el objetivo de subsanarlas.

- Conocer el cumplimiento de la legislación ambiental aplicable.

- Proporcionar a la Entidad local un punto de arranque para la ejecución y establecimiento de actuaciones medioambientales en el territorio (proyectos, estudios, organización interna).

- Facilitar la puesta en marcha de los sistemas de participación ciudadana y marcar el punto de partida para el desarrollo y la aplicación de la Agenda 21 Local.

En este documento se dividen los factores considerados clave para el análisis en tres categorías: ambientales, socioeconómicos y organizativos. Resulta imprescindible el estudio de todos estos factores, sin obviar ninguno.

Para el estudio de la elaboración de Auditorías Medioambientales, la FEMP, las subdivide en su Código de Buenas Prácticas Ambientales (CBPA) en varios apartados:

\section{DIAGNOSIS}

El objetivo de ésta es llegar al conocimiento de la situación actual de los factores ambientales, socioeconómicos y organizativos del municipio, identificando las deficiencias sobre las que se deberá actuar.

Los factores a estudiar serán los siguientes:

- Ambientales: paisaje, vegetación, fauna, planificación territorial, medio urbano, demografía, movilidad y transporte, agua, residuos, atmósfera, ruido, energía y suelos.

- Socioeconómicos: índices de ocupación y actividades económicas.

- Organizativos: planes de emergencia y riesgos ambientales y estructura funcional del medio ambiente municipal.

DIAGNOSIS TÉCNICA

En primer lugar habrá de llevarse a cabo una diagnosis técnica, cuyos primeros pasos consistirán en:

- Crear un equipo de trabajo con integrantes internos y externos, formado tanto por políticos como por técnicos.

- Elaborar un plan de trabajo, que contemplará los conceptos: fase o etapa, actuaciones, responsables, tiempo, medios necesarios, presupuesto.

En segundo lugar se llevará a cabo la recopilación de información:

- Identificación de la información necesaria.

${ }^{59}$ FEMP. “Código de Buenas Prácticas Ambientales”. 2004. www.femp.es/life. 
- Identificación de las fuentes.

- Recopilación de requisitos legales.

Se realizarán trabajos de campo, que serán comprobaciones, estudios, analíticas y mediciones del entorno con el fin de determinar los efluentes, residuos generados, contaminación y demás actividades sobre cada factor ambiental, socioeconómico u organizativo.

Y todo lo anterior se realiza para poder hacer una correcta descripción del municipio con el objetivo de realizar un informe acerca del estado actual del mismo, estos informes, no deberán ser una mera descripción, deberán ir acompañados de cartografía, fotografías, gráficos, tablas y todo aquello que pueda aportarles claridad.

Partiendo del informe realizado se llevará a cabo un análisis de todos los factores estudiados que permitirá emitir un diagnóstico de la situación. Será también de vital importancia considerar las interacciones y sinergias que existen entre los valores estudiados, ya que no se trata de factores aislados sino de componentes de un todo.

DIAGNOSIS CUALITATIVA

Se trata con ella de conocer las opiniones y necesidades de los ciudadanos, sin los cuales todo el trabajo de la Agenda 21 sería baldío. Por esto la diagnosis debe ser imparcial y representativa de la población local.

Con los datos obtenidos se elaborará una previsión que permita tomar medidas para llegar a alcanzar el objetivo de la sostenibilidad.

\section{PLAN DE ACCIÓN AMBIENTAL}

Está concebido como la herramienta que permitirá llevar a la práctica las estrategias propuestas con el consabido objetivo de alcanzar la sostenibilidad.

Este plan tiene unos objetivos prioritarios:

- Reducir las emisiones contaminantes.

- Mejorar y conservar la calidad ambiental de la Entidad Local.

- Proteger y conservar la riqueza natural del territorio.

- Optimizar el uso de los recursos naturales (agua, energía u otros recursos).

- Disminuir la dependencia de los recursos no renovables.

- Promover el ejemplo del Ayuntamiento de cara a la ciudadanía.

- Fomentar la participación ciudadana en la toma de decisiones.

- Fomentar cambios de hábitos y actitudes por parte de la población en la línea de la sostenibilidad.

\section{DEFINICIÓN DE LÍNEAS ESTRATÉGICAS}

Esta es la primera gran decisión que se debe tomar y consiste en definir los ejes principales que han de regir todo el proceso de mejora del medio ambiente, será en definitiva un reflejo de la política medioambiental del municipio.

\section{DEFINICIÓN DE LOS PROGRAMAS DE ACTUACIÓN}

Se deberá definir un programa de actuación para cada una de las líneas estratégicas que se hayan establecido, sin olvidarse del hecho de que se está hablando de un todo y al abordar cada actuación se deberán tener en cuenta sus posibles repercusiones en otros factores que no son el objeto principal de la actuación. 


\section{DEFINICIÓN DE LOS PROYECTOS}

La definición de los proyectos a abordar viene a concretarse en los trabajos a realizar para conseguir los objetivos perseguidos. Cada proyecto debe presentarse bien documentado y correctamente redactado sin olvidar ningún aspecto que pudiera considerarse relevante a la hora de su ejecución, incluyendo por supuesto un presupuesto y los medios de financiación con que contará.

\section{PLAN DE SEGUIMIENTO}

Como ya se ha comentado, el proceso de Agenda 21 Local es un proceso vivo, que debe adaptarse a los cambios que se produzcan en el municipio, así como mejorar en lo posible las acciones a llevar a cabo si se observa que no se obtiene el efecto deseado. Para ello se debe proyectar un plan de seguimiento que permita controlar el desarrollo del proceso.

CREACIÓN DE LA COMISIÓN DE SEGUIMEINTO

El primer paso será crear una comisión de seguimiento que se encargue de llevar a buen término el Plan de Seguimiento y cuyas funciones básicas serán:

- Aplicación del Sistema de Indicadores de sostenibilidad.

- Efectuar el seguimiento de las actuaciones ambientales.

- Evaluar el grado de implicación de los agentes sociales y económicos en el proceso.

- Informar sobre los resultados obtenidos en el seguimiento.

- Proponer nuevas acciones o estrategias a partir del desarrollo del Plan de Seguimiento.

Esta comisión puede estar integrada por personal de la Corporación Municipal o bien por agentes externos, denominándose entonces Comisión Mixta de Seguimiento.

\section{INDICADORES}

El establecimiento de un sistema de indicadores tiene como objetivo proporcionar una herramienta que permita controlar y evaluar el desarrollo del proceso de Agenda 21, de una manera sencilla y que aporte la máxima información.

Estos indicadores deberán tener ciertas características de las que se relacionan las más relevantes:

- Exactos, inequívocos y específicos.

- Comprensibles y fáciles de interpretar.

- Accesibles y sencillos de obtener.

- Significativos y relevantes.

- Sensibles a los cambios.

- Válidos, científicamente solventes, verificables y reproducibles

- Herramientas útiles para la acción.

La FEMP ofrece también una clasificación de los indicadores:

- Indicadores económicos

o Número de compañías y empresas.

o Ingresos medios.

o Tasa de paro.

o Diversificación económica.

- Indicadores sociales

o Índice de alfabetización. 
o Índice del uso de bibliotecas.

o Vitalidad del asociacionismo del municipio.

o Número registrado de votantes en las elecciones.

o Número de centros sanitarios.

- Indicadores ambientales

o Niveles de contaminación acústica.

o Niveles de contaminación atmosférica.

o Porcentaje de agua que recibe un tratamiento adecuado.

o Porcentaje de residuos recogidos selectivamente.

o Utilización del transporte público municipal.

\section{DECLARACIÓN AMBIENTAL}

Se denominará así al documento final que se obtenga y en el que se expongan los resultados y conclusiones obtenidos de los análisis anteriormente expuestos. Este documento debe hacerse público, ya que su objetivo es el de informar tanto a la población en general como al resto de las administraciones públicas y organismos interesados.

\section{PLAN DE PARTICIPACIÓN SOCIAL}

Ya se ha comentado que este proceso de Agenda 21 no puede llegar a buen término sin la participación de todos, ciudadanos, políticos, empresas y organizaciones de todo tipo, ya que son los ciudadanos en general los que realmente van a llevar a cabo el proceso y van a ser los que disfruten del estado ambiental del municipio. Para ello se están diseñando y poniendo en práctica una gran variedad de instrumentos de participación ciudadana, se pretende mediante debates, estudios y trabajos colectivos, facilitar la transparencia y la participación en la toma de decisiones; se deberá tener en cuenta que cada Entidad Local tiene unas particularidades y adaptar el instrumento de participación a utilizar a la misma.

En la actualidad se están llevando a cabo varios tipos de procesos encaminados a potenciar la participación ciudadana, teniendo en cuenta esto, los municipios podrían clasificarse según la FEMP:

- Municipios sin modelo de participación definido. Donde hay una casi total falta de comunicación entre la Entidades Locales y los ciudadanos, y cuando ésta se produce es por cauces no reglados y puede generar desavenencias.

- Municipios con un modelo "Participativo de Soporte". En estos municipios se informa y consulta a la ciudadanía, pero como sus decisiones no son vinculantes, no siempre se toman en cuenta.

- Municipios con un modelo "Participativo de Decisión". Estos municipios permiten la máxima participación de los ciudadanos en la política local.

El Plan de Participación Social aspira a conseguir la participación de la ciudadanía, estableciendo un vínculo entre la Administración Local y aquella y es importante porque:

- Ayuda a solucionar múltiples problemas simultáneamente.

- Posibilita que la Entidad Local esté al corriente de necesidades e intereses de los ciudadanos, lo que le permitirá llevar a cabo políticas más adaptadas a la problemática real.

- Aumenta la sensibilización, información y corresponsabilización de los ciudadanos ante la problemática medioambiental. 
- Mejora la imagen pública de la administración.

- Aspira a contribuir a la integración de ciudadanos y grupos tradicionalmente aislados de la vida pública.

- Hace aumentar las posibilidades de que los proyectos propuestos alcancen sus objetivos debido a que éstos requieren por definición, el soporte y colaboración de todos.

- Contribuye a la colaboración entre la administración y los ciudadanos

- La participación ciudadana es una vía imprescindible para encauzar un auténtico proceso de Agenda 21 y alcanzar un compromiso global con el desarrollo sostenible.

\section{PRINCIPALES INSTRUMENTOS DE PARTICIPACIÓN}

Como ya se ha comentado, cada Corporación Local deberá elegir el instrumento de participación que mejor se adapte a sus necesidades y a las peculiaridades de su población. Pasamos a describir los instrumentos que propone la FEMP.

- Reglamentos de participación ciudadana. Estos reglamentos tienen como objetivo implicar a los ciudadanos en la política municipal, así como fomentar la tolerancia y el civismo.

- Órganos de participación ciudadana. Como son:

o Consejos Municipales de Medio Ambiente. Estos Consejos no tienen poder de decisión, pero resulta muy útil su función de información y propuesta.

o Foros Ambientales modelo ICLE (International Council Local Environmental Initiatives). La idea original lo concibe como un foro independiente de debate, donde se intercambian opiniones, información, etc.

o Modelo Español de Foro Ambiental. La diferencia con el anterior son las implicaciones políticas y jurídicas. Los ayuntamientos españoles reservan la denominación de Foro Ambiental, para una estructura abierta a los ciudadanos pero sin reglamentación jurídica propia. Las decisiones y acuerdos tomados en el Foro tendrán el carácter de recomendación para la Entidad Local.

\section{PLAN DE COMUNICACIÓN}

Dicho todo lo anterior no es difícil deducir que la comunicación entre la Entidad Local y los ciudadanos debe ser lo más fluida posible, para ello se debe establecer el Plan de Comunicación, con el fin de mantener informados tanto a la población local como a los agentes externos que muestren interés o estén implicados en el proceso.

Este plan, que puede ser llevado a cabo por la propia Corporación Local o bien contratado a una empresa externa, tendrá los siguientes objetivos:

- Informar de la situación actual del medio ambiente municipal.

- Concienciar a los ciudadanos respecto a los problemas ambientales que afectan al municipio y su corresponsabilidad en la solución de estos problemas.

- Informar de la política medioambiental municipal y de las actuaciones medioambientales que la entidad municipal está desarrollando.

- Informar de las mejoras ambientales obtenidas en la Entidad Local.

- Contar con la participación activa del ciudadano en la toma de decisiones medioambientales a través de mecanismos de participación.

- Convocar a los ciudadanos a los procesos participativos. 
- Información sobre los procesos de sostenibilidad en el municipio, auditoría ambiental, Agenda 21 u otros.

Asimismo tendrá las siguientes características:

- La información debe ser comprensible para los ciudadanos. Deben evitarse los tecnicismos.

- El contenido de la información debe ser totalmente objetivo.

- La información debe ser plural, sensibilizadora, estimulante e impulsora de la educación ambiental.

- Para sostener el interés de la ciudadanía, la información ambiental debe presentarse en un formato atractivo, identificable y entretenido.

- La difusión de temas medioambientales debe realizarse a través de diferentes medios para un mayor alcance a todos los colectivos sociales.

- Los sistemas de información pública deben considerarse como una herramienta de consulta tanto para la entidad municipal como para la ciudadanía en general.

- Los sistemas de información ambiental están dirigidos básicamente a:

o Funcionarios de la Entidad Local y trabajadores de empresas subcontratadas (nivel interno)

o Toda la población del término municipal (nivel externo)

o Administraciones, entidades y empresas supramunicipales implicadas con el medio ambiente local.

o A cualquier persona interesada externa a la Entidad Local.

\subsubsection{Sistema de Gestión Medioambiental (SGMA).}

El aumento de la contaminación y el deterioro del medio ambiente en su conjunto han ido sensibilizando a la sociedad y a los políticos que han ido desarrollando legislación para la conservación del medio ambiente, que conduce a la implantación de Sistemas de Gestión Medioambiental.

Un SGMA sería "Aquella parte del sistema general de gestión que comprende la estructura organizativa, las responsabilidades, las prácticas, los procedimientos, los procesos y los recursos para determinar y llevar a cabo la política medioambiental"60.

En 1993, la Unión Europea publicó el Reglamento de adhesión voluntaria 1836/93 de Ecogestión y Ecoauditorías, también conocido como "EMAS". Cuyo objetivo es promover que las empresas del sector industrial mejoren su comportamiento ambiental; estas empresas pueden adherirse a este sistema de gestión y Auditoría Medioambiental, y obtener así un certificado europeo de su comportamiento ambiental.

Algunos países miembros de la UE, en primer lugar Reino Unido, redactaron su propia norma, que no sólo concernía al sector industrial, sino a todo tipo de empresas. En lo que a España se refiere, fue en 1994 cuando se publicaron dos normas UNE-77.801 "Sistemas de Gestión medioambiental" y UNE 77.802 "Auditorías de los Sistemas de Gestión Medioambiental", que hacen referencia a este tema.

${ }^{60}$ FEMP. "Código de Buenas Prácticas Ambientales”. 2004. www.femp.es/life. 
También el Comité Internacional de Normalización ISO aprobó en 1996 algunas de las normas de la serie ISO 14000 "Sistemas de gestión medioambiental".

En 2001 la UE revisó el Eco-Management and Audit Scheme (EMAS) de 1993, ampliando el alcance de éste y no refiriéndose ya a ningún sector concreto. Asimismo, adopta los requisitos de la ISO-14001 relativos al sistema de gestión medioambiental, lo que puede redundar en beneficios para las entidades al evitar la duplicidad de certificaciones.

Para llevar a cabo la implantación de un Sistema de Gestión Medioambiental en una Entidad existen actualmente, pues, dos normas homologadas:

- Reglamento 761/01. (EMAS)

- Norma UNE-EN ISO 14001.

Estos Sistemas de Gestión Medioambiental normalizados llevan implícitos los principios que inspiran la política actual de protección integral del medio ambiente ${ }^{61}$ :

- Quien contamina paga.

- La necesidad de un desarrollo sostenible.

- Utilización de tecnologías limpias.

- Derecho de acceso a la información medioambiental.

\subsection{Implantación de un SGMA}

El primer paso que se debe dar, que incluso puede condicionar la política a seguir, es realizar un análisis de la situación medioambiental actual del municipio, lógicamente sin conocer el estado de partida resulta imposible tomar medidas para mejorarlo. Este análisis se conoce con el nombre de "Revisión Medioambiental Inicial" (RMI).

\subsection{Política Medioambiental}

Es lógico pensar que si una Corporación Local decide implantar un SGMA, tenga una idea muy clara de la política medioambiental que va a adoptar, esta política inicial se deberá ir adaptando a las nuevas condiciones que puedan darse en el municipio, estará en constante revisión, pudiendo incluso fijarse plazos para su obligatorio examen.

Una buena política Medioambiental debe cumplir unos requisitos básicos ${ }^{62}$ :

- Ser apropiada a la naturaleza, magnitud e impactos medioambientales de sus actividades, productos y servicios del Ayuntamiento.

- Reflejará el compromiso con la mejora continua y la prevención de la contaminación.

- Asumirá el compromiso de cumplir con la legislación vigente y la reglamentación ambiental aplicable, así como todos aquellos requisitos o convenios a los que se halla suscrito en materia de medio ambiente.

- Conformará el marco para el establecimiento de las metas y objetivos medioambientales de la entidad.

- Estará documentada, implantada y será comunicada a todos los empleados municipales.

${ }^{61}$ FEMP. "Código de Buenas Prácticas Ambientales”. 2004. www.femp.es/life.

62 FEMP. "Código de Buenas Prácticas Ambientales”. 2004. www.femp.es/life. 
- Tendrá establecidos unos mecanismos de difusión pública y estará a la disposición de las partes interesadas con especial interés en los vecinos del municipio.

\subsection{Ventajas de implantar un SGMA en una entidad local}

En primer lugar merece la pena reseñar el hecho de que cuando una Entidad Local decide implantar un SGMA, con la consiguiente obligación de realizar una declaración medioambiental anual, está ya mostrando su interés en conservar el medio ambiente, lo cual implica una mejor gestión de los recursos y el consiguiente ahorro de energía. Asimismo, dado que el control sobre el medio ambiente será mayor, se reducirán los accidentes medioambientales, lo que redundará en un ahorro de los costos que éstos producen. Huelga decir que una Entidad Local que tenga implantado un SGMA deberá llevar a cabo una política medioambiental activa, lo que motivará una mejora del medio ambiente y con ello de la calidad de vida de los ciudadanos.

El hecho de que en un Municipio se implante un SGMA, provoca un efecto en el resto de la sociedad local, tanto ciudadanos como empresas, que tenderán a comprometerse con la conservación del Medio.

Si el SGMA se implanta de manera similar en todos los organismos, resultará más fácil desarrollar legislación al respecto, así como cumplir la legislación vigente por parte de las entidades que hayan adoptado el SGMA, lo que se traducirá en un ahorro en las sanciones que pudiesen imponerse por el incumplimiento de la legislación desarrollada; del mismo modo, las citadas entidades tendrán una mayor probabilidad de recibir ayudas públicas para abordar actuaciones medioambientales.

\subsection{Contenido del SGMA}

El actual reglamento EMAS asume la norma UNE-EN-ISO 14001 como herramienta propicia para la implantación del SGMA de forma que los elementos que compondrán el sistema son los mismos independientemente de la elección que la Entidad Local haga, sólo existen unas pequeñas discrepancias que se pueden apreciar en la siguiente tabla:

\begin{tabular}{|l|c|c|}
\hline $\begin{array}{l}\text { SEMEJANZAS Y DIFERENCIAS NORMA } \\
\text { UNE-EN-ISO 14001 \& REGLAMENTO 761/01 }\end{array}$ & \multicolumn{2}{l}{} \\
\hline ELEMENTOS & $\begin{array}{l}\text { Norma UN-ISO 14001 } \\
\text { ENeglamento } \\
761 / 01 \text { EMAS }\end{array}$ \\
\hline Evaluación inicial & $\mathrm{X}$ & $\mathrm{X}$ \\
\hline Política medioambiental & $\mathrm{X}$ & $\mathrm{X}$ \\
\hline $\begin{array}{l}\text { Identificación y Control de Aspectos } \\
\text { Medioambientales }\end{array}$ & $\mathrm{X}$ & $\mathrm{X}$ \\
\hline Cumplimiento de Requisitos Legales Aplicables & $\mathrm{X}$ & $\mathrm{X}$ \\
\hline Objetivos y metas & $\mathrm{X}$ & $\mathrm{X}$ \\
\hline Programa de gestión medioambiental & $\mathrm{X}$ & $\mathrm{X}$ \\
\hline Asignación de Responsabilidades & & \\
\hline
\end{tabular}




\begin{tabular}{|l|l|l|}
\hline Formación, sensibilización y comunicación & $\mathrm{X}$ & $\mathrm{X}$ \\
\hline Documentación y Control documental & $\mathrm{X}$ & $\mathrm{X}$ \\
\hline Control operacional & $\mathrm{X}$ & $\mathrm{X}$ \\
\hline Emergencias Medioambientales & $\mathrm{X}$ & $\mathrm{X}$ \\
\hline Comprobación y Acción Correctora & $\mathrm{X}$ & $\mathrm{X}$ \\
\hline Registros de gestión medioambiental & $\mathrm{X}$ & $\mathrm{X}$ \\
\hline Auditorías del SGMA & $\mathrm{X}$ & $\mathrm{X}$ \\
\hline Revisión del sistema & $\mathrm{X}$ & $\mathrm{X}$ \\
\hline Declaración medioambiental & & $\mathrm{X}$ \\
\hline
\end{tabular}

\subsection{Metodología en la Diputación de Valencia}

Las auditorías medioambientales de la Diputación de Valencia, seguirán la metodología siguiente ${ }^{63}$ :

1. RECOPILACIÓN E INTEGRACIÓN DE LA INFORMACIÓN MEDIANTE LOS SISTEMAS DE INFORMACIÓN GEOGRÁFICA (SIG).

- Encuesta Municipal sobre el Medio Ambiente (EMMA). En esta encuesta se deberán valorar tres tipos de factores.

o FACTORES AMBIENTALES:

- Paisaje

- Vegetación

- Fauna

- Planificación territorial

- Medio urbano

- Demografía

- Movilidad y transporte

- Agua

- Residuos

- Atmósfera

- Ruido

- Energía

- Suelos

o FACTORES SOCIOECONÓMICOS

- Índices de ocupación

- Actividades económicas

o FACTORES ORGANIZATIVOS DEL MUNICIPIO

63 Diputación de Valencia. www.dva.gva.es/medioambiente/agenda_21.htm. 
- Planes de emergencia y riesgos ambientales

- Estructura funcional del medio ambiente municipal.

- Conocimiento y recopilación de los datos del municipio: Demografía, estructura urbanística, situación ambiental, recursos naturales y ecosistemas, problemática medioambiental municipal.

La mayoría de los datos así obtenidos deberán ser incorporados a la cartografía, ya que cada evento tiene una localización geográfica concreta. Para ello será necesario disponer de una buena base cartográfica del municipio cuya escala dependerá del tipo de dato a reflejar en ella. Esta cartografía base será complementada con los datos obtenidos, pero para ello será necesario un trabajo de análisis de la simbología a utilizar, que debe ser sencilla e intuitiva.

Los factores ambientales, ya tengan una representación puntual o superficial, requerirán una cartografía con cierto detalle, por lo que lo deseable sería disponer de unas escalas entorno a 1:10.000. También nos serviremos de la cartografía base a esta escala para reflejar el estado actual del municipio en lo referente a demografía, situación ambiental, recursos naturales o problemática medioambiental.

En lo que a factores socioeconómicos se refiere, si se quiere reflejar los datos en la cartografía, se requerirán unas escalas aún mayores, ya que estas actividades suelen estar localizadas en el núcleo urbano. Sería conveniente pues disponer de cartografía a escalas 1:1000 o 1:2000. Esta cartografía resultará también útil a la hora de estudiar la estructura urbanística, que igualmente suele tener mayor interés en el casco urbano.

- Bancos y archivos de datos: Proyectos SIG.

Toda esta cartografía de la que hablamos generalmente nos servirá para introducirla en un Sistema de Información Geográfica, en el que igualmente introduciremos todos los datos gráficos y alfanuméricos obtenidos; esta herramienta informática facilitará considerablemente la gestión de la información.

- Trabajo de campo, toma de datos y tratamiento informático de los datos gráficos y alfanuméricos. Incorporación de toda esta información a los Proyectos SIG.

\section{DIAGNÓSIS}

- Análisis de la situación actual del municipio.

- Elementos estructurales principales: movilidad y accesibilidad, energía, usos del suelo, organización y gestión municipal, planeamiento urbanístico, sistemas naturales, riesgos ambientales, percepción social y participación ciudadana ...

- Principales vectores sectoriales: aire, agua, residuos, suelos, contaminación acústica, contaminación atmosférica, etc.

- Conclusiones: modelo territorial, urbano y socioeconómico, adecuación normativa, déficits y prioridades.

Para llevar a cabo esta tarea resultará muy útil, si no imprescindible, el SIG que hayamos implantado con toda la información disponible ya que nos permitirá disponer de toda la información en un mismo soporte, realizar análisis y generar cartografía. 


\section{PLAN DE ACCIÓN AMBIENTAL}

- Líneas estratégicas: grandes ejes para una mejora ambiental y un desarrollo sostenible.

- Programas de actuación.

- Proyectos y acciones dentro de cada línea estratégica.

- Documento de la auditoría: plan de acción ambiental, plan de participación social, declaración ambiental.

\section{PLAN DE SEGUIMIENTO}

- Presentación pública de la ecoauditoría.

- Seguimiento del Plan de acción ambiental: evaluación y nuevas propuestas de mejora.

- Indicadores ambientales locales.

- Plan de participación social: desarrollo de la Agenda21 y del foro ambiental.

\subsubsection{Código de buenas prácticas ambientales ${ }^{64}$}

El Código de buenas prácticas ambientales (CBPA) ha sido elaborado por la Federación Española de Municipios y Provincias (F.E.M.P.) bajo el patrocinio de un programa LIFE de la Unión Europea y se muestra como una guía metodológica de referencia para facilitar que los Ayuntamientos planifiquen y desarrollen proyectos de Agenda 21 Local, así como para que realicen una correcta gestión ambiental. Para conseguirlo utiliza dos grandes herramientas, la Agenda 21 Local y los Sistemas de Gestión Ambiental según la norma UNE-EN-ISO 14001 y el Reglamento Europeo 760/01 (EMAS).

Las principales características del CBPA son:

- Es una herramienta técnica y práctica. No se trata de un documento informativo, sino de un instrumento de trabajo.

- Es una aportación a la normalización de la gestión ambiental municipal. El objetivo es homogeneizar las actuaciones de las diferentes corporaciones locales, para que entre ellas se puedan hacer comparaciones e intercambiar experiencias.

- Debe considerarse como una guía orientativa y adaptable. Para que pueda ser utilizada por cualquier organismo, independientemente del punto del proceso en que se encuentre.

- Recopila las mejores prácticas españolas y europeas pero sigue abierto a nuevas aportaciones.

- Destinada al mundo local. Aunque puede ser también utilizada por organismos de índole supramunicipal.

${ }^{64}$ FEMP. “Código de Buenas Prácticas Ambientales”. 2004. www.femp.es/life. 


\subsection{Herramientas para la ejecución de la Agenda 21 Local}

La FEMP. propone dos herramientas de trabajo para la elaboración de la Agenda 21, la Auditoría Medioambiental (AM), de la que se ha hablado en el apartado anterior, y el Plan de Participación Social (PPS), que trataremos con más profundidad a continuación, no quedando clara la conveniencia de realizar con anterioridad una u otro.

\subsubsection{Políticas relevantes en materia de conservación del Medio Ambiente}

\subsubsection{Lucha contra la desertificación}

\subsection{Convención de Naciones Unidas de Lucha contra la Desertificación}

El texto de la Convención, que se firmó en París el 17 de junio de 1994, empieza haciendo un análisis de la situación actual de la desertificación en el planeta, teniendo en consideración los siguientes hechos:

- Los seres humanos en las zonas afectadas o amenazadas constituyen el centro de las preocupaciones en los esfuerzos de lucha contra la desertificación y mitigación de los efectos de la sequía.

- La urgente preocupación de la comunidad internacional, incluidos los Estados y las organizaciones internacionales, por los efectos perjudiciales de la desertificación y la sequía.

- Las zonas áridas, semiáridas y subbúmedas secas representan una proporción considerable de la superficie de la Tierra y son el hábitat y la fuente de sustento de una gran parte de la población mundial.

- La desertificación y la sequía constituyen problemas de dimensiones mundiales, ya que sus efectos inciden en todas las regiones del mundo, y que es necesario que la comunidad internacional adopte medidas conjuntas para luchar contra la desertificación y mitigar los efectos de la sequia.

- Un elevado porcentaje de paises en desarrollo y, en especial, de países menos adelantados, entre los países afectados por sequía grave o desertificación, así como de las consecuencias particularmente trágicas que dichos fenómenos acarrean en Africa.

- La desertificación tiene su origen en complejas interacciones de factores físicos, biológicos, políticos, sociales, culturales y económicos.

- El crecimiento económico sostenible, el desarrollo social y la erradicación de la pobreza son las prioridades de los paises en desarrollo afectados, en particular en África, y que son esenciales para lograr los objetivos de un desarrollo sostenible.

- La desertificación y la sequía afectan el desarrollo sostenible por la relación que guardan con importantes problemas sociales, tales como la pobreza, la salud y la nutrición deficientes, la falta de seguridad alimentaria, y los problemas derivados de la migración, el desplazamiento de personas y la dinámica demográfica.

- Los esfuerzos realizados son muy importantes y lo es también la experiencia acumulada por los Estados y las organizaciones internacionales en la lucha contra la desertificación y la mitigación de los efectos de la sequía, particularmente mediante la aplicación del Plan de Acción de las Naciones Unidas de lucha contra la desertificación, que tuvo su origen en la Conferencia de las Naciones Unidas sobre la Desertificación, de 1977. 
- No se han realizado los progresos esperados en la lucha contra la desertificación y la mitigación de los efectos de la sequía, y es preciso adoptar un enfoque nuevo y más efectivo a todos los niveles, en el marco del desarrollo sostenible.

- Las decisiones adoptadas en la Conferencia de las Naciones Unidas sobre el Medio Ambiente y el Desarrollo son válidas y pertinentes.

- Los países desarrollados han adquirido compromisos.

- En el Principio 2 de la Declaración de Río sobre el Medio Ambiente y el Desarrollo se establece que, de conformidad con la Carta de las Naciones Unidas y los principios del derecho internacional, los Estados tienen el derecho soberano de explotar sus propios recursos con arreglo a sus politicas de medio ambiente y de desarrollo, y la responsabilidad de garantizar que las actividades realizadas bajo su jurisdicción o control no causen perjuicios al medio ambiente de otros Estados o zonas situados más allá de los límites de la jurisdicción nacional.

- Los gobiernos de los países desempeñan un papel fundamental en los esfuerzos de lucha contra la desertificación y mitigación de los efectos de la sequía y que los progresos que se realicen al respecto dependen de que los programas de acción se apliquen a nivel local en las zonas afectadas.

- Es importante y la necesaria la cooperación y la asociación internacionales para luchar contra la desertificación y mitigar los efectos de la sequía.

- Es importante que se proporcionen a los paises en desarrollo afectados, en particular los de África, medios eficaces, entre ellos recursos financieros sustanciales, incluso recursos nuevos y adicionales, y acceso a la tecnología.

- Resulta relevante el impacto de la desertificación y la sequía en los paises afectados de Asia Centraly transcaucásicos.

- Es asimismo importante el papel desempeñado por la mujer en las regiones afectadas por la desertificación o la sequía, en particular en las zonas rurales de los países en desarrollo, y la importancia de garantizar a todos los niveles la plena participación de hombres y mujeres en los programas de lucha contra la desertificación y mitigación de los efectos de la sequia.

- Corresponde a las organizaciones no gubernamentales y a otros importantes grupos un importante papel en los programas de lucha contra la desertificación y mitigación de los efectos de la sequia

- Existe una evidente relación entre la desertificación y otros problemas ambientales de dimensión mundial que enfrentan la colectividad internacional y las comunidades nacionales.

- La lucha contra la desertificación puede contribuir al logro de los objetivos de la Convención sobre la Diversidad Biológica, la Convención Marco de las Naciones Unidas sobre el Cambio Climático y otras convenciones ambientales.

- Las estrategias para luchar contra la desertificación y mitigar los efectos de la sequía tendrán la máxima eficacia si se basan en una observación sistemática adecuada y en conocimientos científicos rigurosos y si están sujetas a una evaluación continua.

- Es necesario y urgente mejorar la eficiencia y la coordinación de la cooperación internacional para facilitar la aplicación de los planes y las prioridades nacionales.

Basándose en estas premisas, los asistentes deciden adoptar las medidas adecuadas para luchar contra la desertificación y mitigar los efectos de la sequía en beneficio de las generaciones presentes y futuras. Y a continuación pasan a desarrollar el texto del que extraeremos sus puntos más relevantes. 


\subsection{Cuerpo}

Es importante en primer lugar definir los términos clave del documento, de este modo, parece interesante reseñar las definiciones que se dan en el Artículo 1.

- Desertificación. Degradación de las tierras de zonas áridas, semiáridas y subbuimedas secas resultante de diversos factores, tales como las variaciones climáticas y las actividades humanas.

- Lucha contra la desertificación. Actividades que forman parte de un aprovechamiento integrado de la tierra de las zonas áridas, semiáridas y subbúmedas secas para el desarrollo sostenible y que tienen por objeto:

- La prevención o la reducción de la degradación de las tierras,

- La rehabilitación de tierras parcialmente degradadas, y la recuperación de tierras desertificadas.

- Sequía. Fenómeno que se produce naturalmente cuando las lluvias han sido considerablemente inferiores a los niveles normales registrados, causado un agudo desequilibrio bidrico que perjudica los sistemas de producción de recursos de tierras.

- Mitigación de los efectos de la sequía. Actividades relativas al pronóstico de la sequía y encaminadas a reducir la vulnerabilidad de la sociedad y de los sistemas naturales a la sequía en cuanto se relaciona con la lucha contra la desertificación.

- Tierra. Sistema bioproductivo terrestre que comprende el suelo, la vegetación, otros componentes de la biota y los procesos ecológicos e hidrológicos que se desarrollan dentro del sistema.

- Degradación de las tierras. Reducción o la pérdida de la productividad biológica o económica y la complejidad de las tierras agrícolas de secano, las tierras de cultivo de regadio o las dehesas, los pastizales, los bosques y las tierras arboladas, ocasionada, en zonas áridas, semiáridas y subbumedas secas, por los sistemas de utilización de la tierra o por un proceso o una combinación de procesos, incluidos los resultantes de actividades humanas y pautas de poblamiento, tales como:

o La erosión del suelo causada por el viento o el agua.

- El deterioro de las propiedades físicas, químicas y biológicas o de las propiedades económicas del suelo, y la pérdida duradera de vegetación natural.

- Zonas áridas, semiáridas y subbúmedas secas. Zonas en las que la proporción entre la precipitación anual y la evapotranspiración potencial está comprendida entre 0,05 y 0,65, excluidas las regiones polares y subpolares.

- Zonas afectadas. Zonas áridas, semiáridas o subbúmedas secas afectadas o amenazadas por la desertificación.

- Paises afectados. Países cuy a superficie incluye, total o parcialmente, zonas afectadas.

- Organización regional de integración económica. Toda organización constituida por Estados soberanos de una determinada región que sea competente para abordar las cuestiones a las que se aplique la presente Convención y haya sido debidamente autorizada, con arreglo a sus procedimientos internos, para firmar, ratificar, aceptar y aprobar la Convención y adherirse a la misma.

- Paises Partes desarrollados se entiende los países Partes desarrollados y las organizaciones regionales de integración económica constituidas por paises desarrollados.

En el artículo 2 se definen el objetivo de la Convención y cómo se supone que debe ser alcanzado; el objetivo se reduce a la lucha contra la desertificación y los efectos de la sequía, para alcanzarlo será preciso llevar a cabo políticas a medio y largo plazo que sean capaces de 
producir un aumento de la productividad de las tierras, la rehabilitación, la conservación y el aprovechamiento sostenible de los recursos de tierras y recursos hídricos.

El artículo 3 establece los "Principios de la Convención", que se hacen necesarios al tratarse de un documento adoptado por países tan variopintos. Estos principios vienen a garantizar que las decisiones tomadas tendrán el mayor consenso social y administrativo, sin que puedan darse interferencias entre administraciones de distinto nivel.

Las obligaciones se explican en los artículos 4, 5 y 6, se expone en primer lugar la obligatoriedad de cumplimiento de los compromisos adoptados, y seguidamente otras que se enumeran a continuación:

- Adoptarán un enfoque integrado en el que se tengan en cuenta los aspectos físicos, biológicos y socioeconómicos de los procesos de desertificación y sequía

- Prestarán la debida atención, en el marco de los organismos internacionales y regionales competentes, a la situación de los paises Partes en desarrollo afectados en lo que respecta al comercio internacional, los acuerdos de comercialización y la deuda con miras a establecer un entorno económico internacional propicio para fomentar el desarrollo sostenible.

- Integrarán estrategias encaminadas a erradicar la pobreza en sus esfuerzos de lucha contra la desertificación y mitigación de los efectos de la sequía

- Fomentarán entre los paises Partes afectados la cooperación en materia de protección ambiental y de conservación de los recursos de tierras y los recursos hidricos, en la medida en que ello guarde relación con la desertificación y la sequía.

- Reforzarán la cooperación subregional, regional e internacional.

- Cooperarán en el marco de las organizaciones intergubernamentales pertinentes

- Arbitrarán mecanismos institucionales, según corresponda, teniendo en cuenta la necesidad de evitar duplicaciones.

- Promoverán la utilización de los mecanismos y arreglos financieros bilaterales y multilaterales ya existentes que puedan movilizar y canalizar recursos financieros sustanciales a los países Partes en desarrollo afectados para luchar contra la desertificación y mitigar los efectos de la sequía.

- Otorgar la debida prioridad a la lucha contra la desertificación y la mitigación de los efectos de la sequia y asignar recursos suficientes, conforme a sus circunstancias y capacidades.

- Establecer estrategias y prioridades, en el marco de sus planes y políticas nacionales de desarrollo sostenible, a los efectos de luchar contra la desertificación y mitigar los efectos de la sequí.

- Ocuparse de las causas subyacentes de la desertificación y prestar atención especial a los factores socioeconómicos que contribuyen a los procesos de desertificación.

- Promover la sensibilización y facilitar la participación de las poblaciones locales, especialmente de las mujeres y los jóvenes, con el apoyo de las organizaciones no gubernamentales, en los esfuerzos por combatir la desertificación y mitigar los efectos de la sequía.

- Crear un entorno propicio, según corresponda, mediante el fortalecimiento de la legislación pertinente en vigor y, en caso de que ésta no exista, la promulgación de nuevas leyes y el establecimiento de politicas y programas de acción a largo plazo.

- Apoyar de manera activa, según lo convenido individual o conjuntamente, los esfuerzos de los países Partes en desarrollo afectados, en particular los de África y los países menos adelantados, para luchar contra la desertificación y mitigar los efectos de la sequía.

- Proporcionar recursos financieros sustanciales y otras formas de apoyo, para ayudar a los países Partes en desarrollo afectados, en particular los de Africa, a elaborar y aplicar eficazmente sus 
propios planes y estrategias a largo plazo de lucha contra la desertificación y mitigación de los efectos de la sequía.

- Promover la movilización de recursos financieros nuevos y adicionales.

- Alentar la movilización de recursos financieros del sector privado y de otras fuentes no gubernamentales.

- Promover y facilitar el acceso de los países Partes afectados, en particular los países Partes en desarrollo afectados, a la tecnología, los conocimientos y la experiencia apropiados.

En el Artículo 7 se expresa la total prioridad que debe dársele a África, por su especial situación desfavorecida. Y el Artículo 8 anima a la cooperación con otras iniciativas semejantes.

A continuación, en los Artículos 9, 10, 11, 12 y 13 se habla de los programas de acción, cooperación científica y técnica y de las medidas de apoyo. Se basan estos programas en la cooperación, tanto entre naciones como entre organismos pertenecientes a una misma nación, haciendo hincapié en la participación y coordinación de todos los organismos afectados. Estos programas deben ser lo más específicos posible y tener una gran capacidad de adaptación a las nuevas circunstancias que pudiesen acaecer. Podrá haber programas regionales, nacionales o aún de mayor entidad. Se deberá asistir a los países con menos recursos para que sean capaces de elaborar y ejecutar sus programas de acción, tanto económicamente como mediante la transferencia de tecnología.

Ya se ha comentado en el apartado anterior, pero se cita expresamente en los Artículos 16, 17 y 18 la necesidad de cooperación científica y técnica, se pondrán a disposición de todos los firmantes todos los medios disponibles, tanto en lo referente a tecnología, como a recursos o datos. Asimismo se promoverá la investigación dirigida a la lucha contra la desertificación.

En lo que a las medidas de apoyo se refiere, se cita en los artículos 19, 20 y 21 el hecho de la importancia de la sensibilización de la población, así como del compromiso de aportar la financiación necesaria para el correcto desarrollo del proyecto.

Por descontado que se desarrolla todo el mecanismo de funcionamiento de la Conferencia, los órganos que lo componen, funciones, procedimientos de actuación, etc. Pero no se considera que esto sea de especial relevancia para los objetivos de esta tesis. Sí haremos mención al anexo IV que versa sobre la "aplicación regional para el Mediterráneo norte".

En el citado anexo tiene como objeto reseñar las particulares condiciones de la zona en cuestión, señalando las directrices y disposiciones aplicar en ésta, como se menciona en el Artículo 1.

En el Artículo 2 del anexo que nos ocupa se exponen como condiciones particulares de la región del Mediterráneo norte:

- Condiciones climáticas semiáridas que afectan a grandes zonas, sequias estacionales, extrema variabilidad de las lluvias y lluvias súbitas de gran intensidad

- Suelos pobres con marcada tendencia a la erosión, propensos a la formación de cortezas superficiales.

- Un relieve desigual, con laderas escarpadas y paisajes muy diversificados.

- Grandes pérdidas de la cubierta forestal a causa de repetidos incendios de bosques.

- Condiciones de crisis en la agricultura tradicional, con el consiguiente abandono de tierras y deterioro del suelo y de las estructuras de conservación del agua.

- Explotación insostenible de los recursos hidricos, que es causa de graves daños ambientales, incluidos de la contaminación química, la salinización y el agotamiento de los acuiferos.

- Concentración de la actividad económica en las zonas costeras como resultado del crecimiento urbano, las actividades industriales, el turismo y la agricultura de regadio. 
El Artículo 3 define el Marco de planificación estratégica del desarrollo sostenible, poniendo de manifiesto la obligatoriedad de los programas de acción nacionales de pertenecer al marco de planificación estratégica para un desarrollo sostenible de los países Partes afectados del Mediterráneo norte; así como la necesaria participación de todas las administraciones y organizaciones no gubernamentales con el objetivo de permitir una participación local máxima.

Se considera en el Artículo 4 que los países afectados elaborarán programas de acción nacionales y un calendario a la mayor brevedad posible, y en el Artículo 5 se dan las directrices para la elaboración y ejecución de programas de acción nacionales, de este modo, cada país Parte afectado de la región:

- Designará órganos apropiados que se encarguen de la elaboración, coordinación y ejecución de su programa.

- Hará participar a las poblaciones afectadas, incluidas las comunidades locales, en la elaboración, coordinación y ejecución del programa mediante un proceso de consulta local, con la cooperación de las autoridades locales y las organizaciones no gubernamentales pertinentes.

- Examinará el estado del medio ambiente en las zonas afectadas para evaluar las causas y consecuencias de la desertificación y determinar las zonas prioritarias de acción.

- Evaluará, con la participación de las poblaciones afectadas, los programas ya aplicados y en curso de ejecución a fin de establecer una estrategia y determinar las actividades del programa de acción.

- Preparará programas técnicos y financieros.

- Elaborará y utilizará procedimientos y criterios para vigilar y evaluar la ejecución del programa.

El contenido de los programas de acción nacionales, podrá estar relacionado según el Artículo 6 con:

- Las esferas legislativa, institucional y administrativa.

- Las modalidades de uso de la tierra, la ordenación de los recursos hidricos, la conservación del suelo, la silvicultura, las actividades agricolas y la ordenación de pastizales y praderas.

- La ordenación y conservación de la fauna y flora silvestres y otras manifestaciones de la diversidad biológica.

- La protección contra los incendios forestales.

- La promoción de medios alternativos de subsistencia.

- La investigación, la capacitación y la sensibilización del público.

En lo que se refiere al los programas de acción subregionales, regionales y conjuntos el Artículo 7 dice que se podrán preparar y aplicar para complementar e incrementar la eficacia de los programas de acción nacionales. Asimismo, dos o más países Partes afectados de la región podrán convenir en elaborar un programa de acción conjunto. Estos programas podrán incluir la realización de actividades de investigación y desarrollo relativas a determinados ecosistemas de las zonas afectadas. Para elaborar estos programas subregionales, regionales o conjuntos, los países Partes afectados de la región procederán, según corresponda, a:

Determinar, en cooperación con instituciones nacionales, los objetivos nacionales relacionados con la desertificación que puedan alcanzarse más fácilmente mediante esos programas, así como las actividades pertinentes que puedan realizarse efectivamente por conducto de esos programas.

Evaluar las capacidades operativas y las actividades de las instituciones regionales, subregionales y nacionales pertinentes. 
Evaluar los programas existentes en materia de desertificación entre los países Partes de la región y su relación con los programas de acción nacionales.

Resulta lógico pensar que al tratarse de programas que no afectan a un país completo, se deba establecer un comité de coordinación, compuesto de representantes de cada uno de los países Partes afectados de que se trate, encargado de examinar los progresos en la lucha contra la desertificación, armonizar los programas de acción nacionales, hacer recomendaciones en las diversas etapas de preparación y aplicación del programa de acción subregional, regional o conjunto, y servir de centro para el fomento y la coordinación de la cooperación técnica.

\subsection{Cooperación}

Dada la evidente coincidencia en sus objetivos últimos, es lógico que exista una Cooperación entre la Oficina de la Convención sobre los Humedales "Convención de Ramsar" (Irán, 1971) y la Secretaría de la Convención de las Naciones Unidas de Lucha contra la Desertificación en los países afectados por sequía grave o desertificación, en particular en Africa. Este acuerdo se plasmó en un memorando redactado en Dakar, Senegal, el día 5 de diciembre de 1998.

Los aspectos más relevantes de los acuerdos a los que se llegó fueron el compromiso de cooperación institucional, con la existencia de un flujo de información en ambos sentidos, existiendo un intercambio de información periódico tanto de datos como de tecnología. En este sentido la cooperación será total a la hora de coordinar sus respectivas actividades de investigación, capacitación y concienciación del público, intentando armonizar los programas nacionales y locales de desarrollo integral en el marco de la Convención de Naciones Unidas de Lucha contra la desertificación (CLD) y las Políticas/Estrategias Nacionales de Humedales con arreglo a la Convención de Ramsar.

\subsection{Programa de Acción Nacional contra la Desertificación (PAND)}

\subsection{Introducción}

Este programa emana de la ratificación por parte del Estado español de los acuerdos de la cumbre de Río de 1992, plasmados en el Convenio Mundial de lucha contra la desertificación de $1994^{65}$. Resulta ser, por otro lado, el principal compromiso contraído por España como firmante de la Convención de Naciones Unidas de Lucha contra la desertificación (CLD) ${ }^{66}$.

En el artículo 10 de la CLD, se establece el objetivo del Programa de Acción, consistente en averiguar cuáles son las causas que contribuyen a la desertificación y las acciones a llevar a cabo con el objetivo de frenarla y reducir en lo posible los efectos de la sequía.

La CLD establece como características de los PAND, además de su carácter participativo, la flexibilidad para adaptarse a situaciones cambiantes y la dedicación de atención especial a la prevención de la desertificación.

\footnotetext{
65 García Camarero, J. "Programa de acción contra la desertificación”, 2001.

${ }^{66}$ Ministerio de Medio Ambiente. Diversidad. "Lucha contra la desertificación”. www.mma.es.
} 


\subsection{Objetivos}

Se establece como objetivo fundamental del PAND contribuir al desarrollo sostenible de las zonas áridas, semiáridas y subhúmedas secas del territorio nacional y, en particular, la prevención o la reducción de la degradación de las tierras, la rehabilitación de tierras parcialmente degradadas y la recuperación de tierras desertificadas ${ }^{67}$.

Como ya se ha comentado, el PAND asienta sus bases en la CLD, en cuyo Anexo IV, de Aplicación Regional de la Convención para el Mediterráneo Norte, se señalan las condiciones específicas de los países de la Región, así como algunos aspectos particulares a tener en cuenta en los Programas de Acción Nacional de acuerdo a dichas condiciones. Por esto, según el Artículo 6 del Anexo mencionado, el PAND podrá incluir medidas que afecten a los siguientes ámbitos, siempre que guarden relación con la lucha contra la desertificación y la mitigación de los efectos de la sequía:

- Legislativo, institucional y administrativo.

- Modalidades de uso de la tierra, ordenación de los recursos hídricos, conservación del suelo, silvicultura, actividades agrícolas y ordenación de pastizales y praderas.

- Ordenación y conservación de la fauna y flora silvestres y otras manifestaciones de la diversidad biológica.

- Protección contra los incendios forestales.

- Promoción de medios alternativos de subsistencia.

- Investigación, capacitación y sensibilización del público.

\subsection{Diagnóstico}

Si el objetivo es paliar el problema, el primer paso consiste en el diagnóstico de la situación actual, para a partir de éste adoptar las medidas que se crean oportunas. A la hora de realizar el diagnóstico de la situación actual del problema, se procedió al análisis de los factores tanto naturales como humanos que pudieran resultar causantes de desertificación y de los procesos que desencadenan. De este modo se tratan la aridez, la sequía, la erosión, los incendios forestales, el uso no sostenible de los recursos hídricos, y los factores socioeconómicos. Asimismo se describen los principales escenarios en que se desarrolla la desertificación en España (cultivos leñosos de secano, cultivos herbáceos de secano, cultivos marginales abandonados, terrenos sobrepastoreados, regadíos con problemas de salinización de suelos, formaciones de erial y matorrales degradados,...). Esta descripción y sobre todo, la reflexión sobre las causas últimas reales de su desarrollo, los motores del fenómeno, pretenden contribuir a sentar las bases para la concepción de las soluciones.

Como punto de partida para la toma de decisiones acerca de las acciones a llevar a cabo se estudian las actuaciones que ya están en marcha y cuyo objetivo es la lucha contra la desertificación. Se llega a la conclusión de que las actuaciones serán múltiples y diversas debido al carácter multisectorial de los recursos suelo y agua.

El Ministerio de Medio Ambiente aporta una lista donde se enumeran y exponen los sectores de actividad vinculados a la desertificación en España:

${ }^{67}$ Ministerio de Medio Ambiente. Diversidad. "Lucha contra la desertificación”. www.mma.es. 
- Las acciones en el contexto agrícola: la política de conservación de suelos, los elementos medioambientales en la política de precios y mercados de la Unión Europea, las medidas derivadas de la reforma de la Política Agrícola Común (PAC) de 1992 (medidas agroambientales y forestación de tierras agrarias) y la lucha contra la desertificación en la nueva PAC surgida tras la reforma de 1999.

- Las acciones en el ámbito forestal: la ordenación y restauración hidrológico-forestal de cuencas degradadas, las ayudas a actuaciones forestales en terrenos particulares, la defensa y prevención de los incendios forestales y el estado de la planificación forestal española.

- La gestión de los recursos hídricos, inmersa en un proceso de exhaustiva planificación y profunda renovación.

- El tratamiento que de la sequía se ha dado en los últimos años.

- El estado de la investigación y desarrollo en la desertificación.

- Las acciones no gubernamentales de lucha contra la desertificación.

- La relación del PAND con otras convenciones, en concreto la del cambio climático, la de la biodiversidad y la aplicación de los principios forestales.

\subsection{Elaboración}

El primer paso dado para la elaboración del PAND, tuvo lugar en octubre de 1996, cuando el Ministerio de Medio Ambiente presentó al Consejo Asesor de Medio Ambiente (C.A.M.A.) un documento de principios, que fue favorablemente informado. A continuación se creó un grupo de trabajo para la elaboración de un primer documento (Borrador del PAND).

Es la Dirección General para la Biodiversidad la encargada de la elaboración del PAND, en colaboración con los restantes Ministerios implicados y cualquier organismo ya sea oficial o no, interesado en el citado Plan.

En junio de 2000 se presentan las directrices del PAND y en noviembre del mismo año se celebra la mesa redonda de representantes de las distintas adminitraciones, estatales, autonómicas y locales. Participaron 80 representantes que tras analizar el documento Borrador de Trabajo del PAND, llegaron a la conclusión de que se trataba de una problemática muy compleja, debiendo tener en cuenta la cantidad de intereses encontrados que existen, sobre todo cuando se trata de cuestiones tan delicadas como los usos del suelo y actuaciones que pudieran implicar cambios de dichos usos.

Por esta razón, la mencionada Dirección General envió en enero de 2001 el documento en elaboración del PAND a diversas entidades, como centros oficiales de investigación, universidades, sociedades científicas, asociaciones agrarias, forestales, cívicas, profesionales y ONG, entre otras; el objetivo fue abrir el debate en torno al tema y conseguir los mejores resultados. En el mes de marzo del mismo año se celebra la segunda reunión en el marco del Proceso de Debate del PAND; las instituciones asistentes a la reunión organizada a tal efecto fueron: Instituto Nacional de Investigaciones Agrarias, Centro de Investigación Forestal, Instituto Técnico Geominero de España, Centro de investigaciones sobre desertificación, distintas universidades de Andalucía, Canarias, Castilla La Mancha, Cataluña, Extremadura, Madrid, Murcia y Valencia, y algunas asociaciones agrarias, ONG, asociaciones cívicas y 
empresariales, asociaciones forestales, asociaciones profesionales, colegios profesionales y empresas.

Este proceso consultivo llevó al análisis e incorporación de aportaciones y sugerencias recogidas durante y después de la celebración de estas reuniones, y con el establecimiento de una colaboración con el Ministerio de Agricultura, Pesca y Alimentación para tratar aquellos aspectos vinculados al sector agrario paulatinamente incorporados al documento ${ }^{68}$.

En la actualidad se cuenta con un Documento de Trabajo del PAND que será presentado próximamente a los órganos colegiados de coordinación y tratamiento institucional vinculados a las esferas de acción de la lucha contra la desertificación.

\subsection{Propuestas}

Estas propuestas se centran en encontrar respuesta a dos preguntas ${ }^{69}$ :

\subsection{1 Cuáles son las áreas con riesgo de desertificación.}

Se determinará los espacios físicos y socioeconómicos sobre los que debe desarrollarse la política de lucha contra la desertificación en España. Para ello se basan en el estudio de una serie de indicadores biofísicos y socioeconómicos de la desertificación.

El diagnóstico realizado en este documento permite realizar un ejercicio de definición preliminar y teórica del nivel de riesgo de desertificación, aludiendo solamente a aspectos de tipo cualitativo, que ofrece una primera aproximación de la distribución del problema de la desertificación en el territorio español.

Los indicadores utilizados han sido:

- Índice de aridez.

- Erosión: pérdidas de suelo.

- Incendios: porcentaje de superficie acumulada recorrida por el fuego durante 10 años.

- Sobreexplotación de acuíferos: existencia de problemas de sobreexplotación.

Con los datos así obtenidos se ha obtenido un mapa de subcuencas con riesgo de desertificación, clasificadas según el nivel de riesgo definido por el modelo aplicado.

La distribución de superficies por categorías y el número de subcuencas en cada una se resumen en la tabla aportada por el Ministerio de Medio Ambiente:

\begin{tabular}{|c|c|c|c|}
\hline Riesgo de desertificación & $\mathrm{N}^{\circ}$ de subcuencas & Superficie $\left(\mathrm{km}^{2}\right)$ & Proporción \\
\hline Muy alto & 42 & 56.053 & $11,08 \%$ \\
\hline Alto & 74 & 103.284 & $20,41 \%$ \\
\hline Medio & 72 & 109.712 & $21,68 \%$ \\
\hline Bajo & 46 & 70.728 & $13,98 \%$ \\
\hline $\begin{array}{c}\text { Total Zonas áridas, semiáridas y } \\
\text { subhúmedas secas }\end{array}$ & 234 & 339.776 & $67,14 \%$ \\
\hline Zonas húmedas y subhúmedas húmedas & 106 & 166.284 & $32,86 \%$ \\
\hline Total Nacional & 340 & 506.061 & $100 \%$ \\
\hline
\end{tabular}

68 Ministerio de Medio Ambiente. Diversidad. "Lucha contra la desertificación”. www.mma.es.

${ }^{69}$ Ministerio de Medio Ambiente. Diversidad. "Lucha contra la desertificación”. www.mma.es. 
De esta tabla se deduce que la distribución por nivel de riesgo se puede considerar grave (grados muy alto y alto) en un $31,49 \%$ de la superficie española, lo cual indica la magnitud del problema a que nos enfrentamos.

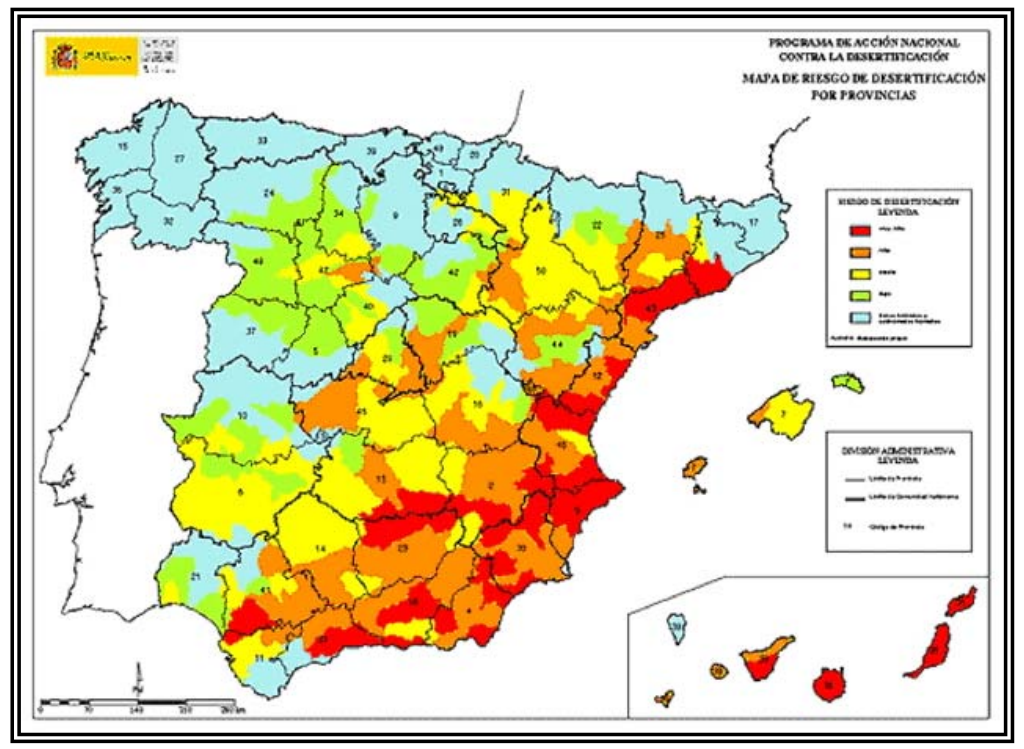

Figura 1.26. Mapa de riesgo de desertificación. Fuente: Ministerio de Medio Ambiente

2.3.6.1.2.5.2 Cuáles son las medidas de lucha contra la desertificación a aplicar en dichas áreas.

Estas medidas que se proponen en el PAND constituyen un catálogo completo de las acciones que es preciso desarrollar en las esferas de acción indicadas por el Anexo IV de Aplicación Regional para el Mediterráneo Norte en su mencionado Artículo 6.

Ya identificadas las medidas a adoptar para paliar la desertificación, el PAND establece los métodos y procedimientos para llevarlas a cabo. Estos métodos se agrupan en dos caminos o estrategias fundamentales y complementarias:

- La coordinación de políticas como única respuesta eficaz para la aplicación de medidas muy diversas que implican a distintos sectores de actividad. La coordinación de políticas es la pieza clave de la lucha contra la desertificación.

- La identificación y desarrollo de las líneas de acción específicas de lucha contra la desertificación. Estas líneas de acción son de aplicación directa y pueden constituir el punto de partida de la aplicación del PAND. 
Las líneas de acción específicas de lucha contra la desertificación propuestas en el Documento de Trabajo del PAND, algunas de las cuales son continuación de actividades que ya se vienen realizando o se han iniciado recientemente, $\operatorname{son}^{70}$ :

- Evaluación y seguimiento de la desertificación en España. Se propone el establecimiento de un Sistema Integrado de Vigilancia de la Desertificación, constituido por los siguientes elementos:

o Inventario, evaluación y seguimiento de áreas afectadas por desertificación:

- Realización del Inventario Nacional de Erosión de Suelos

- Continuación y actualización de los Mapas de Suelos elaborados en el marco del Proyecto LUCDEME (Lucha contra la desertificación en el Mediterráneo).

- Establecimiento de un programa de seguimiento de la dinámica de la desertificación en distintas escalas temporales mediante el empleo de las posibilidades que ofrece la teledetección para la evaluación dinámica de indicadores de la desertificación.

- Establecimiento de actuaciones de seguimiento de áreas afectadas por grandes incendios forestales, con el objeto de evaluar su recuperación, incluyendo recomendaciones de restauración de aquéllas áreas afectadas cuya recuperación natural sea insuficiente.

- Establecimiento de un programa de prevención, inventario, evaluación y seguimiento de la salinización de los suelos

o Desarrollo de un sistema de indicadores y alerta de riesgos.

o Evaluación y seguimiento, a escala de proceso, de los parámetros y procesos que rigen el fenómeno de la desertificación en nuestro país mediante la Red de Estaciones Experimentales de Seguimiento y Evaluación de la Erosión y la Desertificación (Red RESEL).

- Análisis, divulgación y explotación de resultados de programas de Investigación, Desarrollo e Innovación Tecnológica sobre desertificación. Promoción de estudios y proyectos. Reforzamiento del Proyecto LUCDEME. Esta línea de acción pretende alcanzar los siguientes objetivos:

o Recopilar, analizar y difundir la información existente, facilitando el intercambio entre los distintos actores, tanto productores como usuarios de la información.

o Extraer los resultados de investigación y conocimiento que tengan la madurez suficiente para su desarrollo en aplicaciones prácticas y difundirlos entre los usuarios finales de dichos resultados, incorporándolos de esta forma a la respuesta operativa frente a la desertificación en nuestro país.

o Formular una estrategia integrada de adquisición de conocimientos en materia de desertificación adaptada a las necesidades actuales y basada en la experiencia de dos décadas de estudio e investigación.

- Incorporación de los sectores sociales afectados al desarrollo del PAND. Dentro de esta línea se han identificado tres acciones a realizar en una primera etapa:

o Caracterización y promoción del sector español vinculado a la desertificación.

${ }^{70}$ Ministerio de Medio Ambiente. Diversidad. "Lucha contra la desertificación”. www.mma.es. 
o Establecimiento de un sistema de información sobre la desertificación en España

o Acciones de concienciación y divulgación.

- Restauración de tierras afectadas por la desertificación: Ordenación y restauración de cuencas en zonas áridas y semiáridas degradadas.

- Fomento de la gestión sostenible de los recursos naturales en zonas afectadas por la desertificación: Red de Proyectos Demostrativos de Restauración y Gestión Sostenible de Áreas Afectadas por Desertificación.

\subsection{Proyecto LUCDEME}

Las siglas LUCDEME hacen referencia a la "Lucha contra la desertificación en el Mediterráneo".

En la Conferencia de Nairobi en septiembre de 1977, a la que asistieron delegados de 94 países, se planteó el problema de la desertificación como consecuencia de la grave sequía que afectó África. En esta conferencia se barajaron datos como que un 19\% de la Tierra sufre procesos de desertificación ${ }^{71}$.

En España, para frenar los efectos de la desertización se puso en marcha el proyecto LUCDEME, partiendo de datos tan alarmantes como que las cuencas de los ríos Tajo, Júcar y Ebro tienen poco más del 20\% de sus superficies con masas boscosas, la del Guadalquivir por debajo del 20\% y las del Segura y Sur de España con menos del 15\%.

La finalidad del proyecto era la de controlar la desertificación en el área mediterránea. La erosión hídrica es el principal de los procesos de desertificación que afectan a dicha zona, el sudeste español.

Ha resultado de vital relevancia la acción humana, que ha incidido negativamente mediante usos abusivos del suelo y sus recursos en este medio especialmente frágil, donde el desarrollo de la vegetación es prácticamente imposible, por lo que los ecosistemas alterados por el hombre pueden hacerse irrecuperables.

Este proyecto LUCDEME tiene como área de actuación toda la vertiente mediterránea española, pero presentaba una primera fase que incluía a las provincias de Almería, Murcia y vertiente mediterránea de la provincia de Granada. Todas las acciones debían tener como marco el de la cuenca hidrográfica. Así pues, se presentaba una zona de $22.597 \mathrm{Km}^{2}$ de cuenca hidrográfica afectando a una población de 1.300 .000 habitantes.

\subsection{Objetivos}

Los principales objetivos del proyecto se describen a continuación:

- Análisis de los distintos recursos y factores implicados en los procesos de desertificación. Haciendo hincapié en conocer los recursos naturales existentes, su evolución, nivel de degradación y sus causas; conocer también los recursos humanos y su evolución, así como la relación entre ambos. Del mismo se deberán determinar las carencias básicas que los procesos de degradación han introducido en el medio

\footnotetext{
${ }^{71}$ Ministerio de Medio Ambiente. Diversidad. "Lucha contra la desertificación”. www.mma.es.
} 
natural y la influencia de estos procesos sobre la declinación socio-económica de las áreas naturales afectadas.

- Determinación de los sistemas y técnicas aplicables a la lucha contra la desertificación. Planificación integrada de las acciones de ordenación y restauración de las cuencas torrenciales. Para ello se deberán:

o Contrastar y mejorar sistemas y técnicas de lucha contra la desertificación. Trata las facetas importantes relativas a erosión y mejora de suelos. Incluye también, vegetación y sus efectos y distintas especies de posible utilización, es decir, repoblaciones, alternativas a cultivos, etc.

o Determinar los costes reales y sociales directos de la restauración de los recursos naturales necesarios para lograr el desarrollo de las áreas naturales a niveles superiores de calidad de vida.

o Definir y experimentar metodologías para el cálculo de beneficios y determinación de rentabilidades, con especial referencia al empleo de modelos matemáticos.

o Diseñar métodos de seguimiento de los sistemas y técnicas que se apliquen, es decir, ver la eficacia de los mismos y la posible necesidad de correcciones.

o Establecer, si es posible, modelos de integración ordenada para las áreas afectadas por procesos de desertificación.

- Formación, capacitación y extensión sobre la temática del proyecto. Es el objetivo más importante para el carácter internacional del Proyecto LUCDEME, ya que se extendía la posibilidad de utilizar la información adquirida a través de los objetivos anteriores. Abarca el aspecto formativo y educacional desde técnicos hasta afectados directamente por la desertificación.

o Realización de programas de extensión, dirigidos a todo el mundo, tanto técnicos como interesados o afectados nacionales e internacionales.

\subsection{Desarrollo del proyecto}

Lleva en desarrollo desde finales de 1.979 pero la Orden Ministerial que ordenó al entonces I.C.O.N.A. que se hiciera cargo del proyecto es de Junio de 1.982.

Se llevaron a cabo una serie de trabajos previos, que fueron principalmente:

Un mapa de suelos del área de la primera fase del Proyecto.

"Materiales del Sureste Español", que corrió a cargo del I.N.I.A. (Instituto Nacional de Investigaciones Agrarias).

"Estudio Integrado del Medio Físico de la Cuenca del Río Adra".

Para realizar la prueba piloto se seleccionó una cuenca hidrográfica representativa del área de la primera fase del Proyecto, se escogió la cuenca del río Adra, en la que están representados la mayor parte de los ecosistemas presentes en dicha zona, con una gran diversidad litológica y edáfica. Las altitudes oscilaban desde las cumbres de Sierra Nevada hasta el nivel del mar. El factor antrópico en esta zona ha sido muy elevado. La Universidad de Granada fue elaborando distintas memorias y estudios de las muestras de suelo para la evaluación de la pérdida real del suelo en la cuenca del río Adra. Los objetivos del trabajo se concentraron en la búsqueda de los diferentes procesos de erosión, cobrando especial relevancia la acción del hombre. 
También se estudiaron la calidad de las aguas de los ríos Guadalhorce y Guadiera y sobre las del río Guadalfeo.

El C.E.S.I.C., realizó trabajos sobre la erosión eólica, incidencia de la fauna y microfauna en el suelo, también en la cuenca del río Adra.

\subsection{Fondo documental}

A partir de la puesta en marcha del proyecto, y sobre todo mediante trabajos financiados por el propio Proyecto LUCDEME, se creó en 1998 el fondo documental del Proyecto LUCDEME, donde se encuentran catalogados un gran número de trabajos, estudios e investigaciones que tienen como tema central la desertificación. A principios del año 2005 hay catalogados 339 trabajos, de los que 237 han sido financiados por el Proyecto LUCDEME, sobre todo a través de convenios firmados entre distintos Organismos Públicos y empresas privadas.

En este fondo, los trabajos se han clasificado en 15 áreas temáticas, que se enumeran a continuación, reseñándose entre paréntesis el número de trabajos con el que se cuenta de cada área:

- Suelo (124 trabajos)

- Zoología (7 trabajos)

- Erosión hídrica (6 trabajos)

- Erosión eólica (5 trabajos)

- Vegetación (37 trabajos)

- Geomorfología (8 trabajos)

- Hidrología (8 trabajos)

- Desertificación (7 trabajos)

- Calidad de aguas (3 trabajos)

- Ordenación del territorio (13 trabajos)

- Clima (1 trabajo)

- Planificación ganadera (7 trabajos)

- Gestión del Proyecto Lucdeme (3 trabajos)

- Capacidad de uso agrícola (21 trabajos)

- Microcuencas (2 trabajos).

De estos trabajos hay varios que resultan especialmente interesantes, como son los Mapas de Suelos de las diferentes hojas de los territorios incluidos en la zona de actuación del proyecto, que todavía se están ejecutando y la RESEL (Red de Estaciones Experimentales de Seguimiento y Evaluación de la Erosión y la Desertificación) del Proyecto LUCDEME; de estos se hace una breve reseña en los puntos siguientes.

\subsection{1 Mapa de suelos}

A principios del 2005 se contaba ya con 132 hojas, a escala 1:100.000 y 9 más estaban en proceso de ejecución.

Estos mapas resultan de gran utilidad a la hora de adoptar decisiones acerca de las actuaciones a adoptar de cara a la restauración o rehabilitación de las áreas afectadas por la desertificación. 


\subsection{2 RESEL}

Tiene sus inicios en 1995 y su objetivo primordial es el mantenimiento de una red de estaciones de campo que permitan un seguimiento de los procesos de desertificación. Esta red consta de 48 campos experimentales de dimensiones y características diferentes de modo que sean representativos de los diferentes paisajes que nos podemos encontrar afectados por la desertificación.

La RESEL cuenta con 23 centros asociados, y con más de 100 investigadores vinculados a organizaciones de gran relevancia.

Los objetivos de esta red son ${ }^{72}$ :

- Avanzar en el conocimiento riguroso de los procesos que caracterizan a la desertificación.

- Homologar los métodos de medición de campo así como el almacenamiento, tratamiento y explotación de los datos.

- Establecer un banco de datos con relación al ciclo de erosión y ciclo hidrológico, que pueda ser consultado en tiempo real por cualquier investigador o gestor del medio ambiente.

- Diseñar sobre bases ciertas, acciones preventivas y planes de uso y gestión en áreas sensibles a la desertificación.

- Ensayo de nuevas técnicas de control de la erosión, y el establecimiento y calibración de modelos de simulación y gestión adaptados a las condiciones mediterráneas.

Y para alcanzarlos se desarrollan los siguientes temas de investigación ${ }^{73}$ :

- Obtención de tasas reales de pérdida de suelo por erosión hídrica y de generación de escorrentía y sedimentos en diferentes ecosistemas.

- Análisis del papel del bosque mediterráneo en la producción y calidad de agua y sedimentos.

- Evolución de campos agrícolas abandonados.

- Evaluación del grado de erosionabilidad de la lluvia.

- Ensayos de repoblación con especies y técnicas variadas con relación a la mejora del suelo y protección frente a la erosión.

- Efectos de la deforestación e incendios.

- Calibración de modelos precipitación-escorrentía-erosión.

Con todos estos datos se consigue tras su procesado ${ }^{74}$ :

- Información anual y mensual de cada una de las parcelas y cuencas: temperatura media, precipitación, ET, ETP, escorrentía, coeficiente de escorrentía, tasa de erosión, suspensión, acarreo, rebajamiento del suelo.

- Información de los eventos producidos en las estaciones: datos sobre la duración e intensidad máxima del evento, escorrentía, caudal máximo instantáneo, coeficiente de escorrentía, tasas de erosión y sedimentos en suspensión y acarreo.

\footnotetext{
72 Ministerio de Medio Ambiente. Diversidad. "Lucha contra la desertificación”. www.mma.es.

${ }^{73}$ Ministerio de Medio Ambiente. Diversidad. "Lucha contra la desertificación”. www.mma.es.

${ }^{74}$ Ministerio de Medio Ambiente. Diversidad. "Lucha contra la desertificación”. www.mma.es.
} 
El Ministerio de Medio Ambiente expone como objetivo la "elaboración de la Cartografía de Evaluación Biológica y Modelos de Regeneración de la Vegetación en el área del Proyecto LUCDEME" y explica el proceso de la siguiente forma:

"En función del estado inicial de la vegetación (Mapa de Vegetación Actual) y del objetivo que para la zona se ha asignado, se desarrollan los modelos de restauración de la vegetación, en los cuales se marca el estado final de la vegetación en cada una de las unidades. Además del estado inicial y final, se reflejan cuales son los tipos de gestión y actuaciones necesarios para llevarlas a término. Por lo tanto, existe un modelo de restauración distinto para cada estado inicial o grupo de estados iniciales.

Cada modelo de restauración consta de una tabla de especies a utilizar, ordenadas por los biotipos a los que hace referencia el modelo. Como las especies que se pueden utilizar van a variar según la serie de vegetación, se desarrolla un modelo de restauración para cada serie de vegetación.

Tanto los estados iniciales de los que se parte, como los modelos de restauración a aplicar, así como los estados finales en los que quedará la vegetación una vez restaurado el territorio se representan en una cartografía a escala 1:100.000 que acompaña a las memorias de las diferentes áreas estudiadas: Cuencas de los ríos Andarax, Adra, Antas y Ramblas de Morales."

\subsection{La agenda 21 y la desertificación ${ }^{75}$}

Dentro del programa 21 de las Naciones Unidas, hay un capítulo fuertemente relacionados con la desertificación, se trata del capítulo 12, que lleva por título "Ordenación de los ecosistemas frágiles: lucha contra la desertificación y la sequía" y de cuyo contenido vamos a reseñar los aspectos que nos parezcan más relevantes.

El citado capítulo se refiere a los recursos de tierras en los desiertos, en las zonas áridas y semiáridas y en las zonas subhúmedas secas, refiriéndose a la desertificación como a la degradación de éstos ya sea por causas naturales u ocasionadas por el hombre.

Los datos que ofrece Naciones Unidas son alarmantes, la desertificación afecta a la sexta parte, aproximadamente, de la población mundial, al 70\% de todas las tierras secas, equivalente a 3.600 millones de hectáreas, y a la cuarta parte de la superficie total de tierras del mundo. Los efectos más visibles de la desertificación, aparte de la pobreza generalizada, son la degradación de 3.300 millones de hectáreas de pastizales, que constituyen el $73 \%$ de la superficie total de estas tierras y tienen poca capacidad de sustento; la pérdida de fertilidad de los suelos y la degradación de su estructura en cerca del $47 \%$ de las tierras secas, que constituyen tierras marginales de cultivo de secano; y la degradación del 30\% de las tierras de cultivo de regadio en tierras secas con una gran densidad de población y un gran potencial agrícola.

Es fundamental que en la lucha contra la desertificación se impliquen las administraciones a todos los niveles, local, regional, nacional, etc., así como todas las organizaciones que puedan estar afectadas por el tema, y que la colaboración entre ellas sea total.

La ONU sugiere que las acciones a llevar a cabo deberían empezar por la prevención en aquellas zonas en las que la degradación no es todavía demasiado acusada, pero sin olvidar las zonas fuertemente degradadas.

Se tratan en el capítulo que nos ocupa las áreas de los siguientes programas:

\footnotetext{
75 Naciones Unidas. "Programa 21”, 2004. www.un.org.
} 
2.3.6.1.4.1 Fortalecimiento de la base de conocimientos y elaboración de sistemas de información y observación sistemática respecto de las regiones propensas a la desertificación y la sequía, y de los aspectos económicos y sociales de esos sistemas.

El tema de la desertificación no está todavía bien documentado y es preciso avanzar en el tema de la investigación.

Los objetivos de esta área de programas son la promoción de centros nacionales de coordinación, que permitan un tráfico fluido de la información en todas las direcciones; así como la creación de redes de observación y vigilancia.

2.3.6.1.4.2 Lucha contra la degradación de las tierras mediante, entre otras cosas, la intensificación de las actividades de conservación de suelos, forestación y reforestación.

Como ya se ha comentado los esfuerzos deberían centrarse en llevar a cabo acciones preventivas en aquellas zonas que todavía no está afectadas pero que son susceptibles de estarlo, mejorando los sistemas de regadío. Del mismo modo, se debería aumentar la productividad en las zonas moderadamente afectadas y rehabilitar las gravemente desertificadas. Una medida interesante es el aumento de la cubierta vegetal.

Los objetivos de esta área son: la conservación de la diversidad biológica, la protección de las cuencas, la sostenibilidad de su producción y su desarrollo agrícola en las zonas ligeramente afectadas; la rehabilitación de las tierras secas moderada o gravemente desertificadas para su utilización con fines agrícolas mediante la conservación de los suelos y del agua; el aumento de la cubierta vegetal de las regiones afectadas por la desertificación y la sequía; la mejora de la ordenación de los recursos forestales, entre ellos los de leña.

\subsection{Elaboración y fortalecimiento de programas integrados para la erradicación de la pobreza y la promoción de sistemas de subsistencia distintos en las zonas propensas a la desertificación.}

Los sistemas tradicionales de subsistencia basados en la agricultura y el pastoreo son frecuentemente insuficientes e insostenibles, esto unido a que se desarrollen en zonas propensas a la desertificación y la sequía hace que resulte necesario tomar medidas para rehabilitar y mejorar los sistemas basados en la agricultura y la ganadería para conseguir la sostenibilidad.

Los objetivos a conseguir en esta área de programas son la creación de comunidades rurales sostenibles, tanto económicamente como desde el punto de vista medioambiental, mediante el aumento de la productividad, siempre teniendo en cuenta la conservación de los recursos naturales. Resulta también interesante ofrecer sistemas de subsistencia alternativos para aminorar la presión sobre los recursos existentes. 
2.3.6.1.4.4 Fomento de los programas amplios de lucha contra la desertificación e integración de esos programas en los planes nacionales de desarrollo y en la planificación ecológica nacional.

La problemática es mayor en los países en desarrollo, que generalmente basan su economía en la agricultura y la ganadería, se hace entonces necesario un enfoque integrado de la planificación y la ordenación de los recursos de tierras.

Los objetivos de esta área de programas son, por un lado, conseguir un aumento en la capacidad de las instituciones nacionales para formular programas apropiados y por otro crear un sistema de planificación y control de estrategias para el aprovechamiento, la protección y la ordenación de los recursos naturales de las tierras secas. Todo esto desde la más estrecha colaboración entre instituciones regionales, nacionales e internacionales.

2.3.6.1.4.5 Elaboración de planes amplios de preparación para la sequía y de socorro en casos de sequía, incluidos arreglos de autoayuda, para las zonas propensas a la sequía, y formulación de programas para hacer frente al problema de los refugiados ecológicos.

Según datos de Naciones Unidas, a mediados del decenio de 1980 unos 3 millones de personas perecieron a causa de la sequía en el África al sur del Sahara. El costo económico de los desastres relacionados con la sequía es también alto en términos de pérdidas de producción, desaprovechamiento de insumos y desvío de los recursos destinados al desarrollo.

Sería conveniente la puesta en marcha de sistemas de alerta temprana para pronosticar la sequía, estos serían planes integrados a nivel de explotación agrícola o de cuenca hidrográfica que prevean, por ejemplo, estrategias sustitutivas de cultivo, la conservación del suelo y del agua y la promoción de técnicas de captación de agua. Con ello se reduciría al mínimo el número de refugiados ecológicos y la necesidad de un socorro de emergencia durante la sequía. Además, se deberían prever sistemas para suministrar socorro durante períodos de extrema escasez.

Los objetivos de esta área de programas son conseguir un conjunto de planes nacionales capaces de prever las épocas de sequía, con miras a reducir los efectos de las mismas. Asimismo el flujo de información será fluido entre las autoridades y los usuarios de tierras, para que los países puedan aplicar con la mayor probabilidad de éxito las estrategias de intervención y los planes de socorro.

2.3.6.1.4.6 Fomento y promoción de la participación popular y la educación sobre el medio ambiente, con especial hincapié en la lucha contra la desertificación y las actividades para hacer frente a los efectos de la sequía.

Todos estos proyectos no pueden llegar a buen término sin la colaboración de toda la población, por esta razón resulta imprescindible lograr una participación real y activa de la población basada en la responsabilidad compartida y el mutuo interés de todas las partes. 
Los objetivos de esta área de programas son el aumento de la conciencia pública sobre las cuestiones de desertificación y sequía, así como sobre el medio ambiente. Se tratará también de fomentar la colaboración entre todos los organismos implicados intentando que estén completamente comprometidos con el tema. 


\subsection{E1 Paisaje}

\subsubsection{Diferentes conceptos de paisaje}

La primera definición que ofrece el Diccionario de la Real Academia de la Lengua del vocablo "Paisaje" es: "Extensión de terreno que se ve desde un sitio.". Esta definición resulta insuficiente para precisar el concepto que nos ocupa.

Otra definición de paisaje, formulada por Paulowski y recogida por Hartshorne ${ }^{76}$ (1939) dice así: "El paisaje lo forman todos aquellos objetos y fenómenos que ocupan un cierto espacio, objetos que son observables con los órganos sensibles".

Por paisaje también podemos entender la percepción del medio a partir de la expresión externa de éste. El medio se hace paisaje cuando alguien lo percibe. Esta percepción es subjetiva, variable por tanto, en razón del tipo de perceptor y se adquiere a través de todos los órganos de percepción, directos e indirectos, que operan en el observador. Es la experiencia perceptiva quien induce en el individuo los sentimientos determinantes de la clasificación y valoración del paisaje $\mathrm{e}^{77}$.

Expresaba Víctor Hugo en una acertada frase: "una cosa es el espectáculo de los Alpes y otra quién sea el espectador".

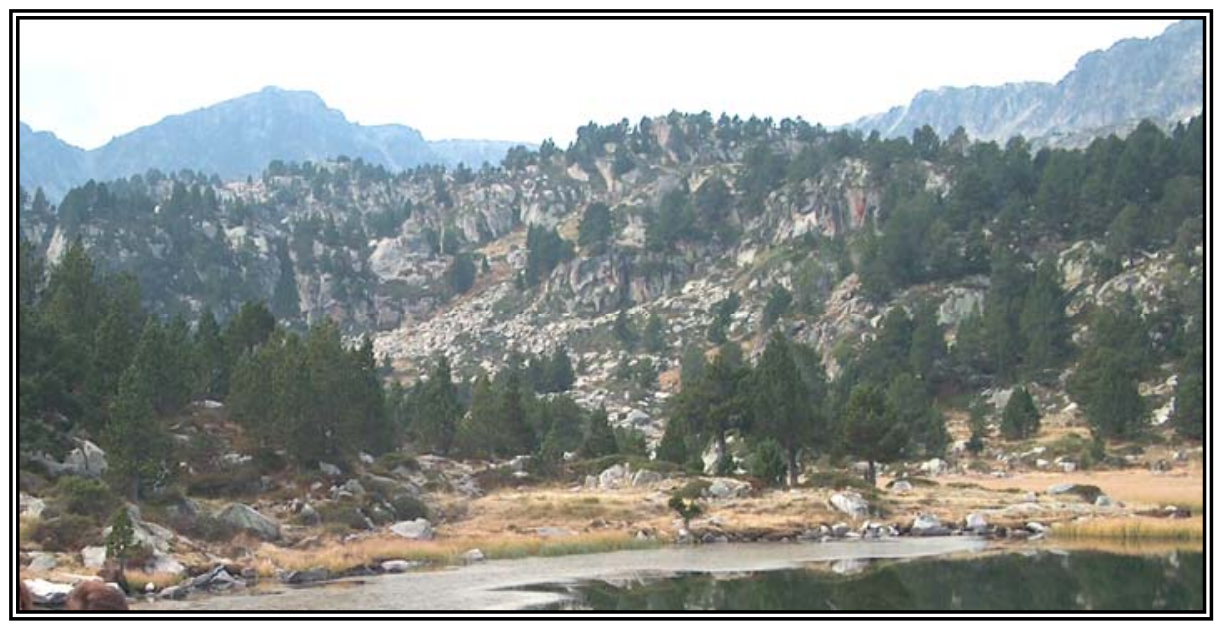

Foto 1.27. Paisaje Positivo. Andorra la Vella. Fuente: Propia.

\footnotetext{
${ }^{76}$ Hartshorne, R., “The Nature of Geography”. Tomado de Higueras, A, “Teoría y método de la Geografía”, 2003.

77 Gómez Orea, D., “Ordenación del Territorio”, 1994.
} 
Fijándonos en estas definiciones, resultaría harto difícil regular el paisaje en cuanto que estamos hablando de una percepción, que en teoría no debe ser la misma para todos los seres humanos. Sin embargo, en la práctica sí existen unos estándares estéticos que permiten analizar el paisaje con cierta objetividad, y tras este análisis conservarlo o mejorarlo.

Aunque la apreciación del paisaje viene determinada por el nivel cultural del observador, como se ha comentado existen unas constantes en la apreciación positiva de un gran número de componentes: relieve variado, presencia de agua limpia y en movimiento, de vegetación frondosa, de elementos topográficos sobresalientes, de sonidos y olores gratos, de orden, posibilidad de observar animales silvestres, etc., así como en la aportación negativa de otras: presencia de escombros y basuras, de agua sucia y/o estancada, de olores pestilentes, de sonidos discordantes como el ruido del tráfico, de edificaciones construidas con materiales, colores y diseños estridentes, de monotonía, etc. ${ }^{78}$. Esto puede apreciarse claramente en la foto 1.28., donde se ve una zona de bosque que resultaría agradable si no fuese por los escombros que se han vertido en ella. Igualmente, en la foto 1.27. tenemos un paisaje que resultaría positivo a la inmensa mayoría de los espectadores, por la presencia de agua limpia, vegetación, relieve variado...

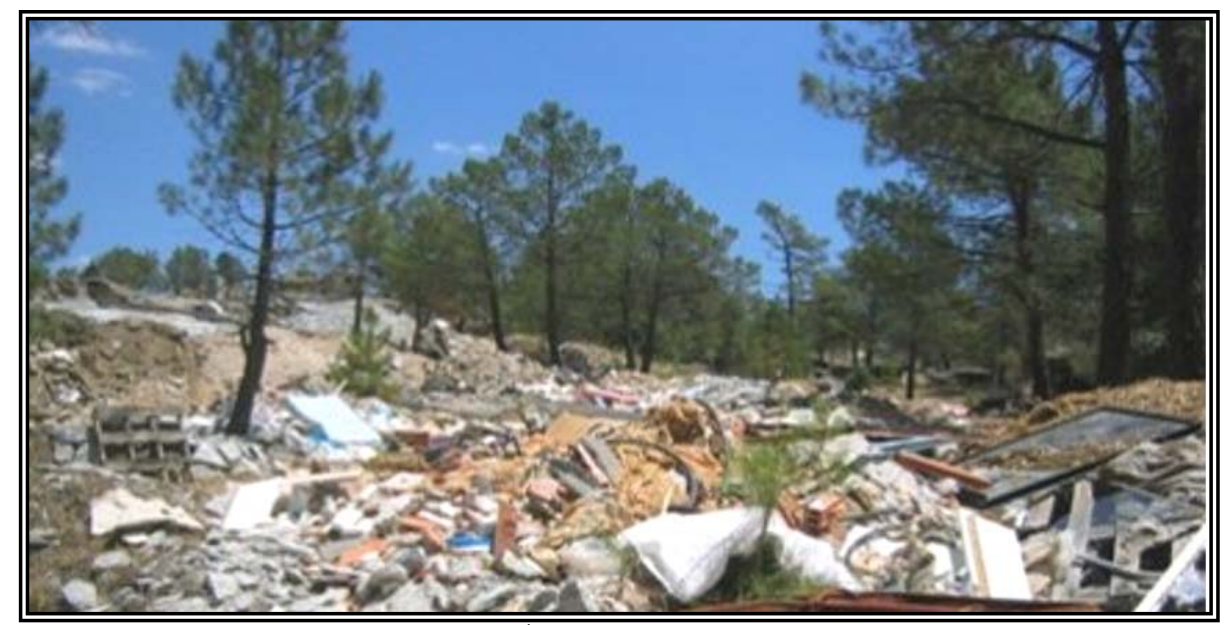

Foto 1.28. Paisaje negativo. Hoyo de Pinares (Ávila). Fuente: www.elhoyodepinares.net

Existe también la posibilidad de considerar el paisaje como un Recurso Natural, al igual que se consideran el agua, el aire, el suelo, etc. En este concepto de recurso va implícito su aprovechamiento humano ${ }^{79}$. En este caso se trataría de un recurso intangible, que guarda relación con las necesidades espirituales del ser humano, pero que no por ello tiene menos importancia; esta relevancia se incrementa conforme las sociedades se consideran más desarrolladas, ya que cuando una sociedad tiene cubiertas sus necesidades básicas es cuando empieza a generar otras necesidades, que en el caso del paisaje pueden ser estéticas.

\footnotetext{
78 Gómez Orea, D., “Ordenación del Territorio”, 1994.

${ }^{79}$ Ayuga Téllez, F. et al., “Gestión sostenible de paisajes rurales”, 2001.
} 


\subsubsection{Evolución del concepto}

El término "Paisaje" deriva del latín pagus que significa país, y tiene un sentido de país, de sector territorial. ${ }^{80}$. Esta acepción sigue siendo válida con ciertos matices.

Es a finales del siglo XV cuando encontramos una nueva acepción, muy ligada a las artes pictóricas. Es entonces cuando aparecen pintores de paisajes o paisajistas, cuya definición del paisaje venía ser "una porción de tierra firme", no se consideraba entonces el mar.

Empezamos a encontrar una serie de definiciones a partir de mediados del siglo XVII, muy similares a las que podemos ver en algunos diccionarios actuales.

En el diccionario Webster un paisaje es "la imagen que representa la vista de un sector natural" (significado pictórico); "superficie terrestre, relieve de una región en su conjunto producido o modificado por fuerzas geológicas" (significado de territorio físico); y "territorio o parte de la superficie terrestre que la vista puede observar simultáneamente, incluyendo todos los objetos discernidos" (visión global del conjunto del mosaico) ${ }^{81}$.

A. Hommeyerem introduce a partir del siglo XIX el término en el campo de la Geografía mediante la forma alemana "Landschaft", a partir de entonces su utilización empieza a ser muy común en este campo, entendiéndose como el conjunto de "formas" que caracterizan un sector determinado de la superficie terrestre ${ }^{82}$.

Alexander Von Humboldt, científico alemán de principios del XIX, se empieza a plantear la tierra como un todo y acepta una definición de Naturaleza adaptada al concepto de paisaje integrado. La naturaleza es "lo que crece y se desarrolla perpetuamente, lo que sólo vive por un cambio continuo de formas y de movimiento interior" (Humboldt, 1874).

La mayor parte de las bases teóricas de la concepción científica del paisaje se establecen en la segunda mitad del siglo XIX y la primera del XX y son los alumnos de Humboldt quienes, siguiendo sus pasos, estudian la estructura de la superficie terrestre.

J. Ch. Smuts creó una doctrina denominada "holismo" que aportaría una clarificación fundamental acerca de las características de los conjuntos o unidades que se forman en la superficie terrestre; según esta doctrina, el universo y sus componentes tienen tendencia a generar unidades que forman un todo que se complica de forma creciente. Estas unidades son combinación de las materias inerte, viva y pensante (hombre), pero nunca una unidad es la simple suma de los elementos que la componen, depende de las interconexiones existentes entre ellos.

\subsubsection{Elementos que componen el paisaje}

Generalmente para hacer cualquier tipo de valoración o estudio acerca del paisaje, el primer paso será identificar los diferentes elementos que lo constituyen. Adoptaremos la división de Forman y Godron (1981) $)^{83}$, que señalan la "matriz" como elemento dominante, que estará compuesto por "manchas", elementos superficiales, y "corredores", elementos

\footnotetext{
${ }^{80}$ De Bolós, M., "Manual de ciencia del paisaje", 1992.

${ }^{81}$ De Bolós, M., "Manual de ciencia del paisaje", 1992.

82 De Bolós, M., "Manual de ciencia del paisaje”, 1992.

83 Burel, F. et al., "Ecología del Paisaje”, 2002.
} 
lineales; partiendo de estas premisas, las manchas constituirán un "mosaico" y los corredores una "red".

La disposición espacial de estos elementos es a lo que llamaremos "patrón" paisajístico y nos servirá para comparar paisajes desde el punto de vista estructural.

\subsubsection{Aproximaciones cuantitativas}

Estas aproximaciones pueden ayudarnos a clasificar los paisajes, sobre todo con la ayuda de programas informáticos. Veamos qué conceptos podemos utilizar.

- Fragmentación. Se refiere al tamaño de las manchas, en realidad se estudia la cantidad de un cierto tipo de paisaje y su distribución en el espacio.

- Conectividad. Que obviamente se refiere al grado de enlace entre las diferentes manchas. La conectividad puede ser "espacial", es decir, que dos manchas estén físicamente conectadas o "funcional", que pueda haber intercambio de individuos de unas a otras.

- Heterogeneidad. La heterogeneidad, que encontramos en todos los paisajes, tiene dos componentes: la diversidad de elementos paisajísticos y la complejidad de sus relaciones espaciales. Existen estudios acerca de la cuantificación de la heterogeneidad ${ }^{84}$.

- Escala. La gran importancia que tiene la escala de representación radica en que ésta determina la resolución espacial del trabajo, el elemento mínimo representable en cada cartografía viene determinado por la escala de la misma y esto nos define el nivel de detalle de nuestro trabajo.

\subsubsection{Elementos visuales del paisaje}

Trataremos aquí los elementos del paisaje desde una perspectiva estética. El aspecto de cualquier objeto o escena viene definido por colores, texturas, formas y lineas que se muestran en determinadas escalas o proporciones y en un determinado espacio ${ }^{85}$.

Existe una técnica denominada "de elementos visuales o estéticos" (Smardon, 1990) que utiliza esta clasificación.

Sabemos que el observador no aprecia todos los colores y texturas del mismo modo, sino que existen colores y texturas dominantes y esta cuestión, aunque estudiada, no puede cuantificarse.

La técnica antes mencionada, que será la que comentemos en este apartado, separa y estudia cada uno de los elementos del paisaje y las relaciones entre ellos. De cada elemento deberemos conocer su distribución y su tipo dominante, a continuación haremos un breve estudio de estos elementos.

\footnotetext{
${ }^{84}$ Burel, F. et al., "Ecología del Paisaje”, 2002.

85 Español Echaniz, I., "Las obras públicas en el paisaje”, 1998.
} 
Podemos hacer una clasificación de los elementos visuales como sigue ${ }^{86}$ :

\begin{tabular}{|c|c|c|c|}
\hline GRUPOS & ELEMENTOS & SUBELEMENTOS & CARACTERÍSTICAS \\
\hline \multirow{3}{*}{$\begin{array}{l}\text { PROPIEDADES } \\
\text { DE LAS } \\
\text { SUPERFICIES }\end{array}$} & COLORES & & $\begin{array}{l}\text { Tinte } \\
\text { Tono } \\
\text { Brillo }\end{array}$ \\
\hline & \multirow{2}{*}{ TEXTURAS } & De color & \multirow{2}{*}{$\begin{array}{l}\text { Tamaño de grano } \\
\text { Densidad } \\
\text { Regularidad } \\
\text { Contraste interno }\end{array}$} \\
\hline & & De formas & \\
\hline \multirow[b]{3}{*}{ ELEMENTOS } & \multirow{3}{*}{ LÍNEAS } & Bandas & \multirow{3}{*}{$\begin{array}{c}\text { Nitidez } \\
\text { Complejidad } \\
\text { Orientación }\end{array}$} \\
\hline & & Límites & \\
\hline & & Siluetas & \\
\hline \multirow[t]{2}{*}{ FORMALES } & \multirow{2}{*}{ FORMAS } & Bidimensionales & \multirow{2}{*}{$\begin{array}{l}\text { Geometría } \\
\text { Complejidad } \\
\text { Orientación }\end{array}$} \\
\hline & & Tridimensionales & \\
\hline \multirow{3}{*}{$\begin{array}{c}\text { ELEMENTOS } \\
\text { DE } \\
\text { COMPOSICIÓN }\end{array}$} & ESPACIO & & $\begin{array}{l}\text { Composición escénica } \\
\text { Localización de unidades } \\
\text { Fondo Escénico }\end{array}$ \\
\hline & \multirow{2}{*}{ ESCALA } & Absoluta & \multirow{2}{*}{$\begin{array}{c}\text { Ocupación } \\
\text { Contraste de escalas } \\
\text { Dominio campo visual }\end{array}$} \\
\hline & & Relativa & \\
\hline
\end{tabular}

\subsubsection{Color}

Es la propiedad de las superficies de reflejar con cierta intensidad, cierta longitud de onda de la luz recibida. Partiendo de esta definición, nos damos cuenta de que el color de un objeto está completamente condicionado por la fuente de luz recibida, su intensidad y su tinte.

Como se indica en el cuadro anterior, las características básicas del color $\operatorname{son}^{87}$ :

- El Tinte. Que es lo que coloquialmente conocemos como color y se refiere a la longitud de onda reflejada por el objeto. En general los colores que denominamos cálidos (rojos, amarillos y naranjas) suelen centrar la atención del observador aún cuando se presenten en una proporción menor que los colores fríos (azules, verdes o violetas).

- El Tono. Este término se refiere a la intensidad de energía reflejada, coloquialmente lo que conocemos por tonalidades claras y oscuras.

\footnotetext{
86 Español Echaniz, I., "Las obras públicas en el paisaje”, 1998.

${ }^{87}$ Español Echaniz, I., "Las obras públicas en el paisaje”, 1998.
} 
- El Brillo. Que alude a la dispersión de la luz reflejada, generalmente las superficies más pulimentadas reflejarán más la luz que las superficies rugosas. En este caso son las superficies brillantes las que atraen la atención del observador.

Estas diferencias de color se aprecian claramente en la foto 1.29., donde vemos diferencias de tinte, tono y brillo por la presencia de agua y vegetación, en contraste con la montaña y el cielo. También en esta foto podemos apreciar diferencias de textura, que explicaremos a continuación, debido a la presencia de agua y a lo escarpado de la montaña.

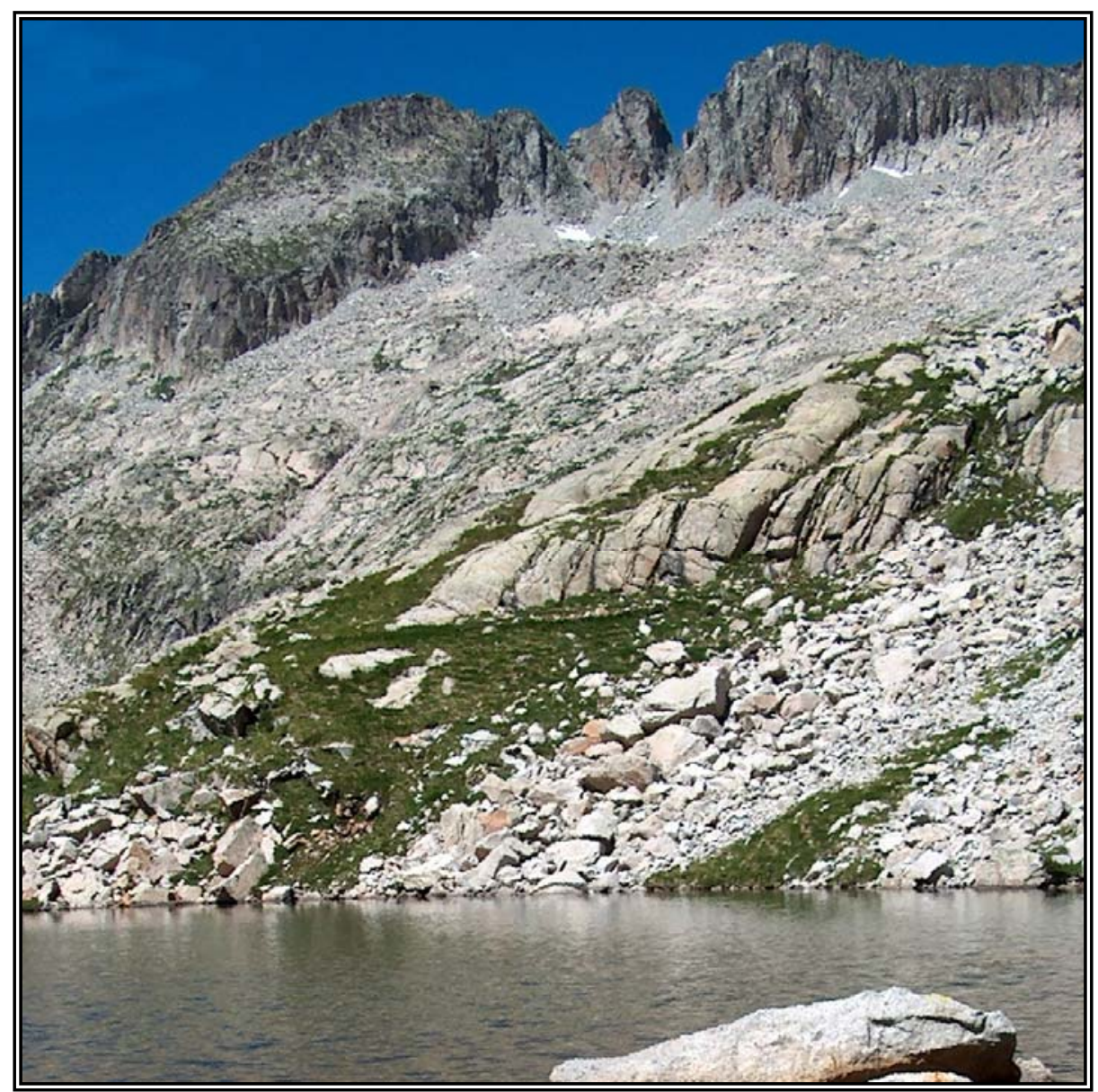

Foto 1.29. Paisaje con grandes diferencias de color. Pirineo Aragonés. Fuente: Propia. 


\subsubsection{Textura}

Denominamos así al conjunto de pequeñas formas o mezclas de color distribuidas en pautas superficiales continuas de tal manera que las partes agregadas son lo suficientemente pequeñas para no aparecer como objetos discretos en la composición de la escena ${ }^{88}$.

Podemos encontrar dos tipos de texturas; de color, que se refiere al contraste entre pequeñas zonas y zonas mayores; y de grano, que hace relación al afecto de luz y sombra que puede producir el reflejo de la luz en las diferentes caras de los elementos del paisaje, por pequeñas que sean éstas.

Y como muestra el cuadro, las características básicas de la textura son:

- El tamaño de grano. Tiene que ver con la rugosidad de la superficie o el tamaño de la unidad de color. El observador aprecia de forma dominante las texturas finas frente a las gruesas.

- La densidad. Se refiere al número de granos o pautas de color por unidad de superficie.

- La regularidad. Es función de la distribución de la densidad de grano.

- El contraste interno. Que hace referencia a las diferencias entre colores o tonos de luz y sombra. El espectador fijará más su atención en aquellas texturas en las que el contraste interno sea mayor.

\subsubsection{Línea}

Es el camino que recorre el ojo cuando se perciben diferencias bruscas en los volúmenes, el color o la textura ${ }^{89}$.

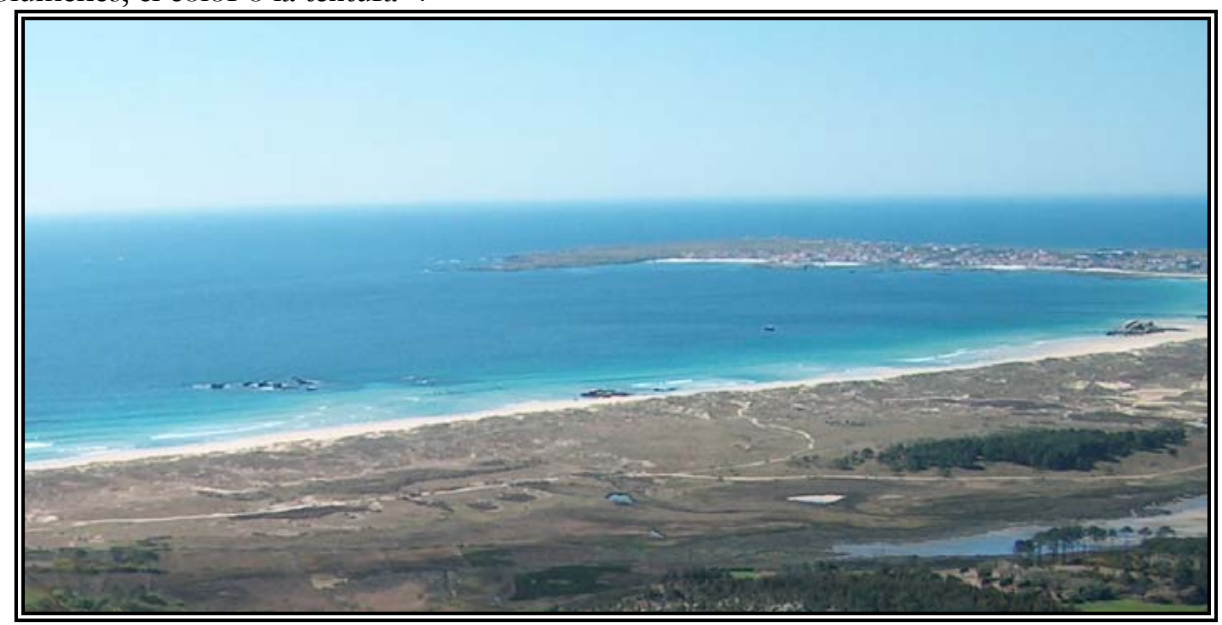

Foto 1.30. Paisaje con línea de horizonte en el mar. Costa gallega. Fuente: Propia.

88 Español Echaniz, I., "Las obras públicas en el paisaje”, 1998.

${ }^{89}$ Español Echaniz, I., "Las obras públicas en el paisaje”, 1998. 
Encontramos en el paisaje tres tipos de líneas:

- Bandas. Formas bidimensionales de carácter lineal.

- Límites o bordes. Generalmente están mal definidos y vienen determinados por cambios relevantes en las propiedades de las diferentes zonas del paisaje.

- Siluetas. Son las líneas que se forman al comparar ciertas formas con el fondo, el ejemplo más claro sería la línea de horizonte, que resulta del contraste de los elementos con el cielo. Este contraste lo observamos en la foto 1.30., donde la línea de horizonte es la superficie del mar, produciendo una línea muy bien definida.

Y las características básicas del elemento línea son:

- Nitidez. Se refiere al grado de definición de la línea. Las líneas más nítidas suelen captar la atención del espectador.

- Complejidad. Hace referencia a la simplicidad del trazo, a los quiebros o cambios de dirección. Suelen llamar más la atención las líneas simples que las complejas.

- Orientación. Es el ángulo formado por el trazo y la horizontal. Las orientaciones verticales suelen destacar sobre las demás.

\subsubsection{Forma}

Se define como la masa o extensión delimitada por el contorno superficial de uno o varios objetos que aparece dotada de una cierta unidad ${ }^{90}$. La apreciación de la forma tiene un mayor grado de subjetividad que los elementos estudiados hasta ahora, ya que el observador es capaz de percibir las formas porque las relaciona con formas que ya conoce. Podemos distinguir entre formas bidimensionales (áreas) y tridimensionales (volúmenes).

Las características básicas de la forma son:

- Geometría. Se refiere a la forma, asociada con un elemento geométrico simple. Las geometrías puras llaman más la atención del espectador que las amorfas.

- Complejidad. Es la composición de geometrías básicas. Tienen dominancia las formas simples y regulares sobre las complejas e irregulares.

- Orientación. Al igual que en el caso de la línea, será el ángulo formado con la horizontal y de manera semejante, atraerán más la atención las formas verticales.

\subsubsection{Escala}

Es la relación de tamaño entre los diferentes componentes del paisaje $\mathrm{e}^{91}$.

La escala puede ser relativa o absoluta, según se refiera al tamaño real de los objetos o a la relación de proporción de estos tamaños.

Las características de la escala son:

- Contraste de escalas. Distribución de los tamaños de los elementos en el paisaje, puede ser pequeña si los tamaños están uniformemente distribuidos, de forma escalonada, o grande en caso contrario.

90 Español Echaniz, I., "Las obras públicas en el paisaje", 1998.

91 Español Echaniz, I., "Las obras públicas en el paisaje”, 1998. 
- Ocupación de la escena. Se trata de estudiar las dimensiones de un objeto en relación el conjunto.

- Dominio del campo visual. Es la proporción del campo visual del espectador ocupada por un solo objeto y depende totalmente del punto de vista del espectador.

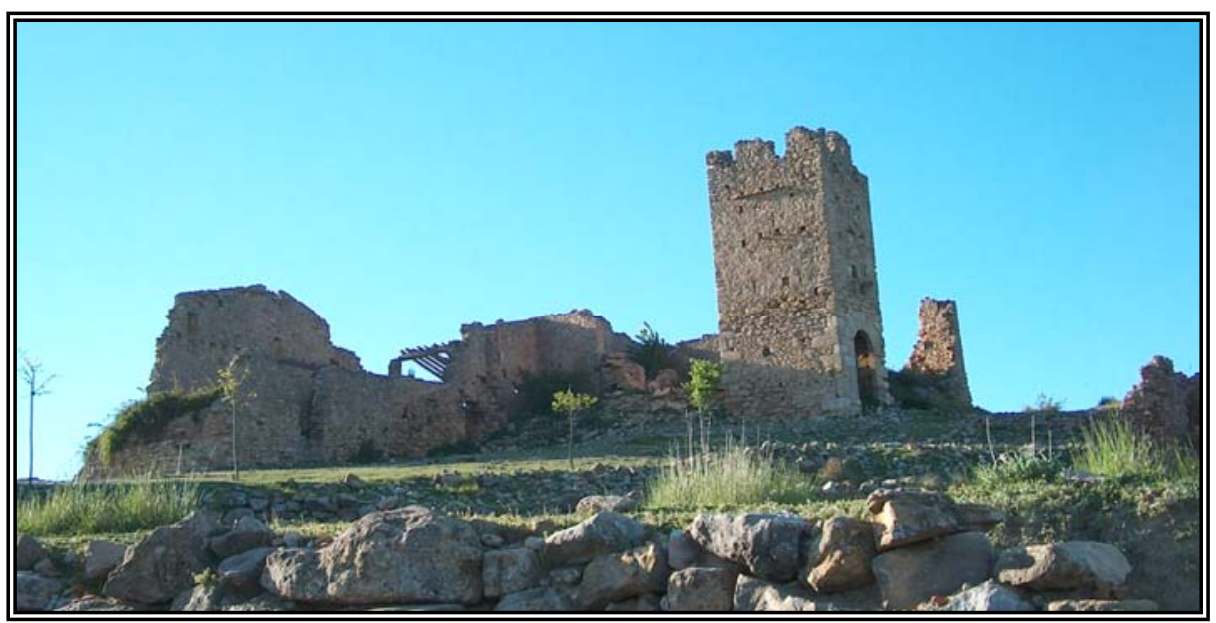

Foto 1.31. Paisaje con elemento destacado. Castillo de Pradas. San Agustín (Teruel). Fuente: Propia.

\subsubsection{Espacio}

Hablaremos en este punto de la disposición tridimensional de los objetos ${ }^{92}$, que determina la organización de los elementos y sus relaciones espaciales.

Las características del espacio son:

- Composición escénica. Se refiere a la organización espacial de los elementos que componen el paisaje. Las composiciones escénicas pueden ser abiertas, con una alta componente de horizontalidad; cerradas, donde impera la verticalidad o cualquier situación intermedia y de mayor complejidad.

- Localización de unidades. Hace referencia a la situación de aquellos objetos singulares, fácilmente reconocibles por el espectador, con respecto al conjunto. Suelen ser objetos que centran la atención del espectador.

- Fondo escénico. Es aquello que se aprecia detrás de los elementos singulares del paisaje.

92 Español Echaniz, I., “Las obras públicas en el paisaje”, 1998. 


\subsubsection{Clasificación de los paisajes}

Podríamos realizar múltiples clasificaciones del paisaje, la clave reside en que la clasificación que adoptemos responda a nuestras necesidades de análisis. Cada autor propone diversas clasificaciones, basadas en el estudio de diferentes factores. Veremos a continuación varias clasificaciones, establecidas en los estudios de la Dra. María de Bolós i Capdevila ${ }^{93}$.

\subsubsection{Clasificación por dominancia de elementos}

Como punto de partida, consideraremos que existen tres tipos de elementos estructurales: abióticos, bióticos y antrópicos. Clasificaremos el paisaje dependiendo de la mayor representación que tenga en el mismo cada uno de los elementos citados. Esta clasificación nos permite catalogar cualquier tipo de paisaje, independientemente de su localización geográfica y por lo tanto de su clima, así como de la extensión que ocupe.

Se trata de una clasificación que no es constante en el tiempo, ya que los paisajes evolucionan, variando la proporción que en ellos tengan cada uno de los tres elementos considerados. El cambio en el paisaje, que supone un cambio en la clasificación, se produce por un cambio en la aportación de energía, esta energía puede ser antrópica o natural.

Para llevar a cabo esta clasificación, deberemos fijar: el nivel de escala de estudio, el grupo dominante de elementos y la dinámica actual del paisaje.

Con todo esto, podemos establecer una clasificación:

- Paisajes con predominancia de un solo grupo
o Abióticos
o Bióticos
o Antrópicos

- Paisajes con dominancia de un grupo sobre otro, también representado

o Abiótico sobre bióticos

o Abióticos sobre antrópicos

o Bióticos sobre abióticos

o Bióticos sobre antrópicos

o Antrópicos sobre bióticos

o Antrópicos sobre abióticos

- Paisajes combinación de los tres grupos

o Abiótico sobre bióticos y trazas de antrópicos

o Abióticos sobre antrópicos y trazas de bióticos

o Bióticos sobre abióticos y trazas de antrópicos

o Bióticos sobre antrópicos y trazas de abióticos

o Antrópicos sobre bióticos y trazas de abióticos

o Antrópicos sobre abióticos y trazas de bióticos

93 De Bolós, M., "Manual de ciencia del paisaje”, 1992. 


\subsubsection{Clasificación por características espaciales}

Cuando hablamos de "epigeosfera" nos referimos a la envoltura de la Tierra, la unidad fisicogeográfica mayor; a las unidades inmediatamente inferiores las denominaremos "zonas", estas últimas estarán a su vez divididas en "dominios", asociados a características de azonalidad.

\subsection{Zonalidad}

La Dra. Bolós define la zonalidad como la disposición regular de unidades, en cualquiera de las diferentes escalas espaciales, en relación con un gradiente de cualquier tipo, de energía, agua, etc.

\subsection{Zonalidad latitudinal}

Como el propio término indica, la zonalidad latitudinal se refiere a los cambios que experimenta el paisaje en función de la latitud geográfica, desde el Ecuador a los polos, estamos refiriéndonos a grandes unidades de relieve.

Estos cambios se deben principalmente a variaciones en el clima y la vegetación, producidos estos a su vez por la irregularidad de la radiación solar recibida en función de la latitud. No es la radiación solar la única causante de los cambios mencionados, la circulación de las masas de aire resulta ser un factor determinante, junto con la humedad que transportan.

Fijándonos en el parámetro "balance energético", podemos establecer la siguiente clasificación:

- Zonas Polares, de 0 a 30,35 Kcal./ $\mathrm{cm}^{2} /$ año.

- Zonas Templadas, de 30,35 a 55,60 Kcal./ $\mathrm{cm}^{2} /$ año.

- Zonas Subtropicales, de 55,60 a 65,70 Kcal./ $\mathrm{cm}^{2} /$ año.

- Zonas Tropicales, de 65,70 a 80,90 Kcal./ $\mathrm{cm}^{2} /$ año.

Dentro de cada zona encontraremos diferentes espacios zonales

\subsection{Zonalidad altitudinal}

Todos hemos observado que al ascender una montaña, desciende la temperatura, aumentan las precipitaciones, cambian la flora y la fauna...

En este punto nos referiremos a los cambios que sufre el paisaje en función de la cota a la que se encuentre; no sólo observamos unas diferencias notables entre el paisaje de zonas llanas y el de zonas montañosas, sino también entre vertientes de la misma montaña.

La existencia de esta zonalidad vertical se debe sobre todo al gradiente térmico altitudinal y las diferencias en la cantidad de precipitaciones recibidas. Podemos ver claramente este contraste en la foto 1.32. del Valle de Vallibierna, donde se advierte la falta de vegetación conforme aumenta la altitud. También se aprecian discrepancias por la diferencia de orientación de las laderas, debido a las diferencias de insolación de las mismas. 


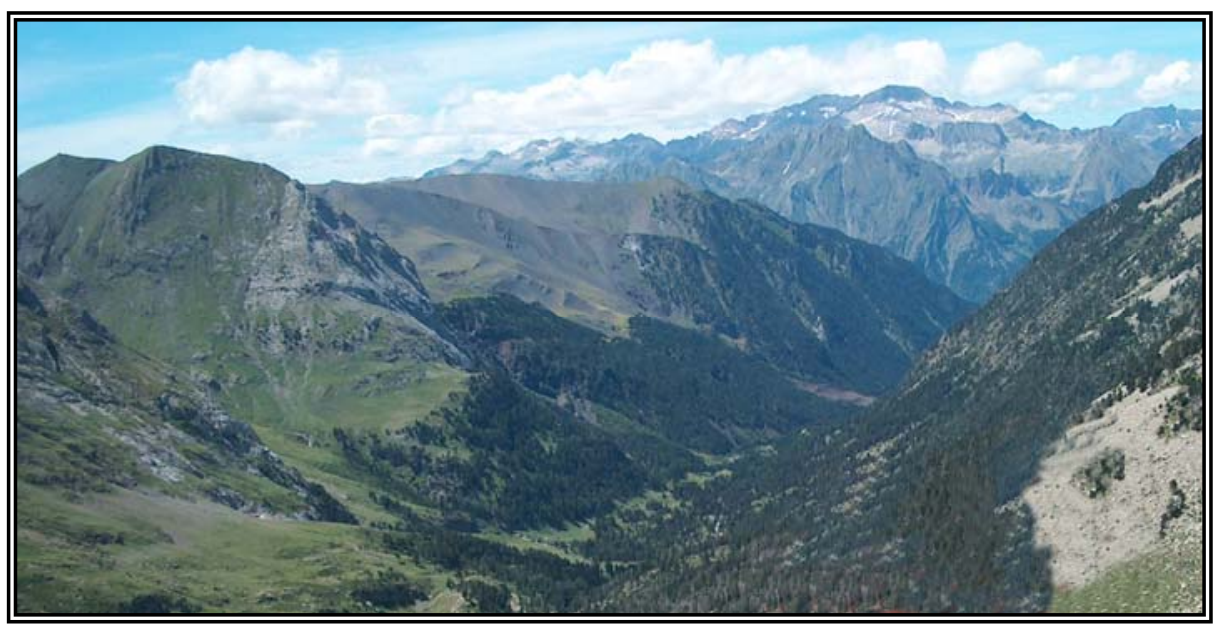

Foto 1.32. Paisaje con contraste altitudinal. Pirineo aragonés. Fuente: Propia.

\subsection{Relación entre ambas}

Existe una estrecha relación entre estas dos zonalidades, hasta el punto de que la zonalidad altitudinal tiene una fuerte dependencia de la latitudinal, así, se podría establecer una zonalidad altitudinal para cada zona latitudinal.

El gradiente térmico vertical, la temperatura baja en torno a $6^{\circ} \mathrm{C}$ cada $100 \mathrm{~m}$ de altitud ascendidos, es mucho mayor que el que se produce con el cambio de latitud, $0,5^{\circ} \mathrm{C}$ por cada grado de latitud. Sin embargo, la distribución de las precipitaciones, aún siendo las diferencias mucho más acusadas en el caso de la altitud que en el caso de la latitud, en el primer caso no puede considerarse uniforme, hay particularidades muy significativas que hacen imposible una generalización, sirva como ejemplo el hecho de las diferencias existentes en el volumen de agua recibido por precipitación en dos laderas opuestas de una misma montaña.

\subsection{Azonalidad}

En el punto anterior hemos estudiado la zonalidad, si bien es cierto que esta zonalidad en sentido estricto sólo sería posible si el planeta Tierra fuese totalmente homogéneo. El hecho de que vivamos en un planeta heterogéneo, hace que existan ciertos factores azonales que condicionan fuertemente el paisaje, destacamos los siguientes:

- Diferencia litogeomorfológica

- Correlación entre superficie topográfica y nivel freático

- Diferencias de drenaje de la superficie

- Distribución de continentes y océanos 


\subsubsection{Clasificación según la escala temporal}

Trataremos aquí de estudiar los paisajes que han existido a través de la historia y los restos que de ellos quedan en la actualidad.

\subsection{Paisajes precuaternarios}

Es en este período, el más antiguo, donde empieza la formación del relieve y es entonces donde se implantan las bases del relieve actual.

\subsection{Entre 4.500 y 570 millones de años.}

No se tiene la certeza de que existiese vida en este periodo, por lo tanto se trata de paisajes abióticos.

El único continente existente originariamente, Pangea, estaba formado por materiales volcánicos, principalmente granito. Diferentes movimientos orogénicos fueron dando lugar a la aparición de los continentes, la última dislocación se cree que tuvo lugar a los -1.800 millones de años y es a partir de entonces cuando debido a cambios climáticos se encuentran los primeros depósitos de sedimentos.

\subsection{Paleozoico}

En este periodo, de 340 millones de años de duración, podemos encontrar dos tipos de rocas sedimentarias, detríticas y carbonatadas; las primeras del periodo más antiguo, conocido como inferior y las carbonatadas del periodo superior.

Durante el Paleozoico, se producen movimientos tectónicos que dan lugar a grandes formaciones montañosas. Es destacable en esta época la aparición de la vida, que generará una gran cantidad de fósiles que han llegado hasta nuestros días.

\subsection{La era Secundaria}

Tiene una duración de 165 millones de años, en este periodo comienza la orogenia alpina, que formó gran parte de las cadenas montañosas existentes en la actualidad. Los sedimentos de esta época son eminentemente carbonatados. Al ser el clima más cálido, se dio una gran proliferación de fauna con esqueletos calcáreos en el entorno marino. Por el contrario se observa en general escasez de formas vivas.

\subsection{E1 Terciario}

Con una duración de sólo 63 millones de años, esta era ha proporcionado estratos sedimentarios de más de $30 \mathrm{Km}$. de potencia. La configuración de los continentes es ya prácticamente la que vemos en la actualidad. Los mamíferos evolucionan de manera que encontramos gran cantidad y diversidad de ellos.

También en este periodo hubo movimientos orogénicos que tuvieron como consecuencia cambios en las líneas de costa; esto unido a las condiciones climáticas hace que encontremos grandes acumulaciones de yesos de esta época. 


\subsection{Los paisajes cuaternarios}

Se trata del que consideramos el periodo actual, que comienza hace 1,8 millones de años. En este periodo se dan grandes variaciones térmicas y el hecho más relevante es la aparición del ser humano.

\subsection{Pleistoceno}

En este periodo destaca la existencia de grandes glaciaciones, que además de dar fe de los grandes cambios climáticos acaecidos, generan transformaciones en el relieve. Estas mismas glaciaciones generaron varios desplazamientos norte-sur tanto de la flora como de la fauna, en función de la zona cubierta por los hielos.

\subsection{Holoceno}

Es también el clima el que produce los principales cambios en el paisaje que se originan en este periodo. Además de la temperatura, hubo grandes cambios en la humedad, con la consiguiente repercusión en la flora y la fauna.

\subsection{Los paisajes históricos}

En este punto veremos el periodo en el que el hombre ha intervenido en la transformación del paisaje, es decir, este periodo comienza con la aparición del ser humano.

Se puede considerar que es en el Paleolítico donde aparece la especie conocida como "homo sapiens sapiens", antecesor del ser humano actual. Durante este periodo la modificación del paisaje por el hombre es prácticamente nula. Es en el Neolítico donde esta transformación empieza a ser algo significativa, ya que aparecen la agricultura y la ganadería.

Conforme la humanidad va alcanzando un mayor nivel de desarrollo, su influencia en el paisaje va siendo cada vez mayor.

Al principio esta transformación del paisaje se debió a las actividades agrícolas y ganaderas, con el consiguiente retroceso de las zonas boscosas.

La introducción de la industria en nuestra sociedad supone un cambio radical en el paisaje, no sólo por la implantación de edificaciones e infraestructuras, sino por lo que supone la contaminación generada y el uso de combustibles, sobre todo fósiles, para generar la energía necesaria.

Por otro lado, el crecimiento desmesurado de nuestras ciudades ha generado y sigue generando una ingente cantidad de residuos así como una contaminación que en algunos casos resulta insostenible.

\subsubsection{Clasificación según su funcionalidad}

Clasificaremos en este apartado los paisajes según su funcionalidad, lo que vendría a ser clasificarlos según su uso, según las actividades socioeconómicas que en él se desarrollan. Tomando pues como base la funcionalidad, tendremos tres tipos de paisaje: natural, rural y urbano. 


\subsection{Paisaje natural}

El paisaje natural se caracteriza por la nula o escasa existencia de elementos antrópicos, pudiendo haber una predominancia de elementos bióticos o abióticos, o bien una combinación de ambos.

Este tipo de paisajes se mantiene gracias a la energía la natural.

Las funciones que pueden atribuirse a estos paisajes son fundamentalmente el mantenimiento de la integridad biológica del sistema, favorecer la evolución del sistema y en ocasiones servir de espacio recreativo y educativo.

Los paisajes naturales suelen ser zonas con duras condiciones para la vida humana, ya que ha sido sólo en los últimos años cuando la sociedad ha empezado a concienciarse de la necesidad de conservar la naturaleza y las zonas con más altos niveles de comodidad para la vida han sido totalmente colonizadas. Podemos dentro de estos territorios distinguir cinco tipos de paisaje.

\subsection{Zonas montañosas}

En estas zonas podemos encontrar paisajes muy diferentes en función del clima, la pendiente, etc. Incluso en una misma montaña seremos capaces de apreciar un paisaje cambiante si vamos incrementando nuestra cota de observación, esto ya lo observamos en la foto 1.6.. En las zonas bajas la vegetación será por lo general muy abundante y conforme vayamos subiendo será más escasa pudiendo incluso llegar a desaparecer. Así pues, el dominio de elementos bióticos se dará generalmente en las zonas bajas y en las altas predominarán los elementos abióticos. En la foto 1.33., el K2 desde el Glaciar Godwin-Austen, apreciamos además la diferencia de clima.

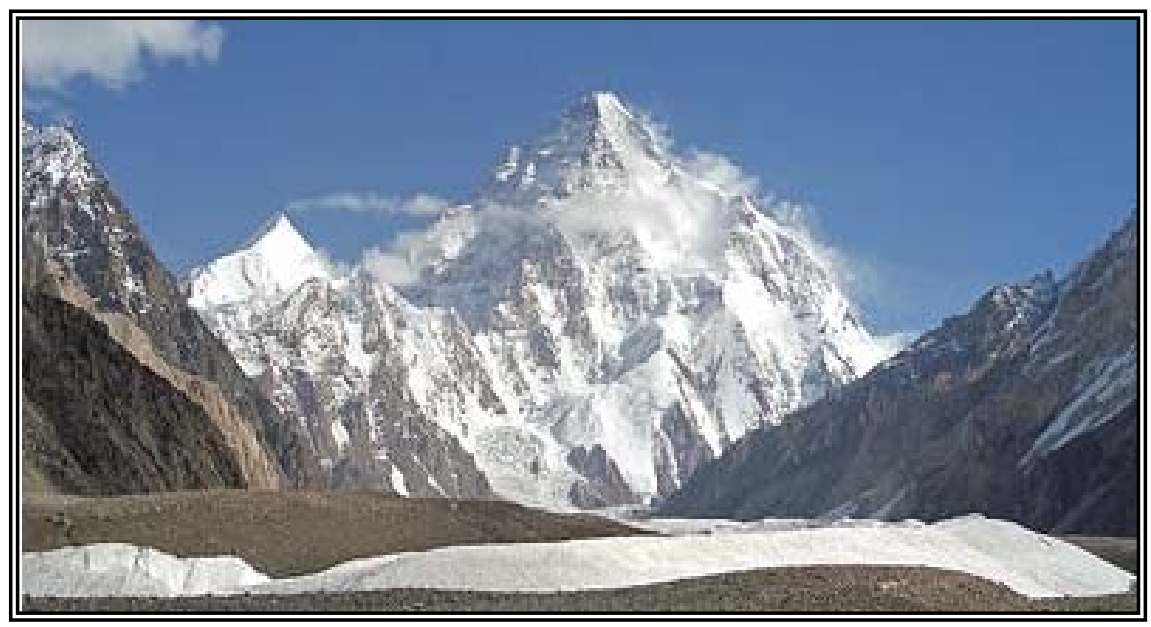

Foto 1.33. Paisaje natural montañoso. Karacorum. Fuente: www.wikipedia.org. 


\subsection{Desiertos cálidos}

Como todo el mundo sabe, los desiertos se caracterizan por la escasez de agua, este hecho hace que la presencia de elementos bióticos sea casi nula, existiendo una dominancia de elementos abióticos. Los paisajes desérticos serán diferentes en función de la zona del planeta en la que se encuentren, así, podemos encontrar tres tipos de desiertos: desierto rocoso o "hamada", desierto de cantos rodados o "reg" y desierto de arena o "erg".

En la foto 1.34. tenemos un ejemplo del tercer tipo de desierto, desierto de arena, se trata del desierto de Atacama, el más seco del mundo.

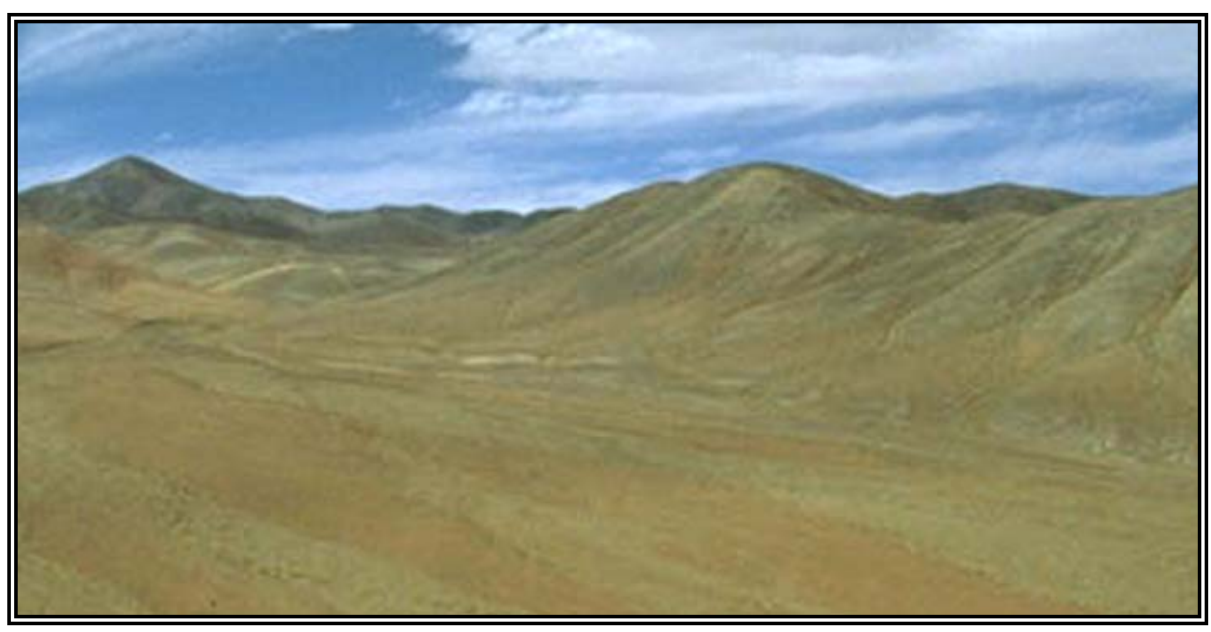

Foto 1.34. Desierto Cálido. Atacama. Fuente: United States of America Federal Government.

\subsection{Desiertos fríos}

Estos paisajes vienen determinados por las bajísimas temperaturas a que están sometidos, en ocasiones por debajo de $0^{\circ} \mathrm{C}$ durante todo el año. Al igual que los del caso anterior, estos desiertos se caracterizan por la escasa presencia de elementos bióticos, siendo en este caso el elemento abiótico predominante en la mayor parte de los casos el agua, generalmente en forma de hielo gran parte del año.

\subsection{Selvas tropicales y ecuatoriales}

Se trata de un paisaje con una dominancia absoluta de elementos bióticos. En estas zonas, la flora y la fauna suelen ser muy abundantes. Existen grandes diferencias entre las diferentes zonas debido a la ingente variedad de especies, tanto animales como vegetales, que ocupan estos espacios. 


\subsection{Costas}

El caso de las costas es diferente, en cuanto que generalmente las costas suelen ser zonas con una acusada presencia de elementos antrópicos. Aún siendo así, existen zonas de costa que tradicionalmente han resultado inhóspitas y actualmente pueden considerarse como paisajes naturales. En ellos, generalmente el elemento abiótico será el predominante, aunque en ocasiones el componente biótico puede tener cierta relevancia.

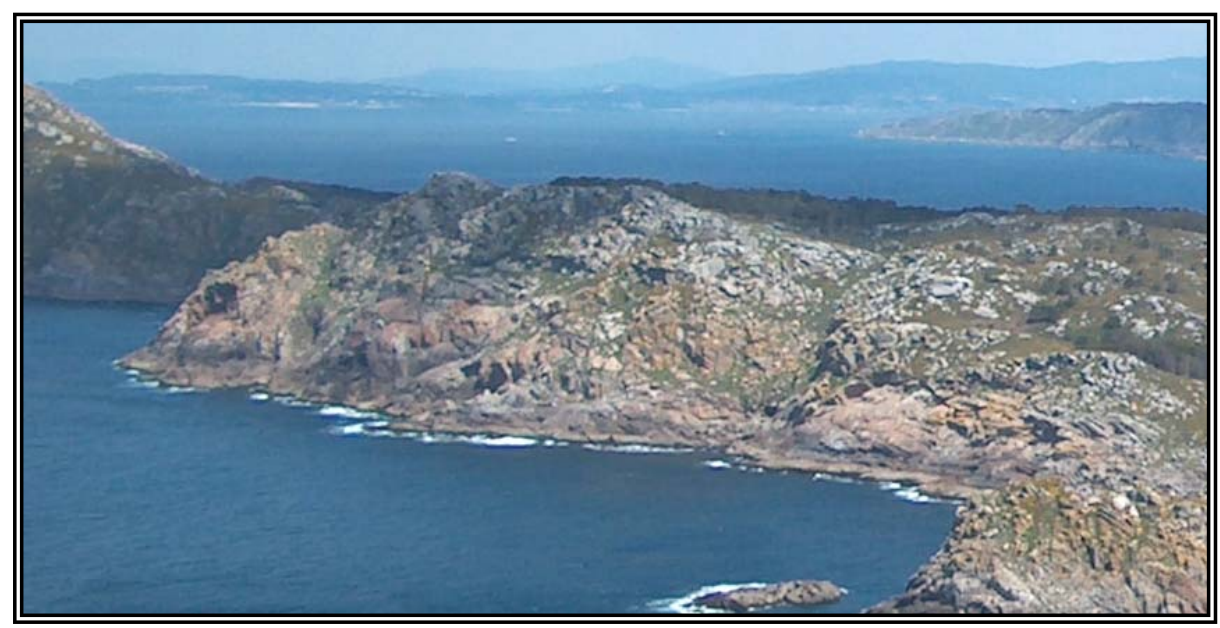

Foto 1.35. Paisaje natural costero. Costa gallega. Fuente: Propia.

\subsection{Otras áreas naturales}

Existen otras áreas naturales, que no por ser de dimensiones más reducidas tienen menor importancia. Estas áreas, suelen estar actualmente protegidas por su alto valor, bien ecológico, bien cultural.

Pueden ser de diversos tipos, zonas volcánicas, bosques ricos en flora y fauna, incluso los océanos, aunque en este caso no se trate de una extensión reducida.

\subsection{Paisaje rural}

El término "rural" está siempre contrapuesto al término "urbano", se entiende por rural lo relativo al campo.

El paisaje rural se caracteriza por la predominancia del elemento antrópico, aunque los elementos bióticos y abióticos tienen también cierta relevancia. Este tipo de paisajes se mantiene gracias a la combinación de dos energías, la natural y la antrópica.

La zona rural incluye no sólo la zona de cultivos, sino también las zonas de pastoreo, las pequeñas construcciones, las poblaciones, incluso las explotaciones forestales; éstas 
transforman en ocasiones el paisaje de una manera drástica, sobre todo si la explotación es, como sucede en la mayoría de los casos, para la obtención de madera.

Las características de los paisajes rurales vienen determinadas por varios factores, como son: las técnicas de cultivo empleadas, el régimen de propiedad, la orientación económica de los cultivos, las explotaciones ganaderas.... Estos factores vendrán a su vez condicionados por elementos como el relieve o el clima.

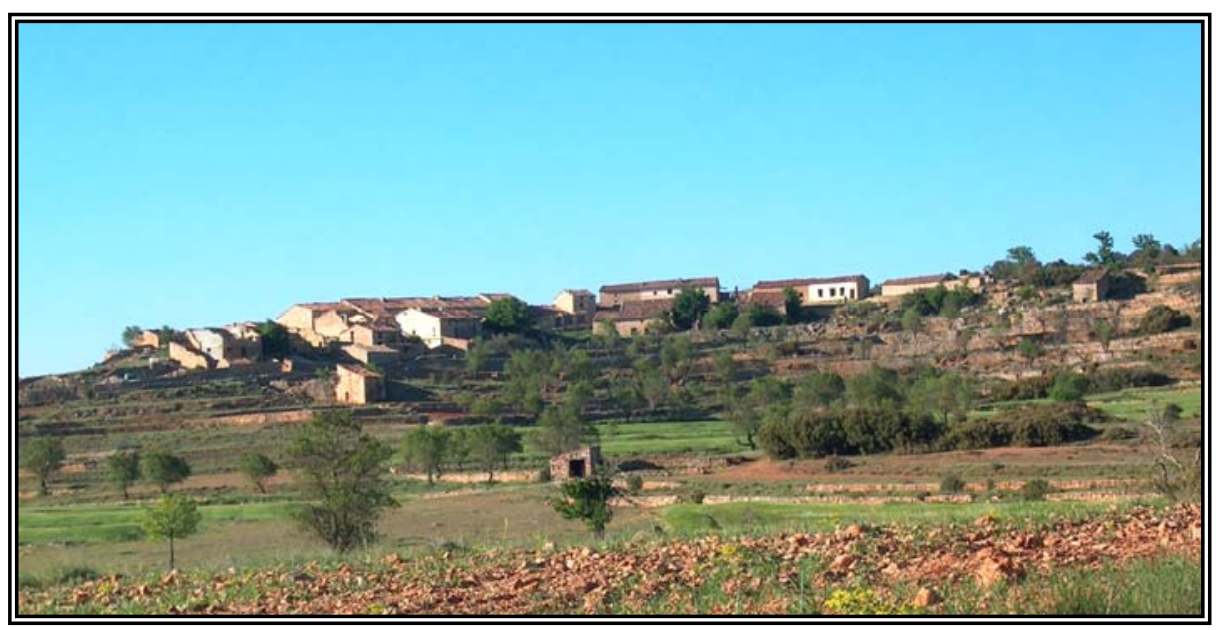

Foto 1.36. Paisaje rural. Mas Blanco. San Agustín (Teruel). Fuente: Propia.

En lo que a las construcciones se refiere, su tipología dependerá también de los factores comentados anteriormente, así como de la tradición de la zona o el nivel económico de los habitantes de la misma.

Aunque la variedad de espacios rurales es muy nutrida, haremos una clasificación que englobe a los más representativos.

\subsection{Paisaje rural mediterráneo}

Como ya hemos adelantado, el clima resulta determinante a la hora de estudiar un paisaje; en este caso se trata de un clima de veranos cálidos y una fuerte estacionalidad en las precipitaciones.

Ateniéndonos al tipo de cultivo, podemos hacer una clasificación de estos paisajes:

- Policultivo en zona de secano. Suele ser habitual en zonas costeras, aunque actualmente en estas zonas se está abandonando la actividad agrícola a favor de la turística. Suelen ser casas encaladas rodeadas de bancales donde se cultivan especialmente cereales. Con frecuencia encontramos también zonas de pastoreo y alguna zona boscosa. 
- Monocultivo en zona de secano. En zonas más continentales, predomina un tipo de cultivo, combinado con zonas de pastoreo (generalmente las que quedan en barbecho) y pequeñas zonas boscosas. Foto 1.37 .

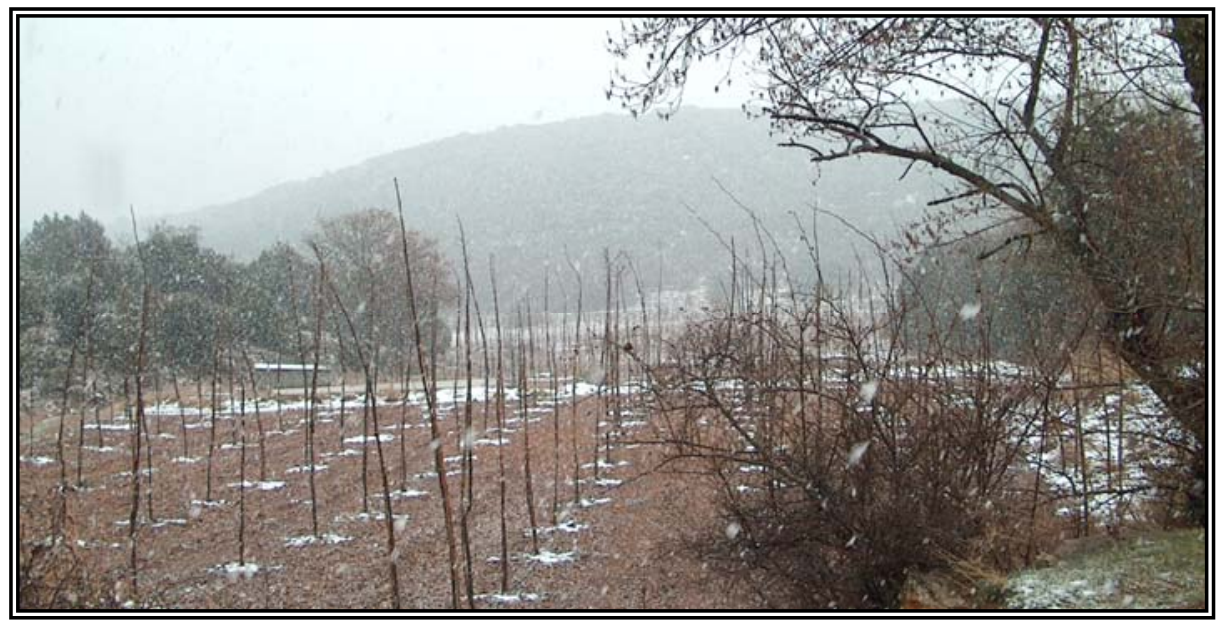

Foto 1.37. Paisaje rural con monocultivo. La Sazadilla. Albentosa (Teruel). Fuente: Propia.

- Regadío. Se trata en general de campos no demasiado extensos, rodeados de acequias para la canalización del agua. Podemos encontrar tanto campos de hortalizas..., como árboles frutales.

\subsection{Paisaje rural de la Europa del Noroeste}

Actualmente se suelen encontrar monocultivos de alta rentabilidad, en ocasiones utilizados para alimentar al ganado, combinados con zonas boscosas de más o menos extensión dependiendo de la zona.

Los cultivos están muy mecanizados, es decir, hay una importante aportación de energía antrópica. En las zonas boscosas obviamente esta aportación es mucho menor.

\subsection{Paisaje rural de países colonizados}

Suele tratarse de paisajes muy monótonos, en cuanto que se trata generalmente de grandes zonas dedicadas a un solo cultivo o a una sola especie de ganado. En zonas tropicales, para la implantación de estos cultivos se han utilizado zonas de selva que han sido previamente deforestadas. Esta deforestación ha producido un cambio drástico en el paisaje, ya que las zonas cultivadas son abandonadas cuando baja su productividad y generalmente no se procede a una reforestación, perdiéndose por este sistema miles de hectáreas de selva y bosque. 


\subsection{Paisaje rural del Asia Monzónica}

Se trata de paisajes donde los elementos bióticos y abióticos tienen gran relevancia, aunque no tanta como el elemento antrópico, que es el componente principal. Son paisajes explotados desde hace milenios, se trata de campos relativamente pequeños, combinados con elementos de riego, canales y presas.

La tendencia es en la actualidad a ampliar las dimensiones de los campos y a modernizar las construcciones agrarias.

\subsection{Paisaje urbano}

En el paisaje urbano se observa un predominio casi total del elemento antrópico y la energía que lo mantiene es desafortunadamente predominantemente antrópica.

Aunque resulta difícil que una ciudad pueda catalogarse por la diversidad que en ella encontramos, haremos una clasificación de los paisajes urbanos dependiendo de su funcionalidad principal.

- Ciudades administrativas y comerciales en espacios rurales. Se trata de ciudades de mediano o pequeño tamaño que dotan de servicios a la zona rural en la que están enclavadas; estos servicios pueden ser además de administrativos y comerciales, médicos, educacionales... Estas ciudades suelen estar relativamente aisladas, aunque con el desarrollo actual de las estructuras viarias este aislamiento se está reduciendo considerablemente.

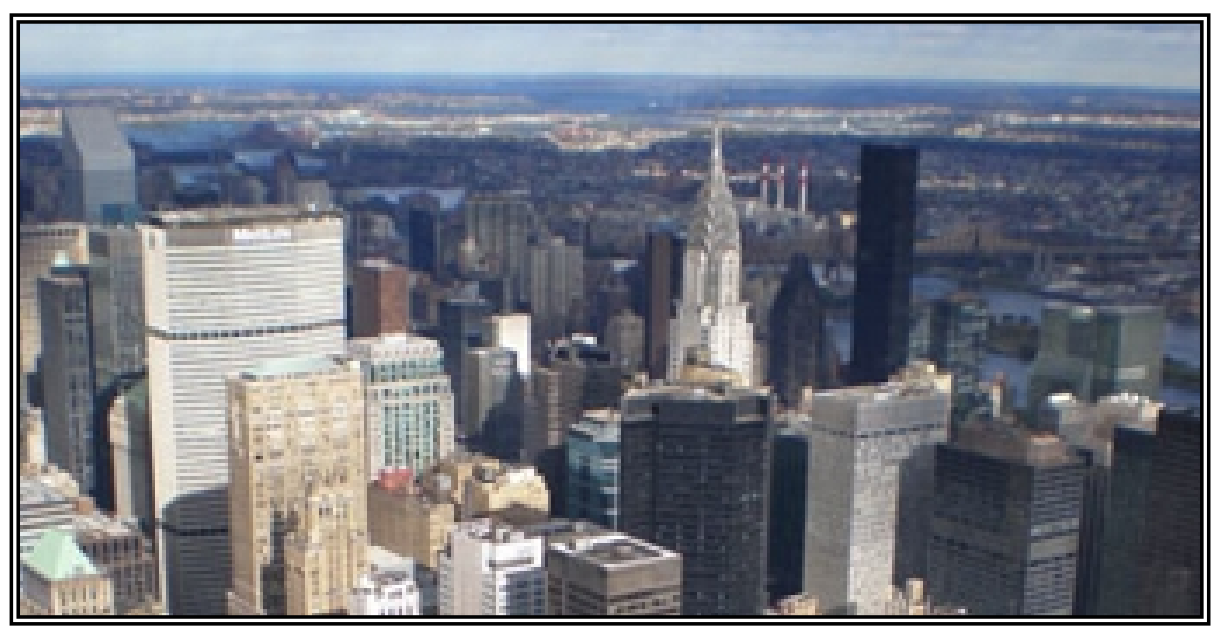

Foto 1.38. Paisaje urbano. New York. Fuente: www.guiadenuevayork.com. 
- Ciudades industriales. Puede tratarse de ciudades eminentemente industriales, o bien de ciudades que combinan esta actividad industrial, situada normalmente a las afueras, con otras funciones, bien sean administrativas, de servicios, etc.

- Ciudades históricas europeas. En este grupo estarían las ciudades que lo han sido históricamente y cuyo centro suele conservarse. Huelga decir que a las afueras de estas ciudades encontraremos paisajes completamente diferentes.

- Metrópolis norteamericanas. El centro de la ciudad no suele tener interés histórico, pero sí como centro económico y financiero. Suelen ser ciudades con una planificación urbanística notable en su zona más desarrollada, pero que cuentan con zonas altamente degradadas donde el paisaje es totalmente diferente. Un ejemplo lo encontramos en la ciudad de Nueva York, Foto 1.12.

\subsubsection{Valoración del paisaje}

La valoración del paisaje se puede llevar a cabo mediante distintos métodos, que dependerán de los criterios elegidos.

La Organización para la Cooperación y el Desarrollo Económico (OCDE) viene recomendando una serie de indicadores ambientales que permitan hacer una valoración de la situación ambiental de cada país miembro. Entre los medios que contemplan se encuentra el paisaje. A fecha de febrero de 2000, la propuesta constaba de cinco indicadores para el paisaje ${ }^{94}$ :

- Valor ambiental

- Valor social

- Valor económico

- Evaluación del paisaje

- Elaboración de tipologías de paisajes

Ignacio Español (1995) clasifica el tratamiento de la calidad paisajística como calidad de contenidos, de comunicación y estética.

En lo referente a la calidad de contenidos diremos que observaremos el paisaje desde un punto de vista científico, es decir, fijándonos en los elementos que componen el paisaje, tanto naturales como antrópicos.

Acerca de la calidad de la comunicación apuntamos que nos centraremos en la calidad visual del paisaje, la tarea consiste en llevar a cabo un análisis geométrico de las relaciones establecidas entre diferentes espacios. Se trata de una visión eminentemente topográfica, donde se divide el territorio en áreas de visibilidad.

Y por último nos queda hablar de la calidad estética, que vendrá determinada por el observador, no es más que una apreciación subjetiva.

Según la clasificación de la Fundación Alfonso Martín Escudero, expondremos cinco métodos de valoración del paisaje ${ }^{95}$.

\footnotetext{
94 García Asensio J.M.. et al., “Gestión sostenible de paisajes rurales”, 2001.

95 García Asensio J.M.. et al., “Gestión sostenible de paisajes rurales”, 2001.
} 


\subsubsection{Métodos indirectos o de análisis de las componentes}

Estos métodos parten de la premisa de que la calidad de un paisaje es la suma de los valores que tengan cada uno de sus componentes y que la percepción que de un paisaje haga el experto que lo evalúe será similar a la del resto de la sociedad. Se trata por lo tanto de métodos bastante subjetivos, aunque realicen un análisis tanto cualitativo como cuantitativo.

Para paliar estas carencias, algunos autores tienen en consideración las zonas de contacto entre componentes, otorgándoles una relevancia en ocasiones mayor que la de algunos componentes.

Según Gómez Orea, las fases de que constan estos métodos son las siguientes:

- Identificación de los componentes

- Medición para cada unidad

- Establecimiento de coeficientes de ponderación

- Obtención de un valor de la calidad global

Aceptando la clasificación de García Asensio y Cañas Guerrero ${ }^{96}$, encontramos tres tipos de métodos indirectos:

- Modelos de estética o formales. En este caso se estudian los aspectos formales abstractos del paisaje, estos son sus formas básicas, colores, texturas, etc. y las relaciones entre ellos.

- Modelos ambientales o ecológicos. Se trata de modelos basados en el estudio de los rasgos biológicos y ecológicos del paisaje, como son la flora y la fauna existentes, los ecosistemas presentes, etc.

- Modelos combinados

\subsubsection{Modelos para predecir la preferencia}

Nos referimos a la preferencia general de una sociedad por un tipo de paisaje u otro. A pesar de que, como ya hemos mencionado, la apreciación del paisaje tiene un alto componente de subjetividad, existen unos estándares estéticos acerca de la calidad del paisaje, como lo es el hecho de la variabilidad del mismo, la calidad de un paisaje será mayor en general cuanto menor sea su monotonía.

Otros elementos que aportan valor a un paisaje pueden ser:

- Presencia de vegetación. Con la salvedad de si ésta se encuentra excesivamente cerca del observador e impide la contemplación del paisaje.

- Agua en movimiento. Pero nunca estancada y de mala calidad o en exceso.

- Complejidad de elementos

- Bosques o montañas. Siempre que se encuentren lo suficientemente alejados del espectador para no impedir la observación del conjunto.

- Elementos únicos o característicos

- Predominancia de elementos naturales. Generalmente la acción del hombre se considera un factor negativo a la hora de valorar un paisaje.

96 García Asensio J.M.. et al., "Gestión sostenible de paisajes rurales”, 2001. 


\subsubsection{Métodos directos o de contemplación de la totalidad}

Se trata en este caso de métodos completamente subjetivos, en los que la valoración del paisaje se realiza en su conjunto y no dividiéndolo en sus componentes. Son los métodos generalmente más aceptados y parten de la idea de que la apreciación de la belleza de un paisaje es semejante para la mayoría de los seres humanos.

Podremos distinguir cuatro métodos:

- De subjetividad aceptada. Este método deja el análisis completamente en manos de una persona, que suele ser un profesional experto de prestigio reconocido. Se suele huir de estos métodos por el hecho de que dejan el análisis a la apreciación de un sólo individuo, con la carga de subjetividad que este hecho aporta.

- De subjetividad controlada. El análisis puede llevarse a cabo igualmente por una sola persona, pero en este caso se trata de un análisis comparativo con paisajes anteriormente estudiados. Se compara el paisaje con unos estándares universales de valores, lo que disminuye considerablemente la subjetividad del método.

- De subjetividad compartida. Se trata de un método consensuado. Al igual que en el primer caso, es personal experto en la materia el que realiza la valoración, pero en este caso se trata de un grupo de expertos que llevarán a cabo una puesta en común que les conducirá al análisis final.

- De subjetividad representativa. Estos métodos tienen en cuenta la opinión de la sociedad, para ello se realizan encuestas a varios miembros de la sociedad. Resulta ser un método con una alta carga de subjetividad, pero si la muestra es representativa del conjunto de la sociedad los resultados pueden ser altamente satisfactorios.

\subsubsection{Métodos mixtos de valoración directa y análisis posterior de las componentes}

Se realizan valoraciones directas por varios individuos, pero desglosando la importancia que tiene cada uno de los factores del paisaje en la valoración realizada.

\subsubsection{Métodos de evaluación económica del paisaje}

Existen varios métodos para valorar económicamente un paisaje, aunque ninguno de ellos ofrece unos resultados óptimos. Parece que lo más adecuado es valorar lo que una persona estaría dispuesta a pagar por vivir en paisaje como el que es objeto del estudio.

\subsubsection{Degradación y conservación del paisaje}

Prácticamente hasta mediados del siglo XX, el ser humano no empieza a tener conciencia de que forma parte de la Naturaleza y que depende de ella para su supervivencia. Es entonces cuando cobra protagonismo la conservación del paisaje y se empiezan a generalizar los estudios de paisaje.

El concepto de conservación del paisaje está íntimamente ligado al de Ecología, ciencia impulsada por Haekel, quien la definió en 1869 como "el estudio de la relaciones de los 
organismos con su medio ambiente inorgánico y orgánico”. Este concepto ha ido variando a través del tiempo ${ }^{97}$.

\subsubsection{Degradación}

Son múltiples las definiciones de este término aportadas por diferentes estudiosos; señalaremos aquí la dada por Cifuente et al.98, que resume el concepto como: "proceso que implica una caída en la calidad o utilidad (en sentido amplio) del medio ambiente, del territorio o de un recurso determinado".

Esta degradación podría considerarse de origen natural o antrópico, aunque una "degradación natural" no debería aceptarse como tal degradación, ya que cualquier fenómeno natural que "destruya" el medio ambiente (pensemos por ejemplo en una inundación o en la erupción de un volcán), por el hecho de ser natural no destruye el paisaje, sino que lo modifica; se trata de cambios que se han ido produciendo a lo largo de la historia y que forman parte del ciclo natural del paisaje, que no es estático, sino que varía continuamente (sólo tenemos que fijarnos en los cambios estacionales). Por el contrario, centraremos nuestro estudio en la degradación antrópica, que es la que podemos considerar como la verdadera degradación del paisaje y además la que somos capaces de controlar.

No podemos caer en el error de pensar que toda actuación antrópica degrada el paisaje, aunque generalmente sea así. Cada vez con más frecuencia las actuaciones del ser humano se integran y respetan el medio ambiente y a su vez el paisaje, e incluso pueden llegar a mejorarlo.

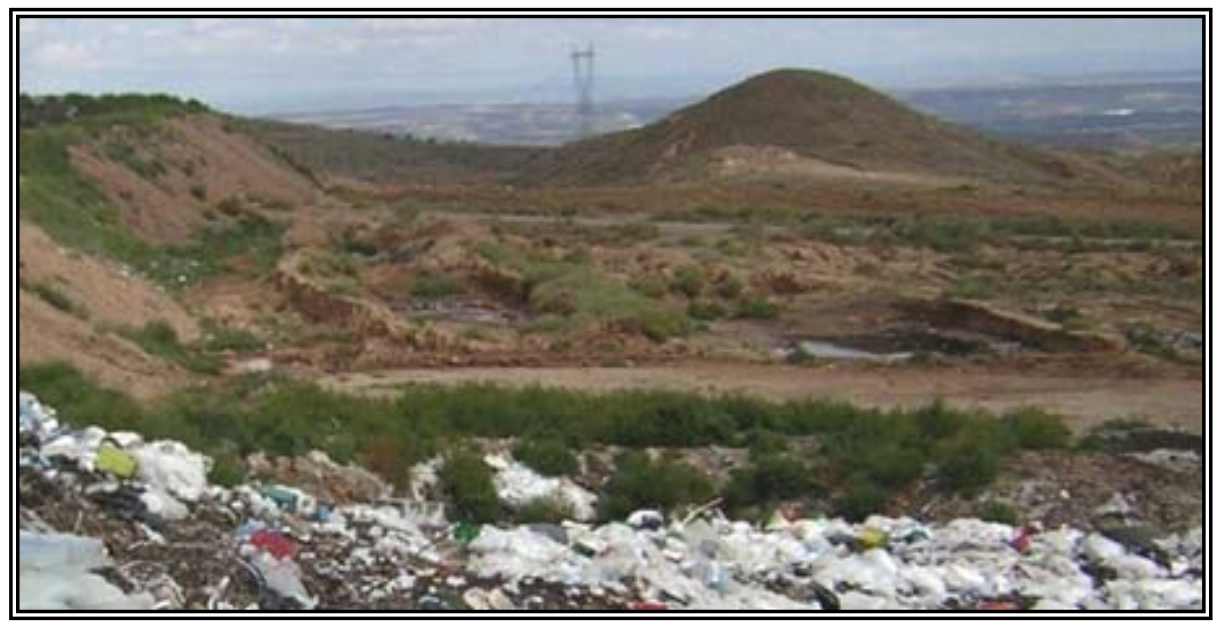

Foto 1.39. Paisaje degradado. Vertedero ilegal en Lamaguilla (La Rioja). Fuente: www.lamaguilla.org

${ }^{97}$ De Bolós, M., "Manual de ciencia del paisaje”, 1992.

98 Cancer Pomar, L., "La degradación y la protección del paisaje”, 1999. 
La degradación del paisaje podemos atribuirla principalmente a tres grandes grupos de actuaciones antrópicas ${ }^{99}$ :

- Degradación del sustrato litológico y el suelo

- Sobreexplotación de los recursos

- Contaminación

\subsubsection{Conservación}

El primer paso hacia la conservación del paisaje pasa por el reconocimiento del valor que éste posee. En la actualidad ya se reconoce el paisaje como una variable medioambiental y se está apoyando institucionalmente su ordenación y conservación, de modo que las actuaciones antrópicas que se vayan a llevar a cabo en un determinado paisaje deberán estar en armonía con el mismo. Como se expone en el punto "legislación aplicable", la Comunidad Valenciana cuenta ya con una legislación específica para la conservación del paisaje.

\subsubsection{Estudios de paisaje}

\subsubsection{Necesidad}

Los estudios de paisaje responden a la necesidad que toda sociedad desarrollada tiene de disponer de un entorno agradable, pero además, la legislación, atendiendo las demandas de la sociedad, exige estudios de paisaje en aquellas ocasiones en las que se vayan a llevar a cabo actuaciones que pudiesen desembocar en una degradación de aquel.

\subsubsection{Metodología}

Dada la complejidad del paisaje y vista la dificultad de su clasificación, podemos imaginar que la adopción de una pauta a seguir para la realización de los estudios de paisaje resultará no menos complicada. En este trabajo partiremos de la metodología propuesta por la Dra. de Bolós, que parte del método general científico apuntado por Mario Bunge ${ }^{100}$.

\subsection{Análisis}

La primera acción que deberemos efectuar cuando nos proponemos realizar un estudio del paisaje consiste en una primera aproximación al mismo, identificaremos los principales elementos que lo definen y llevaremos a cabo una primera toma de contacto, analizando a grandes rasgos los problemas que se pudiesen presentar.

En esta fase, realizaremos una clasificación de los elementos, tanto antrópicos como naturales, que como se ha explicado dividiremos en bióticos y abióticos; estudiaremos su interrelación, cómo pueden afectarse mutuamente y los flujos de energía existentes.

\footnotetext{
99 Cancer Pomar, L., "La degradación y la protección del paisaje", 1999.

${ }^{100}$ De Bolós, M., "Manual de ciencia del paisaje”, 1992.
} 
A la hora de afrontar un estudio de paisaje, tendremos que tener una idea clara de los objetivos que perseguimos, es decir qué utilidad tendrá este estudio, ya que en función de esos objetivos centraremos nuestro análisis en unos elementos u otros.

Del mismo modo, el grado de exigencia de los datos vendrá también determinado por el tipo de análisis requerido; será este grado de exigencia el que condicione las técnicas a utilizar, derivando esto en el tiempo, personal, materiales, etc. que tengamos que invertir.

El análisis del paisaje puede abordarse desde multitud de perspectivas, según las características de aquel en las que centremos nuestro interés. Podemos aceptar que existen dos vertientes principales de estudio, desde el punto de vista de la estructura natural (litología, hidrología, botánica...) y desde el punto de vista socioeconómico, es decir, antrópico (demografía, urbanismo...).

Si centramos nuestra atención en los factores naturales, una vez tengamos acotado nuestro campo de investigación, podremos estudiar múltiples elementos: situación, relieve, substrato litológico, clima, agua, suelo, flora, fauna, etc.

En lo que se refiere a la acción antrópica, los temas a estudiar podrán ser: infraestructuras, usos del suelo, explotación de recursos, datos demográficos, datos socioeconómicos, datos culturales, etc.

\subsection{Diagnosis}

A partir de los datos obtenidos mediante el anterior análisis, deberemos realizar un estudio que nos permita establecer un diagnóstico del estado actual del paisaje que nos ocupa.

En función del uso que se vaya a dar posteriormente al estudio, podremos establecer dos tipos de diagnosis: descriptiva y de potencialidad.

Una diagnosis descriptiva consiste en un estudio general del paisaje, de las estructuras que lo componen, sus flujos de energía, etc. En este tipo de diagnosis se suele realizar una división de las unidades principales, de modo que cada grupo o clase sea homogéneo, denominaremos cada uno de estos grupos como "unidades ambientales".

Una vez definidas estas unidades ambientales, podemos evaluar la calidad de las mismas, también utilizando diferentes metodologías, describiremos aquí la adoptada por la Diputación Provincial de Valencia a la hora de realizar su Mapa Geocientífico de la provincia de Valencia, donde se definen una serie de parámetros a considerar, a los cuales se les otorga la misma importancia a la hora de valorar la calidad del paisaje, estos parámetros son ${ }^{101}$ :

- Complejidad topográfica y relieve

- Desnivel

- Vegetación y usos del suelo

- Presencia de masas de agua

- Actuaciones humanas

- Accesibilidad

- Incidencia visual

A cada uno de ellos se le confiere una puntuación que permite cuantificar la calidad del paisaje.

${ }^{101}$ Diputació Provincial de València, "Mapa Geocientífico de la provincia de Valencia”, 1986. 
Si lo que tenemos que realizar es una diagnosis de potencialidad, el estudio irá orientado a la realización de alguna actividad antrópica concreta, en general será precisamente esta actividad o actividades las promotoras del estudio del paisaje. Se tratará en este estudio sobre todo de examinar la viabilidad del proyecto y su impacto paisajístico.

\subsection{Corrección de impactos ambientales}

Llevada a cabo la fase de diagnosis, tendremos información acerca del estado del paisaje y estaremos en condiciones de establecer medidas correctoras para paliar el "impacto ambiental" en las zonas en las que sea necesario; para ello necesitaremos un estudio de impacto ambiental, que nos informará acerca de las acciones a llevar a cabo, que serán muy diversas según el problema de que se trate.

\subsection{Prognosis}

Para realizar un pronóstico, partiremos del estado actual del paisaje, que tendremos ya perfectamente definido si hemos llevado a cabo el análisis, la diagnosis y la corrección de impactos ambientales. Conociendo los procesos que se van a desarrollar en el citado paisaje, tanto naturales como antrópicos, podremos llegar a tener una idea de cuál será el estado de nuestro paisaje en el futuro.

Estos procesos de transformación del paisaje, se reducen a intercambios de energía y esta energía, como sabemos, puede ser tanto natural como antrópica. Cuanto mayor sea nuestro conocimiento de los procesos, los intercambios de energía, mayor será la calidad de nuestro pronóstico.

\subsection{Sintéresis}

$\mathrm{Y}$ una vez conocemos los problemas del paisaje estudiado, y tenemos un modelo de evolución del mismo, estamos en condiciones de tomar decisiones para llevar a cabo las acciones que consideremos necesarias con el objetivo de conseguir un paisaje óptimo, bien conservándolo, bien mejorándolo.

\subsubsection{Breve introducción a los indicadores de paisaje}

\subsubsection{Definición}

El paisaje no es algo fácilmente cuantificable, por lo que resulta de vital importancia a la hora de abordar un estudio o una valoración del mismo la utilización de unos indicadores correctos, estos son según el Observatorio del Paisaje de Cataluña elementos cuantitativos o cualitativos que permiten conocer y seguir la evolución y el estado de los paisajes, la satisfacción de la población con su paisaje.

Según la Agencia Europea de Medio Ambiente constituyen una herramienta de comunicación para informar sobre el estado de una materia en particular. Es importante la correcta elección de los indicadores de paisaje para que los resultados sean los deseados. 
Huelga decir que estos indicadores se aplicarán para el estudio de las unidades de paisaje que previamente han debido ser definidas.

La Profesora Josepa Bru aporta la idea de que los indicadores son variables críticas, seleccionadas con mucha intención y con mucha efectividad en relación con un objetivo claro; el uso de indicadores tiene como objetivo cambiar la realidad, o dirigir esta realidad sobre bases racionales, cada indicador responde pues a la búsqueda de un objetivo. Los indicadores reflejan acciones y no solamente situaciones. Además comportan siempre medida. Es una recolección de datos muy selectiva siempre marcada por un objetivo. Los indicadores no pretenden modelizar la realidad pero son capaces de dar información esencial de la misma, son capaces de descubrir, desde una determinada perspectiva aspectos de la realidad que dependen de nuestra mirada y no son accesibles desde la pura objetividad.

\subsubsection{Características}

Teniendo todo esto en cuenta, deberemos elegir los indicadores que más se adecuen al resultado que queremos obtener, sabiendo que podemos encontrar indicadores que hagan referencia a diferentes aspectos del paisaje, dependiendo de bajo qué perspectiva queramos abordar el estudio.

En general los indicadores deben responder a las siguientes características:

- Ser fáciles de comprender ${ }^{102}$, y tener relevancia normativa ${ }^{103}$.

- Proveer información objetiva, cuantitativa ${ }^{104}$, aunque combinando metodologías cualitativas y cuantitativas ${ }^{105}$.

- Ser comparables con la situación de partida ${ }^{106}$.

- Ser científicamente sólidos y estadísticamente válidos ${ }^{107},{ }^{108}$.

- Responder a cambios en el espacio y en el tiempo ${ }^{109}$.

- Ser técnicamente factibles y económicos, dentro de límites aceptables en lo que se refiere a la recogida de información ${ }^{110},{ }^{111}, 112$.

- Ser útiles para prever posibles futuros escenarios ${ }^{113}$.

102 Seguin, J. "La perspectiva disciplinar". Seminario: Indicadores de paisaje. Retos y perspectivas. Barcelona, noviembre 2007.

103 Jornada Técnica sobre los indicadores de biodiversidad y paisaje del programa marco ambiental. Gobierno Vasco

104 Jornada Técnica sobre los indicadores de biodiversidad y paisaje del programa marco ambiental. Gobierno Vasco

105 Sala, P. "Los indicadores de paisaje de Cataluña" Seminario: Indicadores de paisaje. Retos y perspectivas. Barcelona, noviembre 2007.

106 Jornada Técnica sobre los indicadores de biodiversidad y paisaje del programa marco ambiental. Gobierno Vasco

107 Jornada Técnica sobre los indicadores de biodiversidad y paisaje del programa marco ambiental. Gobierno Vasco

108 Seguin, J. "La perspectiva disciplinar". Seminario: Indicadores de paisaje. Retos y perspectivas. Barcelona, noviembre 2007.

109 Jornada Técnica sobre los indicadores de biodiversidad y paisaje del programa marco ambiental. Gobierno Vasco

110 Jornada Técnica sobre los indicadores de biodiversidad y paisaje del programa marco ambiental. Gobierno Vasco

111 Sala, P. "Los indicadores de paisaje de Cataluña" Seminario: Indicadores de paisaje. Retos y perspectivas. Barcelona, noviembre 2007.

112 Seguin, J. "La perspectiva disciplinar". Seminario: Indicadores de paisaje. Retos y perspectivas. Barcelona, noviembre 2007. 
- Estar diseñados teniendo en cuenta las necesidades del usuario ${ }^{114}$

- Deberán tener en cuenta la transversalidad del concepto de paisaje. Dimensión natural, cultural, perspectiva, social ${ }^{115}$.

- Deben ser fáciles de medir, observar o cartografiar ${ }^{116,117}$.

- Podrán integrar diversos niveles de paisaje ${ }^{118}$.

Además deben informar acerca de ${ }^{119}$ :

- El estado del paisaje

- La evolución del paisaje (Identificación de problemas)

- Las políticas de paisaje (Éxito o fracaso)

- El comportamiento de la sociedad

- El grado de satisfacción paisajística

\subsubsection{Clasificación}

Una vez sentadas las bases de qué y cómo debe ser un indicador, podemos pasar a enumerar los indicadores más frecuentemente utilizados en el contexto europeo, agrupándolos en diferentes clases, según sea el objetivo del estudio paisajístico que se quiere llevar a cabo.

Estableceremos entonces esta clasificación de los indicadores:

\subsection{Estructurales}

Hacen referencia a la estructura o configuración de los tipos de paisajes, teniendo en cuenta que se estudiarán las unidades de paisaje o "manchas" previamente definidas.

Los indicadores que se enumeran a continuación son de utilización frecuente y parece existir cierto consenso a la hora de su elección; aunque hay ciertas diferencias de nomenclatura, en esencia se trata de conceptos muy similares.

Pasemos entonces a enumerar los indicadores que se propusieron por ejemplo en la "Jornada Técnica sobre los indicadores de biodiversidad y paisaje del programa marco ambiental del Gobierno Vasco", que se han propuesto recientemente también en el "Seminario: Indicadores de paisaje. Retos y perspectivas" por el profesor Almo Farina, utilizados en Italia o por Pere Sala, usados en Cataluña:

\footnotetext{
113 Jornada Técnica sobre los indicadores de biodiversidad y paisaje del programa marco ambiental. Gobierno Vasco

${ }^{114}$ Jornada Técnica sobre los indicadores de biodiversidad y paisaje del programa marco ambiental. Gobierno Vasco

115 Sala, P. "Los indicadores de paisaje de Cataluña" Seminario: Indicadores de paisaje. Retos y perspectivas. Barcelona, noviembre 2007.

116 Sala, P. "Los indicadores de paisaje de Cataluña" Seminario: Indicadores de paisaje. Retos y perspectivas. Barcelona, noviembre 2007.

117 Seguin, J. "La perspectiva disciplinar".Seminario: Indicadores de paisaje. Retos y perspectivas. Barcelona, noviembre 2007.

118 Sala, P. "Los indicadores de paisaje de Cataluña" Seminario: Indicadores de paisaje. Retos y perspectivas. Barcelona, noviembre 2007.

119 Sala, P. "Los indicadores de paisaje de Cataluña" Seminario: Indicadores de paisaje. Retos y perspectivas. Barcelona, noviembre 2007.
} 
- El número de "manchas" o unidades de paisaje120

- El tamaño de las "manchas"121 122 teniendo en cuenta la fragmentación paisajística ${ }^{123},{ }^{124}$ y proporcionando información acerca de la continuidad territorial, ecológica, visual y social.

- La forma de las "manchas"125126

- Estructura marginal (Irregularidades) ${ }^{127}$

- El grado de conectividad entre "manchas"128129

- Diversidad paisajística ${ }^{130},{ }^{131}$, diferentes tipos de manchas existentes.

- Biodiversidad ${ }^{132}$

\subsection{Sociales}

En este apartado enumeraremos los indicadores que hacen referencia a las modificaciones del paisaje causadas por la acción humana. Pueden abordarse desde el punto de vista estático o dinámico, según se estudie el estado actual o la evolución en le tiempo.

Así, plantearemos los siguientes indicadores:

- Usos del suelo ${ }^{133}$

- Evolución de los usos del suelo ${ }^{134}$ o transformación del paisaje ${ }^{135}$. Que hace referencia a los cambios de las características culturales del paisaje, cambio en los usos

\footnotetext{
120 Jornada Técnica sobre los indicadores de biodiversidad y paisaje del programa marco ambiental. Gobierno Vasco

121 Jornada Técnica sobre los indicadores de biodiversidad y paisaje del programa marco ambiental. Gobierno Vasco

122 Farina, A. "Indicadores ecológicos del paisaje". Seminario: Indicadores de paisaje. Retos y perspectivas. Barcelona, noviembre 2007.

123 Sala, P. "Los indicadores de paisaje de Cataluña" Seminario: Indicadores de paisaje. Retos y perspectivas. Barcelona, noviembre 2007.

124 Rodríguez, J y Villar A. Seminario: Indicadores de paisaje. Retos y perspectivas. Barcelona, noviembre 2007.

125 Jornada Técnica sobre los indicadores de biodiversidad y paisaje del programa marco ambiental. Gobierno Vasco

${ }^{126}$ Farina, A. "Indicadores ecológicos del paisaje". Seminario: Indicadores de paisaje. Retos y perspectivas. Barcelona, noviembre 2007.

127 Farina, A. "Indicadores ecológicos del paisaje". Seminario: Indicadores de paisaje. Retos y perspectivas. Barcelona, noviembre 2007.

128 Jornada Técnica sobre los indicadores de biodiversidad y paisaje del programa marco ambiental. Gobierno Vasco

${ }^{129}$ Farina, A. "Indicadores ecológicos del paisaje". Seminario: Indicadores de paisaje. Retos y perspectivas. Barcelona, noviembre 2007.

130 Sala, P. "Los indicadores de paisaje de Cataluña" Seminario: Indicadores de paisaje. Retos y perspectivas. Barcelona, noviembre 2007.

131 Rodríguez, J y Villar A. "Indicadores de paisaje para Andalucía. Propuesta para el informe de medio ambiente". Seminario: Indicadores de paisaje. Retos y perspectivas. Barcelona, noviembre 2007.

132 Farina, A. "Indicadores ecológicos del paisaje". Seminario: Indicadores de paisaje. Retos y perspectivas. Barcelona, noviembre 2007.

133 Luginbül, Y. "Indicadores sociales del paisaje". Seminario: Indicadores de paisaje. Retos y perspectivas. Barcelona, noviembre 2007.

${ }^{134}$ Luginbül, Y. "Indicadores sociales del paisaje”. Seminario: Indicadores de paisaje. Retos y perspectivas. Barcelona, noviembre 2007
} 
del suelo, superficie construida, estudio en el cambio de la forma de los asentamientos...

- Conocimiento del paisaje $\mathrm{e}^{136}$. Entendido como el grado de reconocimiento e interacción del paisaje que tiene una población.

- Satisfacción paisajística ${ }^{137}$. Que será el grado de contento de la población en relación con un paisaje determinado.

- Sociabilidad paisajística ${ }^{138}$. Con lo que se trata de calibrar las relaciones sociales vinculadas al paisaje o generadas por el paisaje. (Organizaciones que lo defienden...)

- Comunicación en el paisaje ${ }^{139}$. Publicidad, realidad virtual, prensa, radio, televisión...

\subsection{Económicos}

Para abordar este tipo de indicadores deberemos hacernos la siguiente pregunta: ¿Es el medio ambiente un recurso económico?

La respuesta es obviamente sí, sólo tenemos que pensar que en general gastamos dinero en admirar un paisaje, el valor de un estado aumenta con la bellaza de su medio ambiente, un medio ambiente favorable contribuye al aumento del turismo y produce indirectamente beneficios económicos ${ }^{140}$.

Veamos pues qué indicadores podemos utilizar para valorar económicamente el paisaje.

- Valor económico del paisaje ${ }^{141}$

- Ingresos perdidos por hectárea ${ }^{142}$. Que hace referencia a lo que se podría haber ingresado de haber contado con un paisaje mejor valorado.

- Coste de mantenimiento de los elementos ${ }^{143}$. Obviamente de los elementos que aportan valor al paisaje.

- Beneficios recreativos por hectárea ${ }^{144}$. Los beneficios que se estima genera el paisaje al poder dedicarse a actividades recreativas.

135 Sala, P. "Los indicadores de paisaje de Cataluña" Seminario: Indicadores de paisaje. Retos y perspectivas. Barcelona, noviembre 2007.

136 Sala, P. "Los indicadores de paisaje de Cataluña" Seminario: Indicadores de paisaje. Retos y perspectivas. Barcelona, noviembre 2007.

137 Sala, P. "Los indicadores de paisaje de Cataluña" Seminario: Indicadores de paisaje. Retos y perspectivas. Barcelona, noviembre 2007.

138 Sala, P. "Los indicadores de paisaje de Cataluña" Seminario: Indicadores de paisaje. Retos y perspectivas. Barcelona, noviembre 2007.

139 Sala, P. "Los indicadores de paisaje de Cataluña" Seminario: Indicadores de paisaje. Retos y perspectivas. Barcelona, noviembre 2007.

140 Marangon, F. y Tempesta, T. "La valorización económica del paisaje. Una propuesta de indicadores". Seminario: Indicadores de paisaje. Retos y perspectivas. Barcelona, noviembre 2007.

141 Sala, P. "Los indicadores de paisaje de Cataluña" Seminario: Indicadores de paisaje. Retos y perspectivas. Barcelona, noviembre 2007.

142 Marangon, F. y Tempesta, T. "La valorización económica del paisaje. Una propuesta de indicadores". Seminario: Indicadores de paisaje. Retos y perspectivas. Barcelona, noviembre 2007.

143 Marangon, F. y Tempesta, T. "La valorización económica del paisaje. Una propuesta de indicadores". Seminario: Indicadores de paisaje. Retos y perspectivas. Barcelona, noviembre 2007. 
- Beneficios recreativos por hectárea al cambiar algún elemento ${ }^{145}$. Los beneficios que se estima generaría el paisaje al poder dedicarse a actividades recreativas si se produjeran mejoras.

- Precio de la vivienda por metro cuadrado ${ }^{146}$. Es importante tenerlo en cuenta, porque en general se valora el hecho de que una vivienda se encuentre en un paisaje positivo.

- Voluntad de gasto por hectárea para la preservación o mejora del paisaje ${ }^{147}$. Por supuesto deberá tenerse en cuenta a la hora de plantear cualquier mejora o modificación del paisaje, siempre será preceptivo realizar una previsión económica adecuando los planes al presupuesto disponible.

- Coste de mantenimiento por unidad de paisaje ${ }^{148}$. Otro factor a valorar, no sólo se trata de generar paisajes que puedan ser valorados positivamente sino que además se deberá contar con el gasto de mantenimiento que estos paisajes necesiten.

\subsection{Subjetivos}

Son indicadores que, debido a su naturaleza serán difíciles de cuantificar, pero aún así deberemos hacerlo. La información acerca de estos indicadores se obtendrá generalmente por medio de encuestas a la población. Los indicadores más relevantes son:

Relacionados con la tranquilidad ${ }^{149}$ :

- Presencia o ausencia de gente.

- Apertura

- Apreciación de vida salvaje

- Visibilidad del mar

- Visibilidad de bosques y bosques variados

- Visibilidad de carreteras, áreas urbanas...

- Polución del aire

- Visibilidad de plantaciones

- Ruido

\footnotetext{
144 Marangon, F. y Tempesta, T. "La valorización económica del paisaje. Una propuesta de indicadores". Seminario: Indicadores de paisaje. Retos y perspectivas. Barcelona, noviembre 2007.

145 Marangon, F. y Tempesta, T. "La valorización económica del paisaje. Una propuesta de indicadores". Seminario: Indicadores de paisaje. Retos y perspectivas. Barcelona, noviembre 2007.

146 Marangon, F. y Tempesta, T. "La valorización económica del paisaje. Una propuesta de indicadores". Seminario: Indicadores de paisaje. Retos y perspectivas. Barcelona, noviembre 2007.

147 Marangon, F. y Tempesta, T. "La valorización económica del paisaje. Una propuesta de indicadores". Seminario: Indicadores de paisaje. Retos y perspectivas. Barcelona, noviembre 2007.

148 Marangon, F. y Tempesta, T. "La valorización económica del paisaje. Una propuesta de indicadores". Seminario: Indicadores de paisaje. Retos y perspectivas. Barcelona, noviembre 2007.

149 Haggett, C. "La tranquilidad como indicador de paisaje". Seminario: Indicadores de paisaje. Retos y perspectivas. Barcelona, noviembre 2007.
} 


\subsubsection{Legislación aplicable}

Existe actualmente por parte de las administraciones públicas una tendencia a estudiar y conservar el paisaje, concretamente en la Comunidad Valenciana esta predisposición se vio reflejada en la ley 4/2004, de 30 de junio, de la Generalitat, de Ordenación del Territorio y Protección del Paisaje. Ésta se desarrolla en el "Reglamento de Paisaje de la Comunitat Valenciana”, aprobado por el Consell en el decreto 120/2006, de 11 de agosto de 2006.

El Artículo 11 de la citada ley habla específicamente de la Protección del Paisaje y dice:

1. Los planes de ordenación del territorio, los planes generales y los instrumentos de planificación urbanística que prevean un crecimiento urbano incorporarán un estudio sobre el paisaje que necesariamente deberá identificar los hitos geográficos y aquellas características del territorio que constituyan referentes del paisaje del ámbito de la planificación y ordenación.

2. La Generalitat aprobará un Plan de Acción Territorial del Paisaje en el que, además de identificar y proteger los paisajes de relevancia regional en el territorio valenciano, se establecerán directrices y criterios de elaboración de estudios de paisaje, de su valoración y de su consecuente protección.

3. El paisaje actuará como criterio condicionante de los nuevos crecimientos urbanos y de la implantación de las infraestructuras. Los planes que prevean los crecimientos urbanos y los planes y proyectos de infraestructuras contendrán un estudio sobre la incidencia de la actuación en el paisaje, que se incluirá en los estudios de evaluación estratégica ambiental.

4. Los estudios de paisaje deberán proponer medidas correctoras y compensatorias de los impactos paisajísticos que hagan viable el proyecto, y las administraciones con competencias para su aprobación las incorporarán al contenido de la resolución.

Con la lectura de este artículo podemos comprobar el relieve que está alcanzando el concepto de paisaje y el interés creciente de la administración por su conservación.

Pero es en el Reglamento donde verdaderamente se dan las pautas a seguir para la elaboración de los estudios de paisaje.

Ya en la exposición de motivos se dice que el Reglamento se desarrolla con el fin de que la Ley no se convierta a medio plazo en una frustración o en mera retórica.

El Reglamento permite concretar conceptos básicos, criterios, directrices y metodologías relativas al paisaje, abordados con un sentido pedagógico que resulta necesario para que la reglamentación de una materia tan desconocida, por novedosa, resulte efica:

El título I regula el ejercicio de la política de paisaje por los poderes públicos de la Comunitat Valenciana. Establece también los principios, mecanismos, programas y procedimientos efectivos de Participación Pública, en la toma de decisiones en materia de paisaje, mediante procesos de participación que incorporan a un público objetivo en el proceso de adopción de decisiones que afecten al paisaje conforme a los criterios del Convenio Europeo del Paisaje, según el cual la participación social efectiva ha de pasar, necesariamente, por un proceso de educación y concienciación de la población con relación a los valores paisajisticos, que puedan hacer realidad los objetivos de calidad paisajistica adoptados, de forma que permitan el bienestar individual y social, y el desarrollo económico de las sociedades.

El titulo II establece las Normas de Aplicación Directa y Directrices de Integración. Las primeras son de aplicación inmediata y obligada observancia en cualquier procedimiento y las segundas constituyen criterios a los que deben acomodarse los Estudios de Paisaje que acompañen a los planes territoriales y urbanisticos. 
El título III regula los Instrumentos para la Protección, Ordenación y Gestión del Paisaje contemplados en la ley 4/2004, de 30 de junio, de la Generalitat, de Ordenación del Territorio y Protección del Paisaje: Plan de Acción Territorial del Paisaje de la Comunitat Valenciana, Estudios de Paisaje, Estudios de Integración Paisajística, Catálogos y Programas.

En el capítulo III del título III, el reglamento propone una metodología para la elaboración de los Estudios de Paisaje, su elaboración que se limita a concretar y ordenar en secuencia lógica las determinaciones que se recogen en el texto legislativo, y tiene en cuenta las experiencias internacionales a la luz de la Convención Europea del Paisaje.

El concepto de Objetivo de Calidad es traído directamente de la Convención Europea del Paisaje por el texto reglamentario.

Existen varias figuras para el estudio del paisaje de las cuales se ocupa el Reglamento en estudio. Los estudios sobre la incidencia de la actuación en el paisaje a los que hace referencia el artículo 11.3 de la ley 4/2004, de 30 de junio, de la Generalitat, de Ordenación del Territorio y Protección del Paisaje serán denominados en el presente Reglamento Estudios de Integración Paisajística. Tienen por objeto analizar la incidencia de determinadas actuaciones en el paisaje y proponer las medidas correctoras y compensatorias de los impactos paisajísticos que hagan viable el proyecto. Contrastan la actuación propuesta con las Normas de Integración Paisajistica y las restantes conclusiones resultantes del correspondiente Estudio de Paisaje y deben proponer medidas de integración o compensación cuando se produzca un impacto asumible o el rechazo de la actuación en determinadas circunstancias.

Los Catálogos de Paisaje son instrumentos de gran trascendencia puesto que identifican y establecen el régimen jurídico necesario para la preservación y recuperación de los paisajes de mayor valor. Forman parte de los Estudios de Paisaje o tramitarse de forma independiente. El capitulo $V$ del título III del Reglamento los regula con entidad propia, remitiendo la metodología para su elaboración al capitulo anterior en aras a su más adecuado e integrado entendimiento metodológico.

Los Programas de Paisaje materializan las acciones de gestion que se deriven, bien de las conclusiones de los Estudios o politicas de Paisaje, bien de acciones públicas. Forman parte de los Programas para la Sostenibilidad y la Calidad de vida de los Ciudadanos previstos por el artículo 72 y siguientes de la Ley 4/2004, de 30 de junio, de Ordenación del Territorio y Protección del Paisaje.

Resulta interesante la Disposición Adicional:

Segunda. Guías metodológicas para la valoración de paisajes. El Consell elaborará y publicará en un plazo máximo de dos años a partir de la entrada en vigor del Reglamento de Paisaje de la Comunitat $V$ alenciana las guías metodológicas a que se refiere el artículo 37.8 del citado Reglamento, para la valoración a partir de la experiencia adquirida y el intercambio de información internacional conforme a los mecanismos de implementación del artículo 8 del Convenio Europeo del Paisaje.

Y del cuerpo del reglamento vamos a extraer las cuestiones que nos parecen más interesantes por precisar directa o indirectamente actuaciones en materia cartográfica.

Veamos primero algunos artículos que nos introducirán en la cuestión.

Artículo 2. Objetivos del Reglamento

1. Son objetivos de este Reglamento:

a) Regular las acciones de protección, gestión y ordenación de los paisajes valencianos por medio de los instrumentos de paisaje.

b) Integrar y preservar los valores paisajisticos de forma que sean compatibles con su utilización cotidiana, con la creatividad y con la mejora de sus condiciones. 
c) Organizar la cooperación entre órganos de la administración y entre las distintas administraciones territoriales de la Comunitat V alenciana.

2. La consecución de los citados objetivos se abordará desde la concepción emanada del Convenio Europeo del Paisaje, formulado por los Estados miembros del Consejo de Europa en la ciudad de Florencia el 20 de octubre de 2000, a cuyos efectos la Comunitat Valenciana colaborará con el Consejo de Europa con el pleno respeto de las competencias del Estado.

Artículo 4. Ámbito de aplicación

1. Reconociendo que el paisaje abarca la totalidad del territorio y no sólo aquellas porciones dignas de ser preservadas por sus prominentes cualidades estéticas, entendido más allá del simple decoro de algunas de sus partes, y de acuerdo con lo establecido en el artículo 26 de la Ley 4/2004, de 30 de junio, de la Generalitat, de Ordenación del Territorio y Protección del Paisaje y en el articulo 2 del Convenio Europeo del Paisaje, el ámbito del presente reglamento incluye todos los espacios naturales, las áreas urbanas, periurbanas y rurales, y alcanza tanto a los espacio terrestres como a las aguas interiores y maritimas. Se aplica tanto a los paisajes considerados notables, como a los paisajes cotidianos y a los degradados.

2. Todos los paisajes valencianos contienen elementos o aspectos que deben ser simultáneamente protegidos, gestionados $y / 0$ ordenados.

En el Título II se exponen las Normas de aplicación directa y de integración del paisaje en el medio veremos que necesitaremos una buena cartografía tanto para llevar a cabo los trabajos a los que hace referencia este capítulo como para cualquier otro trabajo técnico.

\section{Articulo 20. Integración en la topografía y vegetación}

1. Las actuaciones que se proyecten se adecuarán a la pendiente natural del terreno, de modo que ésta se altere en el menor grado posible y se propicie la adecuación a su topografia natural, tanto del perfil edificado como del parcelario, de la red de caminos y de las infraestructuras lineales.

2. Se probiben los crecimientos urbanisticos y construcciones sobre elementos dominantes o en la cresta de las montañas, cúspides del terreno y bordes de acantilados salvo cuando forme parte del crecimiento natural de núcleos históricos que se encuentren en alguna de tales situaciones y no se modifique sustancialmente la relación del núcleo con el paisaje en el que se inserta, así como las obras de infraestructuras y equipamientos de utilidad pública que deban ocupar dichas localizaciones. En el caso de equipamientos de utilidad pública deberá justificarse técnicamente que es el único lugar posible donde se pueden instalar frente a otras alternativas que supongan un menor impacto para el paisaje. En ningún caso podrán urbanizarse suelos con pendientes medias superiores al 50\%.

3. Los elementos topográficos artificiales tradicionales significativos, tales como muros, bancales, senderos, caminos tradicionales, escorrentías, setos y otros análogos se incorporarán como condicionante de proyecto, conservando y resaltando aquellos que favorezcan la formación de un paisaje de calidad y proponiendo acciones de integración necesarias para aquellos que lo pudieran deteriorar. Las acciones de integración serán coherentes con las características y el uso de los elementos topográficos artificiales, garantizando la reposición de dichos elementos cuando resultaren afectados por la ejecución de cualquier tipo de obra.

4. Cualquier actuación con incidencia en el territorio:

a) Integrará la vegetación y el arbolado preexistente y, en caso de desaparición, por ser posible conforme a su regulación sectorial, establecerá las medidas compensatorias que permitan conservar la textura y la cantidad de masa forestal de los terrenos. 
b) Conservará el paisaje tradicional de la flora y la cubierta vegetal y potenciará las especies autóctonas de etapas maduras de la sucesión y las especies con capacidad de rebrote después de incendios.

c) Utilizará especies adecuadas a las condiciones edafoclimáticas de la zona y en general, que requieran un bajo mantenimiento.

5. Los métodos de ordenación forestal y tratamientos silvicolas potenciarán la presencia de arbolado de dimensiones y vigor que reflejen la calidad real del territorio. Se evitarán tratamientos silvicolas que perpetuien masas forestales de baja calidad. Asimismo, en la apertura o repaso de caminos en suelo forestal se prestará una especial atención a la recuperación del paisaje tanto en su plataforma como en taludes.

6. En general, se mantendrá el paisaje agropecuario tradicional y característico de los espacios rurales por su contribución a la variedad del paisaje e integración en él de las áreas urbanizables previstas, permitiendo aquellos cambios que garanticen su integración paisajística.

Para poder conseguir todos estos objetivos es indispensable contar con una buena cartografía del terreno donde se vean claramente reflejados: la topografía de la zona, la red de infraestructuras lineales, la red viaria, los elementos topográficos artificiales, la distribución de los cultivos o vegetación de la zona, etc.

Articulo 21. Visualización y acceso al paisaje

1. Cualquier actuación con incidencia en el territorio mantendrá el carácter abierto y natural del paisaje agrícola, rural o marítimo, de las perspectivas que ofrezcan los conjuntos urbanos históricos, típicos o tradicionales, y del entorno de recorridos escénicos conforme a la definición establecido en el artículo 36, no admitiendo la construcción de cerramientos, edificaciones u otros elementos cuya situación o dimensiones limiten el campo visual o desfiguren sensiblemente tales perspectivas.

2. Se preservarán los hitos y elevaciones topográficos naturales tales como laderas, cerros, montañas, sierras, cauces naturales y cualquier otro de análoga naturaleza, manteniendo su visibilidad y reforzando su presencia como referencias visuales del territorio y su función como espacio de disfrute escenográfico. A tal efecto se probiben las transformaciones de cualquier naturaleza que alteren o empeoren la percepción visual de tal condición.

3. Las construcciones emplazadas en las inmediaciones de bienes inmuebles de carácter artístico, histórico, arqueológico, típico o tradicional han de armonizar con ellos, aun cuando en su entorno sólo haya uno con esas características. Los Estudios de Paisaje identificarán tales inmuebles en el inventario de recursos paisajisticos y delimitarán los entornos afectados.

4. La planificación territorial y urbanistica y los planes y proyectos de infraestructuras mantendrán las condiciones de visibilidad propias de cada uno de las diferentes Unidades de Paisaje identificables en su ámbito, tales como la linealidad de los valles, apertura de los espacios llanos, vistas panorámicas desde posiciones elevadas, percepción del relieve y de cualquier elemento topográfico significativo.

5. Los Estudios de Paisaje que acompañen a los planes territoriales y urbanisticos establecerán puntos de observación, miradores u observatorios, incluyéndolos, siempre que sea posible, en itinerarios paisajisticorecreativos que contribuyan a la puesta en valor de los recursos paisajisticos, faciliten la contemplación del entorno territorial y de las vistas más significativas de cada lugar, y ayuden a conocer e interpretar su estructura espacial.

6. Los planes a los que se refiere el párrafo anterior, incluirán los puntos de observación en su documentación con eficacia normativa y delimitarán zonas de afección paisajistica en su entorno inmediato que impidan la formación de pantallas artificiales para las vistas más relevantes, quedando probibida la posibilidad de edificar en dichas zonas. 
Para poder cumplir con estos requisitos resulta indispensable contar con mapas de visibilidad que nos permitirán, tanto apreciar si realmente lo proyectado produce un efecto visual negativo en el paisaje existente o no, como establecer los puntos de observación a los que se refiere el punto 5 .

Resulta interesante mencionar el Título III, que versa sobre los Instrumentos para la protección, ordenación y gestión del paisaje, en cuya elaboración es realmente donde se requiere el uso de cartografía de diferente índole.

En el Capítulo I, Determinaciones Generales, se enumeran los diferentes instrumentos que harán posible la protección, ordenación y gestión del paisaje:

Articulo 23. Instrumentos para la protección, ordenación y gestión del paisaje

1. Los instrumentos para la protección, ordenación y gestión del paisaje son los siguientes:

a) Plan de Acción Territorial de Paisaje de la Comunitat Valenciana

b) Estudios de Paisaje

c) Estudios de Integración Paisajística.

d) Catálogos de Paisaje.

e) Programas de Paisaje

2. Los Catálogos [...]

El Artículo 25 hace mención directa al uso de la cartografía:

Artículo 25. Cartografía, técnicas de representación y simulación visual del paisaje

1. Para la realización de los instrumentos de paisaje se utilizarán las cartografías oficiales de la Comunitat V alenciana, tanto en formato vectorial como en formato raster suministradas por el Instituto Cartográfico Valenciano.

2. En aquellas zonas en que el Instituto Cartográfico Valenciano no disponga de cartografía de base adecuada o suficientemente actualizada, la nueva cartografía deberá realizarse atendiendo a los requisitos minimos para ser incorporada al Sistema de Información Territorial, por lo que cumplirán los requerimientos técnicos incluidos en los diferentes pliegos de Prescripciones Técnicas del Instituto Cartográfico Valenciano desarrollados para la realización de las diferentes cartografías oficiales de la Comunitat V alenciana.

3. Cualquier cartografía que se ejecute en el territorio de la Comunitat Valenciana deberá tener como base geodésica la Red de $4^{\circ}$ Orden del Instituto Cartográfico Valenciano y para la toma de datos GPS la utilización de las correcciones diferenciales de la Red de Estaciones de Referencia V alenciana (ERVA).

4. En los estudios de Integración paisajística:

a) Se utilizarán, tanto en su documentación como en el proceso de proyecto, técnicas de modelización y previsualización que permitan controlar el resultado de la acción que se proyecta.

b) Las técnicas de simulación visual tienen por objeto predecir la relación de una actuación y su entorno, ayudando a la visualización de las modificaciones propuestas antes de que lleguen a realizarse, permitiendo la elaboración de alternativas que pueden ser analizadas en su totalidad y comparadas en la toma de decisiones.

c) La documentación gráfica ilustrará de forma clara, realista y entendible por un público no especializado el cambio producido en el paisaje a causa de la nueva actuación y la efectividad de las medidas de integración propuestas.

5. Los Estudios de Integración Paisajística utilizarán una o más de las siguientes técnicas en la justificación de las alternativas valoradas y la definición de la adoptada:

a) Preferentemente, y en cualquier caso, infografía y fotocomposición: combinación de imágenes fotográficas, gráficos y dibujos. 
b) Dibujos, perspectivas y secciones que incluyan los puntos de observación y la actuación.

6. Los instrumentos en materia de paisaje para su tramitación se entregarán en soporte papel y digital con fichero de acceso abierto para su lectura y escritura, en formato con archivos ${ }^{*}$.dxf ${ }^{*}$.shp, ${ }^{*}$. doc e imágenes en formato *.jpg, *.tif, *.ecw o similar. El conseller competente en ordenación del territorio y paisaje, podrá dictar instrucciones que fijen formatos que se adapten a las nuevas tecnologías.

\section{CAPÍTULO II \\ PLAN DE ACCIÓN TERRITORLAL DEL PAISAJE DE LA COMUNITAT $V A L E N C L A N A$}

Articulo 26. Plan de Acción Territorial del Paisaje de la Comunitat Valenciana

1. El Consell aprobará un Plan de Acción Territorial del Paisaje de la Comunitat Valenciana, de conformidad con lo previsto en el apartado 2 del artículo 11 de la Ley 4/2004, de 30 de junio, de la Generalitat, de Ordenación del Territorio y Protección del Paisaje, [...]

2. Establecerá directrices y criterios para la elaboración de los Estudios y demás instrumentos desarrollados en este Reglamento, la valoración de los paisajes y la consecuente adopción de medidas de protección o, en su caso, de ordenación o gestión. [...]

Son los estudios de paisaje los instrumentos últimos que regularán el paisaje de una zona determinada, y para su elaboración resulta imprescindible contar con información cartográfica de muy diferente índole. En el Capítulo III se habla de los citados estudios:

Artículo 27. Estudios de Paisaje

1. Los Estudios de Paisaje contemplados en los artículos 30 y 11.1 de la Ley de Ordenación del Territorio y Protección del Paisaje, son los instrumentos de ordenación paisajistica que tienen como función coadyuvar, en materia de paisaje, a la planificación territorial y urbanistica de ámbito municipal y supramunicipal.

2. Los Estudios de Paisaje establecen los principios, estrategias y directrices que permitan adoptar medidas especificas destinadas a la catalogación, valoración y protección del paisaje en su ámbito de aplicación.

3. De conformidad con lo determinado en el artículo 30 de la Ley de Ordenación del Territorio y Protección del Paisaje deberán contener un Estudio de Paisaje los Planes de Acción Territorial y los Planes Generales.

Articulo 28. Fines de los Estudios de Paisaje

Los Estudios de Paisaje, de conformidad con lo establecido en el articulo 31 de la ley 4/2004, de 30 de junio, de la Generalitat, de Ordenación del Territorio y Protección del Paisaje y a través de la metodología establecida en este Reglamento:

a) Analizan las actividades y procesos que inciden en el paisaje

b) Establecen los objetivos de calidad paisajistica del ámbito de estudio; entendiendo por objetivo de calidad paisajistica, la formulación por las autoridades públicas competentes, para un determinado paisaje, de las aspiraciones de las poblaciones en cuanto se refieran a las características paisajisticas del entorno en el que viven fijadas mediante procedimientos participativos.

c) Indican las medidas y acciones necesarias para cumplir los objetivos de calidad. Las acciones que establezcan podrán ser de protección, ordenación y gestión.

Artículo 29. Contenido del Estudio de Paisaje

El Estudio de Paisaje se ajustará al siguiente contenido: 
1. Plan de Participación Pública.

2. Información del territorio.

3. Caracterización y valoración del paisaje.

4. Fijación de los objetivos de calidad paisajistica

5. Medidas y acciones necesarias para el cumplimiento los objetivos de calidad paisajistica.

Articulo 31. Información del territorio.

1. Los Estudios de Paisaje analizarán las actividades y procesos con incidencia en el paisaje para la determinación de los objetivos de calidad paisajística y de las medidas y acciones necesarias para cumplirlos, en los ámbitos de la ordenación territorial y urbanística, cultural, medioambiental, agraria, social, turística y económica, asi como en cualquier otra que pueda tener un impacto directo o indirecto sobre el paisaje, en relación con lo determinado en el artículo 27.3 de la Ley de Ordenación del Territorio y Protección del Paisaje.

2. Se analizará tanto la situación existente como el futuro previsto por la evolución de los procesos naturales y bumanos en el territorio, incluyendo planes territoriales, urbanisticos y sectoriales y proyectos aprobados por la administración competente, que serán tenidos en cuenta al establecer sus determinaciones.

\section{Artículo 32. Caracterización del paisaje}

1. El análisis y el tratamiento del paisaje exigirá, a efectos instrumentales, la delimitación de las Unidades de Paisaje y de los Recursos Paisajisticos, en los términos definidos en el presente artículo y en los siguientes. Se entiende por caracterización del paisaje, la descripción, clasificación y delimitación cartográfica de las Unidades de Paisaje de un territorio determinado y de los Recursos Paisajisticos que las singularizan.

2. Se entiende por Unidad de Paisaje el área geográfica con una configuración estructural, funcional o perceptivamente diferenciada, única y singular, que ha ido adquiriendo los caracteres que la definen tras un largo periodo de tiempo. Se identifica por su coherencia interna y sus diferencias con respecto a las unidades contiguas.

3. Se entiende por Recursos Paisajísticos los elementos lineales o puntuales singulares de un paisaje o grupo de éstos que definen su individualidady que tienen un valor visual, ecológico, cultural y/ o bistórico.

\section{Artículo 33. Delimitación del Ambito}

1. El ámbito de los Estudios de Paisaje será definido a partir de consideraciones paisajisticas, visuales y territoriales. Serán independientes del plan del que formen parte. Incluirán Unidades de Paisaje completas, con total independencia de cualquier tipo de límite de naturaleza administrativa, tales como lineas de término municipal, lindes de propiedad, límites de sectores o cualquier otro proveniente de planes urbanisticos y similares.

2. En el caso de unidades cuyo ámbito pertenezca a diferentes municipios, o sean objeto de planificación por diferentes administraciones, que ya bubieran sido objeto de un Estudio de Paisaje aprobado definitivamente, se incorporarán las determinaciones de éste. Cuando se encuentren en tramitación, las administraciones responsables estarán obligadas a la coordinación de sus actuaciones que garanticen el tratamiento único para la Unidad de Paisaje. La falta de acuerdo entre diferentes administraciones, será resuelta por el Consell a propuesta de la Conselleria competente en materia de ordenación del territorio y paisaje.

3. Cuando asi lo determine el Plan de Acción Territorial del Paisaje de la Comunitat Valenciana, forme parte de un Plan de Acción Territorial o medie acuerdo del Consell, o de varios municipios, adoptado por sus plenos municipales, el Estudio de Paisaje será de ámbito intermunicipal.

Artículo 34. Caracterización de las Unidades de Paisaje

1. La caracterización de las Unidades de Paisaje tiene por objeto:

a) La definición, descripción y delimitación de las características paisajísticas en el ámbito de estudio.

b) El análisis de sus características y de las dinámicas y presiones que las modifican. 
c) Identificar los recursos paisajísticos que singularizan positivamente su valor y los conflictos paisajisticos que las degradan negativamente.

d) Posibilitar la definición de los Objetivos de Calidad Paisajistica.

2. Las Unidades de Paisaje se delimitarán conforme a los signientes criterios:

a) Las Unidades de Paisaje se definirán a partir de la consideración de los elementos y factores naturales y/ o bumanos, que le proporcionan una imagen particular y lo hacen identificable o único.

Se considerarán, al menos, los siguientes:

. Naturales: relieve, aspectos geológicos e bidrológicos, suelo, clima, especies de fauna y flora silvestres.

- Humanos: población, asentamiento, intervención bumana, patrón y usos del suelo tales como agricultura, trashumancia, silvicultura, actividades rurales, bidráulica, minería, industria, transporte, turismo, servicios, infraestructuras y usos recreativos entre otros.

b) Las Unidades de Paisaje serán coherentes con las Unidades Ambientales para incorporar la información física, biológica, culturaly social en un planteamiento interdisciplinario que mejor integre el patrón ecológico y sus relaciones de forma que la gestión del paisaje promueva los principios de sostenibilidad.

c) La Unidades de Paisaje se delimitarán independientemente de limites administrativos y como tal se enmarcarán en su contexto regional e integrarán con aquellas que ya se han llevado a cabo en las zonas limitrofes, y hayan sido objeto de aprobación por la administración competente.

3. El análisis de las características de las Unidades de Paisaje definidas y delimitadas reflejará para cada Unidad, al menos, los siguientes aspectos:

a) Elementos existentes que definen la singularidad de la unidad, incluyendo aquellos que afectan a otra experiencia sensorial además de la vista.

b) Recursos paisajísticos existentes dentro de cada Unidad conforme a lo dispuesto en el artículo siguiente.

c) Tendencias y procesos de cambio presentes y futuros y como éstas pueden afectar a las características de la unidad de paisaje. En particular se analizarán las procedentes de planes y proyectos que afecten al área de estudio.

d) Principales conflictos existentes y previsibles.

Articulo 35. Caracterización de los Recursos Paisajisticos

1. Se realizará una caracterización de los Recursos Paisajísticos con las áreas o elementos del territorio de relevancia e interés ambiental, cultural y visual que incluirán:

a) Por su interés ambiental, las áreas o elementos que gocen de algún grado de protección, declarado o en tramitación, de carácter local, regional, nacional o supranacional; el dominio público marítimo y fluvial; así como aquellos espacios que cuenten con valores acreditados por la Declaración de Impacto Ambiental. Las áreas o elementos del paisaje altamente valoradas por la población por su interés natural.

b) Por su interés cultural y patrimonial las áreas o los elementos con algún grado de protección, declarado o en tramitación, de carácter local, regional, nacional o supranacional y los elementos o espacios apreciados por la sociedad local como bitos en la evolución histórica y cuya alteración, ocultación o modificación sustancial de las condiciones de percepción fuera valorada como una pérdida de los rasgos locales de identidad o patrimoniales.

c) Por su interés visual las áreas y elementos visualmente sensibles cuya alteración o modificación puede hacer variar negativamente la calidad de la percepción visual del paisaje. Se definirá a partir del Análisis $V$ isual definido en el artículo siguiente y contendrá, al menos, los siguientes elementos:

- Los elementos topográficos y formales que definen la estructura espacial que hace singular un lugar, tales como hitos topográficos, laderas, crestas de las montañas, linea de horizonte, ríos y similares. 
- Los elementos y áreas significativas o características no estructurantes que conforman un paisaje tanto derivadas de su configuración natural como por la acción del hombre-perfiles de asentamientos históricos, hitos urbanos, culturales, religiosos o agricolas, siluetas y fachadas urbanas, y otros similares.

- Las principales vistas y perspectivas hacia los elementos identificados en los apartados anteriores y de los inventariados por causas medioambientales o culturales.

. Los puntos de observación y los recorridos paisajisticos de especial relevancia por su alta frecuencia de observación, o la calidad de sus vistas.

. Las cuencas visuales que permitan observar la imagen exterior de los núcleos urbanos a los que se haya reconocido un extraordinario valor y su inserción en el territorio, su escena urbana interior y las vistas desde ellos del entorno que los circunda.

. Las áreas de afección visual desde las carreteras

Articulo 36. Visibilidad del paisaje. Análisis visual

1. La visibilidad del paisaje determina la importancia relativa de lo que se ve y se percibe y es función de la combinación de distintos factores como son los puntos de observación, la distancia, la duración de la vista, y el número de observadores potenciales.

2. El análisis visual determina la visibilidad del paisaje y tiene por objeto: Paisajisticos.

a) Identificar las principales vistas hacia el paisaje y las zonas de afección visual hacia los Recursos

b) Asignar el valor visual de los Recursos Paisajísticos Visuales en función de su visibilidad.

c) Identificar los recorridos escénicos

d) Identificar y valorar posibles impactos visuales de una actuación sobre el paisaje.

3. Los recorridos escénicos son aquellas vías de comunicación, caminos tradicionales, senderos o similares, o segmentos de ellas que tienen un valor paisajístico excepcional por atravesar y/o tener vistas sobre paisajes de valor natural, bistórico y/ o visual.

4. Los Puntos de Observación son los lugares del territorio desde donde se percibe principalmente el paisaje. Se seleccionarán los puntos de vista y secuencias visuales de mayor afluencia pública que incluirán entre otros los siguientes:

a) Principales vías de comunicación, considerándolas como punto de observación dinámico que definen secuencias de vistas.

b) Núcleos de población.

c) Areas recreativas, turísticas y de afluencia masiva principales.

d) Puntos de observación representativos por mostrar la singularidad del paisaje.

5. Para cada punto de observación el análisis visual:

a) Delimitará la cuenca visual o territorio que puede ser observado desde el mismo, marcando las distancias corta (hasta $300 \mathrm{~m}$ ), media (300 hasta $1.500 \mathrm{~m}$ ) y larga (más de $1.500 \mathrm{~m}$ ) desde el punto de observación. Estas distancias pueden ser modificadas de forma justificada en función del entorno.

b) Identificará los recursos visuales o las áreas y elementos que definen visualmente la singularidad de un paisaje.

c) Determinará el número de observadores potenciales del paisaje objeto de estudio, diferenciando la proporción de los mismos en relación con las siguientes categorías: residentes, turistas y en itinerario, y la duración estimada de la observación

6. Los Puntos de Observación se clasificarán como principales y secundarios, en función del número de observadores potenciales, la distancia y la duración de la visión. 
7. En función del grado de importancia se obtendrán las zonas de máxima visibilidad, las de visibilidad media, las de visibilidad baja y las no visibles o zonas de sombra. Son zonas de máxima visibilidad las perceptibles desde algún punto de observación principal. Son zonas de visibilidad media las perceptibles desde más de la mitad de los puntos de observación secundarios, y baja desde menos de la mitad de éstos.

Articulo 37. Valor Paisajistico

1. El valor paisajistico es el valor relativo que se asigna a cada Unidad de paisaje y a cada Recurso Paisajístico por razones ambientales, sociales, culturales o visuales. Para cada una de las Unidades de Paisaje y Recursos Paisajísticos, se establecerá un valor en función de su calidad paisajística, las preferencias de la población y su visibilidad.

2. La calidad paisajística será propuesta de forma justificada por un equipo pluridisciplinar de expertos en paisaje, a partir de la calidad de la escena, la singularidad o rareza, la representatividad, el interés de su conservación y su función como parte de un paisaje integral.

3. La calidad se manifestará como muy baja, baja, media, alta o muy alta. La administración competente para la aprobación del correspondiente instrumento de paisaje podrá fijar una calidad distinta a la propuesta de forma justificada.

4. La preferencia de la población incorporará los valores atribuidos al paisaje por los agentes sociales y las poblaciones concernidas y se definirá a partir de la consulta pública establecida por el Plan de Participación Pública conforme a lo determinado por el articulo 17.2 de este Reglamento.

5. La visibilidad se determinará desde las principales carreteras y puntos de observación a partir del Análisis Visual desarrollado en el artículo 36.

6. El valor de cada Unidad de Paisaje y de cada RecursoPaisajístico, será el resultado de la media de las puntuaciones resultantes de la calidad otorgada técnicamente y de las preferencias del público, ponderada por el grado de su visibilidad desde los principales puntos de observación. El resultado del valor paisajístico se manifestará como muy bajo, bajo, medio, alto o muy alto.

7. En cualquier caso deberá atribuirse el máximo valor a los paisajes que ya están reconocidos por una figura de la legislación en materia de protección de espacios naturales y patrimonio cultural.

8. La Conselleria competente en ordenación del territorio y protección del paisaje elaborará y publicará guías metodológicas para la valoración de paisajes que actualizará periódicamente incorporando la experiencia adquirida y el intercambio de información internacional conforme a los mecanismos de implementación del articulo 8 del Convenio Europeo del Paisaje. Hasta tanto no se disponga de ellas podrán utilizarse tanto métodos cualitativos como cuantitativos de valoración siempre que se expresen los indicadores o parámetros utilizados y se empleen normas o metodologías técnicas de general aceptación, tales como el Método de $V$ aloración de la Preferencia Visual u otros similares. En este caso se detallarán las metodologías y procesos de cálculo utilizados en la valoración que siempre deberán referirse a muestreos de carácter representativo de la población concernida.

Articulo 41. Delimitación del Sistema de Espacios Abiertos

1. A los efectos del artículo 39 los Estudios de Paisaje delimitarán un Sistema de Espacios Abiertos o conjunto integrado y continuo de espacios en general libres de edificación, de interés medioambiental, cultural, visual, recreativo y las conexiones ecológicas y funcionales que los relacionan entre sí.

2. El Sistema de Espacios Abiertos constituirá una zona de Ordenación Urbanística a los efectos de los artículos 36.1.c) y 45.1.e) de la Ley 16/2005, de 30 de diciembre, de la Generalitat, Urbanistica Valenciana. 
3. El Sistema de Espacios Abiertos tiene por objeto proveer de áreas recreativas al aire libre, proteger áreas y hábitats naturales así como el patrón ecológico del lugar y los valores culturales y paisajísticos, mejorar el paisaje visual y preservar zonas de transición físicas y visuales entre distintos usos y actividades.

4. Incluirán los siguientes paisajes, salvo excepcionalidad que deberá ser objeto de motivación expresa:

a) Los elementos incluidos en el Catalogo de Paisaje.

b) Las conexiones ecológicas y funcionales o franjas de terreno que conectan los espacios del apartado anterior y que aún no teniendo elementos de singularidad manifiesta paisajística o incluso se encuentren degradados, se consideran necesarios como áreas de conexión entre los espacios de interés para lograr una continuidad física, ecológica y funcional. En cualquier caso incluirá la red hídrica, senderos históricos, vías pecuarias, infraestructuras y similares y los corredores verdes a los que se refiere la Ley de Ordenación del Territorio y Protección del Paisaje, que desempeñan funciones de conexión biológica y territorial, todo ello de conformidad con lo establecido en el artículo 20.7 de la Ley de Ordenación del Territorio y Protección del Paisaje.

5. Aunque la inclusión de un terreno en el Sistema de Espacios Abiertos es independiente de su clasificación o calificación urbanistica, la ordenación que se establezca deberá garantizar el carácter de espacio abierto. Las Normas de Integración establecerán las condiciones de uso de tales suelos.

Artículo 44. Documentación del Estudio de Paisaje

La documentación del Estudio de Paisaje, se ajustará al siguiente contenido:

DOCUMENTACIÓN INFORMATIVA

1. Sintesis de los Planes o normas de carácter territorial, urbanístico, medioambiental o cualquier otra de carácter sectorial que le sean de aplicación

2. Determinaciones de carácter paisajístico que le son de aplicación y en especial las contenidas en los Estudios de Paisaje ya aprobados de rango igual o superior, incorporando de los mismos:

a) Plano a escala 1/20.000 con las Unidades de Paisaje y Recursos Paisajísticos diferenciando los catalogados y Sistema de Espacios Abiertos, aprobados o en tramitación en el ámbito del Estudio que se desarrolla. Ficha para cada una de ellos que contenga el carácter, valor y objetivos de calidad ya asignados. desarrolla

b) Normas de Integración Paisajistica y Programas de Paisaje vigentes en el ámbito del Plan que se

3. Información y análisis territorial del ámbito del Estudio.

4. Análisis de las actividades y procesos con incidencia en el paisaje. Características, dinámicas y presiones que los modifican

\section{DOCUMENTACIÓN JUSTIFICATIVA}

$[\cdots]$

7. Ambito territorial del Estudio

a) Descripción y Justificación del ámbito territorial del Estudio y de la adecuación a las determinaciones, normas o planes señaladas en la documentación informativa.

b) Plano a escala 1/20.000 con la delimitación del ámbito territorial

8. Delimitación y caracterización de las Unidades de Paisaje y Recursos Paisajisticos

a) Definición y caracterización de las Unidades de Paisaje y los Recursos Paisajísticos con detalle de cada uno de ellos. Justificación del método seguido.

b) Plano, a escala 1/20.000 o mayor con delimitación de las Unidades de Paisaje y Recursos Paisajisticos. 
c) Inventario de actividades o elementos conflictivos desde el punto de vista visual o paisajístico que al menos incluirá las edificaciones o instalaciones en ruina y ámbitos degradados en los entornos urbanos, rurales, industriales o naturales, por abandono o cese de actividades productivas, deterioro del suelo o su cubierta, suelos contaminados, actividades y elementos impropios, catástrofes naturales, deterioro de la escena o de la vista de elementos singulares, implantación de infraestructuras e instalaciones publicitarias y otros de naturaleza análoga.

9. Análisis Visual

a) Ficha de cada Punto de Observación, con definición gráfica de situación, delimitación de la cuenca visual y Unidades de Paisaje y Recursos Paisajísticos situados en la misma. Observadores y clasificación.

b) Plano de visibilidad, a escala 1/20.000 o mayor con situación de los Puntos de Observación e indicadores de cordenadas UTM, y delimitación de las zonas de visibilidad máxima, media, baja y nula.

10. Valor y objetivos de Calidad Paisajística

a) Justificación del método seguido para la valoración de las Unidades de Paisaje y los Recursos Paisajisticos con detalle de cada uno de ellos.

b) Ficha para cada Unidad de Paisaje y cada Recurso Paisajistico que recoja, su delimitación gráfica, descripción de su carácter, valor y Objetivos de Calidad Paisajistica.

c) Plano, a escala 1/20.000 o mayor con delimitación de las Unidades de Paisaje y Recursos Paisajísticos, clasificados por su valor-objetivo de calidad, en cinco categorías.

11. Justificación de las medidas y acciones propuestas para la consecución de los Objetivos de Calidad Paisajistica

\section{DOCUMENTACIÓN CON CARÁCTER NORMATIVO}

[...]

14. Sistema de Espacios Abiertos que forman parte de la ordenación estructural de conformidad con lo establecido en el artículo 36.1.c) de la Ley 16/2005, de 30 de diciembre, de la Generalitat, Urbanística Valenciana.

a) Normas de Integración Paisajística referidas al Sistema de Espacios Abiertos, que determinen el grado de protección, régimen de usos del suelo.

b) Plano a escala 1/20.000 o mayor con la delimitación del Sistema de Espacios Abiertos, con delimitación de las diferentes zonas de tratamiento establecidas en las Normas de Integración Paisajística

15. Programas de Paisaje

a) Ficha para cada uno de los Programas propuestos explicando en qué consisten, los objetivos y estrategias, y qué deben cumplir para conseguir los objetivos de calidad.

b) Plano E 1/20.000 o mayor que delimite los ámbitos de los Programas de Paisaje.

\section{CAPÍTULO IV}

\section{ESTUDIOS DE INTEGRACIÓN PAIS AJÍSTICA}

Articulo 48. Estudios de Integración Paisajistica

1. Los Estudios de Integración Paisajítica se elaborarán en los casos previstos en el artículo 11.3 de la Ley de Ordenación del Territorio y Protección del Paisaje valorando la incidencia en el paisaje de las actuaciones que tengan por objeto nuevos crecimientos urbanos o la implantación de nuevas infraestructuras.

2. De conformidad con lo establecido en el apartado 4 del citado artículo, deberán proponer medidas correctoras y compensatorias de los impactos paisajísticos que hagan viable el proyecto, y las administraciones con competencia para su aprobación las incorporarán al contenido de la resolución, tanto de la aprobación del plan o 
proyecto como de la Declaración de Impacto Ambiental o Evaluación Estratégica Ambiental, conforme al procedimiento previsto en el articulo 58 de este Reglamento.

3. La justificación del cumplimiento del artículo 12.1 de la Ley del Suelo No Urbanizable, de los apartados 1 a 3 del artículo 8 de la Ley 16/2005, de 30 de diciembre, de la Generalitat, Urbanistica $V$ alenciana y el análisis del impacto paisajistico de los proyectos sometidos a Evaluación de Impacto Ambiental al amparo de lo dispuesto en la Ley 2/1989, de 3 de marzo y de su Reglamento de desarrollo aprobado por Decreto 162/1990, de 15 de octubre, se realizará mediante un Estudio de Integración Paisajística.

4. Consecuentemente deberán ir acompañado de Estudio de Integración Paisajistica:

a) El planeamiento urbanístico de desarrollo contemplado en los apartados b, c, dy $f$ del artículo 38 de la Ley 16/2005, de 30 de diciembre, de la Generalitat, Urbanistica Valenciana .

b) Las solicitudes de licencias urbanisticas dentro de los conjuntos y sus entornos declarados Bienes de Interés Cultural y dentro de los Espacios Naturales Protegidos.

c) Las solicitudes de Declaraciones de Interés Comunitario.

d) Autorizaciones y licencias en suelo no urbanizable no incluidas en los ámbitos anteriores.

e) Los proyectos sometidos a evaluación de impacto ambiental al amparo de lo dispuesto en la Ley 2/1989, de 3 de marzo y de su Reglamento de desarrollo aprobado por Decreto de 162/1990, de 15 de octubre, sustituyéndose el análisis de impacto visual por el citado estudio conforme a lo señalado en el artículo 58 de este Reglamento.

f) Proyectos de Infraestructuras u obras públicas

Articulo 51. Ámbito de los Estudios de Integración Paisajistica

1. El ámbito de los Estudios de Integración Paisajística abarcará, para cada plan, proyecto o actuación para el que es obligatoria su realización conforme a lo establecido en el articulo 48.4 del presente reglamento, la Unidad o Unidades de Paisaje completas afectadas por la cuenca visual de la actuación tanto en su fase de construcción como de explotación.

2. A estos efectos, se entiende por cuenca visual aquella parte del territorio desde donde es visible la actuación y que se percibe espacialmente como una unidad definida generalmente por la topografía y la distancia. La Cuenca Visual puede contener a su vez una parte de una Unidad de Paisaje, una Unidad completa o varias Unidades de Paisaje.

Artículo 52. Contenido de los Estudios de Integración Paisajistica

El contenido de los Estudios de Integración Paisajistica se adaptará al tipo de proyecto y al paisaje donde se ubica, e incluirá:

1. Plan de Participación Pública

2. Descripción y definición del alcance de la actuación.

3. Delimitación del ámbito de estudio y caracterización de las Unidades de Paisaje y de los Recursos Paisajisticos afectados, conforme a la sección 1 del capitulo III del presente titulo.

4. Planes y proyectos en trámite o ejecución en el mismo ámbito.

5. Valoración de la Integración Paisajística o justificación del cumplimiento de las determinaciones contenidas en los instrumentos de paisaje que le sean de aplicación, y en especial del Estudio de Paisaje o Catálogo de Paisaje.

6. La Valoración de la Integración Visual a partir de un Análisis Visual del ámbito desarrollado conforme al articulo 36. magnitud

7. La identificación de los Impactos Paisajísticos y Visuales y la previsión de su importancia y

8. Las medidas de integración y mitigación de impactos y programa de implementación. 
Artículo 55. Valoración de la Integración Visual

1. La Valoración de la Integración Visual valorará especificamente el posible Impacto Visual de una actuación en el paisaje en función de la visibilidad de la actuación.

2. La Valoración de la Integración Visual identificará los impactos visuales en función, al menos, de los siguientes factores:

a) La compatibilidad visual de las características de la actuación: volumen, altura, forma, proporción, ritmos de los elementos construidos, color, material, textura, etc.

b) El bloqueo de vistas hacia recursos paisajísticos de valor alto o muy alto.

c) La mejora de la calidad visual.

d) Los reflejos de la luz solar o luz artificial.

3. La Valoración de la Integración Visual contendrá:

a) El análisis de las vistas desde los principales puntos de observación y la valoración de la variación en la calidad de las vistas debida a la nueva actuación.

b) La clasificación de la importancia de los impactos visuales como combinación de la magnitud del impacto y la sensibilidad de los receptores. Estos pueden ser: sustancial, moderado, leve e insignificante.

c) La identificación del potencial de las medidas correctoras. Estas pueden conducir a adoptar una ordenación diferente, un diseño alternativo o modificaciones del diseño para prevenir y/o reducir al minimo los impactos.

d) La predicción de la importancia del impacto al paisaje antes y después de la aplicación de las medidas correctoras.

Articulo 57. Documentación de los Estudios de Integración Paisajistica

El Estudio de Integración Paisajistica contendrá, como minimo, la siguiente documentación:

DOCUMENTACIÓN Informativa:

1. Descripción de la actuación, incluyendo, al menos, planos de planta, alzados, secciones o perfiles a escala adecuada para su correcta interpretación.

2. Ámbito del Estudio. Constituido por la cuenca visual, o territorio que puede ser observado desde la actuación, en plano a escala 1/20.000, sobre el que se marcarán los umbrales de nitidez a 500, 1.500 y $3.500 \mathrm{~m}$ de distancia desde la misma.

3. Normas, planes, estudios y proyectos de carácter territorial, urbanístico, ambiental o cualquier otra de carácter sectorial que le sean de aplicación.

4. Normas de carácter paisajístico que le son de aplicación y en especial Estudios o Catálogos de Paisaje que afecten al ámbito del Estudio de Integración Paisajistica de la actuación, incorporando del mismo:

- Delimitación, en plano a escala 1/20.000, de las Unidades de Paisaje incluidas en el ámbito del estudio de integración y ficha para cada una de ellas que contenga el carácter, valor y objetivos de calidad.

. Situación, en plano a escala 1/20.000, de los Recursos Paisajísticos inventariados dentro del ámbito del estudio y ficha para cada uno de ellos con su identificación, descripción, valor y objetivos de calidad.

. Ficha de cada uno de los elementos Catalogados

- Normas de Integración Paisajistica

DOCUMENTACION JUSTIFICATIVA

$[\ldots]$

a) Plano de las Unidades Visuales a escala 1/20.000 que muestre:

- La delimitación de las Unidades Visuales.

- La topografía. 
. Los asentamientos urbanos y las infraestructuras de transporte existentes.

- Localización de la actuación que se va a evaluar.

b) Definición de los Puntos de Observación, que incluirá su situación, sobre plano topográfico del Instituto Cartográfico Valenciano a escala 1/20.000, y una ficha gráfica y escrita para cada punto de observación que contenga la siguiente información:

- La cuenca visual que abarca el Punto de Observación.

- Clasificación en Punto de Vista Principal y Secundario según su grado de importancia.

- Una descripción de las Unidades de Paisaje y de los Recursos Paisajísticos que singularizan la vista.

- Definición del número, tipo y expectativas de los observadores potenciales.

. Secciones que ilustren la linea visual entre el Punto de Observación y la actuación.

- Reportaje fotográfico que muestren el campo de visión

c) Mapa de visibilidad conteniendo de forma integrada el conjunto de los puntos de observación, las zonas de máxima visibilidad, las de visibilidad media, las de visibilidad baja y las no visibles o zonas de sombra. $[\ldots]$

CAPÍTULO V

CATÁLOGOS DE PAISAJE

Artículo 59. Catálogos de Paisaje

1. Los Catálogos de Paisaje se elaborarán conforme a la metodología establecida en la sección $1^{a}$ del capitulo iii del presente título.

2. El Catálogo de Paisajes incluirá, los siguientes elementos identificados a partir del proceso de valoración establecidos en la sección $1^{a}$ del capitulo III del presente titulo:

a) Las Unidades de Paisaje o Recursos Paisajísticos objeto de protección especial conforme a la legislación de protección de Espacios Naturales y los entornos de los bienes y conjuntos incluidos en el perímetro de su declaración como bien de interés cultural conforme a la legislación de patrimonio cultural. muy alto.

b) Las Unidades de Paisaje y los Recursos Paisajísticos a los que se haya reconocido un valor alto o

3. Conforme a los dispuesto en el artículo 30.3 de la Ley 4/2004, de 30 de junio, de la Generalitat, de Ordenación del Territorio y Protección del Paisaje, podrán establecerse Catálogos de Paisaje de ámbito local o regional formulados y tramitados independientemente del Estudio de Paisaje.

\section{CAPÍTULO VI}

PROGRAMAS DE PAISAJE

Articulo 61. Programas de Paisaje

1. Los Programas de Paisaje concretan las actuaciones para garantizar la preservación, mejora y puesta en valor los paisajes que por su valor natural, visual, cultural o urbano requieren intervenciones especificas e integradas.

2. Los Programas de Paisaje se formarán, tramitarán y aprobarán de forma independiente o como parte de los Estudios de Paisaje o Estudios de Integración Paisajistica que los prevean.

Articulo 65. Programas de Imagen Urbana

1. Los programas de imagen urbana son instrumentos de gestión del paisaje destinados a mejorar la calidad y el atractivo de los espacios de los núcleos urbanos y de su entorno inmediato en relación con su incidencia sobre el paisaje. [...] 


\section{Artículo 66. Programas de Restauración Paisajistica}

1. Los programas de restauración paisajística, conforme a los dispuesto en el apartado 3 del artículo 27 de la Ley 4/2004, de 30 de junio, de Ordenación del Territorio y Protección del Paisaje, son instrumentos que tienen por objeto la restauración o rehabilitación de aquellos espacios cuyo paisaje ha sufrido un elevado grado de deterioro como consecuencia de las actividades humanas o de la falta de actuaciones para su mantenimiento.

2. Los programas de restauración paisajística tienen por objeto, entre otros, la recuperación de paisajes degradados en entornos urbanos o naturales, por abandono o cese de actividades productivas, deterioro del suelo o su cubierta, actividades y elementos impropios, catástrofes naturales, deterioro de la escena o de la vista de elementos singulares, implantación de infraestructuras e instalaciones publicitarias y otros de naturaleza análoga.

\subsubsection{Cartografía del paisaje}

Dos han sido las estrategias generalmente utilizadas para realizar cartografía del paisaje. La primera, basada en la superposición de mapas temáticos (vegetación, usos del suelo, geomorfología) y en la delimitación de unidades homogéneas desde el punto de vista visual; la segunda, parte de una determinación "a priori" de áreas visuales cerradas o autocontenidas denominadas cuencas visuales.

En la actualidad se está realizando cartografía paisajística combinando ambas estrategias, de forma que se incorporan las ventajas de las dos. Esta cartografía proporciona información referida a conjuntos visuales cerrados, siendo posible también delimitar unidades homogéneas por su textura.

Un modo relativamente sencillo para tipificar los paisajes podría ser el que, según M. Barturen se está utilizando en el País Vasco, que consiste en definir en primer lugar el dominio geomorfológico (grandes formas de modelado) al que corresponden y en un segundo nivel de detalle, se deberían reconocer características de "posición geográfica", dependiendo del relieve, en las que se diferencien las diferentes categorías. Por último, la vegetación y el uso del suelo proporcionan datos de mayor detalle para definir el tipo de paisaje que en el mapa va a constituir una unidad elemental.

Como se ha comentado ya, en la cartografía del paisaje del País Vasco se realiza también una delimitación de las cuencas visuales. Aunque la definición de cuenca visual incorpora el componente básico de contener "el conjunto de puntos que son intervisibles", esto no debe tomarse en sentido estricto, ya que la naturaleza siempre presenta accidentes que, aunque no tienen relevancia territorial, puntualmente ofrecen obstáculos a la visión. En el caso de la Comunidad Autónoma del País Vasco, la delimitación de cuencas visuales se ha apoyado fuertemente en la topografía, especialmente en la existencia de las cuencas hidrográficas. Por supuesto que, en numerosas ocasiones, la cuenca visual puede contener más de una cuenca hidrográfica, mientras que en muchas otras puede ser parte de una cuenca hidrográfica. Esta cartografía, que tiene fundamentalmente un carácter descriptivo, es también el fundamento de un trabajo posterior de valoración del paisaje.

Como se comentará más adelante, la escala de la cartografía resulta un factor determinante, el tamaño de las unidades territoriales que se delimiten debe adaptarse a las posibilidades de percepción de las personas. Bien por la amplitud del campo de visión propio del ser humano, o bien por circunstancias sociales (generalmente culturales), la capacidad de percibir como homogéneo un determinado escenario es lo que va a condicionar el tamaño de 
grano, es decir, hasta qué punto se va a abstraer del conjunto de colores, formas y texturas, la información que posteriormente se recogerá y se transmitirá a través de una parcela delimitada por una línea en un mapa.

Actualmente, en 2007, el Instituto Cartográfico Valenciano (ICV) está generando cartografía base para la realización de "Delimitación de zonas paisajísticas" que está llevando a cabo la empresa LANDAR. Las series que el ICV genera para este propósito son mapas de: pendientes, orientaciones, soleamiento y visibilidad, todos a escala 1:20.000 de acuerdo con el Reglamento. También aporta la ortofoto 1:5000 y el MDT con un paso de malla de $10 \mathrm{~m}$.

\subsubsection{Situación actual}

Deberemos también tener en cuenta que el ser humano perceptor del paisaje forma parte de él, y con su actividad cotidiana lo deteriora o lo mejora, pero siempre lo modifica. Esta estrecha relación entre el hombre y el paisaje se produce por la necesaria adaptación de aquél a éste. El hombre debe adaptarse al paisaje, y a su vez adapta el paisaje a sus necesidades. Lo que se debe procurar es que esta adaptación no produzca un deterioro irreversible de un bien que está cobrando cada vez mayor protagonismo.

El desarrollo de políticas que redunden en conservación y mejora del paisaje está directamente relacionado con el hecho de que se considere, como un hecho generalmente aceptado, que el paisaje es un recurso muy favorable para el progreso económico de una zona.

\subsubsection{El Paisaje en los Planes de Ordenación del Territorio}

Dado que la preocupación por el paisaje es un tema relativamente reciente, existe una gran indefinición acerca de quién y cómo debe tratar el tema, por ello sería deseable que se creara un marco estable y libre de incertidumbres sobre el que operaran las distintas administraciones públicas. Así mismo debería promoverse la formación de especialistas en este nuevo campo, ya que esta falta de definición potencia la individualidad de criterios y opiniones, así como la discrepancia en función de sensibilidades frente a la formación de una conciencia social y la puesta en común de experiencias y conocimientos.

En lo que se refiere al tratamiento que recibe el paisaje en los Planes de Ordenación Territorial, puede decirse que, como apuntaba J. M. Sánchez Biec para el caso andaluz:

- El paisaje no suele reconocerse como un elemento más a considerar en el marco de las actividades económicas.

- La política turística sobre el paisaje se promueve desde las administraciones locales y se caracteriza por su carácter activo, su enfoque fragmentario y su consideración, básicamente, como objeto de intervención.

- La atención al paisaje y medio ambiente de los ámbitos con posibilidades turísticas, detrae esfuerzos y recursos para los paisajes cotidianos, casi siempre mayoritarios.

- Salvo excepciones, las políticas sectoriales no suelen incorporar análisis de viabilidad paisajística en sus diferentes fases de estudio y planificación, siendo habitual una atención al paisaje de carácter reconstructivo y desde la perspectiva de proyecto, que se suele materializar mediante la aplicación de medidas sistemáticas de integración de las actividades productivas, obras públicas e infraestructuras territoriales. 
- Las actuaciones convencionalmente aceptadas en materia de medio ambiente, salud pública, asuntos sociales, cultura, etc., acaban repercutiendo en la mejora del paisaje, pero no siempre hay una relación de eficiencia entre mejora paisajística conseguida y objetivos perseguidos. En este sentido, es frecuente la asignación de acciones y medidas presupuestarias al concepto paisaje, que son más propias del ámbito medioambiental o de uso público y se concretan en espacios protegidos por razones ambientales, llegando a producirse, incluso, confusión entre los conceptos paisaje y medio ambiente.

- Los planes de transformación agrícola no consideran el paisaje. Las decisiones sobre el paisaje en los planes y programas agrícolas y las grandes transformaciones en regadío se vienen concretando en la aplicación de medidas de exclusión de pequeños enclaves de valor ambiental y la liberalización de las actuaciones sobre el espacio productivo, que vienen a regularse en términos de máxima rentabilidad económica y mayor eficacia de las infraestructuras hidráulicas.

- Los espacios extensivos con relevancia paisajística relativa tampoco se quedan al margen de esta situación. Regulados por las consecuencias del declive de la sociedad rural y de los sistemas agroganaderos tradicionales y por una coyuntura de fragilidad e incertidumbre, son proclives a la gestión absentista del territorio, a la intensificación de la agricultura extensiva o a la acogida, a veces indiscriminada, de actividades económicas más rentables que las presentes.

- Los paisajes agrarios más o menos tradicionales, mejor o peor conservados, no solamente se encuentran discriminados dentro de su comarca natural, sino que además, por el hecho "de pertenecer a", constituyen territorios de aplicación no prioritaria de las políticas horizontales en materia de agricultura, medio ambiente y desarrollo rural con incidencia directa en la mejora o conservación del paisaje.

Sin embargo, la protección del paisaje debería ser un tema prioritario a la hora de la elaboración de un Plan de Ordenación. Todo Plan debería contar con un inventario y una valoración de la base paisajística, del potencial de vistas y de la incidencia visual del entorno afectado ${ }^{150}$

Los elementos paisajísticos extraordinariamente distintivos siempre han disfrutado de especial protección, nos referimos por ejemplo a edificios singulares, puntos elevados, y todos aquellos elementos que por tradición han aportado peculiaridad a la zona. Y esta protección afectaba no sólo al elemento en cuestión sino a toda su cuenca visual. Actualmente se debe intentar llegar más allá, restringiendo la colocación de elementos con un fuerte impacto visual; acotando el uso de ciertos materiales, formas y colores en zonas en las que puedan ocasionar un efecto paisajístico negativo; sancionando la construcción en zonas de espacial interés, etc.

150 Gómez, D., “Ordenación Territorial”, 2002. 


\subsection{La Cartografía en los Planes de Ordenación y Desarrollo Territorial}

Tanto si el objetivo es dar respuesta a problemas que puntualmente puedan plantearse, como si se trata de planificar y regular el modelo territorial que se desea alcanzar, resulta imprescindible disponer de la mayor cantidad de información posible. Al igual que otros muchos eventos, la información territorial de que dispongamos estará siempre asociada a un espacio, en el que además se establecen múltiples interrelaciones entre ecosistemas físiconaturales o antrópicos. Por esta razón es por lo que resulta necesario contar con una buena cartografía.

\subsubsection{Estado actual}

Actualmente no existe una cartografía normalizada con carácter estatal referida a Ordenación y Desarrollo Territorial. Este vacío de información podría deberse al hecho de que una vez aprobada la Ley sobre Régimen del Suelo y Ordenación Urbana en 1976, se produjo un traspaso de competencias a las Comunidades Autónomas entre 1980 y 1982.

De este modo, deberían ser las Comunidades Autónomas las encargadas de producir este tipo de cartografía. Es tanta y tan variada la información necesaria para llevar a cabo tareas de Desarrollo Territorial que cada Comunidad Autónoma aborda el tema de manera diferente.

Castilla y León en el año 1993 ya se había planteado un proceso de generación de cartografía a escalas comprendidas entre 1:500000 y 1:50000151.

La Comunidad Valenciana cuenta para estos fines con la cartografía generada por el Instituto Cartográfico Valenciano (I.C.V.), que aunque no está generando ningún tipo de material específico para Ordenación del Territorio, sí lo está haciendo para conservación del Paisaje, como ya se comentó en el capítulo anterior.

\subsubsection{Cartografía del Instituto Cartográfico Valenciano para estudios de paisaje}

Tras la publicación de la ley 4/2004, de 30 de junio, de la Generalitat, de Ordenación del Territorio y Protección del Paisaje, y su reciente desarrollo por el Reglamento de Paisaje de la Comunidad Valenciana, se encargó al I. C. V. la elaboración de cierta cartografía que pudiese servir como base para la realización de los estudios de paisaje citados en las anteriores normas, que ya han sido comentadas en el apartado 1.4.10. del presente trabajo.

El I. C. V., como organismo oficial cuyo cometido es la gestión de la cartografía en la Comunidad Valenciana, proporciona a los organismos encargados de elaborar los estudios de paisaje su serie cartográfica a escala 1:5000, así como su ortofoto a la misma escala, y el Modelo

151 Servicio de Ordenación del Territorio. Junta de Castilla y León. Mapping, 1993. 
Digital de Elevaciones (MDE) con paso de malla de $10 \mathrm{~m}$. Además, está generando una serie de cartografías específicamente para este fin.

Debido a que el Reglamento especifica 1:20.000 como la escala a la que se deberá producir la cartografía para estudios de paisaje, es ésta la escala utilizada por el I. C. V., aunque no se trate de una escala habitual y sea necesario por ello producir toda una serie cartográfica.

Los mapas que se están generando son: pendientes, orientación, soleamiento y visibilidad, estos últimos los más conflictivos. Como datos de partida se toma el modelo digital del terreno (MDE), procedente de la serie CV05, con paso de malla de $10 \mathrm{~m}$.

\subsubsection{Mapas de pendientes}

A partir del citado MDE, también llamado MDT (Modelo Digital del Terreno), se genera el mapa de pendientes. Hay dos formas de representarlo, dependiendo del ángulo de inclinación o bien de la pendiente medida en tanto por ciento. El utilizado por el I.C.V. será este último.

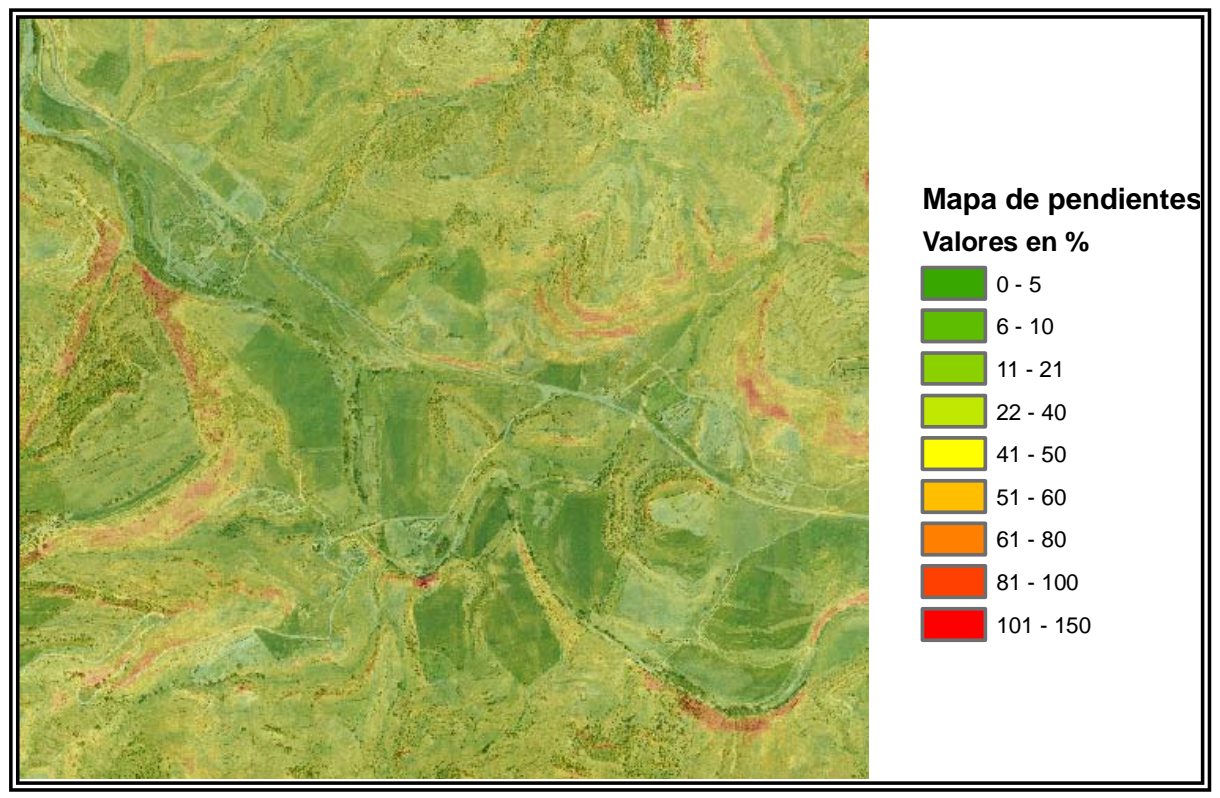

Figura 1.40. Mapa de pendientes para estudios de paisaje. Fuente: I.C.V.

En la figura 1.40 se muestra un mapa de pendientes generado por el I.C.V., se trata de una información extremadamente útil cuando hablamos de Ordenación del Territorio, ya que en zonas con pendiente acusada no es posible ubicar la mayoría de las actividades, o si lo es, resulta muchísimo más costoso. 


\subsubsection{Mapas de orientaciones}

Los mapas de orientaciones resultan también muy útiles porque nos indican hacia donde está orientado cada punto del terreno. Como se aprecia en la leyenda de la figura 1.41, se incorpora una clase para las zonas de orientación nula, zonas con pendiente $0 \%$. Hecho esto se crean 8 clases más correspondiendo cada una de ellas a los diferentes puntos cardinales, que podemos ver igualmente en la leyenda de la citada figura.

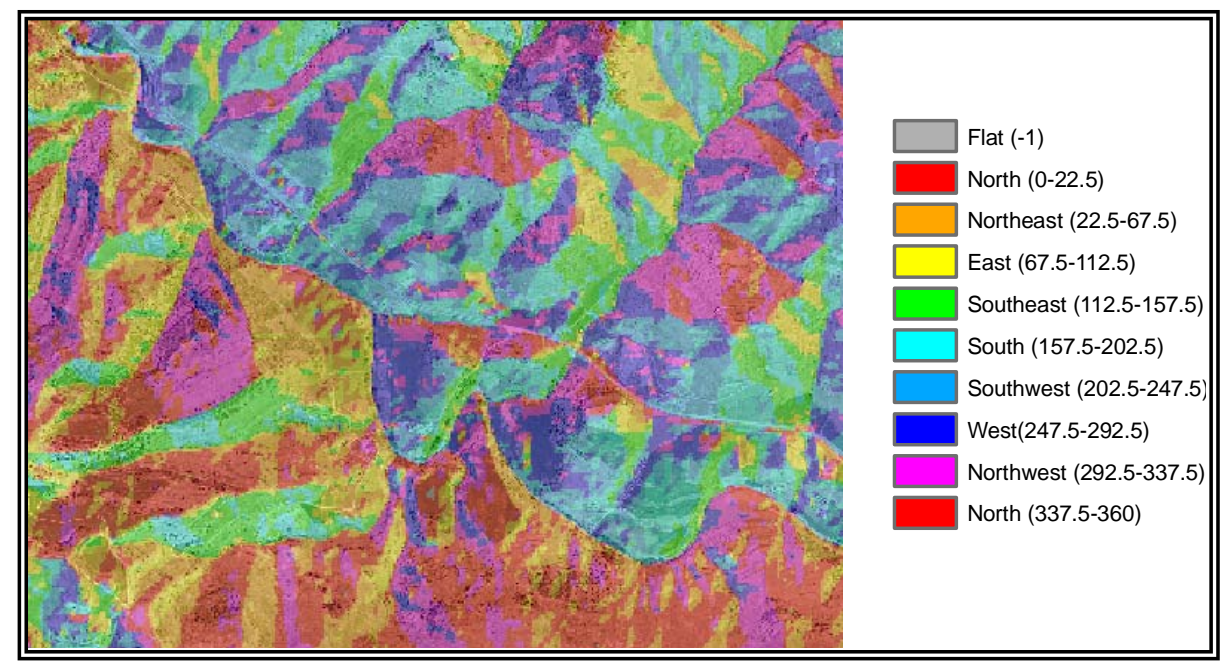

Figura 1.41. Mapa de orientaciones para estudios de paisaje. Fuente: I.C.V.

Para calcular el valor que correspondería a cada una de las celdas o píxels del mapa de orientaciones, se realiza un estudio automático celda a celda, comparando cada celda con sus celdas vecinas, siguiendo el compás de direcciones que se muestra en la figura 1.42, con el resultado se asigna el valor correspondiente a cada celda.

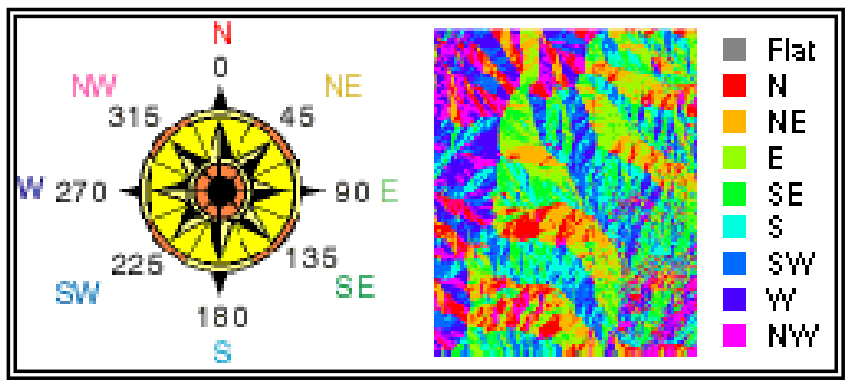

Figura 1.42. Compás de direcciones para la creación del mapa de orientaciones. Fuente: I.C.V. 


\subsubsection{Mapas de soleamiento}

Se trata también de unos datos interesantes dado que la mayor o menor incidencia del Sol en el terreno puede resultar determinante a la hora de tomar la decisión de ubicar en determinado lugar cierto elemento o dedicarlo a un uso determinado.

Los mapas de soleamiento se calculan para un determinado azimut del sol, y cierto ángulo de incidencia. En el caso que se muestra en la figura 1.31 se ha orientado el sol a $180^{\circ}$, hacia el sur, y el ángulo de incidencia es de $45^{\circ}$.

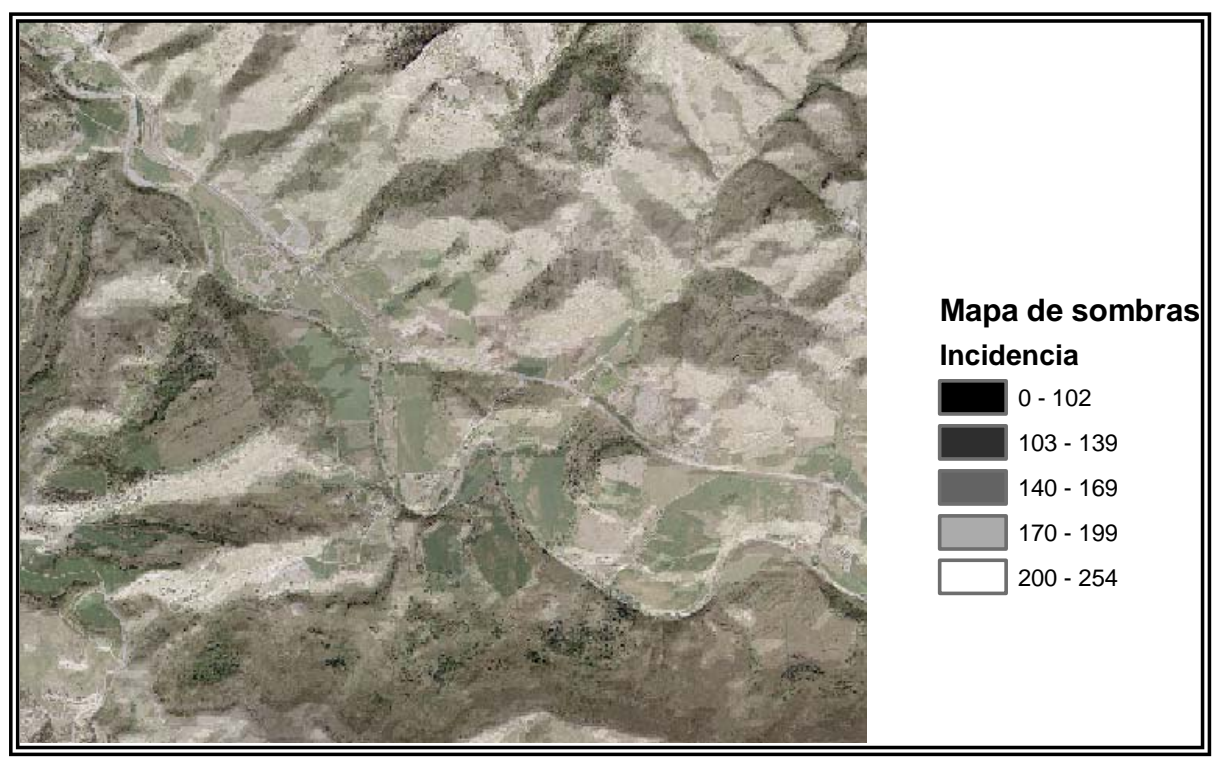

Figura 1.43. Mapa de soleamiento para estudios de paisaje. Fuente: I.C.V.

Para la asignación de cierto valor a una determinada celda se calcula la hipotética luz que llega a la citada celda, para un determinado azimut y elevación del sol.

Una vez realizado el cálculo sobre el MDT, podemos discriminar las celdas por el valor obtenido. Cuanto más grande sea el valor, mayor sombra tiene.

En las figuras 1.44.a. y 1.44.b. vemos un ejemplo de las zonas de sombra generadas.
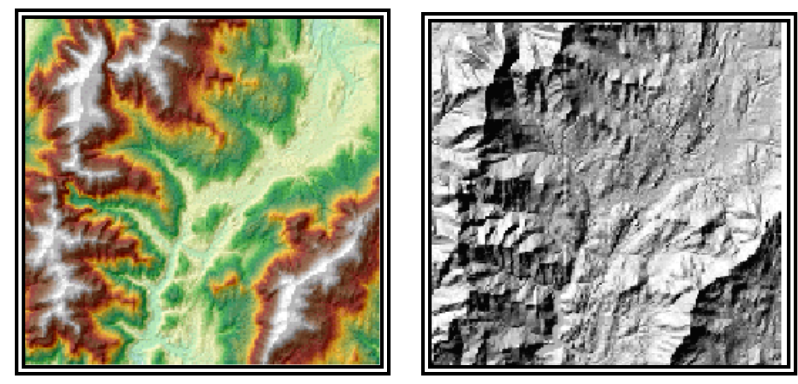

Figuras 1.44.a. y 1.44.b.. Zonas de sombra generadas para la creación del mapa de soleamiento.

Color (izquierda)

Escala de grises (derecha)

Fuente: I.C.V. 


\subsubsection{Mapas de Visibilidad}

Por último veremos los mapas de visibilidad, que resultan imprescindibles cuando tratamos temas relacionados con el paisaje, dado el alto valor que se otorga a la componente estética del mismo.

Los mapas de visibilidad nos permiten saber qué zonas del territorio son visibles desde un determinado punto del terreno.

A partir de esta información se pueden generar dos tipos de mapas, de visibilidad absoluta y de visibilidad relativa.

La visibilidad absoluta nos indica, para cada punto del terreno si es visible o no desde el punto o los puntos de observación. En la figura 1.45 se muestra un ejemplo donde se ha tomado como puntos de observación cada uno de los nodos que componen el tramo de carretera marcado en color rojo. El resultado se ha superpuesto sobre la ortofoto para que resulte más clara la interpretación del mapa final.

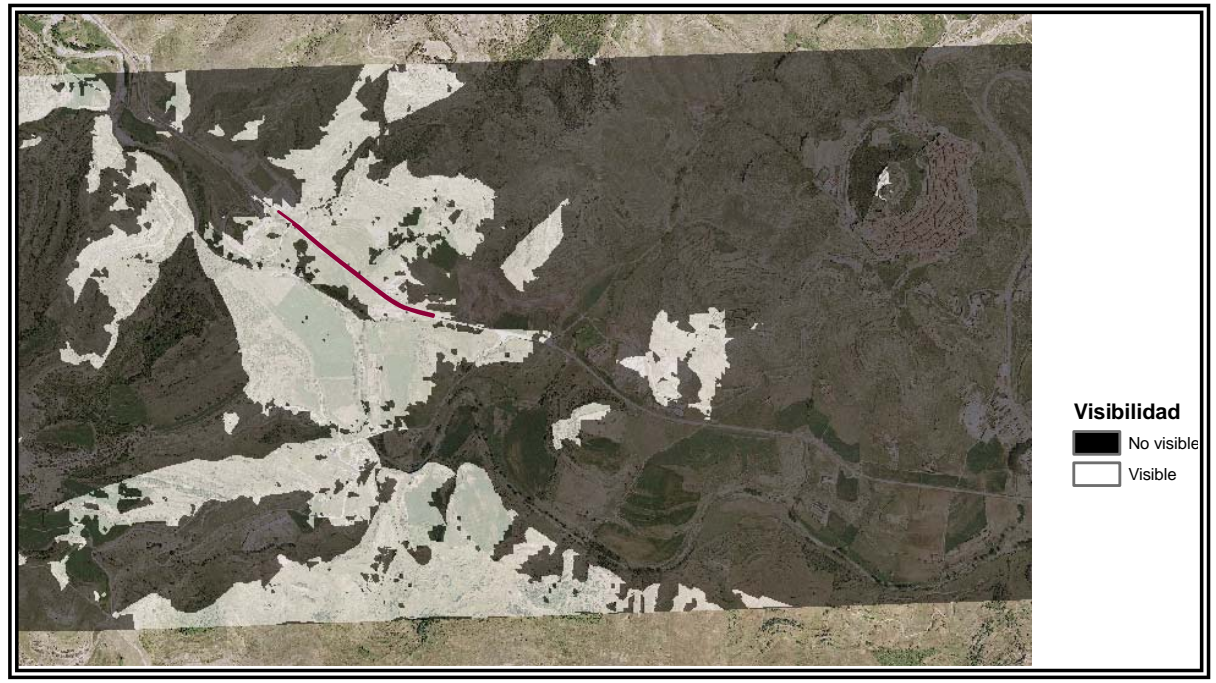

Figura 1.45. Mapa visibilidad absoluta para estudios de paisaje. Fuente: I.C.V.

En lo que se refiere al mapa de visibilidad relativo, el resultado es un mapa distribuido por rangos, siendo cada valor, un sumatorio resultante de un mapa de visibilidad para cada nodo de la carretera. Como en total hay 32 nodos, si un punto es visible desde todos, el valor será 32, y viceversa, si un punto no es visible desde ningún nodo, su valor será 0 . Habrá otros puntos del terreno que serán vistos desde sólo unos nodos de la carretera, luego su valor será el número de nodos desde el cual es visible. $\mathrm{Al}$ igual que se ha hecho para el mapa de visibilidad absoluta, se ha superpuesto el resultado sobre la ortofoto. El mapa resultante se muestra en la figura 1.46. 


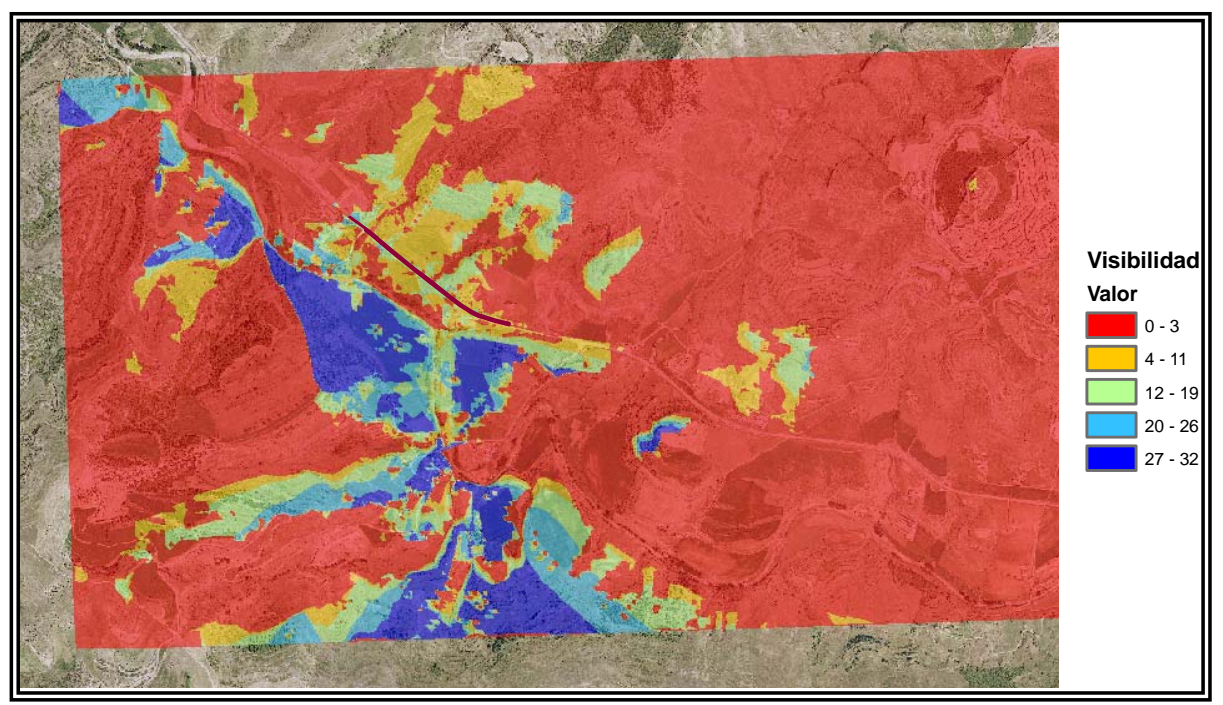

Figura 1.46. Mapa visibilidad relativa para estudios de paisaje. Fuente: I.C.V.

Para calcular estos mapas nos centraremos en la idea de descubrir qué celdas de un modelo digital del terreno en formato raster son visibles desde uno o varios puntos de observación.

En la figura 1.47 se expone la sistemática de cálculo que realiza automáticamente el software ARCGIS utilizado para la generación de todos los mapas comentados en este apartado.

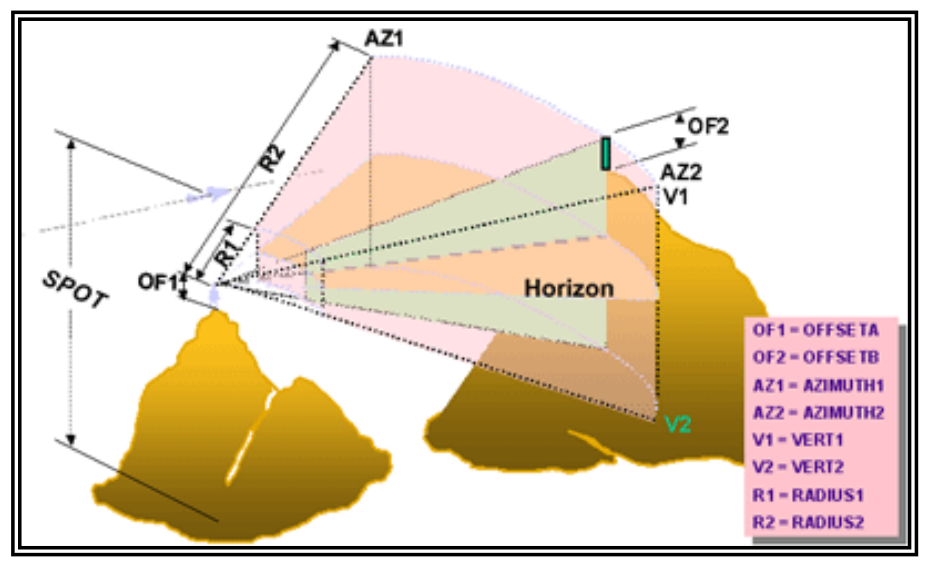

Figura 1.47. Generación de mapas de visibilidad. Fuente: I.C.V. 


\subsubsection{Comparativa}

A continuación vamos a realizar una comparativa de los diferentes mapas que genera el Instituto Cartográfico Valenciano (I.C.V.) para la realización de los estudios de paisaje. Para esto se han realizado los diferentes estudios de una misma zona, en este caso Morella.

En primer lugar se presenta, en la figura 1.48., una vista $3 \mathrm{D}$ en la que se marcan en color azul los puntos desde los que posteriormente se realizará el estudio de visibilidad. Esta vista está conseguida a partir de MDE y la ortofoto de la zona y es el producto más vistoso; y aunque su utilidad a la hora de realizar un análisis puede parecer menor que la de otros elementos, sí resulta úlil porque ofrece una visión "casi”" real de la zona.

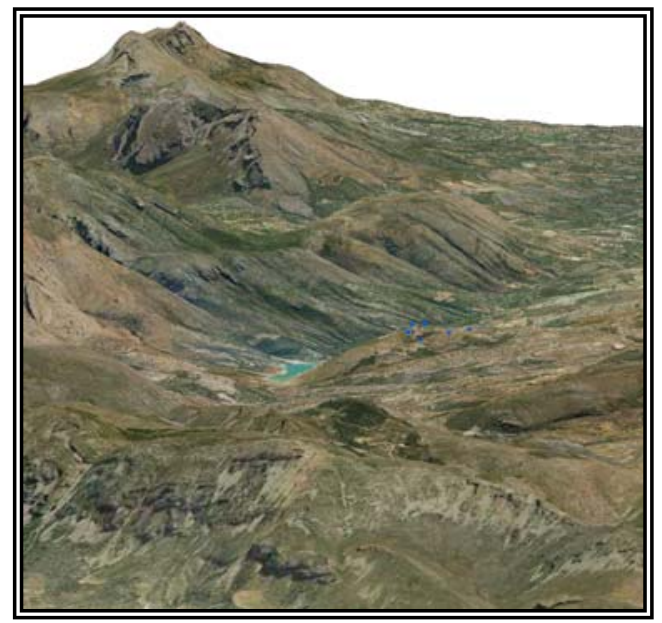

Figura 1.48. Escena 3D a partir de MDE y Ortofoto.

Fuente: I.C.V

A continuación se muestra, en la figura 1.49., una vista 3D sobre la que se ha superpuesto el mapa de pendientes obtenido como se ha explicado en el apartado anterior. En la figura 1.50 se acompaña la leyenda.

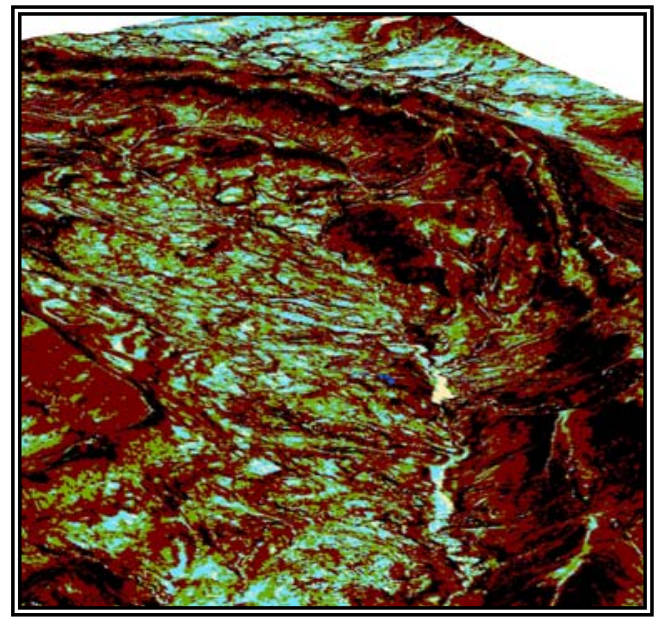

Figura 1.49. (Izquierda) Escena 3D a partir de MDE y Mapa de pendientes.

Fuente: I.C.V.

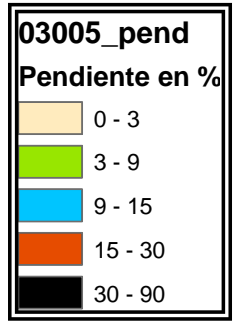

Figura 1.50. (Arriba) Leyenda de la figura 1.36. Fuente: I.C.V. 
Seguidamente vemos en la figura 1.51 una vista 3D sobre la que se ha superpuesto el mapa de orientaciones. En la figura 1.52 se muestra la leyenda.

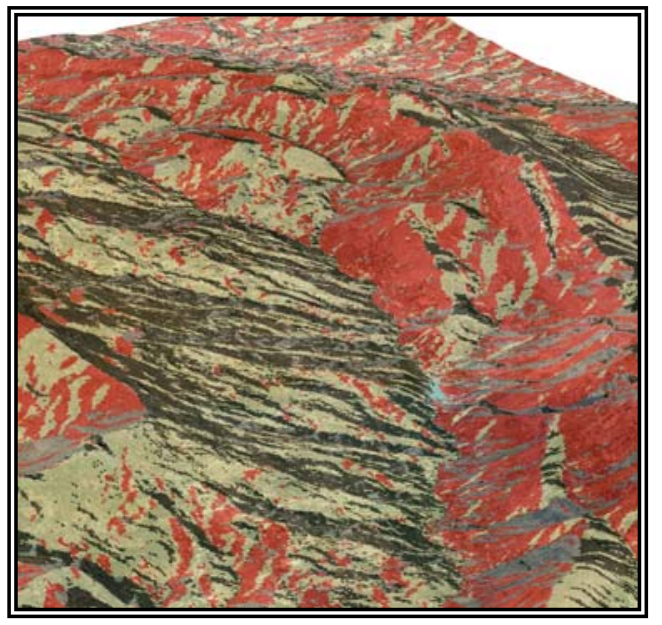

Figura 1.51. (Izquierda) Escena 3D a partir de MDE y Mapa de orientaciones.

Fuente: I.C.V.

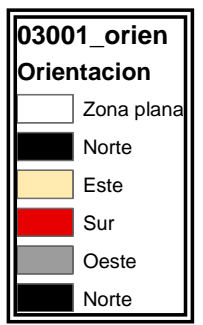

Figura 1.52. (Arriba) Leyenda de la figura 1.38. Fuente: I.C.V.

En la figura 1.40. podemos ver el mapa de sombras o soleamiento, que se ha obtenido simulando una situación del Sol a $315^{\circ}$ de azimut y $45^{\circ}$ de elevación, se trata de una posición irreal, pero que ofrece una muy buena apreciación del relieve.

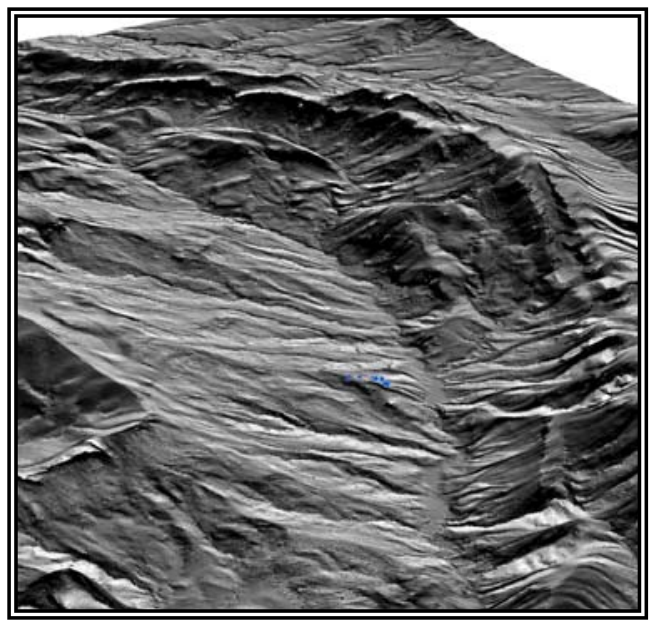

Figura 1.53. Escena 3D a partir de MDE y Mapa de sombras.

Fuente: I.C.V.

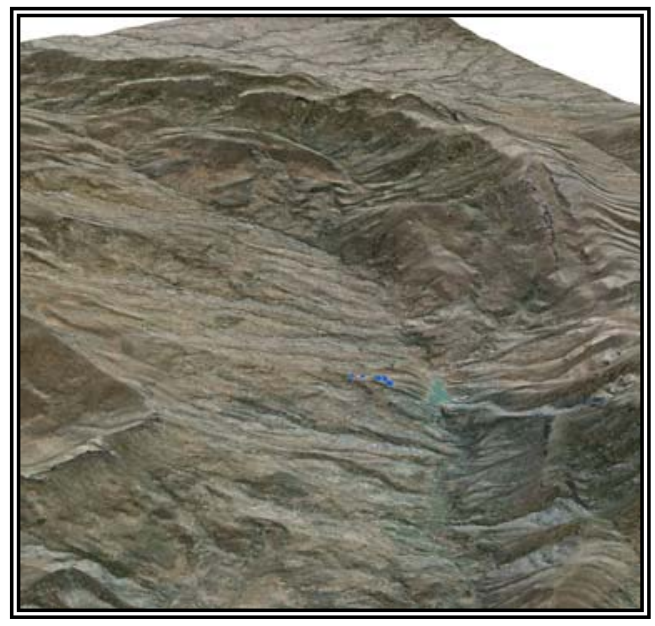

Figura 1.54. . Escena 3D a partir de MDE y Mapa de sombras con superposición de Ortofoto.

Fuente: I.C.V. 
Echemos un vistazo a la figura 1.53., donde vemos el mismo mapa de sombras que en la figura 1.54 pero con la ortofoto superpuesta. Esta combinación ofrece una fuerte sensación de realidad.

Y por último se presentan una serie de vistas en las que se aprecia el mapa de visibilidad desde diferentes puntos de vista, superpuesto sobre la ortofoto. En rojo se marcan los puntos de la carretera de los cuales se ha realizado el estudio y las zonas visibles desde estos puntos tienen un mayor brillo de la ortofoto. (Figuras 1.55., 1.56., 1.57. y 1.58.)

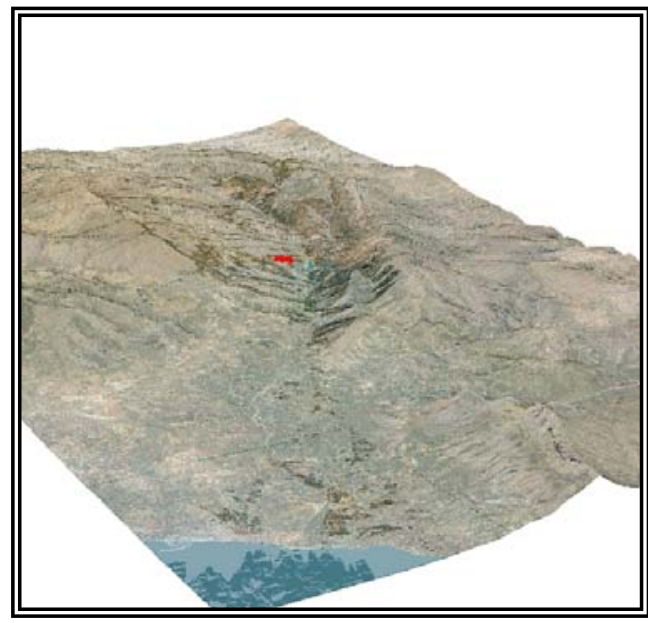

Figuras 1.55. y 1.57.. (Arriba y Abajo) .Escenas 3D a partir de MDE y Mapa de visibilidad con superposición de Ortofoto.

Fuente: I.C.V.

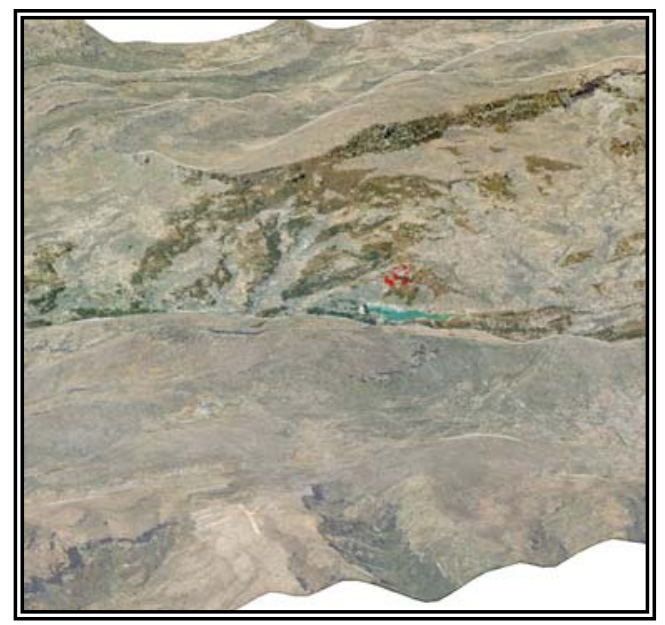

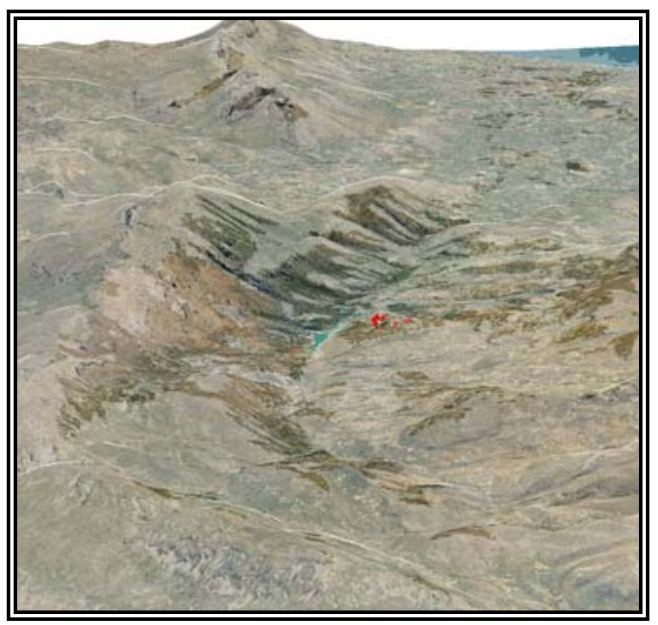

Figuras 1.56. y 1.58.. (Arriba y Abajo). Escena 3D a partir de MDE y Mapa de visibilidad con superposición de Ortofoto.

Fuente: I.C.V.

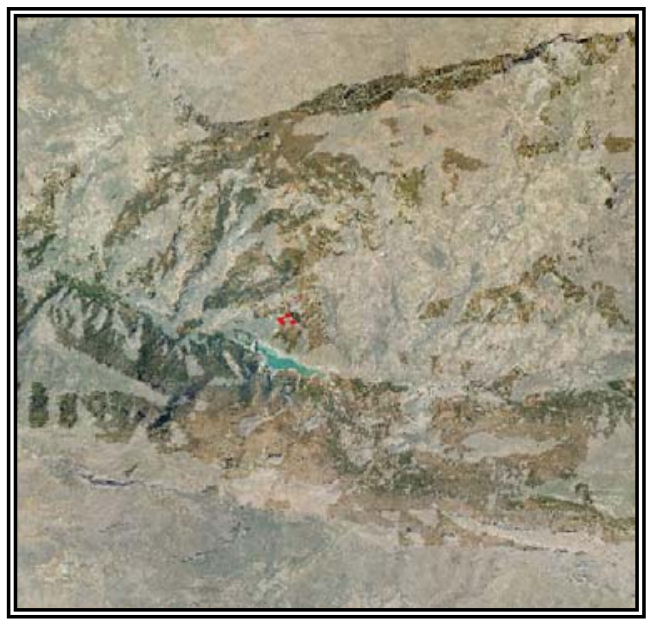




\subsubsection{Base cartográfica}

Anteriormente hemos hecho referencia a la importancia de disponer de una buena base cartográfica sobre la que plasmar toda la información necesaria para abordar las tareas de Planeamiento o Gestión Territorial. Resulta imprescindible, si queremos que los resultados sean lo más fiables posible, que la cartografía básica o georeferencial tenga la precisión suficiente de acuerdo con los fines que persigamos. Y es aquí donde se plantea el primer problema, que pasa por averiguar qué tipo de cartografía base resultará necesaria y dónde se puede conseguir. Este último punto es el que plantea los mayores problemas, ya que la generación de cartografía es un proceso muy costoso y la existente puede no adecuarse a nuestras necesidades.

Esta cartografía base estará constituida por un conjunto de datos vectoriales procedentes de toma de datos de campo, obtenidos por cualquiera de los métodos habituales, generalmente fotogrametría aérea; así como mapas resultantes de procesar estos datos básicos, como son: mapas de pendientes, mapas de orientaciones, mapas de visibilidad.... Actualmente se está imponiendo de tal manera la utilización de ortofotos que quizá deberíamos incluirlas también en este nivel básico de información.

Sobre esta cartografía base iremos materializando el resto de la información, que como mínimo deberá permitirnos generar: mapas de usos del suelo y vegetación, mapas geológicos, mapas de Ordenación Territorial, mapas de riesgos y afecciones, mapas de aptitud edáfica, mapas de clasificación del suelo, mapas de espacios de especial protección, mapas de clasificación del paisaje, mapas climáticos, mapas hidrológicos, mapas y planos de equipamientos, mapas y planos de infraestructuras, planos de alineaciones, planos de calificación del suelo, etc.

\subsubsection{El Dato Único Territorial}

Uno de los principales problemas que se plantean a la hora de realizar estudios de análisis territorial es la multiplicidad de datos, por ello un elemento esencial es la base del "Dato Único Territorial" que marcará las referencias comunes en la producción cartográfica, permitiendo la obtención de una información del territorio eficiente. De esta manera, podrá trabajarse con cualquiera de los mapas sin problemas para la superposición entre ellos.

Para conseguir esto resulta necesario en primer lugar realizar un análisis detallado de todas y cada una de las determinaciones que se emplean en el Análisis Territorial, definirlas unívocamente y plantearse su expresión. Igualmente supone plantearse la agrupación lógica de estas determinaciones y la simplificación de su expresión a través de modelos tipológicos. Esta norma será la clave para lograr la homogeneidad de datos entre distintos trabajos, pero además debe diseñarse pensando en general en la expresión y necesidades de cualquier tipo de planificación física sobre el territorio.

\subsubsection{Escalas necesarias}

Resulta ser este un punto de vital importancia, ya que en función de la precisión que exijamos a la cartografía deberemos poder contar con información a una u otra escala, y el factor escala es determinante a la hora sobre todo de tener en cuenta la inversión económica a 
realizar. Es obvio que la escala deberá estar en consonancia con el tipo de trabajo a efectuar. No debemos olvidar que aunque las modernas técnicas informáticas nos permiten ampliar la cartografía hasta límites prácticamente infinitos, se trata de una ampliación virtual, ya que si una cartografía ha sido ejecutada a una determinada escala, ésta definirá su precisión, la precisión con que fueron tomados los datos de campo.

Teniendo esto en consideración y una vez acotadas las zonas de actuación, veremos que generalmente deberemos distinguir entre tres escalas muy diferenciadas, según estemos hablando de Planeamiento Urbano, Gestión Territorial o Mapas de Síntesis:

- Planeamiento Urbano. Para el que se utilizan escalas grandes, 1/1.000 1/1500 o incluso 1/2.000. Permiten representar elementos más o menos pequeños con una buena precisión métrica y las utilizaremos para reflejar la calificación del suelo, estado de alineaciones, redes de servicios públicos, mobiliario urbano, etc.

- Gestión Territorial. Las escalas medias 1/10.000 ó 1/20.000 son las ideales para llevar a cabo estudios de territorio, en los que deberemos plasmar elementos de tamaño medio y que nos debe permitir tener una visión global de una mayor extensión de territorio.

- Mapas de síntesis. Para los cuales utilizaremos las escalas más pequeñas como $1 / 50.000$ o incluso menores. Se trata de mapas que permiten la representación de toda una comarca o zona de mayor extensión.

Aún llegados a este punto, no existe ningún tipo de norma, escrita o no, que nos indique la escala más apropiada para la realización de nuestros trabajos.

Como se ha comentado cada Comunidad Autónoma tiene competencias para generar el tipo de cartografía que considere más conveniente.

\subsubsection{Formatos}

\subsubsection{Formatos papel}

Aunque el tratamiento de la cartografía actualmente se realiza totalmente en formato digital, es práctica común poder disponer de esa cartografía en formato papel, sobre todo porque las personas que tienen que tomar decisiones políticas basándose en esa cartografía no suelen conocer los programas informáticos utilizados para su tratamiento y se encuentran más cómodos ante un mapa o plano en formato papel.

Son múltiples los formatos que podemos encontrar, dependiendo de la escala y de la magnitud de la zona a representar. Deberemos tener presente que no podremos generar una cartografía con una escala mayor que la escala para la que fueron tomados los datos. Esto es, si los datos se tomaron por ejemplo para realizar una cartografía a escala 1:10.000, no podremos generar una cartografía a escala 1:5.000, porque no tendrá la precisión que se le debería suponer. Esto que en apariencia parece de una lógica aplastante, resulta ser un error que se produce con más frecuencia de la deseada, dada la facilidad de aumentar la imagen cuando se trabaja en formato digital. Sin embargo, sí podríamos realizar el proceso inverso, es decir generar un mapa a escala 1:10.000 a partir de una cartografía a escala 1:5.000, tan sólo sería necesario un proceso de generalización para evitar la superabundancia de información.

Existen unos formatos normalizados que se comentan a continuación y que suelen ser los utilizados para generar la Cartografía Oficial. 
- A4. (210 x $297 \mathrm{~mm}$.). Es un formato poco utilizado, ya que solamente la información anexa a la cartografía, leyenda, nombre del mapa, datos de la proyección, escala, etc., ocupan un espacio que la mayoría de las veces es mayor que el ofrecido por el formato A4. Por otro lado, si lo que nos interesa es exclusivamente la información cartográfica, es un formato muy cómodo, aunque a este resultado no le podamos denominar estrictamente como Cartografía.

- A3. (297 x $420 \mathrm{~mm}$.). Quizá su uso es mayor que el del anterior formato, pero no resulta tampoco demasiado usual por la misma razón anteriormente descrita, aunque al tratarse del doble de superficie, hay ocasiones en que resulta útil por su manejabilidad.

- A2. (420 x 594 mm.). Empieza a ser éste ya un formato frecuentemente utilizado, aunque para representar grandes extensiones de terreno resulte todavía un formato excesivamente reducido si queremos apreciar algunos detalles y siempre por supuesto dependiendo de la escala de representación.

- A1. (594 x 841 mm.). Se trata de uno de los formatos más utilizados, si no el que más, porque se combina el hecho de que es relativamente manejable con el de que en él se puede representar ya una porción de cartografía considerablemente grande.

- A0. (841 x $1189 \mathrm{~mm}$.). Es el mayor de los formatos normalizados, y aunque puede contener la mayor extensión de territorio de todos los formatos, su manejo resulta excesivamente engorroso dadas sus grandes dimensiones. Así y todo es en muchas ocasiones la única solución posible para representar una porción de territorio a la escala deseada.

\subsubsection{Formatos digitales}

Son muchos los formatos en los que podemos encontrar la cartografía si solamente somos usuarios de la misma, si además queremos gestionarla, el abanico se reduce, pero vamos a estudiar cuáles son estos formatos:

- DXF. Se trata del formato de intercambio de CAD más utilizado y el idóneo si se dispone para trabajar de programas como AutoCad o MicroStation.

- DGN. Es el formato propio de Microstation, este programa es uno de los CADs de uso más común y que gestiona archivos de tamaño considerablemente más pequeño que AutoCAD, para trabajar con el mismo volumen de información.

- DWG. Es el formato de intercambio de AutoCAD, otro de los CADs de uso más extendido. Este formato además lo entienden otros programas aparte de AutoCAD.

- SHP. Es el formato de capas propio de ESRI Shapefile (SHP). Es un formato propietario abierto de datos espaciales desarrollado por la compañía ESRI, quien desarrolla y comercializa software para Sistemas de Información Geográfica como Arc/Info o ArcGIS. Originalmente se creó para la utilización con su producto ArcView GIS, pero actualmente se ha convertido en formato estándar de facto por la importancia que los productos ESRI tienen en el mercado SIG. Un Shapefile es un formato vectorial de almacenamiento digital donde se guarda la localización de los elementos geográficos y los atributos asociados a ellos. El formato carece de capacidad para almacenar información topológica. Cada capa del modelo está descrita en 3 ficheros: .SHP, .SHX y .DBF. En los dos primeros se describe la geometría y el 
tercero es un fichero de dBASEIII con atributos. La estructura de campos de estos ficheros viene en la cabecera de los mismos. Además puede haber otros ficheros con índices. Cada tipo de objeto (parcelas, elementos lineales, etc) se descarga en una capa (conjunto de 3 ficheros) diferente.

- GIF. El formato GIF, propietario de CompuServe, corresponde a las siglas de Graphics Interchange Format. Es el formato más utilizado para mostrar gráficos de colores indexados e imágenes en documentos HTML (hypertext markup language) sobre World Wide Web y otros servicios online. Gif es un formato de imágenes comprimidas. Este formato permite visualizar la cartografía sin disponer de ningún programa profesional ni plug-ins. Se deben incorporar ficheros de georreferenciación, para conservar la cartografía con sus coordenadas correctas. Además este formato permite introducir animaciones.

- PDF. No se trata de un formato específico para ver cartografía, pero para los profanos puede resultar útil disponer de los mapas o planos en este formato, que permite con Acrobat Reader, programa gratuito, visualizar e imprimir. Debe tenerse especial cuidado con la escala del mapa a la hora de imprimir si no se quiere falsear la misma. Se basa en el lenguaje PostScript de nivel 2, pudiendo representar gráficos vectoriales y bitmaps.

- TIFF. Formato de imágenes muy utilizado, el formato TIFF, que corresponde a las siglas Tagged-Image File Format (formato de archivo de imágenes con etiquetas), se utiliza para intercambiar archivos entre distintas aplicaciones. El formato TIFF soporta la compresión LZW, que es un método de compresión con menor pérdida.

- JPG. Abreviatura de JPEG, uno de los formatos de imagen más utilizados por ofrecer una buena calidad con un tamaño reducido. El JPEG (Joint Photographic Experts Group) es el formato que se utiliza comúnmente para almacenar fotografías y otras imágenes de tono continuo, y también se utiliza en documentos HTML para Internet. A diferencia del formato GIF, JPEG guarda toda la información referente al color en RGB. JPEG también utiliza un sistema de compresión, que de forma eficiente reduce el tamaño de los archivos mediante la identificación y el descarte de los datos redundantes que no son esenciales para mostrar la imagen, esto supone que habrá una pérdida de información, tanto mayor como mayor sea la compresión realizada.

- BMP. Es un formato estándar de Windows y esto hace que a pesar del gran tamaño de los archivos se utilice con cierta frecuencia.

- PCX. Es también un formato estándar de Windows y esto hace que se utilice con frecuencia, aunque menos que el formato BMP.

- E00. Se trata de un fichero de Importación/Exportación de la empresa ESRI.

- LAN. Es un formato que contiene una imagen continua del programa ERDAS.

- GIS. Es un formato que contiene una imagen temática del programa ERDAS.

- IMG. Es un fichero de imagen que soportan varios programas, entre ellos ERDAS. 


\subsection{Estudio de la información existente en materia de normalización cartográfica}

Como cualquier otra disciplina, la Cartografía cuenta con una ley que la ordena a nivel estatal. Algunas comunidades autónomas gozan a su vez de organismos y legislaciones específicas en materia cartográfica, a continuación se reseñan algunas de ellas.

\subsubsection{Ley de Ordenación de la Cartografía}

La Ley 7/1986, de 24 de enero de Ordenación de la Cartografía surge para dar solución al problema del desarrollo, de manera concurrente y en ocasiones inconexa, de trabajos de cartografía; dado que se comprobó que existía dispersión e incluso duplicidad de los recursos públicos destinados a este tipo de actuaciones.

Se clasifica la cartografía oficial como básica, derivada y temática. Y se incluyen dentro de aquellas funciones de servicio público general a la cartografía básica y a la derivada en aquellas series que bayan de cubrir todo el territorio nacional. Se responsabiliza a la administración del Estado de la producción del mapa topográfico nacional a escalas 1:25.000 y 1:50.000 y a otras escalas que en el futuro se determinen por Real Decreto, previendo, tanto para estas series cartográficas de alcance nacional como para el resto de la cartografía realizada por las distintas administraciones públicas, que la ejecución de los correspondientes trabajos pueda llevarse a cabo mediante fórmulas de cooperación entre las mismas. Al servicio de los fines de coordinación perseguidos por la Ley se crean dos importantes instrumentos: el registro central de cartografía y el plan cartográfico nacional.

Resultan interesantes los artículos 3, 4 y 5 donde se expone la clasificación de la Cartografía:

- Cartografía básica. Aquella que se realiza de acuerdo con una norma cartográfica establecida por la Administración del Estado, y se obtiene por procesos directos de observación y medición de la superficie terrestre. La norma cartográfica será establecida por Orden del Ministro de la Presidencia, tratándose de cartografía terrestre, o por Orden del Ministro de Defensa, en el caso de cartografía náutica.

o La norma cartográfica correspondiente a cada serie cartográfica especificará necesariamente el datum de referencia de las redes geodésica y de nivelación, el sistema de proyección cartográfica y el sistema de referencia de hojas, para la cartografía terrestre y, además, por lo que respecta a la náutica, el datum bidrográfico al que estén referidas las sondas.

- La norma cartográfica contendrá cuantas especificaciones técnicas sobre el proceso de formación del mapa sean necesarias para garantizar que éste refleja la configuración de la superficie terrestre con la máxima fidelidad posible según los conocimientos científicos y técnicos de cada momento.

- La cartografía básica será objeto de aprobación oficial, a propuesta del consejo superior geográfico, por el mismo órgano de la Administración del Estado competente para establecer la norma aplicable.

- Cartografía derivada. Es la que se forma por procesos de adición o generalización de la información topográfica contenida en cartografía básica preexistente.

- La Administración del Estado establecerá la norma geográfica a que habrá de atenerse la formación de cartografía derivada para las series que hayan de cubrir todo el territorio 
nacional. El establecimiento de dicha norma se hará por Orden del Ministro de la Presidencia, si se trata de cartografía terrestre, o por Orden del Ministro de Defensa, si se trata de cartografía náutica.

- La cartografía correspondiente a estas series nacionales será objeto de aprobación por el procedimiento establecido en el apartado cuarto del artículo anterior.

- Cartografía temática. Utilizando como soporte cartografía básica o derivada, singulariza o desarrolla algún aspecto concreto de la información topográfica contenida en aquellas, o incorpora información adicional especifica.

- Los organismos públicos responsables de la realización y publicación de cartografía temática establecerán sus propias normas cartográficas, sin perjuicio de que puedan recabar para tal fin el asesoramiento del Consejo Superior Geográfico.

- La cartografía temática sólo será objeto de inscripción obligatoria en el Registro Central de Cartografía en los supuestos en que, por razones de interés nacional, asi lo acuerde el Ministro de la Presidencia, previos el informe del Consejo Superior Geográfico y, tratándose de cartografia temática militar, la aprobación del Ministro de Defensa.

Como ya se ha mencionado, esta ley dispone la creación del Registro Central de Cartografía, de ésta se habla en el Artículo 7. [...] 2. Todas las producciones de cartografía básica y de cartografía derivada correspondiente a series nacionales, realizadas por las distintas administraciones públicas, serán presentadas, una vez aprobadas, para su inscripción en el Registro Central de Cartografía. 3. La cartografía oficial registrada será de uso obligado por todas las administraciones públicas para la formación de nueva cartografía derivada o temática. 4. En el Registro Central de Cartografía se inscribirán, igualmente, las delimitaciones territoriales establecidas y sus variaciones, acordadas por las administraciones competentes. Corresponde asimismo al Registro Central de Cartografía la formación y conservación del nomenclátor geográfico nacional en el que se registrarán las denominaciones oficiales de las comunidades autónomas, las provincias, las islas, los municipios, las entidades de población y formaciones geográficas, así como sus variaciones, debidamente aprobadas [...].

\subsubsection{Situación en la Comunidad Valenciana}

En la Comunidad Valenciana no existe una legislación específica en materia de Cartografía, las competencias cartográficas de la administración autonómica están recogidas, en el artículo 7 de la Ley 7/1986 de Ordenación de la Cartografía a la que se ha hecho mención en el apartado anterior, y se apoya en la potestad de regulación y organización que se recoge en los artículos 22 y 25 de la Ley 5/1983 del Gobierno Valenciano.

Articulo 22

Las funciones del Consell en materia normativa se concretan en las siguientes competencias:

a. Proponer a las Cortes Valencianas la reforma del Estatuto de Autonomía de la Comunidad Valenciana.

b. La iniciativa legislativa, mediante la aprobación de los proyectos de ley para su remisión a las Cortes $V$ alencianas acompañados de una exposición de motivos y de los antecedentes necesarios para poder pronunciarse sobre ellos. El Consell podrá retirar el proyecto de ley en cualquier momento de su tramitación ante las Cortes V alencianas, siempre que no bubiera recaido acuerdo final de éstas. 
c. La facultad de dictar decretos legislativos en los términos y con las formalidades previstas en la presente ley. Para el control de esta legislación delegada por las Cortes Valencianas, se estará a lo dispuesto por su reglamento.

d. La elaboración de los proyectos de ley de presupuestos de la Generalitat Valenciana para ser presentados a las Cortes Valencianas al menos con dos meses de entelación al comienzo del correspondiente ejercicio. A esta competencia se añaden las demás facultades estatutarias en materia presupuestaria.

e. Ejercer la potestad reglamentaria de la Comunidad Autónoma, de acuerdo con la Constitución, el Estatuto de Autonomía y las Leyes.

f. Emitir Deuda Pública para gastos de inversión, previo acuerdo de las Cortes V alencianas.

Artículo 25

Corresponde al Consell o Gobierno Valenciano el ejercicio de las competencias estatutarias y legales de carácter ejecutivo y reglamentario que vengan atribuidas a la Generalidad o a la Comunidad Valenciana y no estén expresamente atribuidas a otros órganos o instituciones de las mismas.

La única ley relacionada con la Cartografía es la ley 9/1997, de 9 de diciembre, de Creación del Instituto Cartográfico Valenciano. Que se crea, como dice el Artículo 1 con el objetivo de impulsar, coordinar y, en su caso, fomentar las tareas de desarrollo cartográfico, fotogramétrico, geodésico, topográfico y de cualquier otra tecnología geográfica en el ámbito de las competencias de la Generalitat.

\subsubsection{Plan cartográfico de Castilla y León}

El decreto por el que se aprobó el Plan Cartográfico de Castilla y León es del 8 de mayo de 2003, en este mismo decreto se crea el Sistema de Información Territorial de Castilla y León. (B.O.C.yL. $\mathrm{n}^{\circ}$ 90, de 14 de mayo de 2003). En este decreto se manifiesta la importancia de disponer de una cartografía actualizada y de calidad con una base única y es muy similar a la Ley anteriormente comentada.

Resulta reseñable el hecho de que se defina una serie cartográfica oficial básica territorial, de acceso gratuito para todos los usuarios y de utilización obligatoria por los sectores público y privado en todos sus trabajos que tengan una referencia territorial.

De este decreto merece la pena reseñar los Artículos 3 y 4 donde se clasifica la cartografía oficial, y se hace de la siguiente forma ${ }^{152}$ :

- Básica. Es aquella que, realizada de acuerdo con las normas cartográficas, se obtiene por procesos directos de observación y medición de la superficie terrestre. Sirve de base y referencia, y será de uso común generalizado y obligatorio para la representación gráfica del territorio de la Comunidad.

- La cartografía básica regional estará formada por las series a escala 1/25.000 y 1/50.000 que constituyen el mapa topográfico nacional, y corresponde su producción y aprobación oficial a la Administración del Estado, a propuesta del Consejo Superior Geográfico, y será inscrita en el Registro Central de Cartografía.

- La cartografía básica oficial territorial y urbana de Castilla y León será aquélla que esté inscrita como tal en el Registro Regional de Cartografía. Para su inscripción deberá haberse realizado de acuerdo a las Normas Cartográficas. Será de uso obligado por las Administraciones Públicas y por los particulares en sus relaciones con éstas, para la

152 Junta de Castilla y León. “B.O.C.yL”, 2003. 
representación gráfica a escala territorial y urbana de cualquier actividad que se desarrolle sobre el territorio de Castilla y León, así como para la formación de nueva cartografía derivada o temática.

- Derivada. Es la que se forma por procesos de adición o generalización de la información topográfica contenida en la cartografía básica.

- Temática. Es la que, utilizando como soporte cartografía básica o derivada, singulariza o desarrolla algún aspecto concreto de la información topográfica o incorpora información adicional específica.

Es en el anexo I de este decreto donde se describe el Plan Cartográfico de Castilla y León, que es un documento destinado a atender las necesidades cartográficas de las distintas administraciones y ciudadanos en general, en el ámbito territorial de la Comunidad de Castilla y León.

En este documento se habla del Registro Regional de Cartografía, organismo encargado de la inscripción de la cartografía oficial de la Comunidad de Castilla y León, a excepción de las series nacionales.

Se expone asimismo toda la cartografía que en el momento de su redacción se consideraba oficial, distinguiendo entre cartografía básica y cartografía temática. Y se expone cómo debe generarse la cartografía oficial, aunque no se menciona nada acerca de la normalización en lo que se refiere a formatos, simbología, etc., cuestiones que realmente nos interesan.

\subsubsection{Normas cartográficas ambientales de Andalucía}

El 13 de febrero de 2001, la Consejería de Medio Ambiente de la Comunidad Autónoma de Andalucía publicó unos criterios técnicos para la creación de información ambiental con el objetivo de que estos criterios sean tenidos en cuenta siempre que se acometa en esta Comunidad Autónoma un trabajo que implique directa o indirectamente el levantamiento de información ambiental en soporte digital, ya sea para un trabajo de realización interna, ya sea objeto de una contratación externa.

Con esto se pretende minimizar la duplicidad de información que en muchas ocasiones se produce en la administración pública. Para ello se tratará de integrar toda la información en una misma red a la que tengan acceso todas las administraciones.

Esta Comunidad Autónoma asume como oficiales tres bases de referencia territoriales diferentes correspondientes a tres niveles de escala de representación. Dependiendo del nivel de detalle del trabajo se usará una de las siguientes bases de referencia ${ }^{153}$ :

- Nivel de Reconocimiento Territorial: Para trabajos realizados a escalas inferiores a 1:100.000 se empleará como base de referencia el Mapa Topográfico Digital 1:100.000 de Andalucía, generado por la Consejería de Obras Públicas y Transportes y la ortoimagen digital de satélite Landsat-TM generada por la Consejería de Medio Ambiente.

- Nivel de Semidetalle Regional: Para trabajos realizados a escalas entre 1:100.000 y 1:50.000 se utilizará como base el Mapa Topográfico Nacional a escala 1:50.000 Serie L editado por el Servicio Geográfico del Ejército y la ortoimagen de satélite IRS-P AN generada por la Consejería de Medio Ambiente.

153 Junta de Andalucía. Consejería de Medio Ambiente. www.juntadeandalucia.es. 
- Nivel de Detalle: Para trabajos realizados a escalas superiores a 1:50.000 se utilizará el Mapa Topográfico de Andalucía a escala 1:10.000 realizado por el Instituto Cartográfico de Andalucia, así como la ortoimagen de satélite IRS-PAN generada por la Consejería de Medio Ambiente.

\subsubsection{Reglas de normalización cartográfica para Canarias}

Con fecha 1 de julio de 1994 la Consejería de Política Territorial del Gobierno de Canarias, mediante el Decreto 125/1994, crea el Consejo Cartográfico de Canarias y se dictan reglas de normalización cartográfica para la citada comunidad.

El Consejo Cartográfico de Canarias se crea como instrumento básico de planificación, asesoramiento y coordinación en materia cartográfica, en el ámbito de la Comunidad Autónoma de Canarias. Serán de su competencia, entre otras, las funciones de: realización de los estudios destinados a determinar las necesidades cartográficas de las Administraciones Públicas canarias; elaboración y promoción de las normas cartográficas; creación del Registro Regional de Cartografía; centralización de las actividades cartográficas y difusión de la información cartográfica.

En lo que a la normalización cartográfica se refiere, los artículos 9 y 10 rezan como sigue:

Articulo 9.- De la gestión cartográfica.

1. El seguimiento y verificación de los trabajos cartográficos que se realicen por cualquiera de las Administraciones Públicas canarias, corresponderán a la Consejería de Política Territorial.

2. Los distintos órganos de la Administración Pública canaria no admitirán a trámite ningún expediente administrativo que utilice cartografia sin adaptarse a las condiciones de normalización y control establecidos por el Consejo Cartográfico de Canarias.

3. Los presupuestos y programas de inversiones de las Administraciones Públicas canarias que contengan recursos destinados a producción cartográfica, no podrán incluir proyectos que no estén previamente informados por el Consejo Cartográfico de Canarias o previstos en el Plan Cartográfico Regional.

4. La utilización de base cartográfica normalizada será de obligatoria observancia en los instrumentos de Planeamiento Urbanístico Territorial y de la Red Canaria de Espacios Naturales Protegidos, con independencia del carácter público o privado de quien lo promueva.

5. Las condiciones de utilización de la cartografía normalizada serán establecidas por el Consejo Cartográfico de Canarias, debiéndose arbitrar las garantías necesarias para que su uso sea exclusivamente el autorizado, manteniéndose en todo momento los derechos de propiedad intelectual reconocidos en la Ley 22/1987, de 11 de noviembre, de Propiedad Intelectual, respecto de la información y cesión de datos.

Artículo 10.- Registro Regional de Cartografía.

Se crea el Registro Regional de Cartografía en el seno de la Consejería de Politica Territorial. En dicho Registro figurarán, con expresión de sus escalas y características, todos los trabajos topográficos y cartográficos que se realicen en el ámbito de la Comunidad Autónoma de Canarias, y su régimen jurídico y de funcionamiento se establecerá reglamentariamente. 


\subsubsection{Comisión Cartográfica del Principado de Asturias}

También el Principado de Asturias tiene su propia legislación en materia cartográfica, en el Decreto 25/2000, de 9 de marzo, se regula la organización y funcionamiento de la Comisión Cartográfica del Principado de Asturias.

En virtud de esta norma se crea la Comisión Cartográfica del Principado de Asturias, como un órgano de asesoramiento y apoyo adscrito a la Consejería de Infraestructuras y Política Territorial, con funciones de informe, propuesta y coordinación de la producción cartográfica de la Comunidad Autónoma. Las funciones de esta Comisión serán entre otras: proponer al Consejo de Gobierno el Plan Cartográfico Autonómico en el que se reflejarán las previsiones anuales o plurianuales en relación con la producción y publicación de cartografía básica, derivada y temática; promover la creación y desarrollo de un Registro Autonómico de Cartografía, así como la Cartoteca del Principado de Asturias; coordinar los planes de producción cartográfica del Principado de Asturias con los de las distintas Administraciones Públicas; conocer e informar, en su caso, de cuantos temas relativos a la función cartográfica sean sometidos a su consideración por las distintas Consejerías. 



\section{ANÁLISIS Y VALORACIÓN CARTOGRÁFICA}

\subsection{Principales variables cartográficas para la Ordenación del Territorio}

Debido a la cantidad de temas que debe contener la Cartografía para la Ordenación del Territorio, son múltiples las cartografías a analizar. Hemos intentado recopilar el máximo número de mapas relacionados con el tema para que el análisis fuera más completo. Para hacer una selección de la cartografía que puede resultar de interés, se ha acotado la cuestión fijando qué conceptos creemos que debe incluir nuestra cartografía, y se ha llegado a la conclusión de que los elementos mínimos a representar serán:

Medio

Medio físico

Pendientes

Curvas de nivel

- Puntos de cota

- Geología

- Clima

- Litologías

- Vegetación

- Orientaciones

- Insolación

o Aprovechamientos

- Minerales

- Industriales 
- Usos del suelo

- Vías pecuarias

o Paisaje

- Yacimientos arqueológicos

- Unidades ambientales

- Fauna

- Flora

- Espacios naturales de especial relevancia

- Elementos de interés turístico

o Hidrogeología

- Accesibilidad de acuíferos

- Vulnerabilidad de acuíferos

- Permeabilidad de acuíferos

- Fuentes

- Ríos y barrancos

- Cuencas hidrológicas

- Unidades hidrogeológicas

- Manantiales

o Afecciones y riesgos

- Carreteras

- Riesgos de inundación

- Riesgo sísmico

- Riesgo de deslizamientos

- Erosión actual

- Erosión potencial

- Industrias contaminantes

o Impactos

- Vertederos controlados

- Vertederos incontrolados

- Mapas de ruido

- Equipamiento

o Urbano

- Zonas verdes

- Mobiliario

- Contenedores de residuos

o Económico

- Actividad comercial y de servicios

- Actividad industrial y comercio mayoritario

o Social

- Cultural y educativo

- Sanitario

- Deportivo

- Asociaciones

- Otros 
o Movilidad

- Zonas peatonales

- Aparcamientos

- Transporte público

- Señalización horizontal

- Señalización vertical

- Infraestructuras

o Saneamiento

- Depuradoras

- Red de saneamiento

- Puntos de vertido de la red

- Alcantarillas

o Abastecimiento de agua

- Depósitos y balsas

- Pozos y sondeos

- Equipamiento e instalaciones

- Red de abastecimiento

o Abastecimiento de energía

- Líneas y tendidos

- Torres y postes

- Transformadores

o Comunicaciones

- Red de carreteras

- Red de caminos

- Red de ferrocarriles

- Puertos y aeropuertos

o Telecomunicaciones

- Red de telefonía

- Antenas de telefonía móvil

- Turismo

o Interior

- Rutas de senderismo

- Alojamientos

- Áreas recreativas

- Vistas panorámicas

o Litoral

- Puntos de información

- Equipamientos

- Edificios singulares

- Hoteles

- Restaurantes y bares 


\subsection{Cartografías analizadas}

Para el desarrollo de esta tesis se han estudiado las siguientes cartografías:

- Serie CV10 (Instituto Cartográfico Valenciano)

- Mapa 1:10.000 (Instituto Cartográfico de Cataluña)

- 10.000 Ejército

- 25.000 IGN

- $50.000 \mathrm{IGN}$

- 50.000 Ejército

- Mapas temáticos de zonas de interés (Instituto Cartográfico Valenciano)

- Mapa Forestal de España (Ministerio de Medio Ambiente)

- Geología de España (Ministerio de Educación y Ciencia)

- Comunidad Valenciana (Publicación)

- Mapa Geocientífico de la Provincia de Valencia

- Mapa Geológico de España (IGME)

- L’Evaluació d’Impacte Ambiental en el Planejament Urbanístic (Mapa y Publicación)

- Serie Cartografía Temática de la Comunidad Valenciana (Mapa y Publicación)

- Mapa Hidrológico de Castilla y León (Mapa y Publicación)

- Mapa de Series de Vegetación de España (Mapa y Memoria)

- Mapas de National Geographic Society

\subsubsection{Análisis de los datos cualitativos}

Debemos tener presente que estamos analizando datos cualitativos, por lo que para su representación se deberá huir de todo matiz cuantitativo. Para conseguir esto, se deberían utilizar variaciones de forma, color y orientación que intuitivamente no den impresión de jerarquía alguna. De esta forma, se utilizarán colores con valores y saturación parecidos, tramados con similar impresión de sombreado, etc.

Una opción acertada para la representación de datos cualitativos superficiales, teniendo en cuenta por ejemplo una doble relación podría ser' ${ }^{1}$ :

- Colores espectralmente lejanos para la representación de los distintos grupos y colores espectralmente cercanos para la representación de cada clase dentro de un grupo. Un ejemplo lo vemos en el mapa 3.1..

- Colores espectralmente lejanos para la representación de los distintos grupos y rayados de distinta orientación pero igual color para la representación de cada clase dentro de un grupo, lo ideal sería que el rayado tuviese el mismo color que el fondo con una mayor saturación.

- Colores espectralmente lejanos para la representación de los distintos grupos y tramados diferentes de igual color para la representación de cada clase dentro de un grupo, lo ideal sería también que el rayado tuviese el mismo color que el fondo con una mayor saturación.

1 Pérez, R. Propuesta de Normalización para la representación cartográfica en Internet. Tesis Doctoral. Madrid, 2003. 


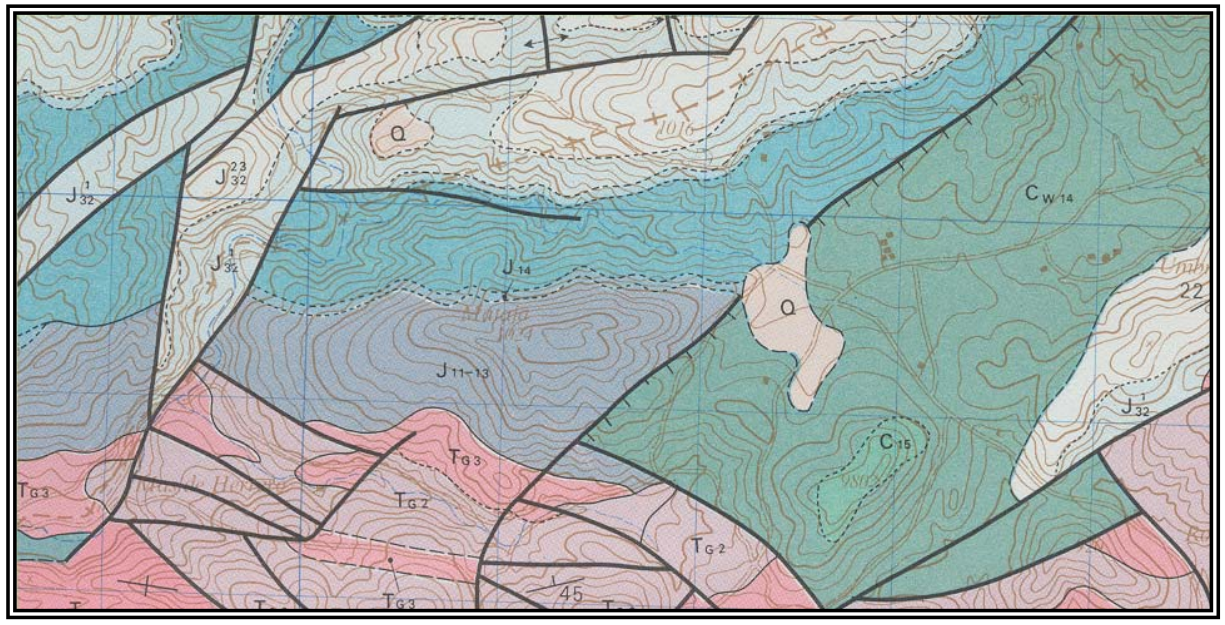

Figura 3.1. Mapa geológico de España. Fuente: I.G.M.

El mismo criterio se seguirá para la representación de datos puntuales cualitativos, teniendo en cuenta en esta ocasión que la representación será simple, nunca doble. Los símbolos utilizados deberán mostrar diferencias de color y forma, pero nunca de valor ya que esto introduciría un elemento de disociación poco deseable cuando tratamos datos cualitativos. Veamos como ejemplo la muestra de mapa de la figura 3.2.

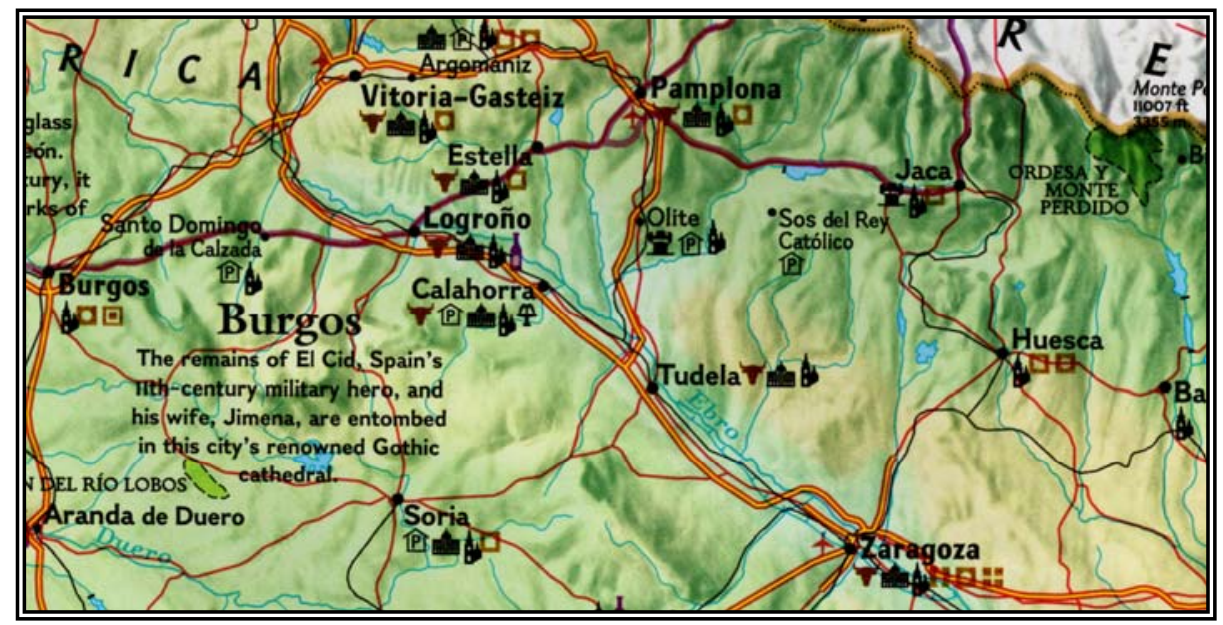

Figura 3.2. A travelers map of Spain and Portugal. 1998. Fuente: N.G.S. 
Resulta útil para la representación de mapas cualitativos el uso de diagramas de sectores y símbolos proporcionales.

Lo que siempre deberemos considerar es que la información que aporta un mapa cualitativo debe poder comprenderse someramente de un vistazo sin necesidad de consultar la leyenda, si no es así la simbología del mapa no está correctamente diseñada.

\subsubsection{Análisis de los datos cuantitativos}

Un mapa con datos estrictamente cuantitativos puede abordarse utilizando diferencias de valor o tamaño. Incluso podríamos introducir elementos cualitativos con el uso combinado de ambos. Si se trata de elementos superficiales, pueden representarse los datos con diferencias de color o incluso de saturación utilizando el mismo color; para los elementos lineales la opción más acertada será el uso del grosor, aunque se pueda utilizar también el color; para elementos puntuales la mejor alternativa será el uso del tamaño. Ver Figura 3.3..

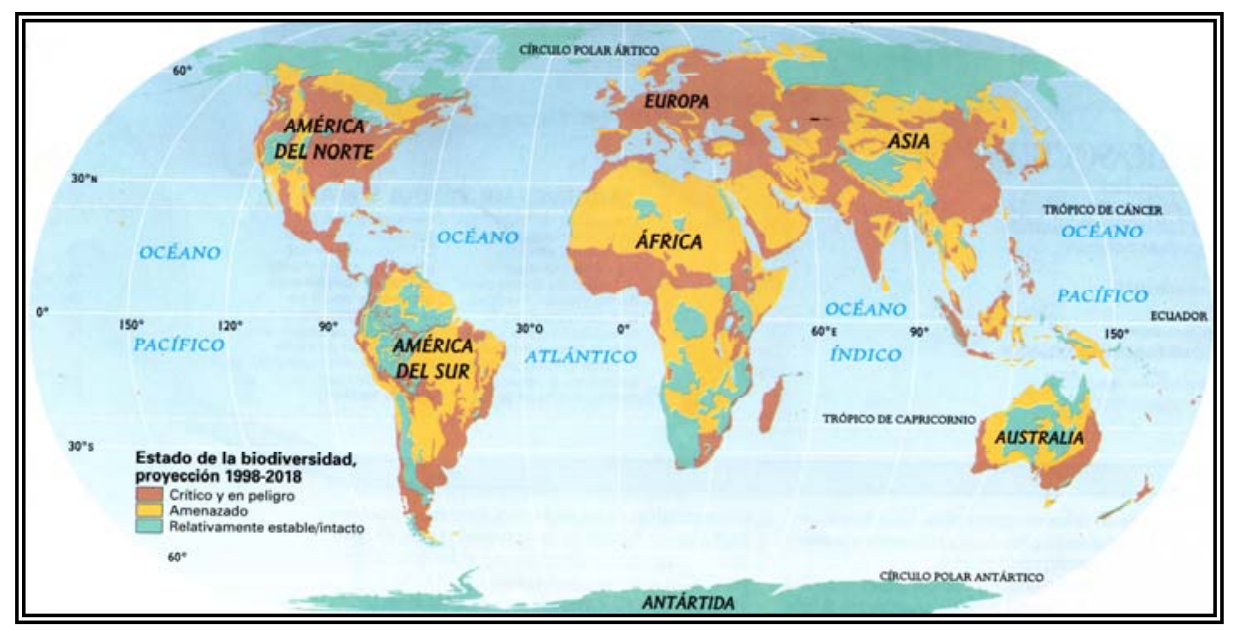

Figura 3.3. Biodiversidad. 1999. Fuente: N.G.S.

Es de vital importancia la correcta elección de los colores a utilizar, lo más correcto sería, dentro de lo posible, utilizar un color con diferencias de tono, asignando siempre los colores más oscuros a los mayores valores.

Otra solución menos acertada pero en ocasiones válida es el uso de colores de una progresión espectral, como son las tintas hipsométricas para el cambio de altitud en mapas de pequeña escala, pero esto no es generalmente válido porque el observador suele asociar los colores oscuros a valores mayores y esto no sucede en el caso de progresiones espectrales. De todas formas la elección de la gradación de colores vendrá determinada por la característica que el autor del mismo quiera destacar. Se muestra un ejemplo en la figura 3.4.. 


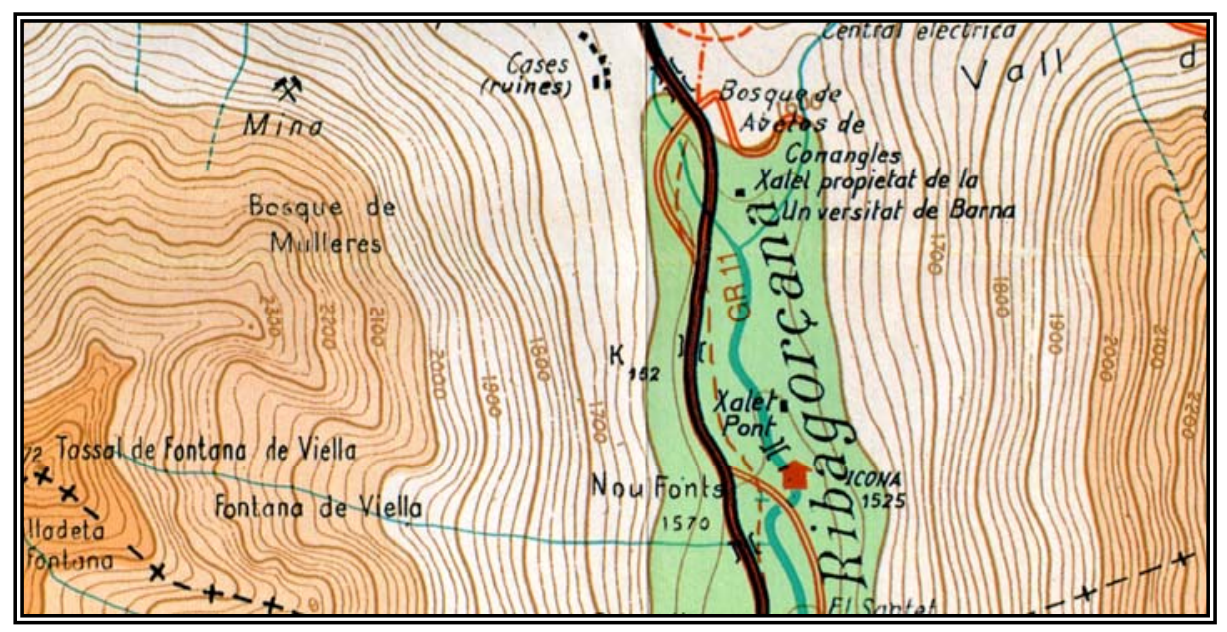

Figura 3.4. Mapa topográfico y excursionista "La Ribagorça". Fuente: Alpina.

Se deberá cuidar el resultado final del mapa, cuyos colores no deberán ser excesivamente claros u oscuros y con un buen contraste entre ellos.

Puede darse el caso de que el mapa a formar requiera una doble escala, que generalmente será de valores positivos y negativos. Si es ésta la cuestión, se resolverá haciendo uso de dos gamas de colores bien diferenciadas, pero teniendo en cuenta todo lo dicho anteriormente para cada una de las gamas. En la medida de lo posible se utilizarán colores que intuitivamente aporten la idea que queremos transmitir, esto vendrá indicado por el tipo de datos a representar. Así por ejemplo a la hora de generar un mapa de temperaturas, sería una elección correcta utilizar colores rojizos para las temperaturas positivas (el rojo es un color cálido) y azules o verdes para las negativas (se trata de colores fríos).

En la figura 3.5. se muestra un mapa de climas. Como se puede observar, se utilizan los colores más cálidos para aquellos climas con temperaturas en general cálidas, y los colores más fríos para las temperaturas frías.

Un ejemplo de mapa con datos cuantitativos y cualitativos se muestra en la figura 3.6., donde se distingue por colores el tipo de batalla y la magnitud de la misma por el tamaño de símbolo. 


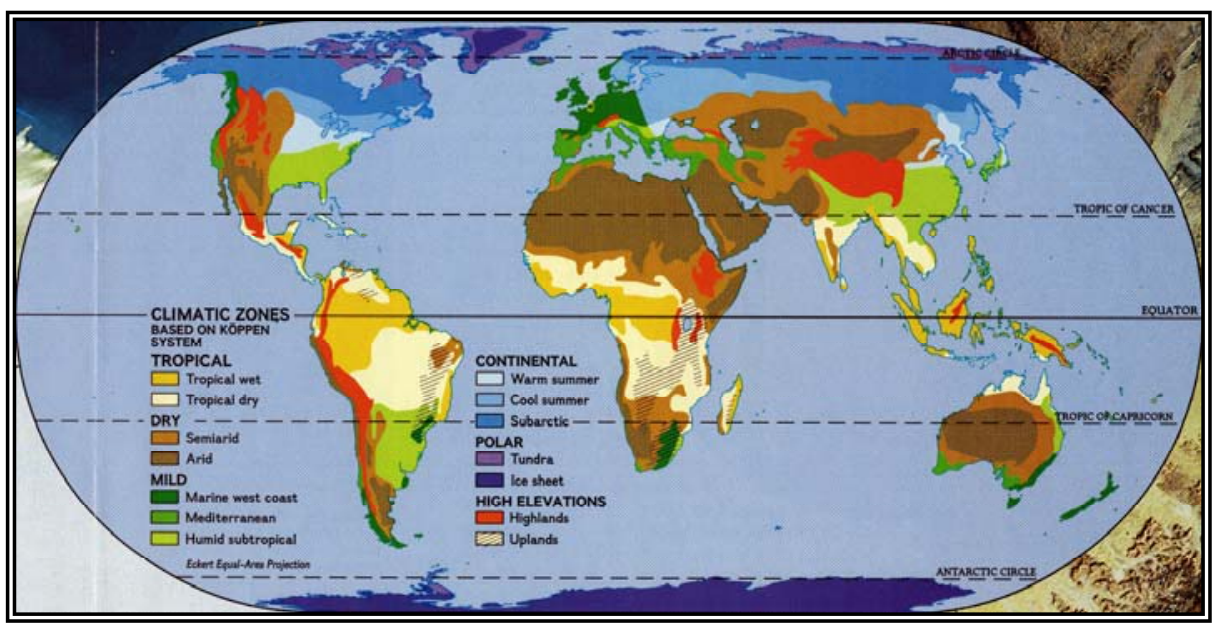

Figura 3.5. Fragmento de "Physical Earth". 1998. Fuente: N.G.S..

Hasta ahora hemos hablado de mapas en los que intentamos reflejar una variable, pero podríamos utilizar el mismo mapa para introducir información acerca de dos fenómenos diferentes. Si así fuese podríamos utilizar color y trama, color y símbolos, etc., siempre considerando lo descrito en los párrafos anteriores.

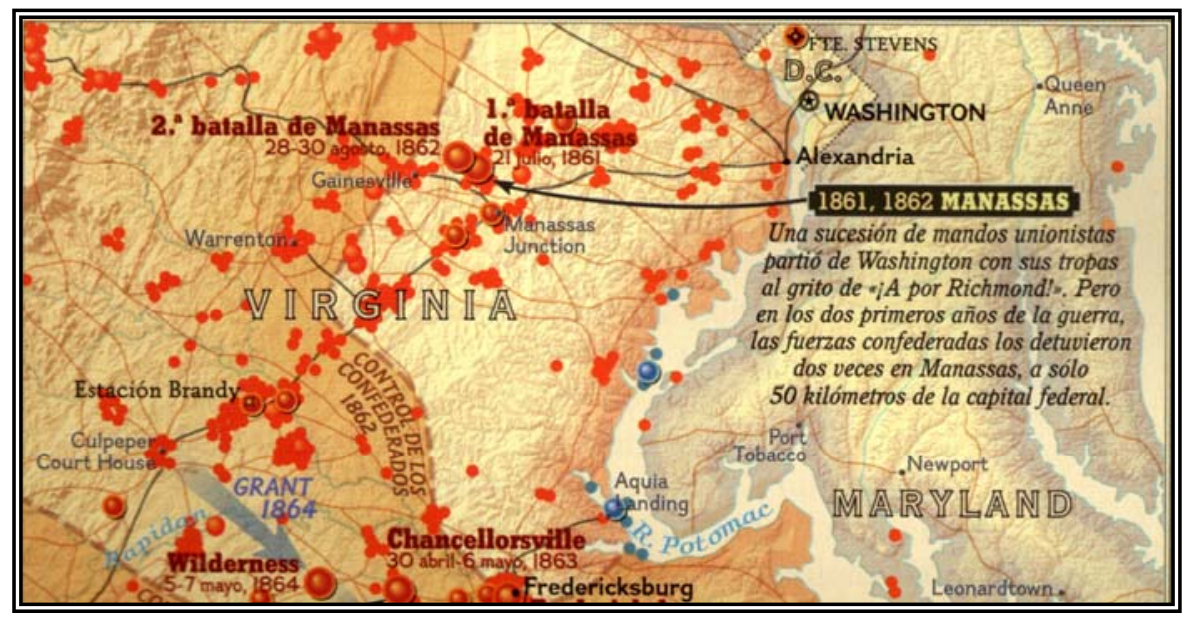

Figura 3.6. Fragmento de “Guerra de secesión”. 2005. Fuente: N.G.S.. 


\subsection{Estudio de los diferentes elementos a representar}

\subsubsection{Cuadrícula y sistemas de representación}

El sistema de representación cartográfica será UTM, Universal Transversa Mercator dado que, conforme al Decreto 2303/1970, de 16 de julio, es sobre la que actualmente se desarrolla toda la cartografía básica y derivada oficial en España.

A pesar de que con la entrada en vigor del "Real Decreto 1071/2007, de 27 de julio, por el que se regula el sistema geodésico de referencia oficial de España" se debería adoptar el sistema de referencia geodésico global ETRS89, que sustituiría al anterior ED50, la cartografía aquí generada se ha realizado en este último sistema, ya que la información utilizada lo estaba igualmente. De todas formas el mismo Real Decreto indica que ambos sistemas pueden convivir hasta el 1 de enero de 2015.

En todos los mapas se incluirá pues la cuadrícula UTM, porque no resta claridad al mapa y puede resultar de utilidad en múltiples ocasiones.

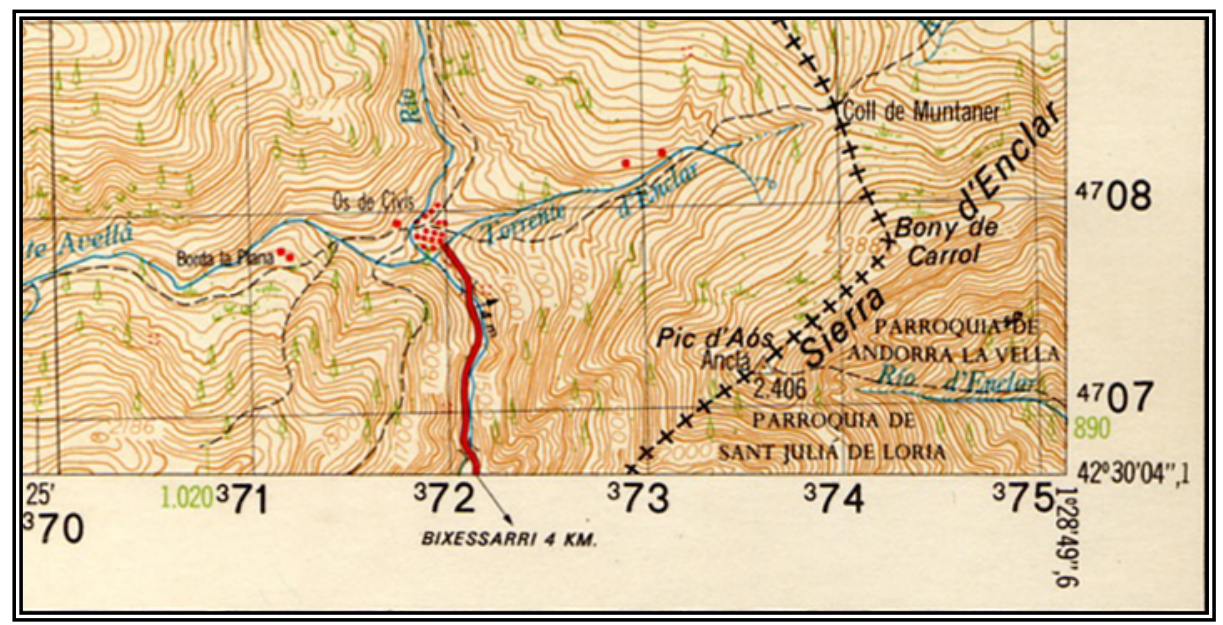

Figura 3.7. Mapa con coordenadas UTM y Geográficas. Fuente: Serie L Ser. Cart. del Ejército.

Es práctica general incluir, además de la cuadrícula UTM, las coordenadas geográficas, al menos de las esquinas de la hoja, como se muestra en la figura 3.7.. Todavía podemos encontrar cartografía sin la cuadrícula UTM, aunque no es muy habitual, y desde luego no debe usarse en cartografía oficial. 


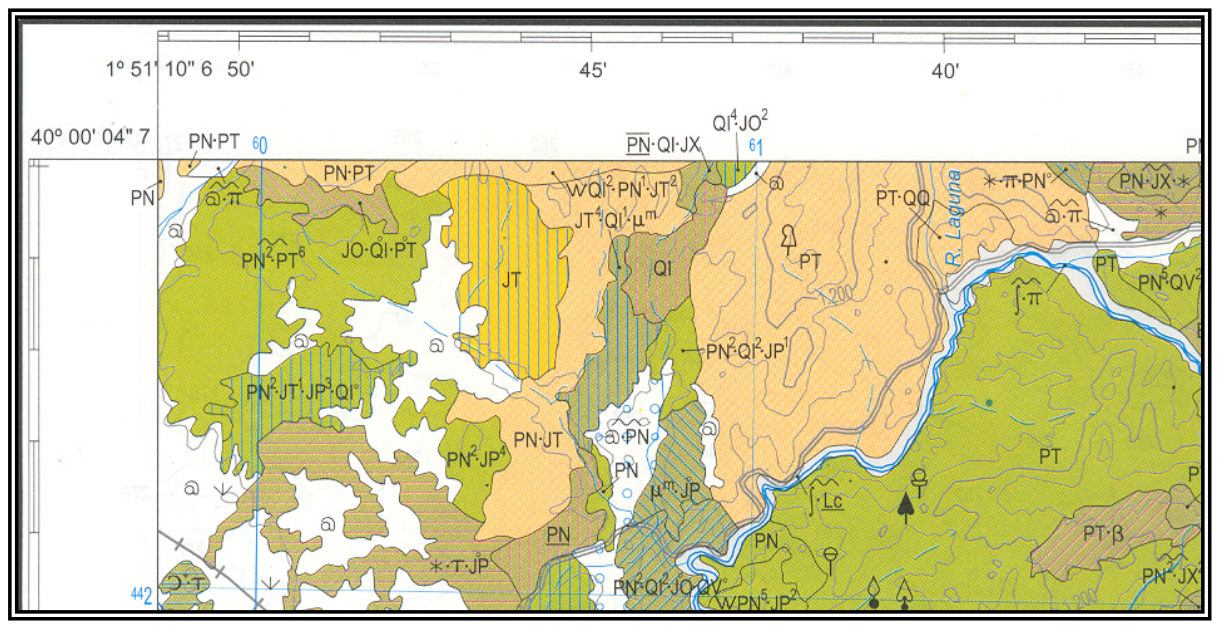

Figura 3.8. Mapa con mayor relevancia de las coordenadas Geográficas. Fuente: Mapa forestal de España.

\subsubsection{Topografía}

La topografía es la base de toda cartografía; sobre esta representación del terreno, expresado actualmente en la mayoría de los casos mediante curvas de nivel y puntos de cota, deberemos plasmar el resto de la información que deseemos incluir en nuestro mapa.

En esencia la topografía consiste en la representación del relieve, la ubicación en un plano de elementos tridimensionales; diremos que la altimetría es la que se encarga de la representación del relieve, en oposición a la planimetría que se encargará de la toma de datos en dos dimensiones.

Esta representación del relieve debe cumplir dos cometidos esenciales, por un lado debe ser capaz de aportar intuitivamente al observador una idea lo más cercana posible a la realidad de la forma del relieve; por otro lado tendrá que ser capaz de otorgar capacidad métrica al mapa, de tal modo que podamos obtener de él datos acerca de desniveles, pendientes, etc. Múltiples han sido a lo largo de la historia de la cartografía los intentos por conjugar de la mejor manera posible estos dos objetivos.

En los primeros mapas la representación del relieve se hacía de una manera "artística", intentando cubrir una de las necesidades comentadas anteriormente, la de ofrecer una idea intuitiva de las formas del relieve. Esta forma se materializaba mediante la representación del roquedo o con la ayuda de dibujos de lo más variopinto. Véase la figura 3.9., donde se intenta representar el relieve sin ningún rigor, pero se ofrece una idea intuitiva del mismo.

En el siglo XVIII se lleva a cabo un primer intento de representación del relieve con cierto rigor, alejándose de lo que había venido siendo la manera tradicional de representación, mucho más "artística", fue mediante el uso de lo que denominamos "normales", que son líneas rectas que coinciden con las líneas de máxima pendiente. Este método, materializado por 
Cassini en el mapa de Francia a escala 1:86.400 no ofreció un resultado excesivamente satisfactorio en cuanto que daba un mal resultado en terreno llano.

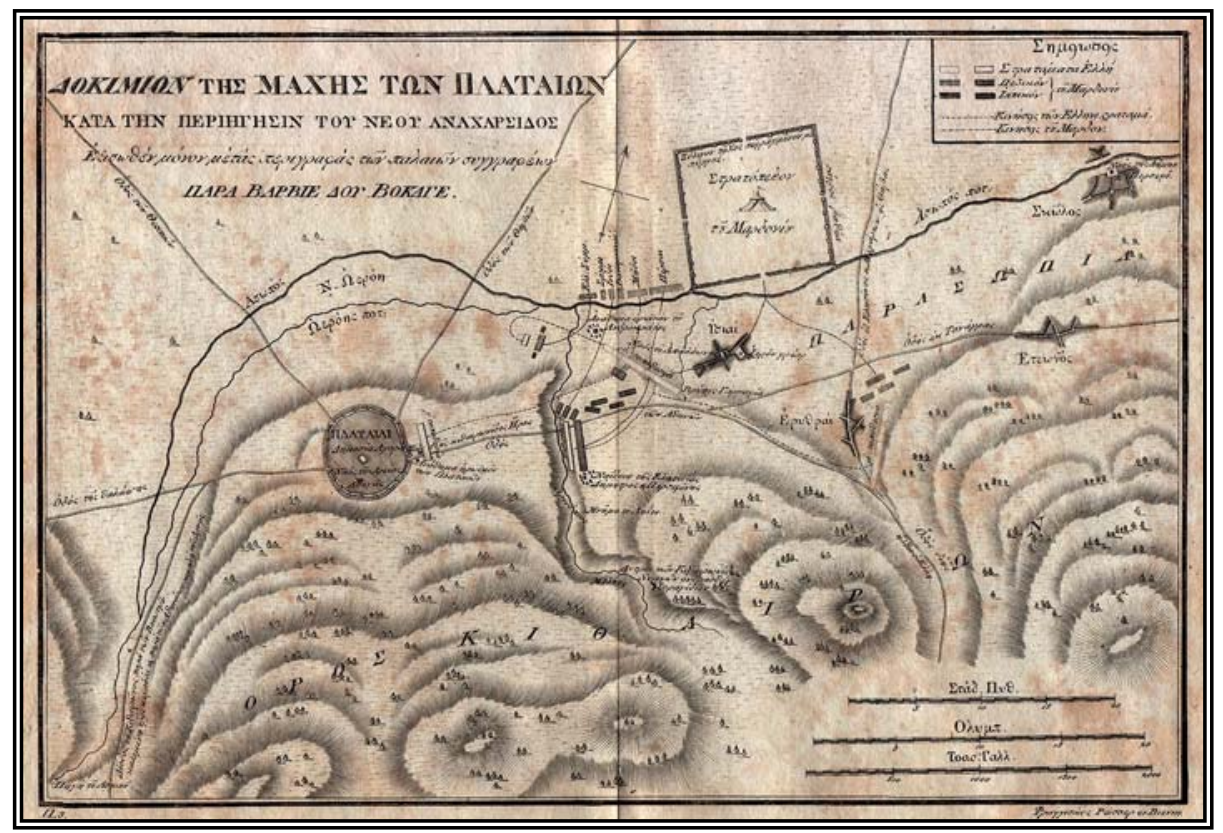

Figura 3.9. Mapa de la Batalla de Platea.

El siguiente intento digno de mención lo llevó a cabo Johann Georg Lehmann en 1799, con la ventaja de que su sistema ofrecía cierta calidad métrica. Este método consistía en la representación de normales, pero con la condición de que la anchura de las mismas debía ser proporcional a la pendiente, esto proporcionaba un sistema válido para expresar pendientes, aunque con limitaciones y restringiendo su uso a zonas no excesivamente montañosas.

Ambos métodos encierran una importante limitación, que es el hecho de la desinformación acerca de si el terreno es ascendente o descendente.

En España encontramos un ejemplo del uso de normales en la Carta Geométrica de Galicia publicada en 1845 por Domingo Fontán.

Debido a los inconvenientes comentados es un sistema que no se utiliza prácticamente en la actualidad.

Ya en 1728 N. Cruquius introdujo una nueva idea para representar el fondo del estuario de Merwede, la novedad consistía en el uso de curvas de nivel. Las curvas de nivel son líneas que unen puntos de igual cota, intuitivamente una curva de nivel es una línea que representa la intersección del terreno natural con un plano de cota constante proyectada sobre un plano de comparación, este plano tendrá obviamente también cota constante.

El primer mapa del que se tiene constancia de la utilización de curvas de nivel se publicó en 1791 y fue el mapa de Francia de Dupain-Triel, este sistema ha sido adoptado para la realización de cartografías nacionales, la primera fue en 1869, el mapa nacional de Austria a 
escala 1:25.000. En 1875 se empieza a publicar el Mapa Topográfico Nacional español, también con la representación del relieve mediante curvas de nivel que se sigue utilizando en la actualidad.

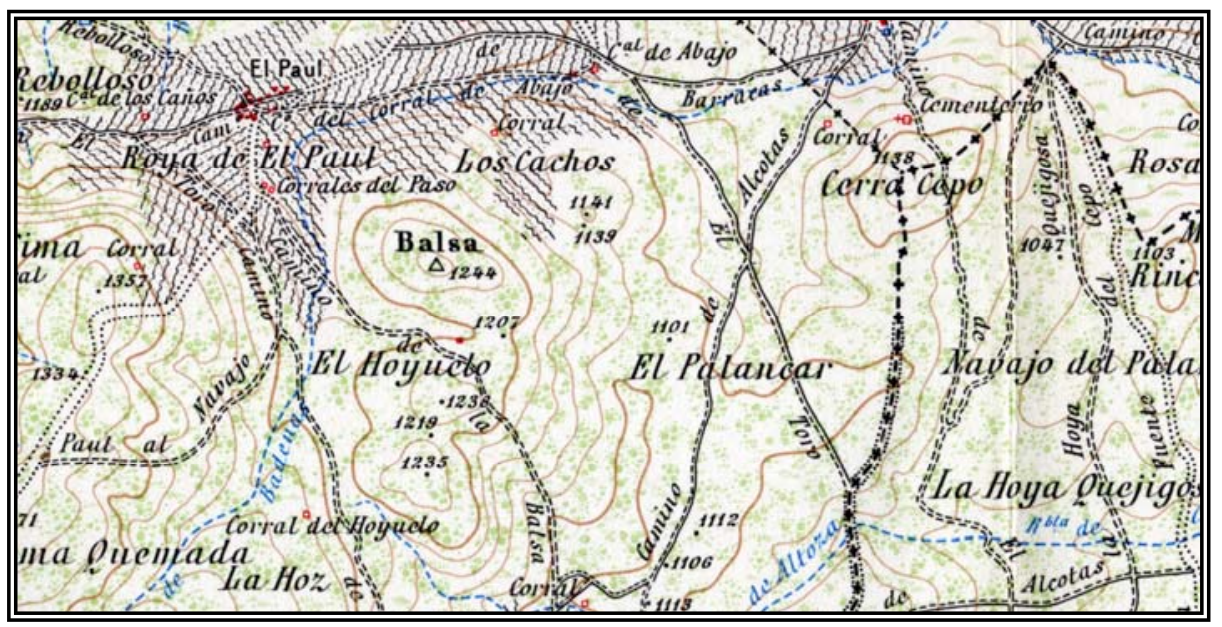

Figura 3.10. Mapa del antiguo Instituto Cartográfico y Catastral. 1951.

Otra forma de representación del relieve que se sigue también utilizando en la actualidad, aunque no de modo tan universal como las curvas de nivel, son las tintas hipsométricas; este sistema utilizado por primera vez en 1873 por E. von Sydow, consiste en el uso de diferentes colores para delimitar zonas comprendidas entre ciertas altitudes, de manera que los límites entre colores coinciden con curvas de nivel, que pueden existir o no. Es un método conveniente para mapas a pequeña escala en los que generalmente se suele utilizar una gradación de colores, estos colores son con frecuencia el verde, que se irá aclarando conforme la cota vaya disminuyendo, y el siena que se oscurecerá con la altitud. Una desventaja que suelen tener este tipo de mapas consiste en la asociación del color verde con la vegetación y los tonos marrones con la aridez, que no tiene porqué corresponderse con la gradación representada por las diferencias de cotas.

Hasta ahora hemos hablado de las curvas de nivel como el método más válido para representar el relieve de manera que se cumpla con el segundo cometido, aportar calidad métrica a la representación del relieve. Para un observador mínimamente especializado, las curvas de nivel aportan también una idea de la forma de aquel, pero no puede decirse que sea esta una idea intuitiva, para ofrecer una visión más instintiva del relieve se utilizan actualmente los sombreados.

Se suelen utilizar principalmente dos tipos de sombreados: el de luz cenital, en el que aparecen más oscuras las zonas de más pendiente; y la iluminación oblicua, donde suele utilizarse una orientación noroeste, que aunque no es real presenta un resultado mucho más intuitivo, una iluminación desde el sur da la impresión de relieve invertido. 


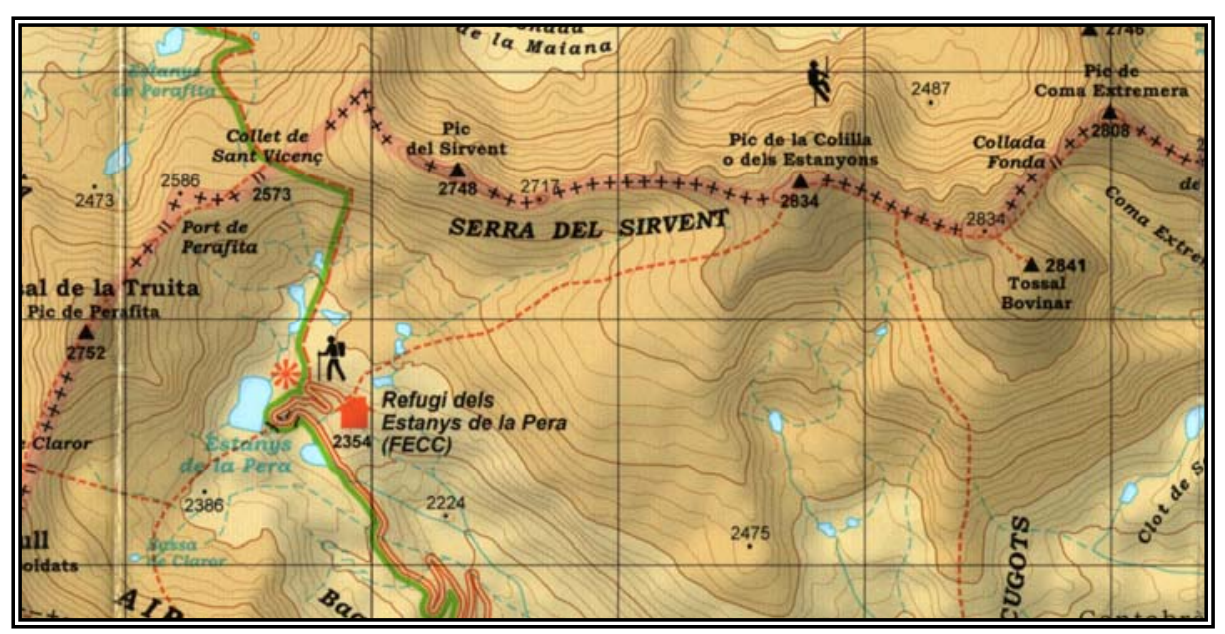

Figura 3.11. Mapa con tintas hipsométricas y sombreado. Fuente: Mapa Andorra. Alpina. 2002.

En un principio los sombreados se hacían manualmente, pero se requiere una enorme pericia para conseguir un efecto que ofrezca una idea realmente aproximada a la realidad. En la actualidad los sombreados de mapas, que generalmente complementan a la representación del relieve mediante curvas de nivel, se realizan de forma automática con la ayuda de programas informáticos que, a partir de un modelo digital de elevaciones y definida una dirección de procedencia de los rayos, generan sombreados muy válidos.

\subsubsection{Cartografía urbana}

En lo que a cartografía urbana se refiere, la representación del relieve no suele ser de vital relevancia, pero sí se utilizan curvas de nivel que se recortarán en el interior de las edificaciones.

Será importante la inclusión de curvas de nivel en las zonas no desarrolladas urbanísticamente, ya que estas curvas de nivel serán de gran utilidad a la hora de ordenarlas. La información altimétrica resultará de utilidad para planificar los servicios, como el alcantarillado, y para prever los riesgos, sobre todo de inundación.

El resto de los métodos de representación del relieve no los utilizaremos porque restarían claridad a la abundante simbología que encontraremos en los mapas a gran escala y no aportan una información excesivamente clarificadora. 


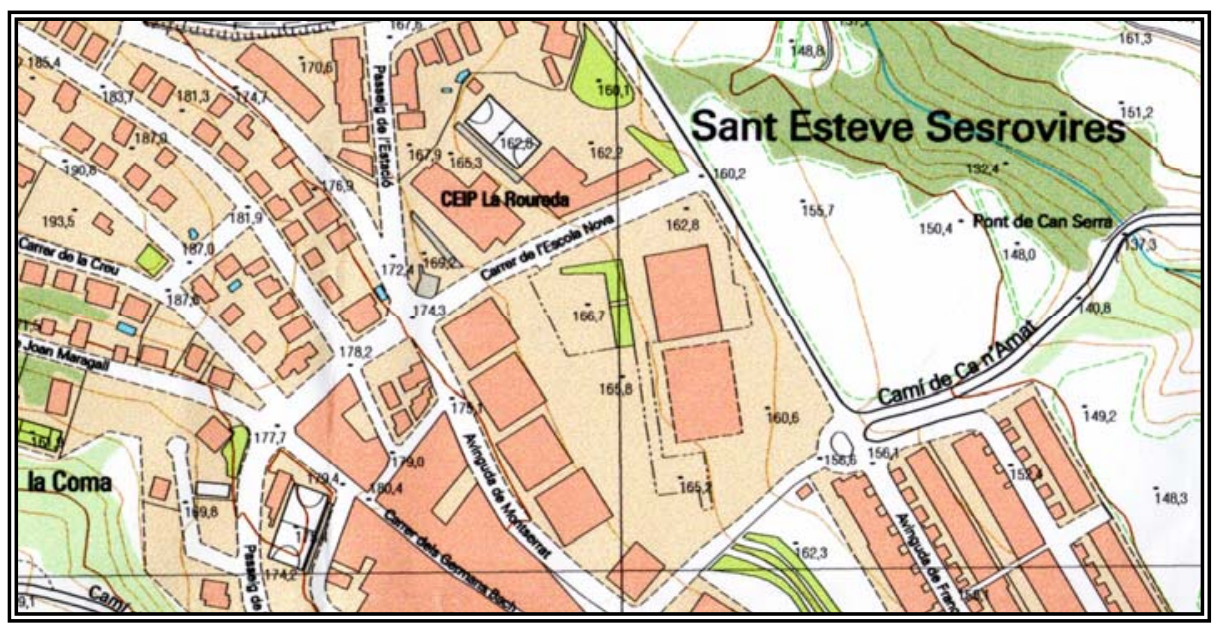

Figura 3.12. Mapa escala 1:5000 con curvado en zona urbana. 1999. Fuente: I.C.C.

\subsubsection{Cartografía territorial}

Visto todo lo anterior, para la cartografía territorial se adopta como la mejor solución el uso de curvas de nivel que aporten calidad métrica al mapa, complementado con un sombreado que proporcione vistosidad y permita a los no iniciados una mejor interpretación del relieve.

Una vez dicho esto, se nos plantean ciertas preguntas, como por ejemplo cuál será la equidistancia apropiada para el mapa que vamos a generar; acerca de este tema podemos discutir bastante. El 12 de diciembre de 1881 el cuerpo de Estado Mayor publicó las "Instrucciones para la ejecución de trabajos topográficos y estadísticos", donde se afirmaba: "La equidistancia en metros corresponderá con la cifra significativa de millares del denominador de la escala del mapa". Pero este precepto no se cumple ni siquiera en las series cartográficas oficiales de 1:50.000 (20 m) y 1:25.000 (10).

Lo único que podemos asegurar es que la equidistancia depende de las exigencias del mapa y la ideal depende tanto de la escala de representación como de la pendiente del terreno, así como del tipo de mapa y la precisión requerida en altimetría.

En cuanto al tipo de curvas, suelen utilizarse principalmente dos tipos de curvas, las normales, que representan un cambio en la cota igual a la equidistancia del mapa, y las maestras, que se utilizan para facilitar la lectura del mapa, ya que si todas las curvas fuesen iguales la interpretación del relieve resultaría más difícil. Estas curvas maestras son de grosor mayor que las normales y suelen colocarse cada cierto número de éstas, siendo la equidistancia entre curvas maestras un número "redondo", que por lo general se escribe en varias de estas curvas, las suficientes como para que en todas las zonas del mapa podamos conocer la cota en la que nos encontramos con relativa facilidad, es lo que se llama "anotar" las curvas. 
También son de uso común, cuando el terreno lo requiere, las curvas de depresión, que aparecen con una simbología diferente y representan, como su nombre indica, depresiones del terreno, zonas de cota inferior al resto de su entorno. Por otro lado, en zonas en las que el desnivel es tan pequeño como para no contener ninguna curva de nivel, utilizamos las curvas intercalares, generalmente representadas con trazo discontinuo y con equidistancia mayor.

Las curvas de nivel no pueden por sí solas ofrecernos un fiel modelo del relieve, para ello necesitamos de los puntos de cota, que son puntos estratégicamente colocados a los que se acompaña una anotación con la cota de los mismos. Estos puntos son indispensables para poder interpretar correctamente el relieve, y suelen colocarse en zonas en las que con el uso exclusivo de las curvas de nivel se produce incertidumbre, como son cumbres, collados, explanadas, etc. La colocación de los puntos de cota debe hacerse cuidadosamente, para que no nos encontremos con un exceso o defecto de los mismos, además, pondremos puntos de cota en puntos importantes del mapa, aunque el conocimiento de su cota no sea imprescindible para el correcto entendimiento del mapa, como pueden ser cruces de ríos o caminos.

Para terminar diremos que, según el uso que se vaya a dar al mapa resultado, una topografía más detallada tendrá más o menos importancia, pero generalmente una base topográfica es fundamental y suele figurar aunque sea solamente como fondo en un color discreto.

Esto puede observarse en el Mapa Forestal de España, donde tanto la topografía como el resto de la cartografía base se encuentran en color gris, dejando los colores intensos para los datos de vegetación, más específicos. Esta cartografía base es la del S.G.E., que durante tiempo ha formado parte de la cartografía oficial. Véase la figura 3.13.

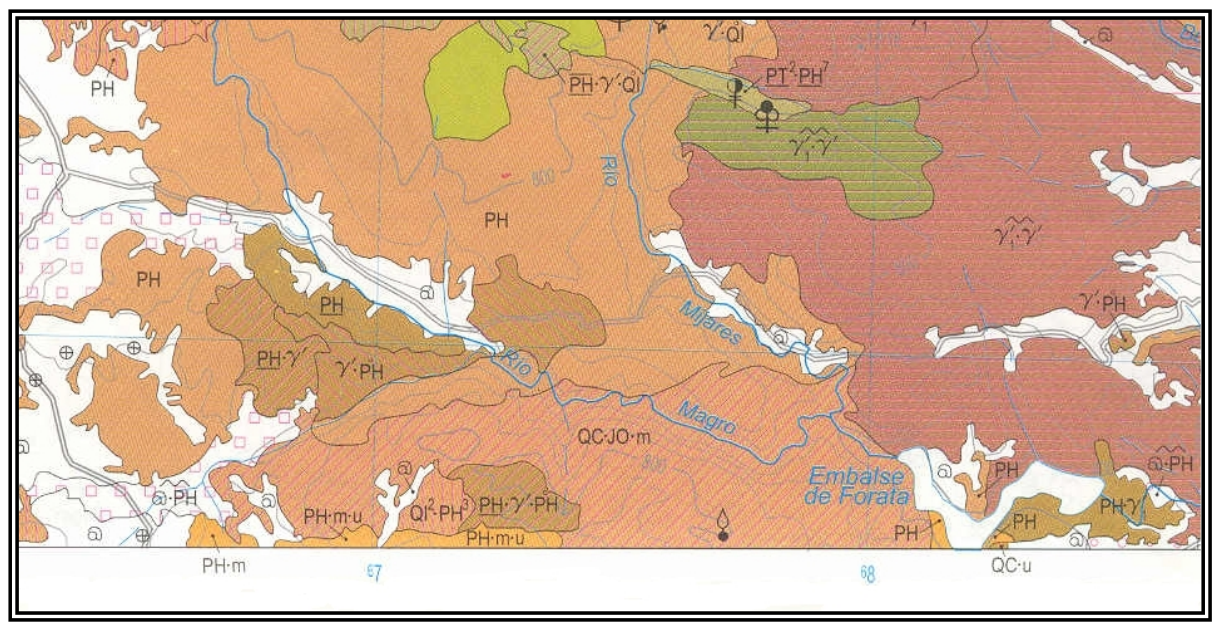

Figura 3.13. Topografía de fondo. Fuente: Mapa Forestal de España. 
Otro ejemplo lo encontramos en el mapa de Clases Agrológicas, en el que aunque la topografía no es la información principal, resulta imprescindible para la correcta interpretación del mapa.

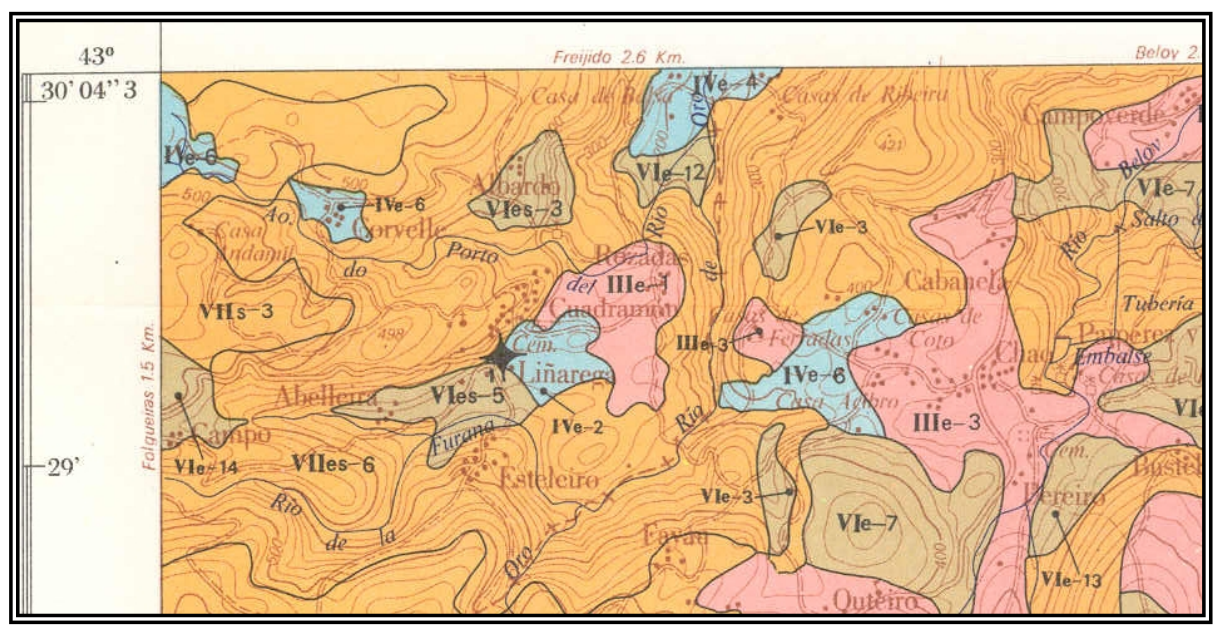

Figura 3.14. Topografía de fondo. Fuente: Mapa de clases agrológicas de España.

Es el mismo el caso del mapa de rocas industriales, todos estos mapas están realizados sobre una base topográfica que conservan en un sólo color que habitualmente es el color siena con el que se suelen representar las curvas de nivel.

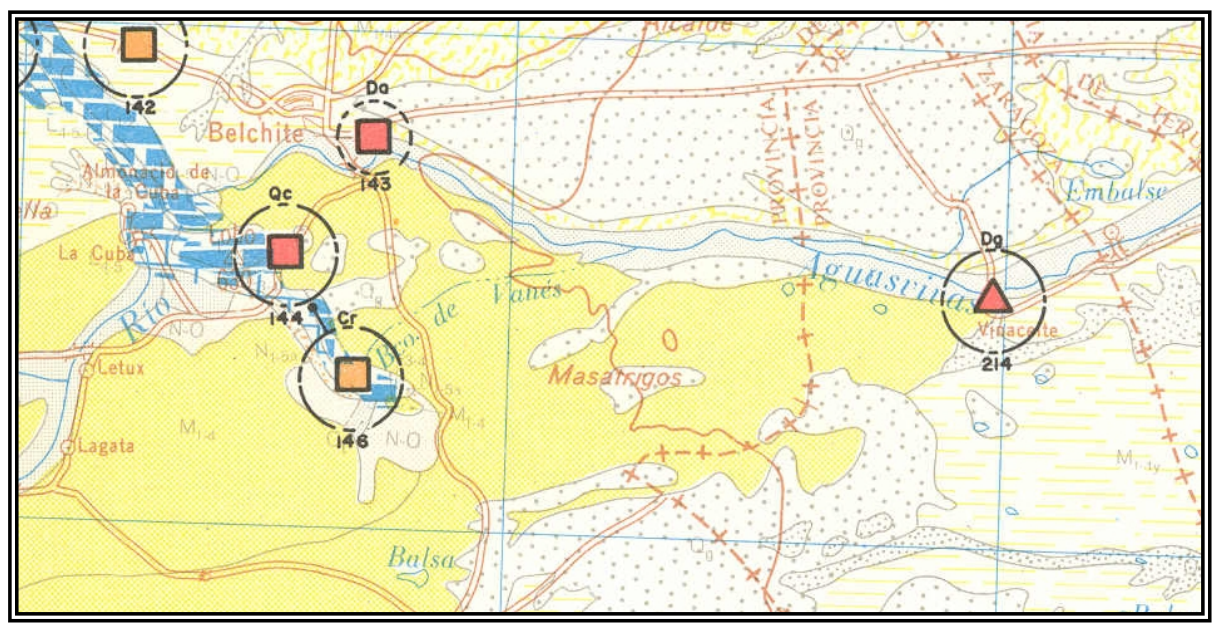

Figura 3.15. Topografía de fondo. Fuente: Mapa de clases Rocas Industriales de España. 
Todas las cartografías anteriores tenían como base topográfica cartografías oficiales completas, en el Mapa Hidrológico de Castilla y León vemos otra manera diferente de representar la topografía. Aunque discutible por su tamaño de letra y grosor, vemos que en este caso se presentan las curvas de nivel en color gris, con una equidistancia de 1 metro para una escala de 1:400.000.

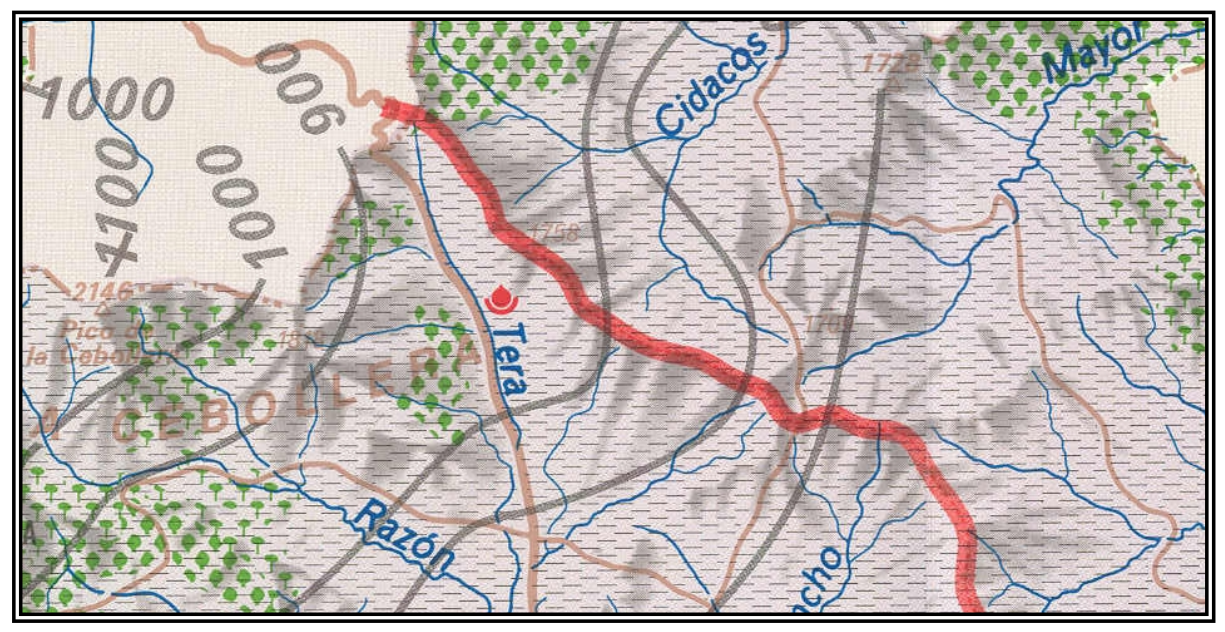

Figura 3.16. Topografía de fondo. Fuente: Mapa Hidrológico de Castilla y León.

\subsubsection{Hidrografía}

Cuando hablamos de hidrografía nos referimos a aquella información que vamos a incluir en el mapa referente a aguas, tanto marinas como continentales y tanto cursos naturales como artificiales, de igual modo lineales (ríos, barrancos, acequias, canales...) que superficiales (mar, lagos, embalses...) o puntuales (fuentes, pozos, depósitos, piscinas, molinos...). El hecho de que un mapa es una representación de la realidad y recordando que la simbología debe ser lo más intuitiva posible, no resulta difícil adivinar el color que tradicionalmente se ha utilizado para la simbolización de la hidrografía, y no hay discusión acerca del hecho de que se siga utilizando el color azul para cualquier tipo de elemento relacionado con el agua.

En primer lugar hablaremos de las corrientes de agua naturales, principalmente ríos y barrancos; generalmente se hará esta distinción en función de si la corriente de agua es continua o estacional, esta distinción se realiza por medio del tipo de línea, continua en aquellas corrientes que fluyen durante todo el año y discontinua en las que no lo hacen. Ver Figura 3.17 .

Un dilema que puede presentarse aparece cuando el río es tan ancho que esa anchura tiene representación a la escala del mapa. En este caso se representará con una línea azul rellena de otro azul de diferente intensidad. También se aprecia esta singularidad en la Figura 3.17 . 
Se suele discriminar también los cursos naturales de los artificiales con algún tipo de simbología, sobre todo porque en los artificiales acostumbra a incluirse el sentido, ya que no tienen porqué seguir necesariamente la topografía del terreno.

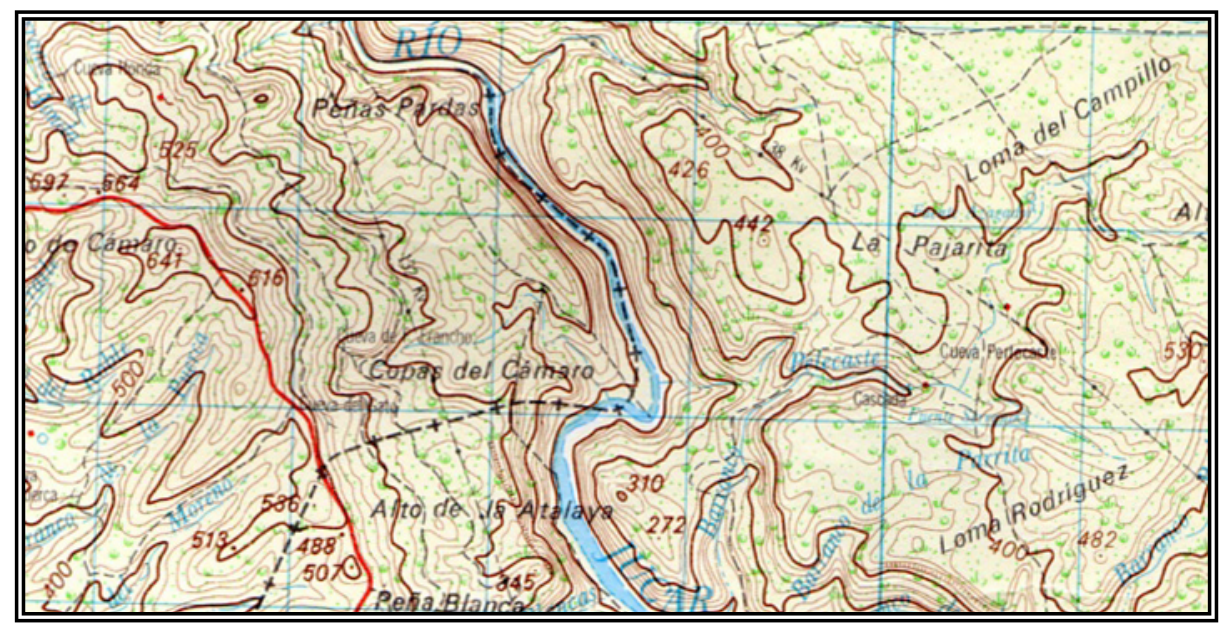

Figura 3.17. Mapa con ríos y barrancos. Fuente: Serie L Servicio Cartográfico del Ejército.

Existen diferencias sustanciales si se trata de mapas continentales o si contienen línea de costa, es la representación de esta última la que suele dar más quebraderos de cabeza por la dificultad en su determinación. En este caso además se presenta el dilema de mostrar la zona correspondiente al mar, pueden adoptarse varias soluciones; la más sencilla pero menos atractiva consiste en dejar una masa de fondo azul, para paliar este efecto sobre todo en mapas con grandes superficies cubiertas por agua, antiguamente se utilizaba un dibujo denominado "dibujo de aguas", para la representación del mar. Se trataba de unas líneas paralelas a la de costa cuya separación aumentaba conforme nos alejábamos de la costa ${ }^{2}$.

Lo más correcto es disponer de información batimétrica e introducir esta información haciendo un curvado del fondo marino. En la figura 3.18 se muestra una de las soluciones más acertadas.

\footnotetext{
${ }^{2}$ Vázquez Maure, F., “Lectura de mapas”, 1995.
} 


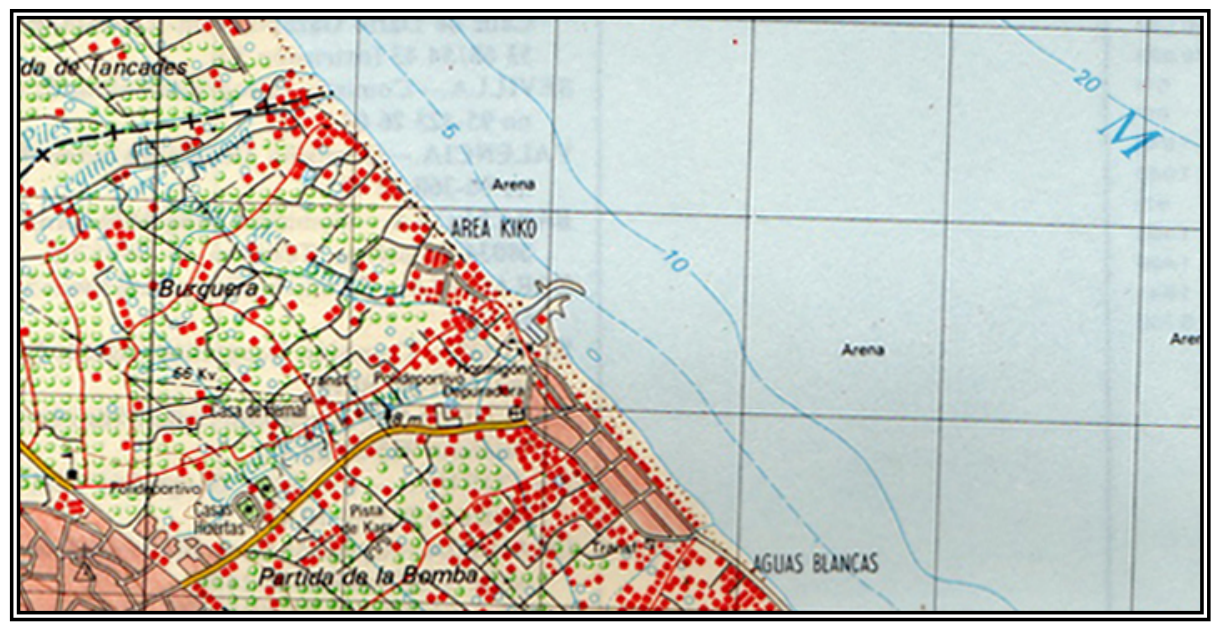

Figura 3.18. Mapa con línea de costa. Fuente: Serie L Servicio Cartográfico del Ejército.

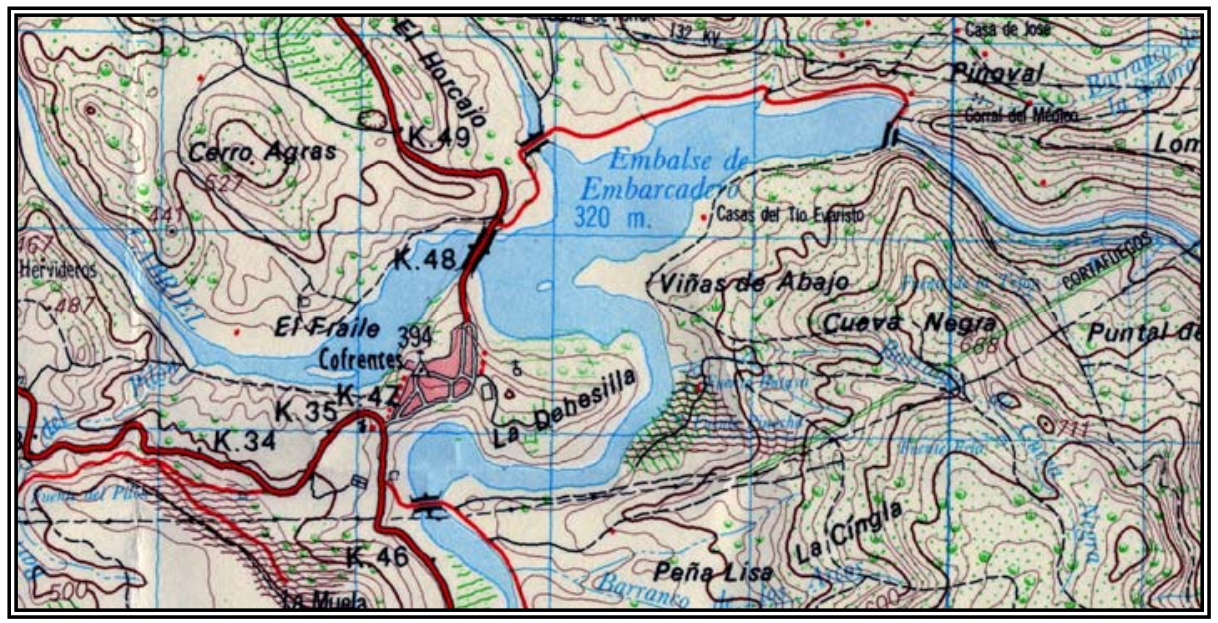

Figura 3.19. Mapa con embalse. Fuente: Serie L Servicio Cartográfico del Ejército.

Todo esto puede aplicarse si demasiados problemas para la representación de lagos, embalses, y en general grandes masas de agua. En la figura 3.19 se muestra un embalse para el que se ha adoptado la solución más fácil, utilizar un color para todo el fondo. 


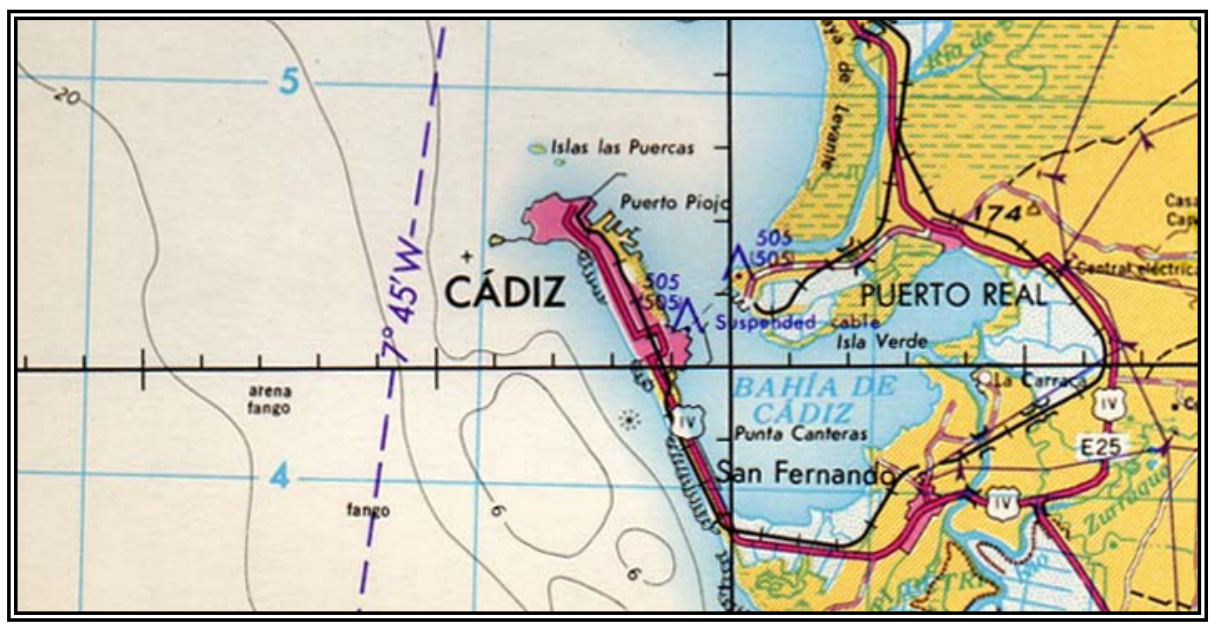

Figura 3.20. Mapa con batimetría y puerto. Fuente: 1:250.000 del centro cartográfico y fotográfico del Ejército del Aire. 1.983.

En la Figura 3.20 tenemos una muestra de una solución diferente, una gradación de color azul conforme nos alejamos de la costa, y además un curvado que muestra la información batimétrica.

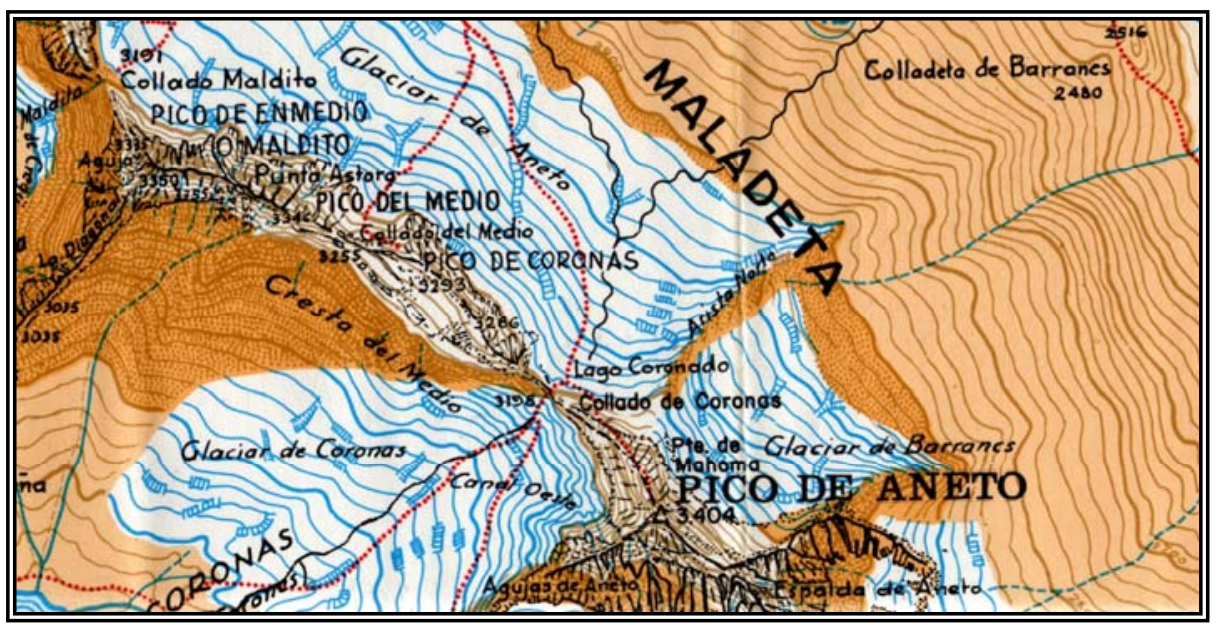

Figura 3.21. Mapa con glaciar. Fuente: 1:25.000 Maladeta-Aneto. Alpina. 1.991.

Además de los comentados, podemos encontrar otros elementos hidrográficos poco comunes, para los que deberemos encontrar solución. En la Figura 3.21. vemos la solución adoptada para la representación del Glaciar del Aneto. 


\subsubsection{Usos del suelo}

En cartografía territorial resulta muy útil la información de usos del suelo, que habitualmente se representa con el empleo combinado de color y tramado.

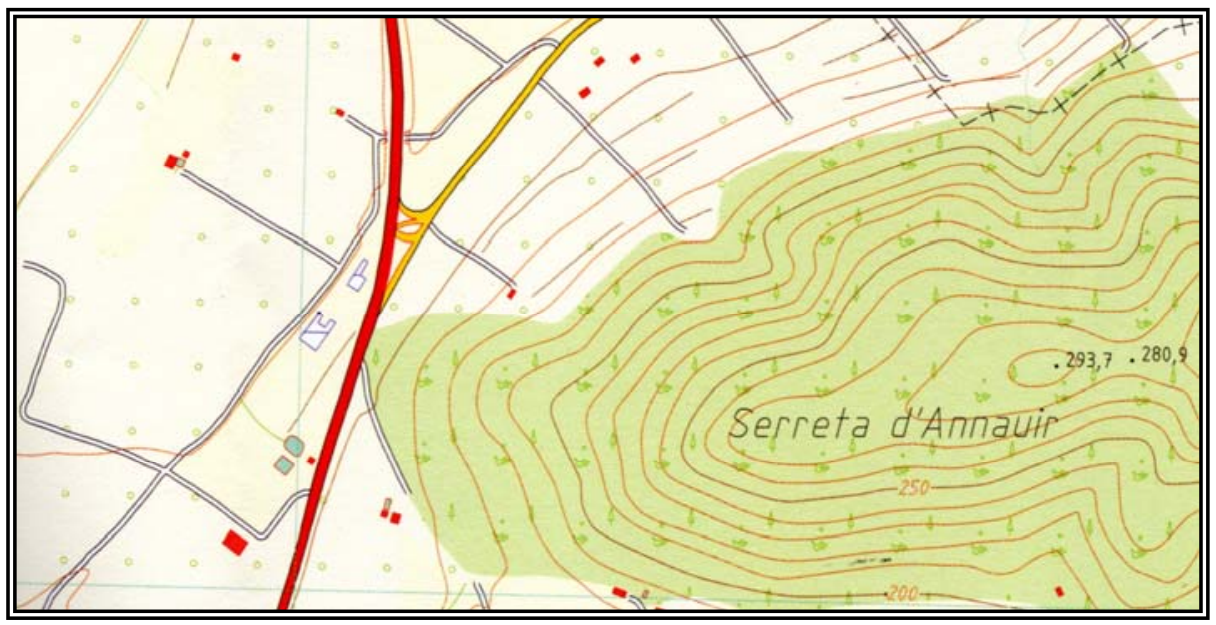

Figura 3.22. Usos del suelo, color y trama. Fuente: Serie CV-10 I.C.V.. 1.998.

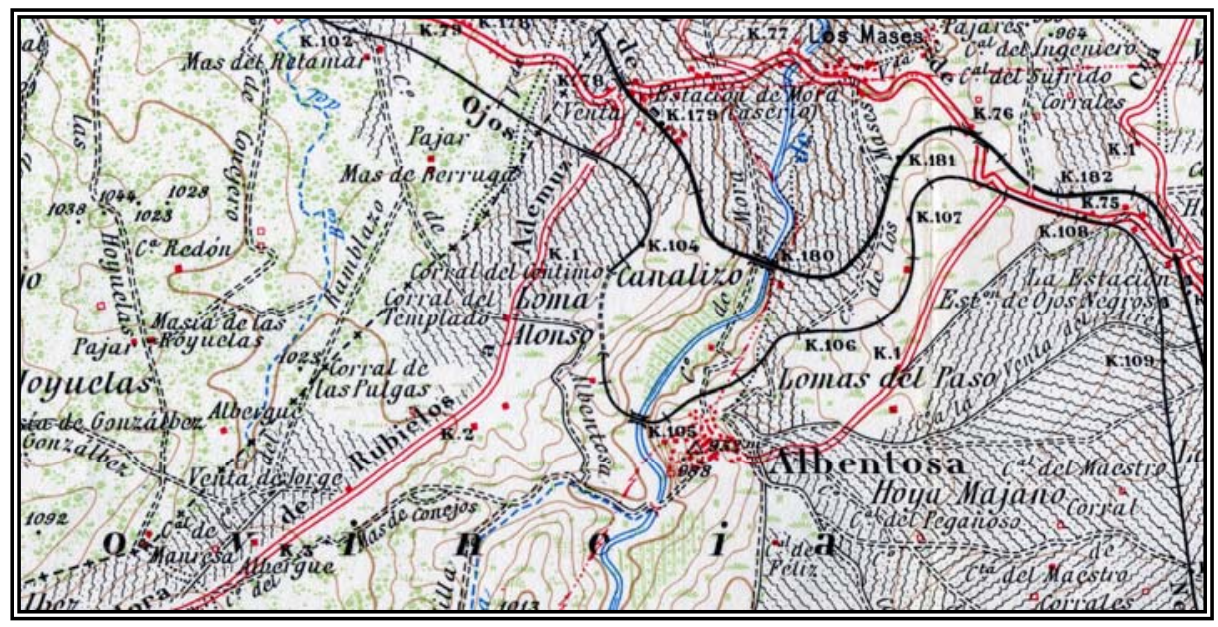

Figura 3.23. Usos del suelo, color y trama. Fuente: 1:50.000 Instituto Geográfico y Catastral. 1.951. 
En las figuras 3.22. y 3.23. se muestran dos soluciones diferentes para la representación de los usos del suelo. La primera visualmente correcta, pero en el segundo caso, la información de usos del suelo hace que la visión general del mapa sea poco clara.

La dificultad radica, como en muchos otros casos, en la disposición de la información base, que en primer lugar no es fácil de conseguir, ya que en ocasiones es difícil distinguir los diferentes usos mediante fotografías aéreas o imágenes de satélite y la visita de campo es económicamente inviable. Y por otro lado, se trata de un concepto que varía con el tiempo, sobre todo si se trata de zonas cultivadas, que pueden pasar de cultivo a barbecho o simplemente cambiar de cultivo.

Una vez se dispone de la información, se deberá clasificar, ya que es del todo imposible plasmar en el mapa todos los tipos de cultivo. Esta simplificación puede generar también alguna que otra complicación.

Hablando ya de simbología, el color suele dar la idea intuitiva de si se trata en general de terrenos de secano o regadío y el tramado especifica de qué tipo de cultivo o uso concreto se trata.

La tónica general es utilizar tonalidades verdes o marrones por su similitud con el terreno real. En lo que al tramado se refiere se suele utilizar un tramado regular para cultivos e irregular para vegetación.

Hay que ser muy cuidadoso con la inclusión de esta información en la cartografía, porque aunque se trata de una información relevante para el tema que nos ocupa, al disponer de información para todo el territorio, según la simbología que elijamos podremos hacer que nuestro mapa pierda claridad.

\subsubsection{Geología, geomorfología y geotecnia}

Los mapas geológicos aportan información acerca de litologías y estructuras, pero esta información por sí sola no es capaz de proporcionar unos datos realmente útiles para las tareas que nos ocupan de gestión territorial, ya que no nos ofrecen detalles cuantitativos acerca de las propiedades de los materiales, ni relacionan los componentes del medio geológico con su significado geotécnico.

El siguiente escalón son los mapas geomorfológicos, que estudian las formas del relieve desde un punto de vista interpretativo, el análisis de las causas que han determinado los procesos y formas, la relación de interdependencia entre éstas, así como las características evolutivas y el grado de equilibrio que mantienen en el ambiente natural. Panizza, 1972. En resumen, el mapa geomorfológico es un documento gráfico en el que están representadas de forma sintética todas las formas de relieve de una región. Se trata de una interpretación subjetiva del paisaje geomorfológico pero debe ser fácilmente referenciable sobre el terreno ${ }^{3}$.

Estos últimos, por sí solos tampoco aportan una información excesivamente útil para nuestros propósitos, así que todavía subiremos un tercer escalón, para llegar a los mapas geotécnicos.

Los mapas geotécnicos, por el contrario, presentan en un formato cartográfico información geológico-geotécnica con fines de planificación y uso del territorio. Aportan datos

\footnotetext{
3 Peña Monné, J. L., “Cartografía geomorfológica básica y aplicada”, 1997.
} 
sobre las características y propiedades del suelo y del subsuelo de una determinada zona para evaluar su comportamiento y prever problemas geológicos y geotécnicos ${ }^{4}$.

Estos mapas resultarán especialmente útiles a la hora de generar mapas de riesgos, que sí deberemos elaborar, ya que resultan imprescindibles para abordar la cuestión del desarrollo territorial.

En lo que se refiere a mapas geotécnicos, no haremos distinción entre cartografía territorial y urbana, ya que la metodología es la misma, variando solamente la escala de representación.

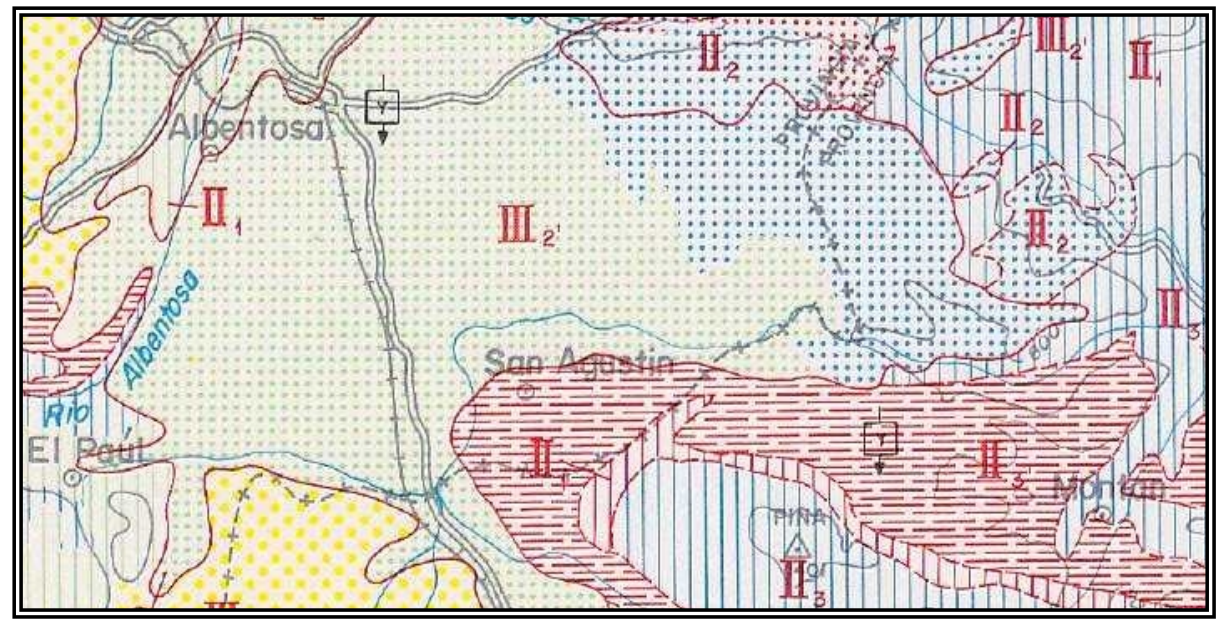

Figura 3.24. Mapa geotécnico. Fuente: Instituto Geológico y minero de España.

\subsubsection{Núcleos urbanos y edificaciones}

Dependiendo de qué tipo de mapa vayamos a elaborar, resultará de mayor o menor relevancia una exhaustiva representación de los núcleos urbanos y las edificaciones en general, pero lo cierto es que para ordenación del territorio y protección del paisaje esta información es imprescindible, ya que lo que pretendemos ordenar es la actividad del hombre en el territorio y el impacto de aquella sobre éste, y resultaría imposible hacerlo sin una información precisa del estado previo del mismo.

En la cartografía española se ha generalizado el uso del color rojo para la representación de edificaciones, seguramente debido al color de las tejas que en la mayoría de los casos se utilizan para cubrirlas.

\footnotetext{
${ }^{4}$ González de Vallejo, L. I., "Ingeniería Geológica”, 2002.
} 


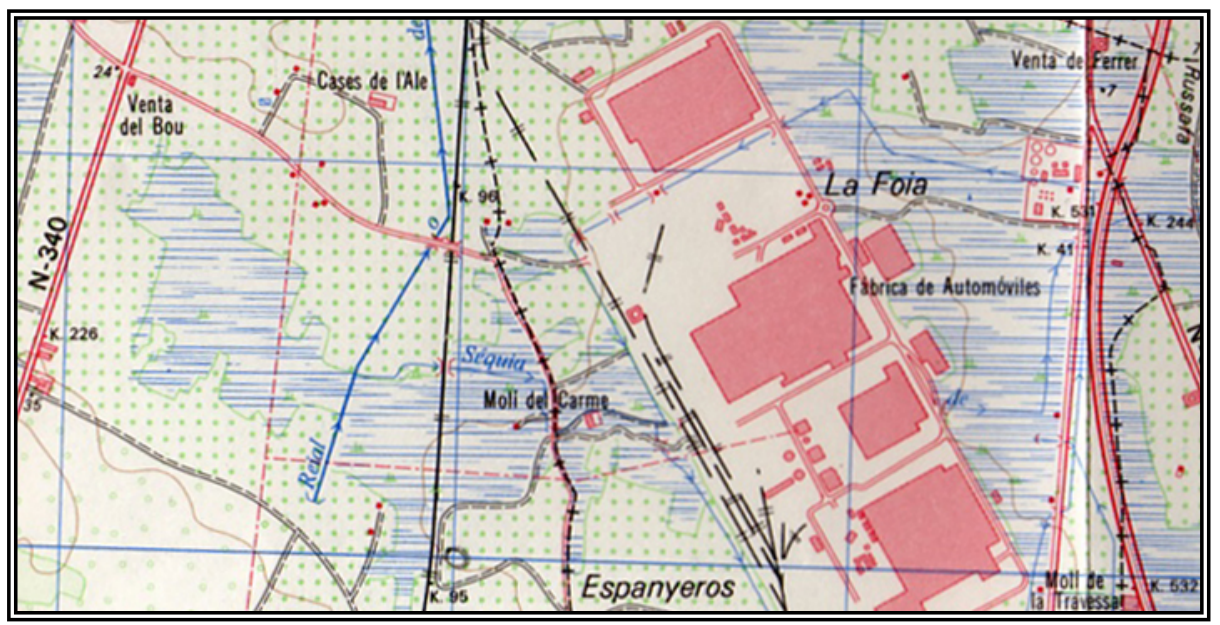

Figura 3.25. Edificio singular a escala 1:25.000. Fuente: IGN.

\subsubsection{Cartografía urbana}

Dada la gran escala de representación que utilizaremos, podremos en la mayoría de los casos plasmar fielmente, esto es en verdadera posición y magnitud, las edificaciones existentes, lo que supone contemplar el callejero de las ciudades o poblaciones.

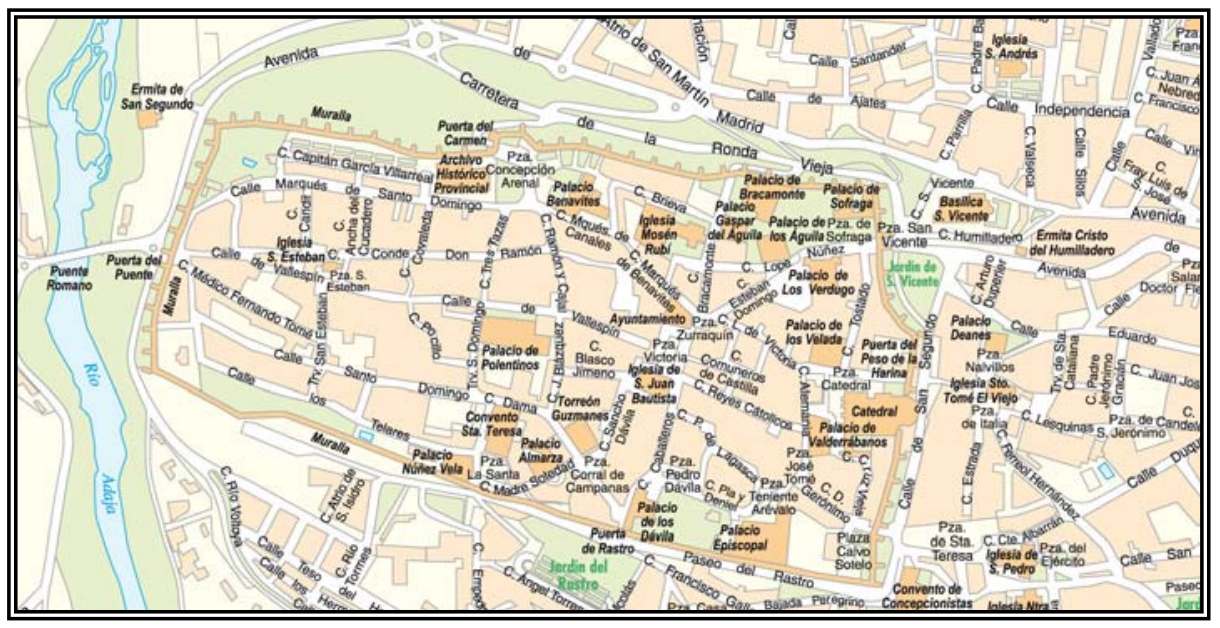

Figura 3.26. Cartografía urbana de Ávila. Fuente: www.rugoma.com. 
En el caso de cartografía urbana, teniendo en cuenta que la mayor parte del mapa (que en realidad será un plano) estará cubierto por construcciones, el uso de un color rojo como sombreado de los edificios puede resultar excesivo y se considera más adecuado el uso de un color más suave, que permitirá además una más adecuada superposición de la abundante simbología que deberá recogerse.

Además de los símbolos utilizados para los servicios públicos, lugares de interés, etc., también se suele utilizar diferente color para los edificios singulares.

\subsubsection{Cartografía territorial}

La escala no nos permitirá en este tipo de mapas una representación exacta de las edificaciones existentes.

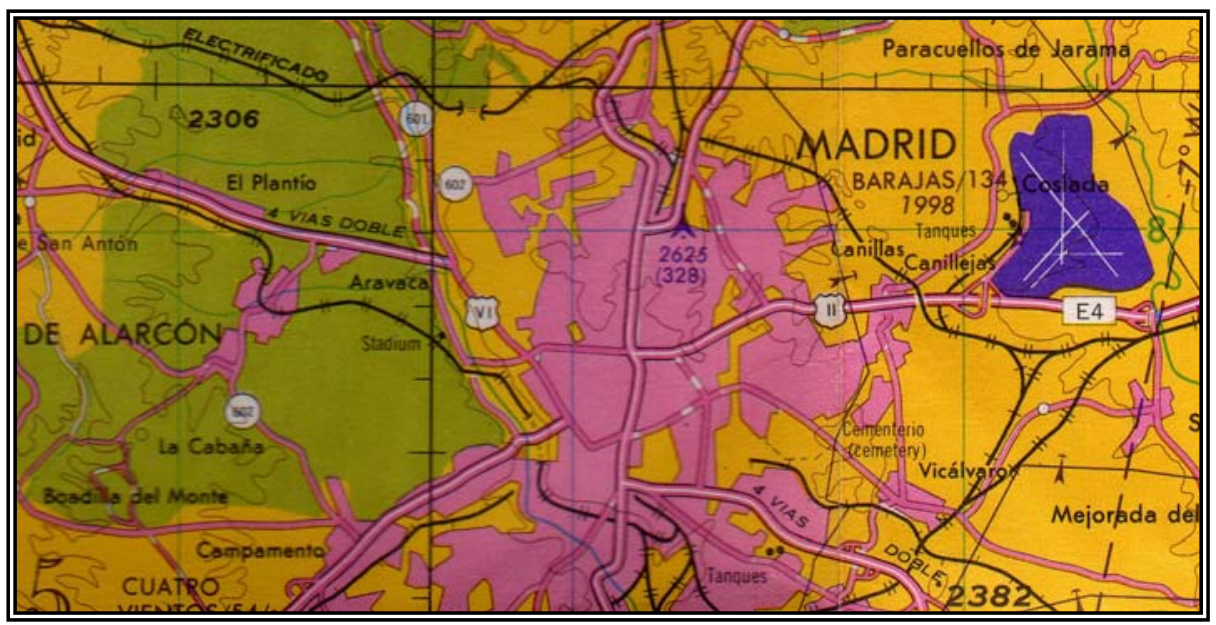

Figura 3.27. Cartografía urbana de Madrid, generalizada. Fuente: 1:250.000 del centro cartográfico y fotográfico del Ejército del Aire. 1.983.

En el caso de edificación aislada optaremos por la representación mediante símbolos, que obviamente tendrán una dimensión mayor que la que tendría el edificio en verdadera magnitud. Si se trata de un edificio singular tendrá una simbología específica, si no es así simplemente se utilizará la superficie mínima representable si se considera que la edificación es digna de mención.

Por otro lado, en el caso de núcleos de población deberemos pasar por la generalización, ignorando los viales menores, y conservando, no necesariamente en verdadera magnitud, aquellas vías que sirven para atravesar la ciudad y las consideradas como vías principales. Para discernir entre vías principales y secundarias lo correcto sería hacer un pequeño estudio histórico y cultural de la población o ciudad. 


\subsubsection{Divisiones administrativas}

La inclusión o no de divisiones administrativas dependerá en gran medida de la utilidad que se le vaya a dar al mapa; así en nuestro caso, será imprescindible incluir la mayor parte de ellas porque definirán cuál será en última instancia el organismo gestor del territorio.

En general se utiliza una simbología que resulta de combinar puntos, rayas y cruces, todos ellos en color negro.

En la figura 3.28. se puede apreciar la diferencia de simbología utilizada en el mapa 1:50.000 de la serie L del Servicio Cartográfico del Ejército para la delimitación local y provincial. Para la primera se utiliza una cruz y dos rayas y para la segunda una sucesión de cruz y raya.

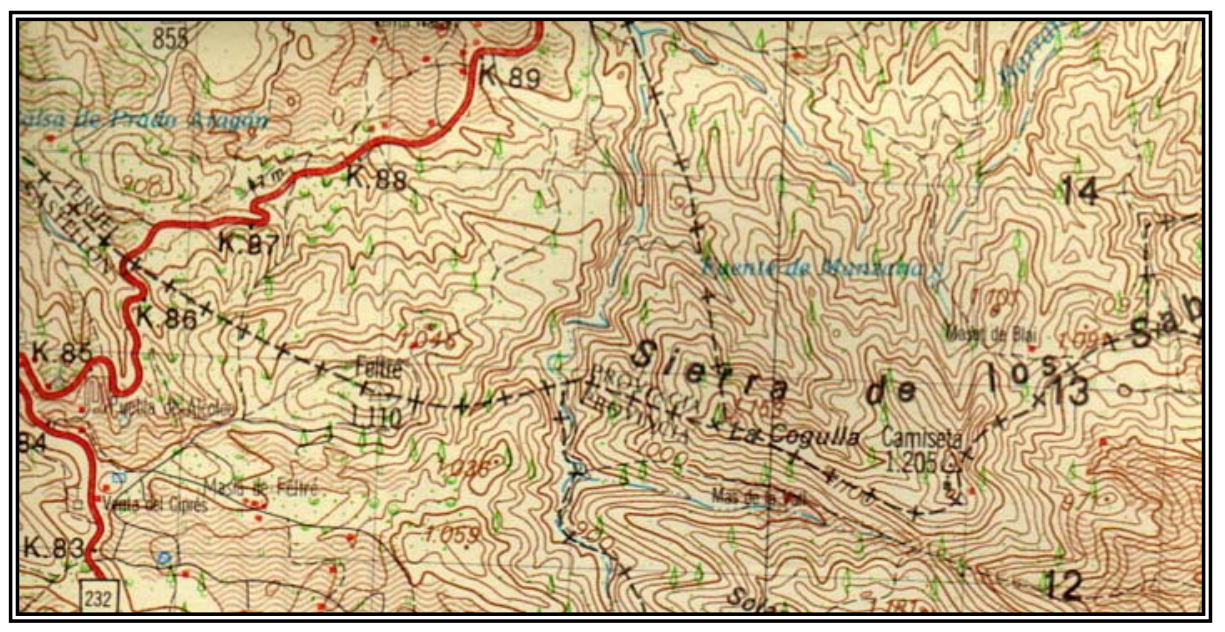

Figura 3.28. Límite local y provincial. Fuente: Serie L Servicio Cartográfico de Ejército.

Mención especial merecen los límites de zonas que cuentan con una especial protección, como Parques Naturales, Parques Nacionales, etc, cuyos límites suelen reseñarse utilizando el color verde para reflejar esa especial cualidad de espacio de interés ecológico.

En nuestro caso, esta delimitación de espacio protegido, o espacio de especial relevancia es fundamental, porque a la hora de ordenar el territorio, son zonas a respetar y además suelen ser zonas de interés paisajístico. 


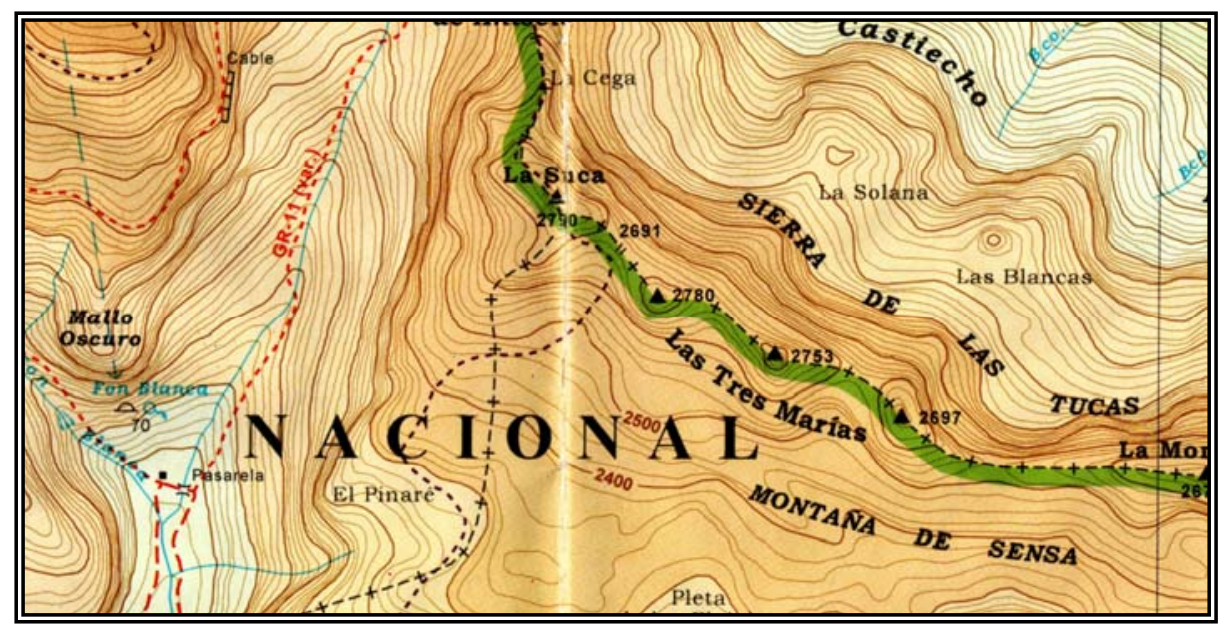

Figura 3.29. Límite de Parque Nacional. Fuente: Ordesa y Monte Perdido. Alpina.1.997.

\subsubsection{Vías de comunicación}

Se trata de elementos de vital importancia, ya que pueden definir el grado de desarrollo de una zona, aislar zonas próximas, crear servidumbres, etc.

En general no prescindiremos de ningún tipo de vías de comunicación, aunque sí podemos hacer alguna salvedad en función de la escala.

\subsubsection{Cartografía urbana}

Las calles serán las principales vías de comunicación que incluiremos en las cartografías municipales, sin que por ello dejemos de reseñar las grandes vías que atraviesen los núcleos urbanos. No definiremos una simbología específica para el viario urbano, puesto que supondremos que es viario todo aquello que no tenga otro tipo de uso.

\subsubsection{Cartografía territorial}

No hay una simbología generalmente utilizada para las vías de comunicación, según la serie cartográfica que consultemos encontraremos unos colores diferentes para los diferentes tipos de vía, en general se utilizan signos convencionales que no expresan el ancho real de la vía, sino la categoría de la misma, lo que deberemos exponer claramente es la correspondencia entre ambos con total claridad en la leyenda.

En las figuras 3.30., 3.31 y 3.32 se muestran varios ejemplos de las mismas. 


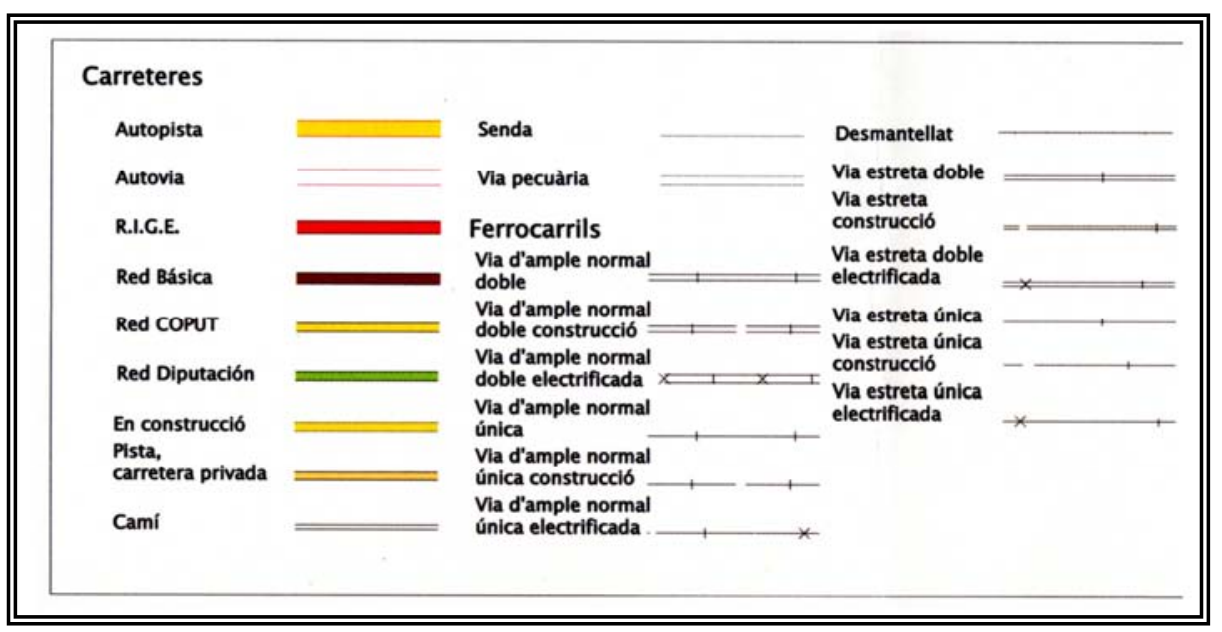

Figura 3.30. Leyenda Vias de Comunicación. Fuente: CV-10. I.C:V.

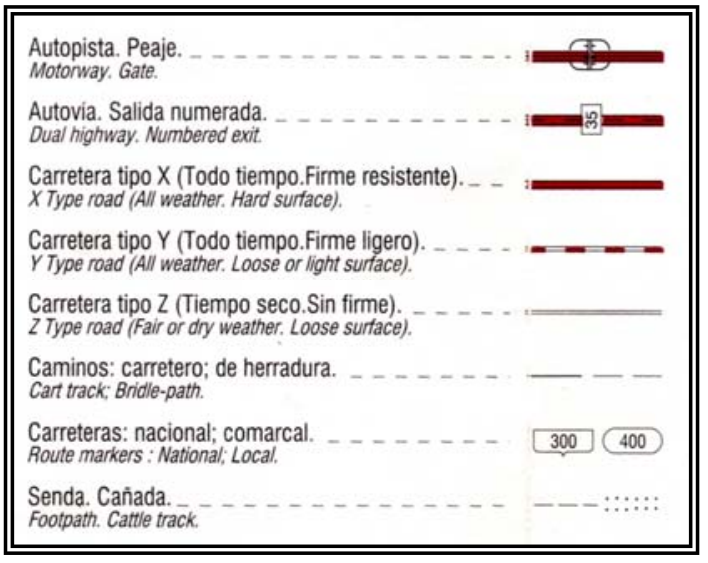

Figura 3.31. Leyenda Vias de Comunicación. Fuente: Ser. Cart. Ejército

Una clasificación ampliamente aceptada de las carreteras vendría a dividirlas en: autopistas, carreteras nacionales, regionales, comarcales y caminos. Estos últimos a su vez podríamos clasificarlos como: caminos transitables para todo tipo de vehículos, caminos transitables por vehículos especiales, y sendas, que sólo son transitables a pie. Conforme la escala aumenta, aumenta también el detalle, por lo que deberá aumentar la distinción entre las diferentes vías de comunicación. 


\begin{tabular}{|c|c|c|}
\hline \multicolumn{3}{|l|}{ Carreteras } \\
\hline Autopista. Autovia. & $\mathrm{N}-340$ & LR-111 \\
\hline Autonómica $2^{\circ}$ orden. Autonómica $3^{\sigma \alpha}$ orden y otras. & C-634 & CR-326 \\
\hline En construcción. Pistas y viales de urbanización. & $==\pi=\pi=\pi$ & \\
\hline Caminos. Sendas. & & \\
\hline Vía pecuaria. Estación de Servicio. & & $\operatorname{res}^{\mathrm{ES}}$ \\
\hline Ferrocarriles & & \\
\hline Via ancho normal: doble, sencilla. & & \\
\hline Via estrecha: doble, sencilla. & & \\
\hline Electrificado. En construcción. & & $1-1$ \\
\hline Abandonado. Teleférico. & & \\
\hline Telesilla. Telesqui. & $\tau$ & \\
\hline Estación. Túnel. Kilómetro. & - & K.54 \\
\hline Paso: a nivel, superior, inferior. & t & 1 \\
\hline & $f$ & $f$ \\
\hline
\end{tabular}

Figura 3.32. Leyenda Vias de Comunicación. Fuente: 1:25.000 I.G.N.

En lo que a ferrocarriles se refiere, se suelen representar en color negro y con una simbología que haga pensar en las traviesas del ferrocarril. Una muestra de ello la tenemos en la Figura 3.33.

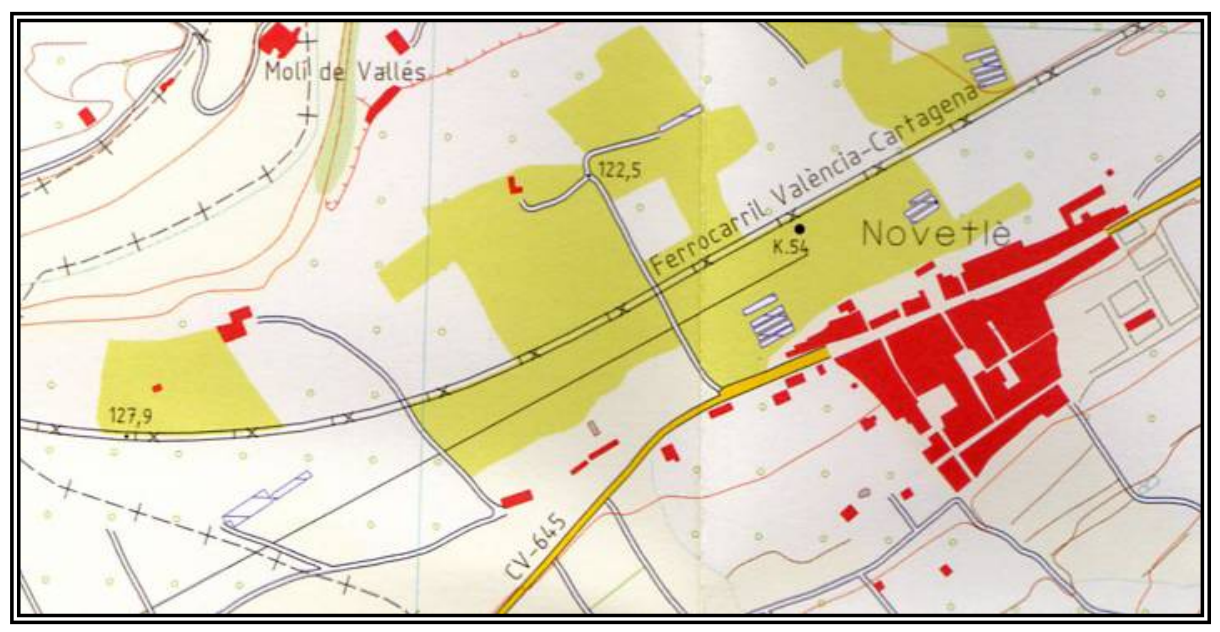

Figura 3.33. Ferrocarril en cartografía a 1:10.000. Fuente: CV-10. I.C:V. 
Todas estas vías irán generalmente acompañadas de su correspondiente PK (Punto Kilométrico), donde éste sea un número entero.

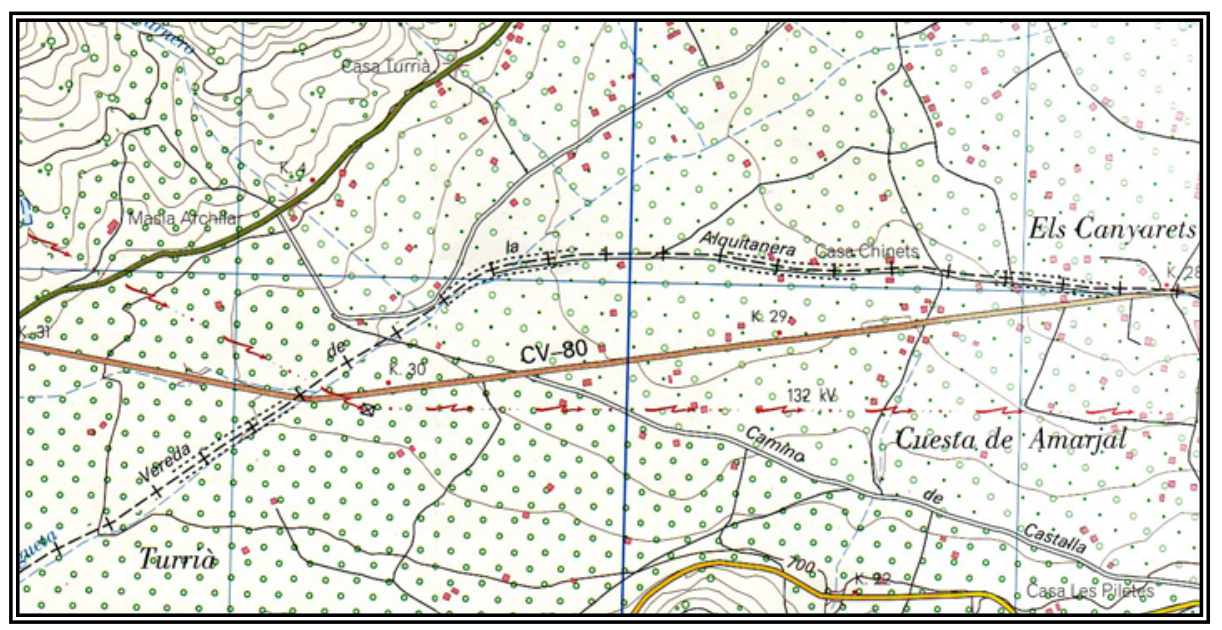

Figura 3.34. Representación de Via Pecuaria. Fuente: 1:25.000 I.G.N..

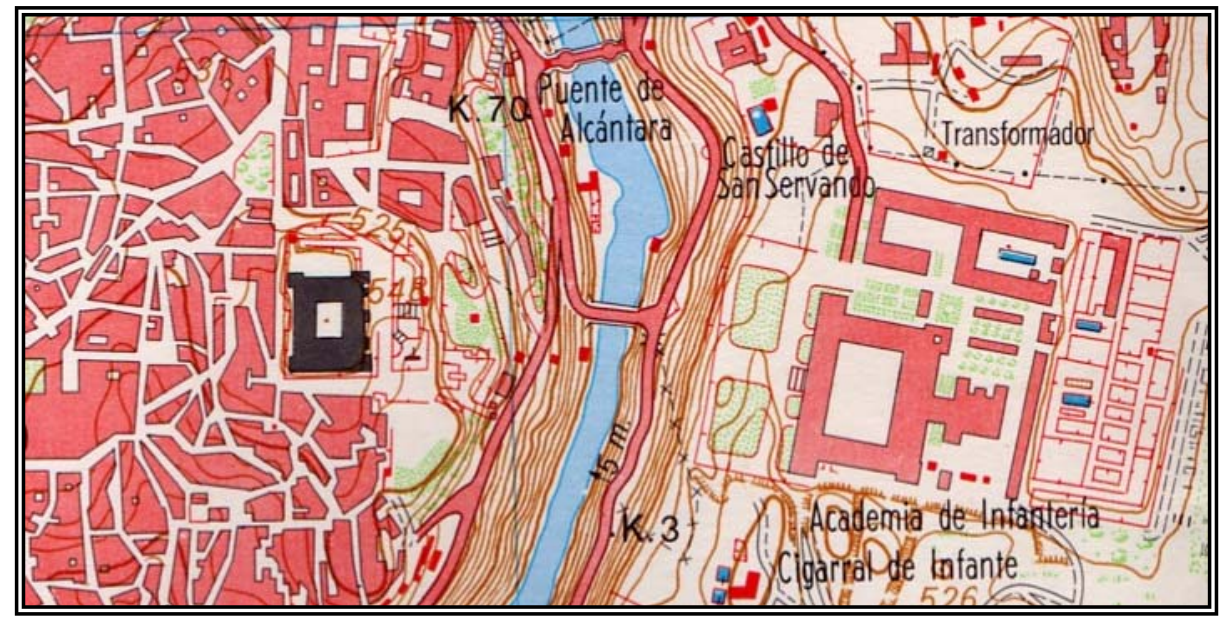

Figura 3.35. Representación de Puente. Fuente: 1:10.000 Serv. Cart. Del Ejército.

Otro tipo de vías de comunicación son las vías pecuarias, que deben figurar en una cartografía destinada a la Ordenación del Territorio por su carácter especial, ya que sobre ellas es aplicable una legislación y unas servidumbres particulares que se deberán respetar. Tenemos la solución adoptada por el I.G.N. en la Figura 3.34. 
Dentro de este apartado podemos estudiar también el tratamiento que se da a los puentes, que según la relevancia que tengan se representarán o no, pero siempre con un tamaño que permita distinguirlos con claridad, aunque esto suponga que no estén a escala. Un ejemplo lo podemos ver en la Figura 3.35..

\subsubsection{Toponimia}

La verdadera dificultad de la Toponimia no radica tanto en cómo colocar los topónimos sobre el mapa, sino en obtener y en su caso seleccionar los nombres correctos que finalmente colocaremos sobre la cartografía.

El proceso de recopilación de topónimos resulta lento y laborioso, ya que para conseguir las denominaciones "correctas" de los parajes de un territorio hay que realizar multitud de entrevistas a los lugareños y contrastar todas las informaciones obtenidas hasta hacernos con una serie de topónimos que de verdad reflejen la denominación popular de cada lugar entre las personas que allí habitan. Para ello, la persona encargada de esta tarea deberá tener unos mínimos conceptos de filología y un conocimiento bastante extenso en materia de Geografía, así como una paciencia considerable y mucha mano izquierda. Es por ello que una toponimia correcta es poco frecuente en la cartografía en general.

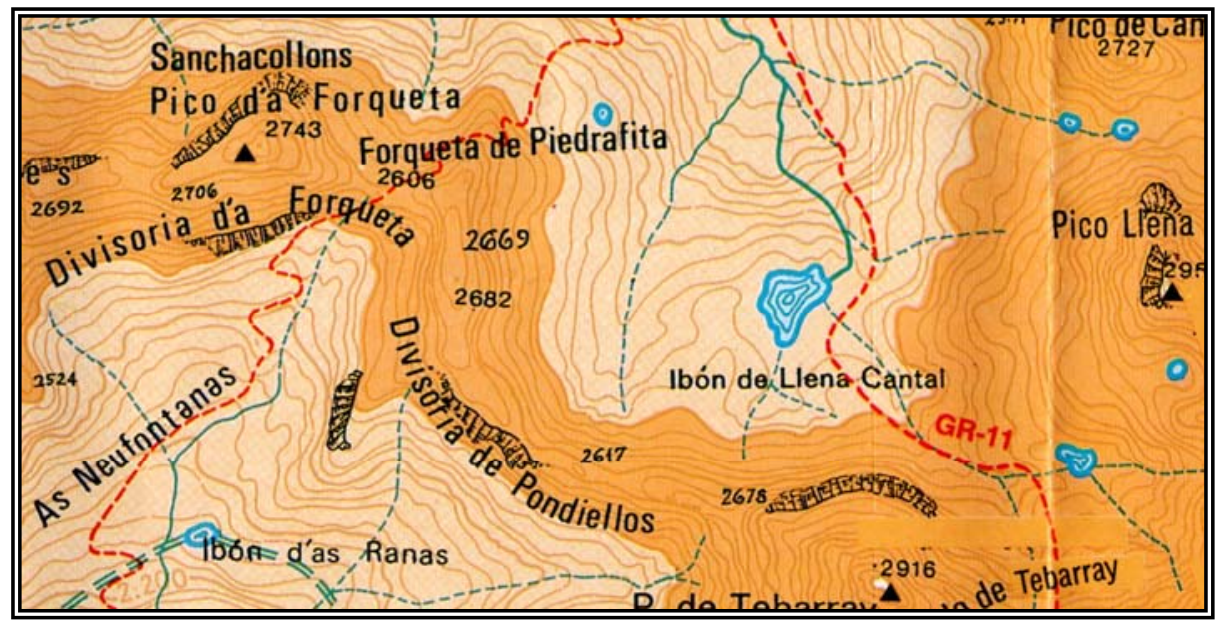

Figura 3.36. Toponimia en Fabla. Fuente: Panticosa-Formigal. 1:25.000 Alpina. 1.996.

Quizá la mayor dificultad la aporte el hecho de que un topónimo no designa unívocamente a una zona bien delimitada espacialmente, antes bien, existen topónimos que se refieren a grandes extensiones de terreno, que a su vez contienen pequeñas zonas que cuentan también con su propio topónimo. Estas pequeñas zonas pueden contener también otros topónimos de menor entidad, incluso puntuales, pero no por ello menos importantes, quizá su relevancia esté relacionada con algún hecho cultural y no podamos por ello obviarlo. 
Otro problema que se puede presentar es el uso en la zona de varias lenguas, generalmente en topónimos se prefiere conservar la lengua local que mayoritariamente utilice la población de la zona. Excepcionalmente se utilizan ambas lenguas. En la Figura 3.36. podemos apreciar el uso de la fabla en varios topónimos, como "Divisoria d'a Forqueta" o "Ibón d'as Ranas".

\subsubsection{Cartografía urbana}

Es en las grandes escalas donde podemos incluir la práctica totalidad de los topónimos que encontremos en una determinada zona, pero quizá nuestro problema sea aquí que no contemos con la información suficiente o correcta para ofrecer un resultado satisfactorio en aquellas zonas que no cuenten todavía con urbanización, ya que como hemos comentado, seleccionar la información no es tarea fácil.

La tónica general será la utilización de los nombre oficiales que cada Ayuntamiento haya adoptado para sus calles, plazas, barrios, etc, y no debe presuponerse mayor problema.

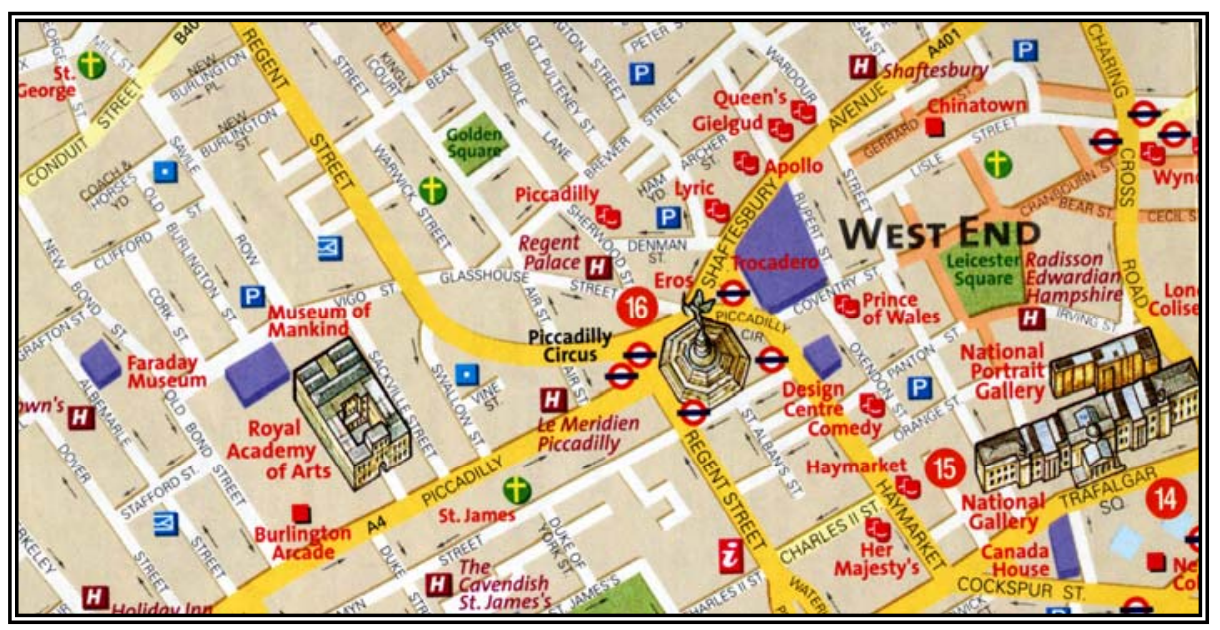

Figura 3.37. Cartografía urbana de Londres. Fuente: N.G.S..

\subsubsection{Cartografía territorial}

En lo que se refiere a la cartografía territorial, el problema es mucho más complejo. Debido a la escala, que impone la necesidad de eliminar parte de la información toponímica, nos veremos en la tesitura de tener que realizar una criba de los datos con los que contemos en principio, y no resultará fácil discernir entre lo que deberemos incluir y lo que no. 


\subsubsection{Riesgos}

Como puede suponerse, si estamos generando cartografía para Ordenación del Territorio, no podemos obviar la información acerca de los riesgos, que pueden condicionar severamente los usos que se le vayan a dar al territorio y cómo no, las actuaciones a llevar a cabo en un paisaje que se desee proteger y en el cual haya algún tipo de riesgo.

La susceptibilidad y el riesgo de que se produzca cualquier fenómeno nocivo no implica necesariamente un "riesgo", hasta que se pueda traducir en daños, bien sea en vidas humanas o en pérdidas económicas, por esta razón, para generar un verdadero mapa de riesgos se deberá contar, además de con un mapa de susceptibilidad, con información acerca de la actividad antrópica ${ }^{5}$.

La mayoría de los riesgos suelen deberse a la acción del hombre sobre el medio ambiente, aunque los grandes desastres se generan en su mayoría por catástrofes naturales. Tendremos pues dos tipos de riesgos, los naturales y los antrópicos.

Los riesgos naturales se deben principalmente a las características geológicas del terreno, aunque generalmente para que realmente exista un riesgo se debe dar una conjunción de condiciones adversas que no sólo serán geológicas, sino también climatológicas, ecológicas, etc, al margen de la actividad antrópica, que siempre estará presente.

Como riesgos propiamente geológicos podemos reseñar: vulnerabilidad a la contaminación de las aguas, deslizamientos, inundación, subsidencia y colapso y riesgos sísmicos $^{6}$. Si hablamos de riesgos climatológicos, podemos señalar los tornados, huracanes e inundaciones, estas últimas condicionadas siempre por la acción antrópica.

En los estudios de riesgo se utiliza una terminología propia para definir la peligrosidad, el riesgo y la vulnerabilidad.

De este modo, hablaremos de peligrosidad cuando nos refiramos al proceso y la definiremos como "probabilidad de ocurrencia de un proceso de un nivel de intensidad o severidad determinado, dentro de un periodo de tiempo dado y dentro de un área específica" (Varnes, 1984; Barbat, 1998); riesgo cuando hablemos de las pérdidas, su definición incorpora consideraciones socio-económicas y será "pérdidas potenciales debidas a un fenómeno natural determinado"; y por último vulnerabilidad si hacemos referencia a los daños, la definiremos como "grado de daños o pérdidas potenciales en un elemento o conjunto de elementos como consecuencia de la ocurrencia de un fenómeno de intensidad determinada. Depende de las características del elemento considerado y de la intensidad del fenómeno y se suele evaluar de 0 (sin daño) a 1 (destrucción total). ${ }^{.7}$.

Un mapa de riesgos tendrá como finalidad dividir el territorio en zonas con distinto grado de riesgo potencial. González de Vallejo, L. propone la siguiente clasificación de mapas de riesgos ${ }^{8}$ :

${ }^{5}$ González, M.R.. Método de validación del análisis SIG para la obtención de mapas de susceptibilidad a deslizamientos. Topografía y Cartografía N. 105.

${ }^{6}$ Diputació provincial de València et al., "Mapa Geocientífico de la provincia de Valencia”, 1986.

${ }^{7}$ González de Vallejo, L. I., "Ingeniería Geológica”, 2002.

${ }^{8}$ González de Vallejo, L. I., "Ingeniería Geológica”, 2002. 
Inventario. Se trata de mapas que incluyen la localización de los procesos, las características de los mismos y las zonas de afección. Se trata pues de información a posteriori.

Susceptibilidad. Se puede definir la susceptibilidad como la posibilidad de que una zona quede afectada por un determinado proceso. Los mapas de susceptibilidad podrán realizarse a partir de mapas inventario y mapas que incluyan los factores que pueden considerarse relevantes para que un proceso pueda ocurrir en una zona concreta.

Peligrosidad. En los que se cartografiará el grado de peligrosidad de las diferentes zonas. Se trata de analizar los factores y realizar una predicción espacial y temporal de la ocurrencia del proceso en cuestión.

Vulnerabilidad. Parece lógico pensar que en los mapas de vulnerabilidad se delimitarán las zonas con diferentes vulnerabilidades, para ello será necesario estudiar la peligrosidad de cada zona y los elementos expuestos.

Riesgo. Se trata de la cartografía final, resumen de todos los estudios realizados, en ella se reflejará el riesgo o grado de riesgo de cada zona, lo que conlleva la evaluación de las pérdidas potenciales debidas al proceso en estudio.

Multirriesgo. Si somos capaces de plasmar en una cartografía información acerca de diferentes procesos y el consiguiente riesgo que generan, hablaremos de mapas multirriesgo, que no serán más que la recopilación de varios mapas de riesgo en una única cartografía.

La simbología a utilizar suele ser bastante sencilla, ya que en la inmensa mayoría de los casos se trata de dividir el territorio en zonas con distinta susceptibilidad. Esto puede hacerse simplemente con cambios de color o trama.

\subsubsection{Cartografía urbana}

Aunque los mapas de riesgos suelen hacerse a nivel territorial, es principalmente en las zonas urbanas donde, como se ha comentado, existe un "riesgo" propiamente dicho.

En el caso de los mapas de riesgos, la única diferencia entre un plano urbano y un mapa territorial es la escala de representación, ya que incluso la simbología puede ser similar. Ni que decir tiene, que la cartografía base sobre la que se genere el mapa de riesgos sí será diferente, ya que para poder evaluar los daños potenciales en una zona urbana deberemos poseer información detallada de los elementos que encontramos en la citada zona.

\subsubsection{Cartografía territorial}

Es en esta cartografía, como ya hemos comentado, donde realmente se plasman los mapas de riesgo originales, ya que los procesos que generan estos riesgos suelen afectar a zonas generalmente extensas.

\subsubsection{Calificación y clasificación del suelo}

Es cuando hablamos de calificación y clasificación del suelo cuando estamos refiriéndonos realmente a Ordenación Territorial, pero para poder realizar un nuevo estudio de Ordenación Territorial y Conservación del Paisaje deberemos tener en cuenta la situación de 
partida, es decir, necesitaremos la información acerca de calificación y clasificación del suelo existente en el momento del estudio.

No podemos ofrecer una información acerca de clasificación y calificación del suelo válida para cualquier territorio, ya que dependerá de la legislación vigente en cada ocasión y zona, pero lo que sí podemos afirmar es que la clasificación del suelo se realiza en todo el territorio, tiene pues una escala territorial, y la calificación del suelo se centra en zonas urbanas, teniendo pues escala urbana.

\subsubsection{Cartografía urbana}

A esta escala vendrá representada la calificación del suelo, ésta está íntimamente relacionada con el uso autorizado para cada zona. Así, siempre teniendo en cuenta que dependerá de la legislación correspondiente, encontraremos suelo residencial, verde, industrial, servicios, equipamiento...

\subsubsection{Cartografía territorial}

Será esta pues la escala de representación de la clasificación del suelo que, también como hemos dicho según dicte la ley en vigor, nos informará utilizando unas u otras figuras de la capacidad o no de urbanización del suelo. Generalmente se utilizarán términos como suelo urbanizable, no urbanizable, urbano...

\subsubsection{Información marginal}

Denominaremos así a toda aquella información generalmente no gráfica que deberemos incluir en nuestra cartografía para aportar legibilidad a la misma. De este modo estudiaremos la leyenda, el título, las escalas a incluir y los gráficos de situación.

\subsubsection{Estructura de la leyenda}

La leyenda es un elemento enormemente útil en todo mapa o plano, indispensable en aquellos con cierta complejidad. Servirá para explicar la simbología utilizada en el mapa, y cuando hablamos de simbología no nos referimos únicamente a los símbolos propiamente dichos, sino también a los colores, grosores de línea, toponimia, etc.

Nuestra leyenda debe ser siempre un elemento de fácil distinción, ya que el usuario final deberá poder encontrarla rápidamente.

$\mathrm{Ni}$ que decir tiene que los colores de la leyenda deben coincidir exactamente con los del mapa, así como los grosores, tipos de línea y simbología, para que sea posible identificar sin margen de duda cualquier elemento de la cartografía en la leyenda.

Deberán incluirse absolutamente todos los símbolos que se utilicen en el mapa, por muy intuitivos que éstos nos parezcan, ya que pueden no serlo para un usuario menos experto.

La leyenda deberá estar separada del mapa claramente, generalmente se incluye en un cuadro aparte. 


\subsubsection{Título}

Es importante dotar a nuestra cartografía de un título que la haga fácilmente identificable, sobre todo si forma parte, como suele ser usual, de una serie cuyos ejemplares son parecidos, en ocasiones de la misma zona o bien difícilmente identificables.

El título debe ser fácil de encontrar, aunque no por ello tiene que ocupar una porción excesiva del formato, esto dependerá del diseño del mapa y de la función para la que se esté elaborando.

\subsubsection{Escalas}

La escala es un concepto importantísimo que, como ya se ha comentado en el apartado 2.5.4, condiciona la información a incluir en la cartografía. Generalmente se suele trabajar con el concepto de "límite de percepción visual", esto es, se considera que el cerebro humano no es capaz de discernir entre dos líneas que estén separadas una distancia menor de $0,2 \mathrm{~mm}$, esto tiene como consecuencia que cualquier objeto que a escala vaya a tener unas dimensiones menores de $0,2 \mathrm{~mm}$ no tendrá representación. Por esta razón una de las primeras cuestiones que el cartógrafo deberá tener en cuenta a la hora de abordar la toma de datos para la realización de un trabajo será el objeto mínimo a representar, que obtendrá simplemente multiplicando $0,2 \mathrm{~mm}$ por el denominador de la escala de representación. Así, la toma de datos condiciona la escala final de representación de manera que será correcto obtener cartografía a escalas menores que la fijada en principio, mediante procesos de generalización, pero nunca mayores.

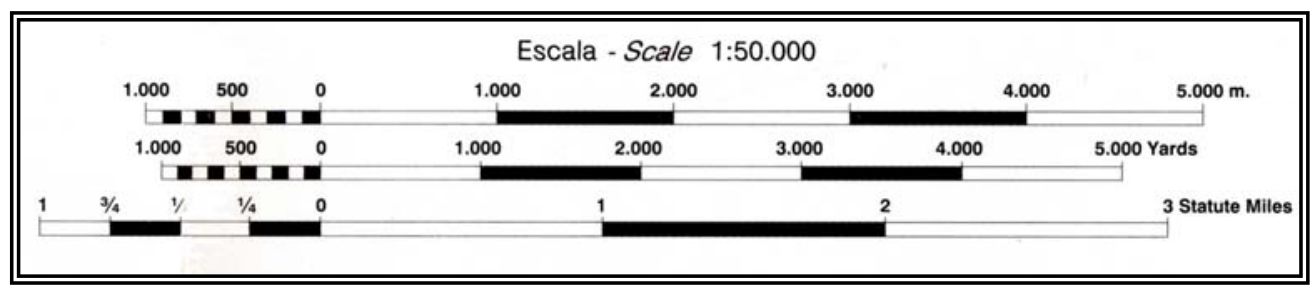

Figura 3.38. Escalas gráficas y numérica. Fuente: Serv. Cart. Del Ejército.

Dependiendo del tipo cartografía y del usuario final, incluiremos un tipo de escala u otro. Existen varias formas de expresar la escala en un mapa, pero las más usuales son: la escala numérica, que debe incluirse siempre y que simplemente es una relación entre las dimensiones de cualquier elemento en el mapa y en la realidad; y la escala gráfica, que no es más que un gráfico que nos muestra la dimensión real de una porción de mapa, esta escala puede tener diferentes diseños, aunque suelen ser siempre combinaciones de trazos blancos y negros para facilitar su uso. 


\subsubsection{Gráficos de situación}

No se trata de un elemento imprescindible, pero sí extremadamente útil.

Se utilizará sobre todo en el caso de que nuestra cartografía no sea un ejemplar aislado, sino que forme parte de una serie o proyecto o bien simplemente para situar espacialmente la porción de terreno que estamos representando en una zona más amplia y generalmente más fácilmente reconocible por el usuario.

En ambos casos lo que se incluyen son "mapas" de situación, que no son más que mapas de una escala mucho menor, sin necesidad de consignar cuál es esta escala, donde se reseña de forma muy vistosa la zona que se amplía en la cartografía a realizar.

Obviamente no se trata de un elemento tan importante como la escala o la leyenda, por lo que no deberá ocupar un lugar especialmente relevante del conjunto. Existe cartografía, como la serie L del Servicio Cartográfico del Ejército en la que esta información se incluía en el reverso. Ver Figura 3.39.

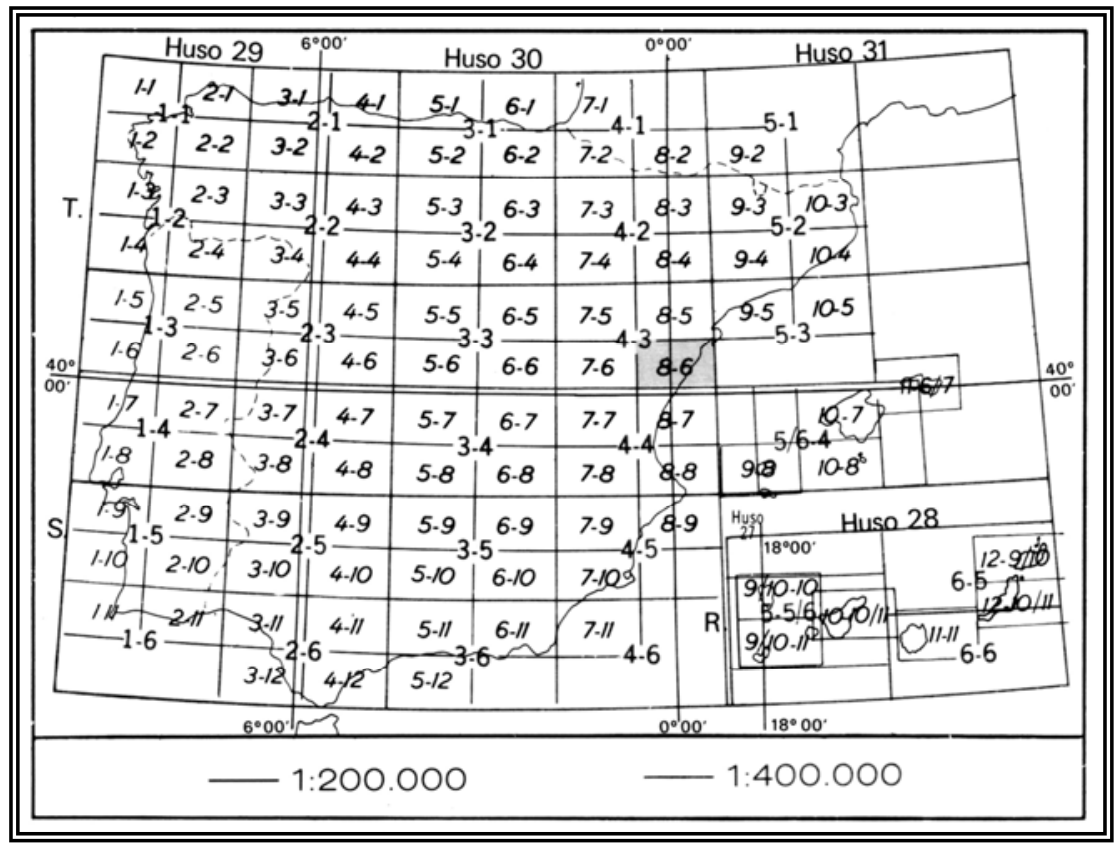

Figura 3.39. Gráfico de situación en el reverso. Fuente: Serv. Cart. Del Ejército. 



\section{ELABORACIÓN DE UNA PROPUESTA DE NORMALIZACIÓN}

\subsection{Elección del tipo de mapa en función de las necesidades}

La Cartografía resulta ser una potente herramienta para la Ordenación del Territorio y el estudio del Paisaje, pero resulta imprescindible una correcta elección del material a utilizar, sobre todo de la información contenida en éste, para que podamos sacar el mayor partido a la citada información.

\subsubsection{Diferentes mapas necesarios para la Ordenación del Territorio}

Debido a la amplitud del concepto de Desarrollo Territorial será también considerable la variedad de la cartografía a utilizar, según el uso que se vaya a hacer de la misma se tendrán unas u otras restricciones que estudiaremos mediante el análisis de los siguientes puntos.

\subsubsection{Precisión y escala}

Son éstos conceptos íntimamente relacionados en cartografía, ya que la escala a utilizar dependerá de la precisión requerida. Ya se ha comentado en los apartados 2.5.4. y 3.4.12.3. la importancia de la escala en Cartografía, en este trabajo se propondrá una normalización de las escalas cartográficas a utilizar para cada tipo de gestión intentando optimizar recursos, esto es, utilizando la escala que nos proporcione toda la información necesaria con un menor coste. Pero a la vez tendremos en cuenta el contexto en el que se realiza este trabajo, así, haremos lo 
posible por ajustarnos a lo que dicta el "Reglamento de Paisaje de la Comunitat Valenciana", del que ya hemos hablado en el apartado 2.4.10..

Siguiendo las pautas marcadas el apartado 2.5.4., distinguiremos tres tipos de cartografía en función de la escala, según su posterior uso: Planeamiento Urbano, Gestión Territorial o Mapas de Síntesis. En esta tesis nos ocuparemos únicamente de Planeamiento Urbano y Gestión Territorial, por considerar que los Mapas de Síntesis son unas pautas comarcales, y no verdadera Ordenación Territorial.

El Reglamento mencionado aconseja como escala para los Estudios de Paisaje, que podemos considerar Gestión Territorial la escala 1:20.000, que aunque no es una escala nada usual, es a la que está elaborando el Instituto Cartográfico Valenciano toda la cartografía base para ponerla a disposición de Ayuntamientos u otros organismos que lo soliciten.

\subsubsection{Cartografía topográfica y temática}

El Desarrollo Territorial tiene un alto componente multidisciplinar; siempre tomando como base la información topográfica, deberemos ser capaces de generar múltiples mapas temáticos que contengan la información referente a cada materia a tener en consideración. Se propondrá en el presente trabajo la simbología a aplicar para cada uno de los mapas que se considere que pueden aportar información útil para nuestro propósito.

\subsubsection{Cartografía disponible}

Por descontado, somos conscientes de que vamos a generar cartografía a partir de información o cartografía ya existente, por lo tanto resulta imprescindible realizar un estudio de la cartografía disponible, no sólo para conocer los datos de que disponemos sino también para que no se produzca duplicidad y la consiguiente pérdida de recursos económicos.

Estudiaremos la cartografía disponible a nivel estatal, aunque también nos centraremos en la cartografía de la Comunidad Valenciana, que al fin y al cabo es de la que podemos disponer con mayor comodidad y la que vamos a utilizar para nuestra aplicación.

Recopilada toda la información disponible, estaremos en disposición de seleccionar aquella que consideremos útil para conformar los mapas que ofreceremos como resultado.

\subsection{Datos a incluir}

Como llevamos haciendo a lo largo de todo el trabajo, distinguiremos dos tipos de cartografía, urbana y territorial, también a la hora de estudiar los datos a incluir.

Aunque, como se ha comentado en el apartado 3.2., la cartografía que utilizaremos para realizar la ordenación del territorio y los estudios de paisaje contendrá mucha y muy variada información, estos datos nos servirán para realizar el análisis, pero no podremos ni deberemos incluirlos todos en la cartografía final.

En estos mapas o planos que obtendremos como resultado de nuestro estudio, deberemos incluir la información básica para la situación correcta en el terreno de cualquier usuario, elementos importantes como pueden ser: 
En cartografía territorial:

- Ríos y barrancos

- Elementos hidrográficos

- Curvas de nivel

- Vías de comunicación

- Límites administrativos

- Edificaciones

- Red eléctrica

- Toponimia

En cartografía urbana:

- Ríos y barrancos

- Elementos hidrográficos

- Curvas de nivel

- Vías de comunicación

- Límites administrativos

- Edificaciones

- Red eléctrica

- Toponimia

Y por supuesto aquellos datos que se deriven del trabajo realizado; vamos a dividir estos elementos además en superficiales, lineales y puntuales:

En cartografía territorial:

- Superficiales:

o Microreservas

o Espacios de especial relevancia

o Riesgos geológicos

o Vegetación

o Clasificación del suelo

o Usos del suelo

- Lineales

o Unidades fluviales

o Vías pecuarias

o Corredores (según su anchura pueden considerarse superficiales) 
- Puntuales
o Fuentes
o EDAR
o Vertederos
o Granjas
o Industrias contaminantes
o Canteras (abandonadas o no)

En cartografía urbana:

- Superficiales:

o Calificación del suelo

o Ruido

- Lineales

o Viales

o Alineaciones

o Conducciones

- Puntuales

o Edificios singulares

o Servicios

o Mobiliario urbano

Como puede imaginarse, todos estos datos se pueden representar en un sistema de información geográfica, pero no en un solo mapa, ya que la información, sobre todo la superficial, se solapa y resulta incompatible su representación. Ha sido necesario pues estudiar el tipo de información y ver cuántos mapas se necesitan como mínimo para la correcta representación de la misma. Tras esta tarea se llegó a la conclusión de que son necesarios tres mapas territoriales y un plano urbano. 


\subsection{Normalización y maquetación}

Una vez tengamos clara la cartografía que vamos a generar y la escala de la misma, en función de la precisión y el detalle requeridos para cada caso, pasaremos a estudiar la forma más adecuada de representar los eventos en el mapa.

\subsubsection{Diseño de la hoja}

Cualquier cartografía no cumple su función si además de la información propiamente cartográfica no contiene un cajetín que nos dé información acerca de: quién ha elaborado el mapa, a qué zona se refiere, escala, fecha, etc.,; del mismo modo deberá contener una leyenda que nos permita interpretar la simbología que encontremos, es lo que hemos llamado en el apartado 3.4.12. información marginal. Estos y otros detalles, que aunque parecen puramente estéticos son de vital importancia, deberán ser considerados a la hora de proponer una cartografía normalizada, ya que forman también parte integrante del mapa.

\subsubsection{Elección del formato del papel}

El tamaño de la hoja en la que vamos a plasmar la información tratada depende en gran medida de la escala utilizada y de la superficie a cartografiar. En ocasiones será esta superficie la que condicione la escala de representación, debido a que las dimensiones del papel no son ilimitadas.

Ya se han expuesto los formatos de papel normalizados, que son los que habitualmente se utilizarán; deberemos elegir el que mejor se adapte a nuestras exigencias según el objetivo perseguido en cada ocasión, teniendo en cuenta que los mapas que vamos a generar deben servir de herramienta a los distintos profesionales implicados y por ello se tendrá también en cuenta la manejabilidad de la cartografía.

La solución adoptada en nuestro caso, intentando dar prioridad al formato A1 por su manejabilidad, fue: utilizar un formato A1 (en realidad algo menor) para la cartografía urbana; y ante la imposibilidad de incluir todo el término municipal a escala 1:20.000 en el formato mencionado, se adoptó uno algo mayor para la cartografía territorial. Esto se hizo por tratarse de una cartografía piloto y no una serie; a la hora de producir una serie debería normalizarse el tamaño para que fuese el mismo en todos los ejemplares.

\subsubsection{Diseño del cajetín}

El cajetín debe permitir, al primer vistazo, averiguar de forma clara qué tipo de cartografía tenemos en nuestras manos y dentro de esa serie, qué mapa en concreto. Y esto debe ser posible no sólo para especialistas, sino generalmente para un amplio abanico de profesionales de diferentes sectores.

La cuestión del diseño del cajetín, altamente relacionada con la estética, debe estudiarse cuidadosamente, porque el cajetín debe aportar la información necesaria sin ocupar un espacio excesivo, pues se trata de un elemento que, aunque importante, no deja de ser secundario. 


\subsubsection{Diseño de la leyenda}

Herramienta imprescindible para la correcta interpretación del mapa, la leyenda debe aportar información acerca de la simbología utilizada en el mismo y su correspondencia con los elementos reales, la colocaremos en un lugar que permita consultarla con facilidad, siendo así, sólo la colocaremos en el reverso de la hoja cuando no tengamos otra opción.

Se diseñará una leyenda tipo que sea común para toda la cartografía generada con el fin de que los usuarios puedan recordarla y no se vean obligados a interpretar una simbología diferente en cada mapa de la serie.

\subsubsection{Configuración de la hoja}

Una vez tomada la decisión de qué formato utilizar y teniendo en cuenta el tamaño del cajetín y la leyenda, deberemos distribuir todos los elementos que compondrán el mapa final sobre la hoja. Lo haremos de forma que resulte fácil la interpretación del mapa y teniendo en cuenta que los mapas se presentarán en general plegados, por lo que se intentará que el cajetín sea visible sin necesidad de desplegar el mapa.

En los mapas generados, se colocará el cajetín en la esquina inferior derecha, ocupando toda la superficie que ocupe el mapa plegado, a su izquierda en una franja que llene toda la anchura del mapa, colocaremos la leyenda.

\subsubsection{Estudio de la simbología a utilizar}

A la hora de elaborar cualquier cartografía vamos a encontrar elementos que queramos representar pero cuyo tamaño sea menor que el tamaño mínimo representable de acuerdo con la escala, para resolver este problema es para lo que vamos a utilizar la simbología. Cuando hablamos de simbología en general nos referimos tanto a los símbolos puntuales (iconos que representan por ejemplo lugares de interés) como lineales (por ejemplo carreteras de distinta jerarquía) o superficiales (como serían áreas con distinta vegetación).

Una vez elegida la simbología que consideremos adecuada, nos cuidaremos de que, como ya se ha comentado, sea la misma para toda la serie y por supuesto coincidente en mapa y leyenda.

\subsection{Tratamiento de la información}

Es obvio que no podemos utilizar toda la información de que dispongamos, entre otras cosas porque no aporte datos interesantes para el objetivo que nos ocupa. La información reunida deberá ser meticulosamente estudiada y clasificada con el fin de extraer de ésta la que realmente nos resulte interesante. 


\subsubsection{Generalización cartográfica en los casos en los que resulte necesario}

Dado que, aunque actualmente las técnicas informáticas lo permiten con excesiva facilidad, no es correcto obtener de una cartografía otra de menor escala, nos plantearemos el caso contrario, con el que podemos encontrarnos con relativa frecuencia.

Es considerablemente común el hecho de la generalización cartográfica, que no es otra cosa que la eliminación de ciertos datos de una cartografía para conseguir otra de menor escala; se trata de una operación laboriosa que podemos simplificar mediante el uso de aplicaciones informáticas, aunque será siempre precisa una revisión posterior de un técnico cualificado.

En nuestro caso, la generalización cartográfica fue necesaria en los mapas territoriales, ya que la cartografía base con que contábamos fue el mapa a escala 1:10.000 del Instituto Cartográfico Valenciano, y los mapas a generar tendrían escala 1:20.000. En el caso de la cartografía urbana, este proceso no fue necesario ya que la información de partida se justaba a la escala final de representación.

\subsubsection{Depuración y clasificación de los datos}

Lógicamente, de la misma forma deberemos proceder con los datos no cartográficos, de los que deberemos extraer aquellos que necesitemos y clasificarlos para su correcta incorporación a la cartografía. Estamos hablando de la información en forma de símbolos puntuales que deberemos incluir.

En el caso de que incorporemos toda nuestra información a un Sistema de Información Geográfica, la correcta clasificación de los datos no sólo resulta útil, sino imprescindible, ya que tendremos que incorporar toda la información a tablas que asociaremos a la cartografía.

\subsection{Análisis de la simbología necesaria}

La elección de la simbología vendrá condicionada por la previa elección de los datos a incluir, a partir del listado de todos los datos que contendrá nuestra cartografía, elegiremos, teniendo en cuenta todas las variables estudiadas, los que permitan con mayor facilidad la legibilidad del mapa.

Los datos que más nos interesan no son los que hemos considerado como cartografía básica, aún así, no optaremos por otorgarles a éstos una menor relevancia consignándolos todos en un único color discreto, ya que son lo suficientemente relevantes como para que les dotemos de su propia simbología.

Obviamente deberemos estudiar la simbología necesaria para cada uno de los datos expuestos en el apartado 3.5.2.. 


\subsection{Niveles de percepción, propiedades perceptivas y estudio de las variables visuales}

Una vez analizados los datos que formarán parte de nuestra cartografía, será conveniente analizar las relaciones entre ellos para, a partir de estas relaciones, disponer unos niveles de percepción que nos permitan estructurar la información que aportarán nuestros mapas finales.

A partir de estos niveles de percepción podremos establecer unas propiedades perceptivas diferentes para cada uno de los temas a representar.

Como es de suponer, la información básica se ubicará en el nivel inferior, al que se dotará de menor protagonismo y por ello menor peso visual. El resto de los elementos, a los que se concederá una importancia mayor, serán objeto de un estudio más exhaustivo.

Y tras la identificación de las propiedades perceptivas de cada uno de los grupos de información, así como las de los elementos de cada grupo, el siguiente paso consistirá en la identificación de las variables visuales que nos permitirán materializarlas en la cartografía ${ }^{1}$.

\subsection{Diseño de la simbología}

Resulta imprescindible realizar un estudio de la simbología a utilizar ya que, independientemente de que el mapa cuente con una leyenda que aclare la correspondencia de cada símbolo con la realidad, los iconos utilizados, los colores y grosores deben evocar de forma intuitiva el elemento al que representan, para que en la medida de lo posible se pueda prescindir de la consulta continua de la leyenda.

A continuación procederemos a estudiar de forma separada cada uno de los elementos que formarán parte de nuestros mapas con el objeto de encontrar la simbología más adecuada para su representación, siempre teniendo en cuenta el conjunto de la cartografía final.

\subsubsection{Ríos y barrancos}

Unos de los datos más útiles a la hora de localizarse en una zona suelen ser los cursos fluviales, por esta razón los consideraremos parte de nuestra cartografía base y los incluiremos en todos los mapas que realicemos, ya sean a escala territorial o urbana.

\subsubsection{Estudio del color}

Los elementos hidrográficos objeto de este apartado, ríos y barrancos, se han representado tradicionalmente en color azul, y aunque en nuestro caso se considera esta información como cartografía base, conservaremos este color azul para su representación por considerar que aporta claridad y legibilidad a nuestros mapas.

1 Pérez, R. Propuesta de Normalización para la representación cartográfica en Internet. Tesis Doctoral. Madrid, 2003. 
Por otro lado, precisamente por tratarse de cartografía base y para no restar relevancia a los datos temáticos, elegiremos un azul claro $(168,235,255)$. Y un azul más oscuro $(0,168$, 255) para las ocasiones en que haya que representar espacialmente el río, en cuyo caso se bordeará el sombreado azul claro con este segundo azul más oscuro.

\subsubsection{Elección de la simbología}

Al tratarse en su mayoría de símbolos lineales, no se hará necesaria una simbología específica, aparte de los tipos de línea que se detallan en el siguiente punto, sólo en el caso de que la magnitud del río requiera una representación espacial se utilizará un sombreado de los colores anteriormente comentados.

\subsubsection{Elección del grosor y tipo de línea}

Deberemos distinguir generalmente entre ríos y barrancos y lo haremos mediante la elección del tipo de línea, utilizando una línea continua para los ríos, o cursos de agua permanentes, y una línea discontinua para los cursos intermitentes o barrancos. Podemos ver el resultado en la figura 3.40. No haremos ningún tipo de distinción por medio del grosor en este caso.

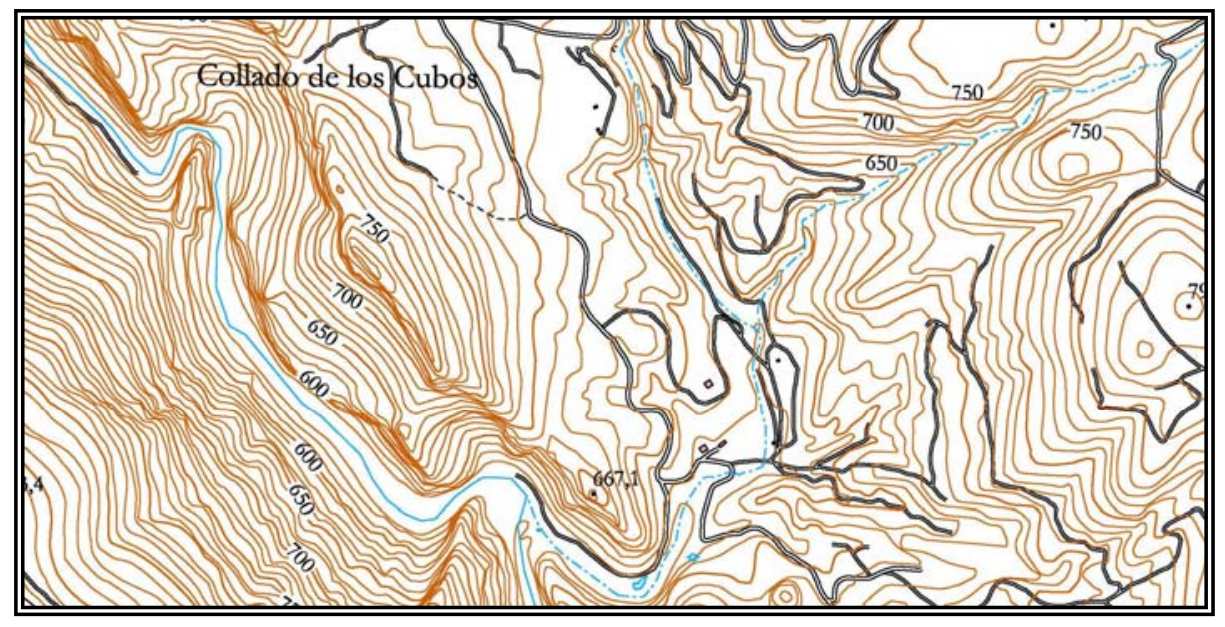

Figura 3.40. Representación de ríos y barrancos en la cartografía base.

\subsubsection{Otros elementos hidrográficos}

Además de ríos y barrancos podemos encontrar un gran número de elementos hidrográficos, en este trabajo definiremos la simbología a aplicar para la representación de los más comunes, depósito de agua, manantial, pozo, fuente, estanques, piscina, canalizaciones... 


\subsubsection{Estudio del color}

Dado que se trata también de elementos relacionados con el agua, utilizaremos los mismos colores azules que ya utilizamos para los ríos y barrancos, combinándolos con negro para que resalte más sobre el fondo. Las únicas excepciones serán: el uso de un color marrón $(126,109,0)$ para las conducciones de saneamiento y el uso de un azul básico $(0,0,255)$ para las acequias, para distinguir los cursos naturales de los artificiales.

\subsubsection{Elección de la simbología}

Como en todos los casos intentaremos que los símbolos sean lo más intuitivos posible, facilitando siempre su distinción pero procurando que el usuario aprecie que todos estos elementos pertenecen a una misma familia. Esto ya se conseguirá en gran parte con el uso del color azul. El tamaño será suficiente para que se puedan distinguir con claridad los símbolos pero lo convenientemente pequeños para que no se sature el mapa.

El criterio adoptado será el uso de un rectángulo de tamaño 4x2 mm para los elementos más grandes y un círculo de diámetro $2 \mathrm{~mm}$ para los más pequeños, siempre de color azul (168, $235,255)$ a partir de esto se realizarán pequeñas modificaciones para conseguir el símbolo final.

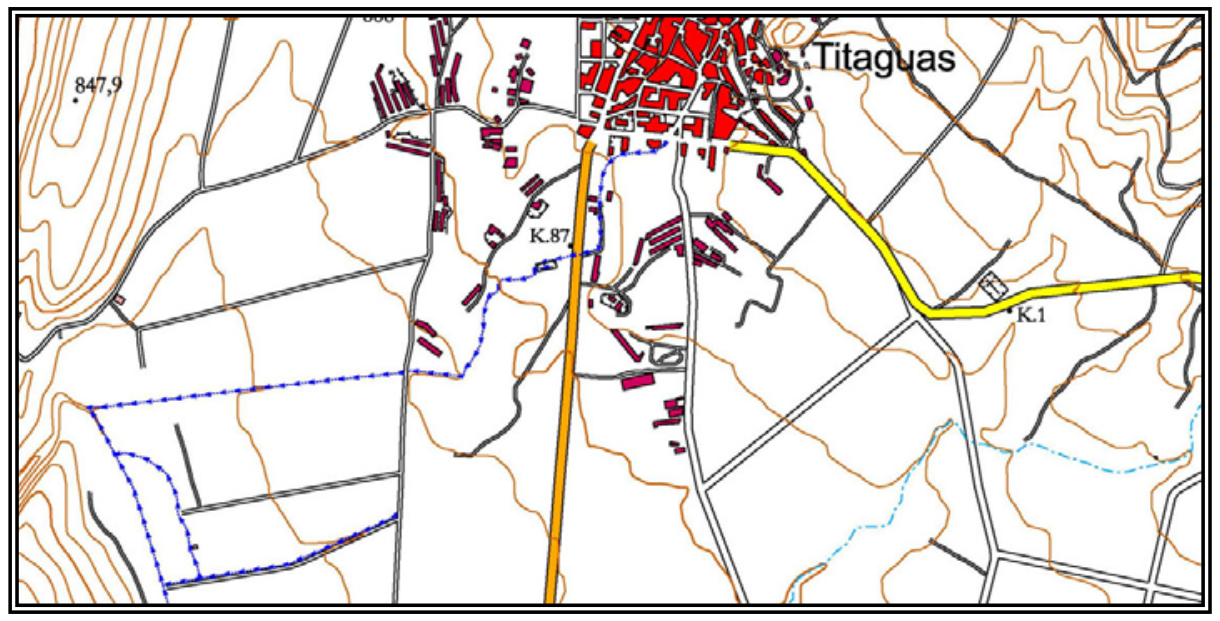

Figura 3.41. Representación de acequias y barrancos.

Estudiemos cada elemento por separado:

- Estanque. Partiremos del rectángulo básico y lo rodearemos de un borde azul oscuro $(0,168,255)$.

- Piscina. Partiremos del rectángulo básico y lo rodearemos de un borde negro $(0,0,0)$.

- Depósito de agua. Utilizaremos el rectángulo básico, con un borde de azul oscuro (0, $168,255)$ y una diagonal de este mismo color.

- Pozo. Partiendo del círculo básico, lo rodearemos de azul oscuro $(0,168,255)$.

- Manantial. Partiendo del círculo básico, lo rodearemos de azul oscuro $(0,168,255)$ y le añadiremos una línea vertical en la parte inferior de este mismo azul oscuro. 
- Fuente. Partiendo del círculo básico, lo rodearemos de azul oscuro $(0,168,255)$ y le añadiremos dos líneas horizontales, una a cada lado, de este mismo azul oscuro.

\subsubsection{Elección del grosor y tipo de línea}

No utilizaremos grosores en lo que a elementos hidrográficos se refiere, pero sí, además de un color distinto, un tipo de línea diferente para las canalizaciones artificiales.

El grosor que utilizaremos será $0,1 \mathrm{~mm}$.

En la figura 3.41. se pueden apreciar todos estos símbolos.

\subsubsection{Curvas de nivel}

Se trata también de información básica para la correcta interpretación del mapa, ya que nos aporta detalles acerca del relieve. Como su nombre indica, se trata de curvas, por lo que sólo procederá estudiar el color, grosor y tipo de línea.

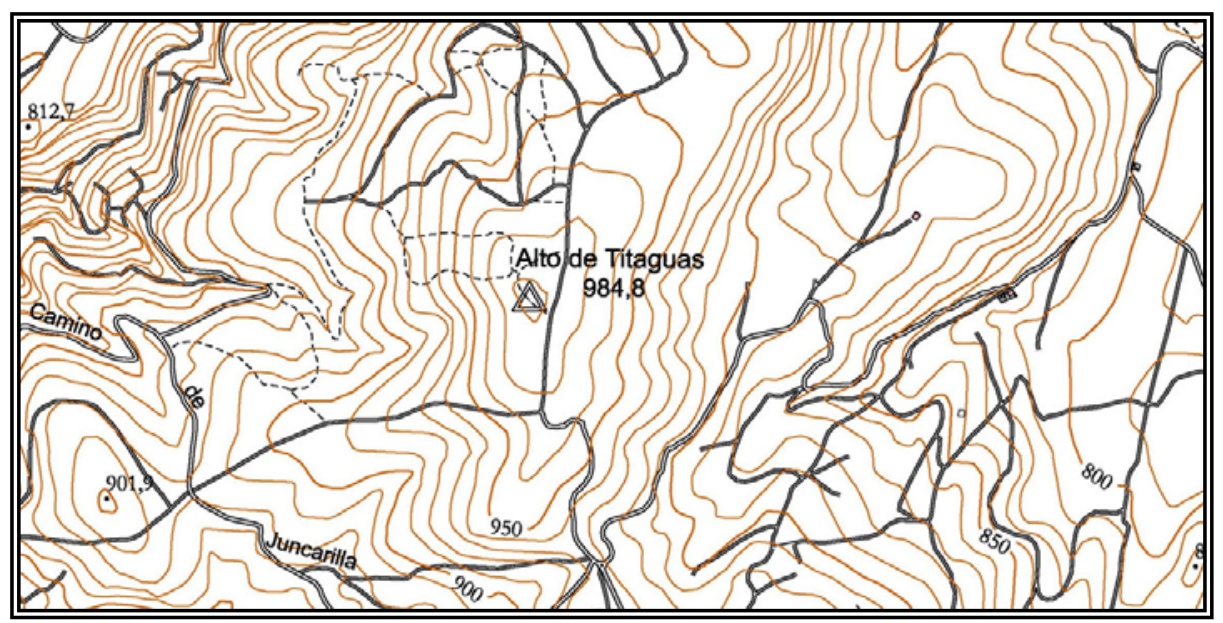

Figura 3.42. Curvas de nivel

\subsubsection{Estudio del color}

Para la cartografía en general se utiliza el color siena en la representación de las curvas de nivel, así que para facilitar la lectura de los usuarios acostumbrados a trabajar con cartografía adoptaremos también este color, concretamente $(205,96,0)$. No haremos distinción de color entre normales y directoras, así como tampoco con las curvas de depresión; esta diferencia la haremos notar con diferencias de grosor y tipo de línea, como veremos más adelante.

La anotación de las curvas, siempre en curvas directoras, la pondremos en color negro y controlaremos que no sea excesiva ni deficiente, así como que esté correctamente colocada, si es posible con las cotas alineadas en dirección perpendicular a las curvas los textos tendrán un tamaño de 1,4 mm. 


\subsubsection{Elección del grosor y tipo de línea}

Dado que incluiremos, como es habitual, dos tipos de curvas de nivel, normales y directoras, elegiremos dos grosores de línea para las mismas, 0,1 para las normales y 0,25 para las directoras.

De la misma forma, deberemos distinguir las curvas de nivel de depresión, para las que utilizaremos una simbología diferente, como se muestra en la figura 3.42. Siguiendo también el mismo criterio de grosor de línea.

\subsubsection{Vías de comunicación}

Como ya se ha visto, es considerablemente variada la simbología utilizada para la representación de las vías de comunicación, estudiando las más frecuentes hemos creado una simbología que sea de uso común para la mejor identificación de los elementos por cualquier usuario $^{2}$.

\subsubsection{Estudio del color}

Los colores elegidos, con una base de negro $(0,0,0)$ excepto en el caso de la autovía son:

- Autovía. Rojo $(255,0,0)$ y amarillo $(255,255,0)$.

- Carretera nacional. Negro y rojo $(255,0,0)$.

- Autonómica de $1^{\circ}$ orden. Negro y naranja $(255,168,0)$.

- Autonómica $2^{\circ}$ orden. Negro y amarillo $(255,255,0)$.

- Pista. Negro y verde $(230,230,153)$.

- Camino. Negro y beige $(255,235,168)$.

\subsubsection{Elección de la simbología}

Con la simbología hemos procedido de la misma manera, teniendo en cuenta que debe ser una simbología bien diferenciada de otras que utilicemos para representar otros elementos.

El criterio tomado a la hora de elegir la simbología para las vías de comunicación ha sido utilizar el color correspondiente y rodearlo de dos líneas negras, una a cada lado; excepto en el caso de la autovía, en el que las líneas del borde son rojas y de grosor 0,25 mm y además se ha añadido una tercera línea de grosor $0,1 \mathrm{~mm}$ en el centro.

\subsubsection{Elección del grosor y tipo de línea}

La única distinción que se hará por grosor o tipo de línea será la ya indicada para la autovía, el uso de un grosor 0,2 $\mathrm{mm}$ para la línea exterior. El resto del los elementos tendrán grosor $0,1 \mathrm{~mm}$ y tipo de línea continuo.

2 Palomar Vázquez, J.M., "Desarrollo de estrategias, métodos y herramientas para la automatización y mejora de los procesos de producción cartográfica. Aplicación a la generación de mapas excursionistas”(Tesis Doctoral), 2003. 


\subsubsection{Límites administrativos}

Aunque en nuestra cartografía sólo encontraremos límite de término municipal por tratarse de cartografía municipal, definiremos también la simbología a utilizar para otros límites.

\subsubsection{Estudio del color}

El color a utilizar será el negro, como se viene utilizando generalmente en la cartografía existente y que resalta perfectamente junto a cualquier otro color.

\subsubsection{Elección del grosor y tipo de línea}

$\mathrm{Al}$ tratarse siempre de elementos lineales, la distinción entre ellos la realizaremos con la ayuda del tipo de línea, el grosor para el límite municipal será $0,1 \mathrm{~mm}$ y para dar más importancia al límite provincial, utilizaremos para el mismo un mayor grosor, concretamente 9,25 mm. Los tipos de línea elegidos, tras el estudio de las cartografías más comunes serán los que se muestran en la figura 3.43 .

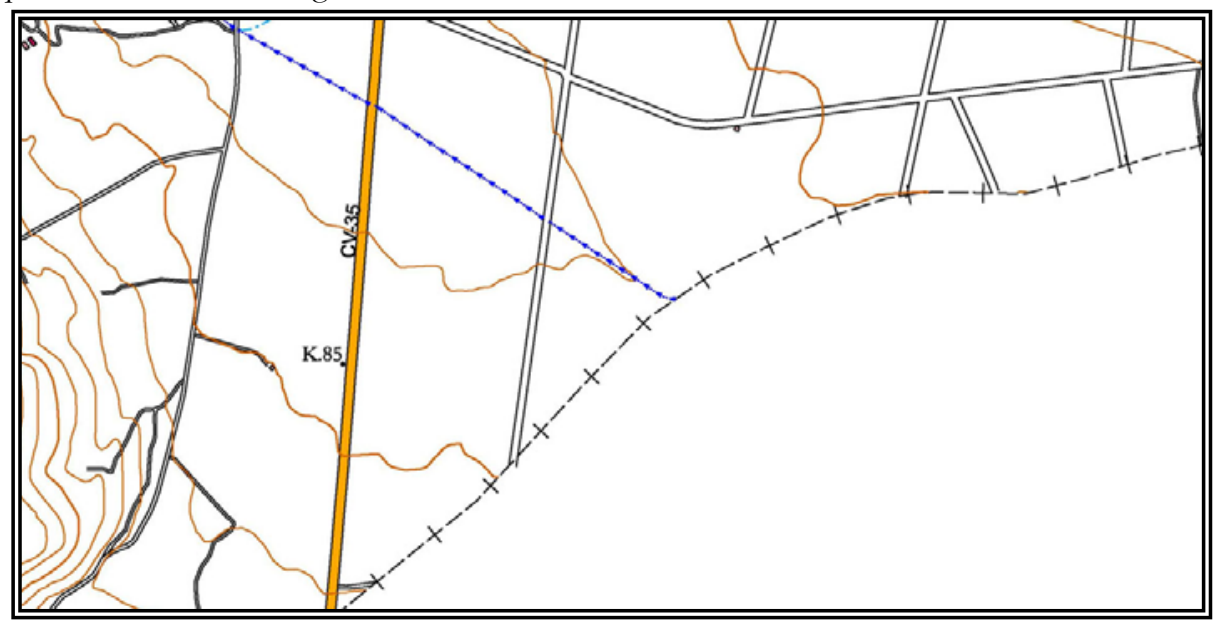

Figura 3.43. Representación del límite municipal

\subsubsection{Edificaciones}

En el caso de las edificaciones, como no les daremos el mismo tratamiento si hablamos de cartografía urbana que si hablamos de cartografía territorial, deberemos distinguir entre estas dos cartografías. 


\subsubsection{Estudio del color}

\subsection{Cartografia urbana}

En un plano a escala urbana, no podremos como es lógico utilizar un único color para todas las edificaciones, antes bien, será importante diferenciarlas según ciertos criterios, principalmente según la calificación del suelo.

Creemos conveniente diferenciar entre lo que es suelo urbano y lo que no lo es, a las edificaciones situadas en este último les daremos el mismo tratamiento que a las que incluyamos en la cartografía territorial, así que remitiremos al lector al apartado siguiente.

Para el suelo urbano utilizaremos una simbología específica que se estudiará más adelante, en el apartado de calificación del suelo.

\subsection{Cartografía territorial}

Otro criterio totalmente diferente será el que utilizaremos cuando se trate de cartografía territorial, ya que en ésta las edificaciones deberán ser fáciles de identificar en el conjunto del mapa por ser elementos extremadamente relevantes para la ordenación del territorio.

Ya se comentó que tradicionalmente ha sido el rojo el color empleado para las edificaciones, para facilitar la legibilidad del mapa por usuarios acostumbrados a trabajar con cartografía adoptaremos también este color para las edificaciones en general, aunque para aportar nitidez, utilizaremos una línea negra rodeándolas. El color utilizado será en concreto $(255,0,0)$.

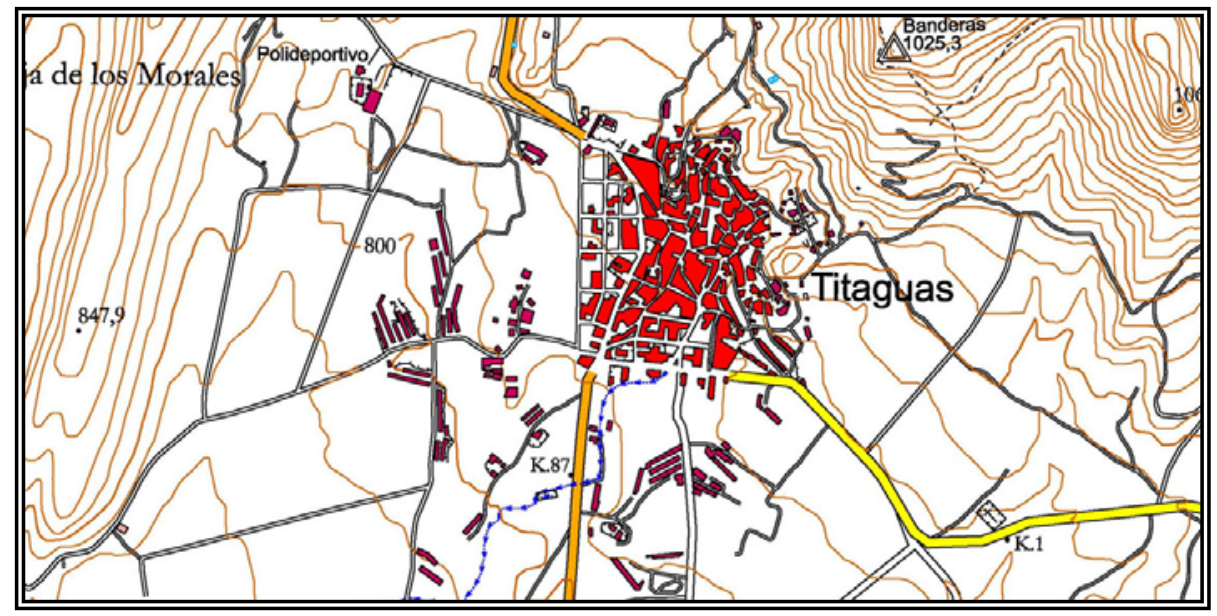

Figura 3.44. Representación de edificaciones aisladas y en casco urbano

Aunque hemos dicho que en este tipo de mapa no haremos prácticamente distinción entre las edificaciones, sí señalaremos con otro tipo de simbología las edificaciones aisladas, utilizando un color rojo con un menor brillo, concretamente el $(235,168,168)$, del mismo modo trataremos las naves industriales, para las que utilizaremos un color granate $(205,0,96)$, 
y los edificios singulares los señalaremos con un amarillo para distinguirlos del resto, este será el $(230,230,0)$, igualmente rodeándolos con una línea negra.

Otro tipo de edificaciones que merecerán un tratamiento diferente serán las ruinas y las tapias o muros (aunque estas últimas no sean edificaciones propiamente dichas), para las que no utilizaremos relleno, las diferenciaremos por el tipo de línea como veremos más adelante.

\subsubsection{Elección del grosor y tipo de línea}

En el caso del grosor, no lo vamos a utilizar en esta ocasión pero, como ya hemos dicho, sí el tipo de línea. En general se utilizará una línea continua, excepto para el caso de las ruinas, en el que utilizaremos una línea discontinua, y el de las vallas, a las que pondremos el tipo de línea que se muestra en la figura 3.44..

\subsubsection{Red eléctrica}

En el caso de disponer de esta información, no haremos distinción entre los dos tipos de cartografía que estamos tratando.

\subsubsection{Estudio del color}

$\mathrm{Al}$ tratarse de una información generalmente escasa, que no va a restar claridad al mapa, utilizaremos un color negro para todo lo referente a la información de la red eléctrica, ya que el negro es el color que más destaca si lo situamos sobre otros colores, como deberemos hacer en este caso.

\subsubsection{Elección de la simbología}

Si tenemos una buena información acerca de la red eléctrica, contaremos con las líneas de alta y media tensión y además con las torres, para estas últimas deberemos diseñar un par de símbolos que intuitivamente nos hagan pensar en los elementos de que se trata, para tener que consultar la leyenda el menor número de veces posible y facilitar así el uso de la cartografía. El tamaño de los mismos será de $1 \mathrm{~mm}$.

\subsubsection{Elección del grosor y tipo de línea}

El tipo de línea será lo que nos permita diferenciar las redes eléctricas de cualquier otro elemento lineal del mapa, así que elegiremos para las mismas dos tipos que nos permitan reconocerlas al primer vistazo.

\subsubsection{Microreservas}

Es importante, a la hora de ordenar el suelo, tener perfectamente delimitadas aquellas zonas que tengan una peculiaridad por la cual deban preservarse, lo que supondrá que se mantendrán al margen de los trabajos de ordenación. Unas de estas zonas son las microreservas, generalmente de flora o fauna, áreas que por sus características especiales deben permanecer intactas. 
Como en este estudio se ha intentado plasmar la máxima información en el menor número de mapas, se ha generado uno cuyo título es "Clasificación del suelo y medio ambiente", en el que se incluyen las microreservas. Al tratarse de elementos zonales disponemos de dos opciones, color o trama. Dado que el color se utilizará para diferenciar las diferentes clases de la clasificación del suelo, sólo nos queda el uso de una trama para resaltar las microreservas, así que esta será la opción elegida.

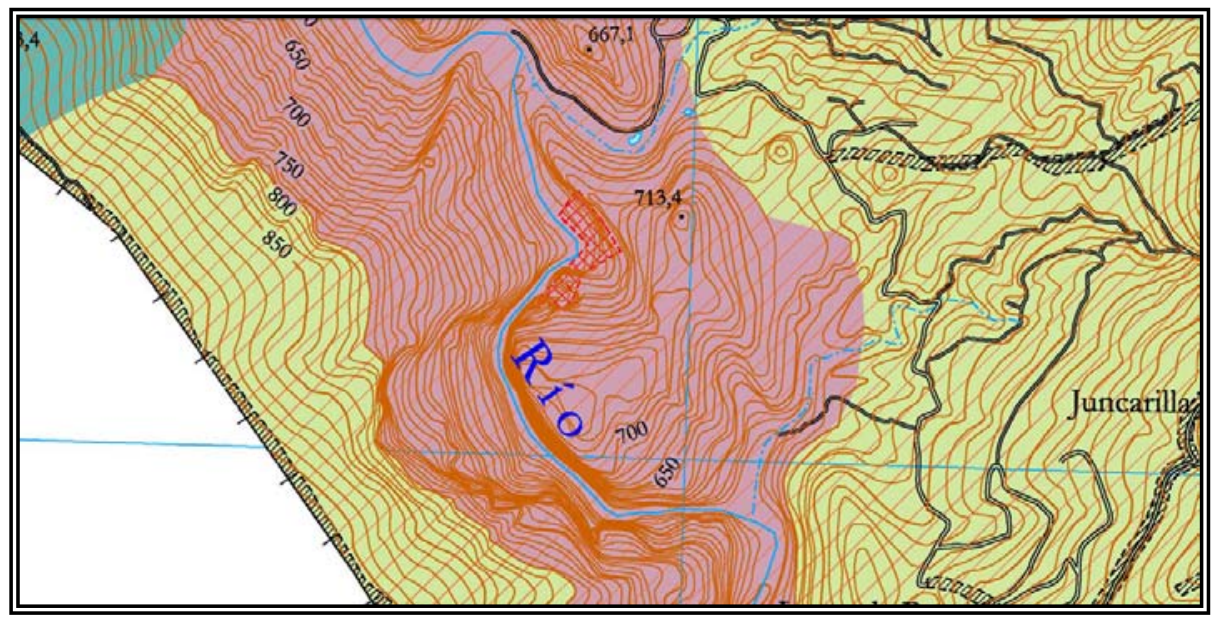

Figura 3.45. Representación de microrreservas y clasificación del suelo

\subsubsection{Estudio del color}

Al tratarse de una diferenciación por trama, sólo será necesario que elijamos un color para reseñar las microreservas. Como se trata de unas zonas que deben ser fácilmente identificables y para que resalte el color sobre el resto, se utilizará el color rojo $(255,0,0)$.

\subsubsection{Elección de la simbología}

Como ya se ha dicho, se utilizará un tramado, sabiendo que deberemos utilizar también tramado para los "Espacios de especial relevancia", y considerando que las microreservas serán en general menos numerosas, por lo que deberán resaltar más, hemos elegido un doble rayado, a $45^{\circ}$, con inclinación a derecha e izquierda, lo que produce una sensación de cuadrícula girada.

\subsubsection{Elección del grosor y tipo de línea}

Para el rayado de la trama se utilizará el tipo de línea continuo que da una mayor sensación de conjunto, pero para la línea exterior, por tratarse de una línea que realmente no tiene representación en el terreno, se utilizará un tipo de línea discontinuo.

El grosor será $0,1 \mathrm{~mm}$ para al rayado y $0,25 \mathrm{~mm}$ para la línea que lo delimita. No se considera necesario que el rayado sea muy grueso, ya que resalta lo suficiente dándole el grosor 
mínimo, pero para que no haya confusión a la hora de la delimitación de las zonas y pensando que además el tipo de línea es discontinuo, a la línea límite sí se dará un grosor mayor.

\subsubsection{Espacios de especial relevancia}

Un caso similar al de las microreservas se nos presenta con los "Espacios de especial relevancia", para los que adoptaremos una solución similar, un tramado, en este caso con diferente color y trama.

\subsubsection{Estudio del color}

Con el objeto de dar uniformidad de color al mapa, se utilizará el mismo color para este tramado que el que se utiliza para las curvas de nivel $(205,96,0)$, ya que esto no llevará a confusión dado que el tramado serán siempre líneas rectas y las curvas de nivel, como su nombre indica serán curvas.

\subsubsection{Elección de la simbología}

En este caso se ha elegido, pensando como siempre en hacer un mapa lo más fácil de interpretar que nos resulte posible, el tramado más simple, un rayado con una inclinación de $45^{\circ}$.

\subsubsection{Elección del grosor y tipo de línea}

En lo que respecta al grosor y tipo de línea se ha adoptado igualmente el mismo criterio que con las microreservas, línea continua de grosor mínimo $0,1 \mathrm{~mm}$ para el tramado y línea discontinua de grosor $0,25 \mathrm{~mm}$ para la línea del límite.

\subsubsection{Riesgos geológicos}

Dado que el riesgo geológico más común es el de erosión y generalmente es por deforestación del territorio, hemos hecho una distinción entre éste y el resto de los riesgos. Consideraremos los riesgos geológicos como elementos puntuales, por lo que para su identificación utilizaremos un símbolo puntual, en nuestro caso dos símbolos, uno para "Zona deforestada con problemas de erosión" y otro para "Riesgo geológico", este último como es lógico para el resto. Como todos los trabajos de Ordenación del territorio van acompañados de una memoria, será allí donde se especificará el riesgo concreto que afecta a la zona.

\subsubsection{Estudio del color}

Como siempre que se quiere dar sensación del peligro, utilizaremos el color rojo (255, $0,0)$ que nuestro cerebro identifica con aquel, y como usualmente hacemos, rodearemos el símbolo con una línea negra para dotarlo de mayor claridad. 


\subsubsection{Elección de la simbología}

No ha resultado sencillo encontrar unos símbolos que evoquen riesgos geológicos, de este modo, los símbolos diseñados no nos harán pensar intuitivamente en que en esa localización hay cierto riesgo geológico, aunque se ha intentado que sean al menos fáciles de recordar.

Para el riesgo de deslizamiento se han utilizado tres triángulos invertidos, pretendiendo que el hecho de que las figuras sean inestables, con la base menor que el resto, y señalando hacia abajo, dé la idea de terreno en movimiento.

En el caso de riesgo geológico en general simplemente se ha diseñado un símbolo parecido a una montaña, intentando que el usuario relacione la geología con la montaña y el riesgo con el color rojo.

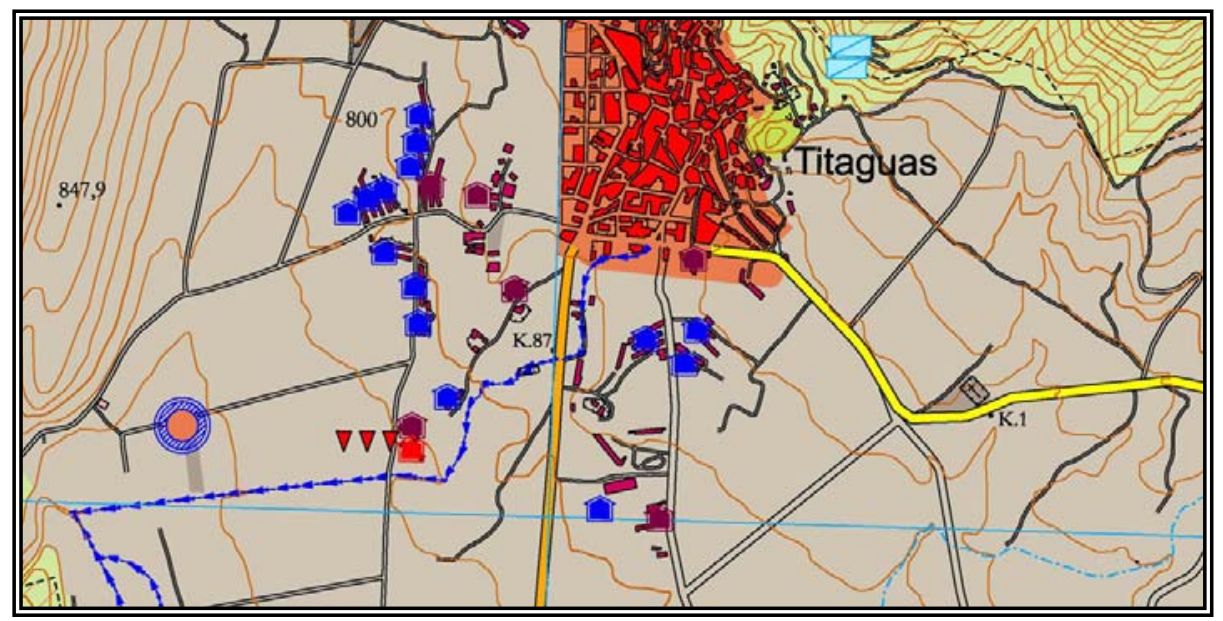

Figura 3.46. Representación de zona de riesgo geológico

\subsubsection{Vegetación}

Cuando nos enfrentamos a la tarea de diseñar la simbología para representar la vegetación, lo primero que deberemos tener en cuenta es que es muy importante reducir el número de clases para dar legibilidad al mapa ${ }^{3}$. Aún así, el número de clases es tan grande que no resulta fácil su diferenciación mediante ningún recurso, se ha utilizado en este caso el color, ya que el uso combinado de color y trama no nos pareció adecuado debido a las grandes diferencias de tamaño de las manchas; a la hora de diseñar los símbolos del tramado, un

3 Palomar Vázquez, J.M., "Desarrollo de estrategias, métodos y herramientas para la automatización y mejora de los procesos de producción cartográfica. Aplicación a la generación de mapas excursionistas”(Tesis Doctoral), 2003. 
símbolo muy grande o muy espaciado no es útil para manchas pequeñas, y un símbolo muy pequeño o muy tupido resta claridad al mapa en zonas con manchas muy extensas.

\subsubsection{Estudio del color}

Ha sido ésta una de las tareas más difíciles, como ya se ha comentado, debido a la gran cantidad de clases existentes, aún así, se ha intentado emplear colores que fueran fácilmente asociables con el elemento al que simbolizan, así, se ha tomado una misma gama para los colores que pertenecen a la misma clase, intentando que fuese fácil discriminar entre elementos de diferente clase. Los colores elegidos, por grupos, son los siguientes:

\begin{tabular}{|c|c|c|}
\hline Almendro: & - Almendro & $(243,233,174)$ \\
\hline & - Almendro y viñedo & $(212,194,125)$ \\
\hline & - Almendro - Barbecho blanco & $(179,168,68)$ \\
\hline Olivar: & - Olivar - Almendro & $(136,142,70)$ \\
\hline & - Olivar - Viñedo & $(166,158,106)$ \\
\hline Barbecho: & - Barbecho blanco & $(162,146,133)$ \\
\hline & - Barbecho blanco - Viñedo & $(209,194,177)$ \\
\hline & - Barbecho semillado & $(229,197,194)$ \\
\hline & - Barbecho semillado - Almendro & $(206,161,165)$ \\
\hline & - Barbecho semillado - Viñedo & $(170,115,127)$ \\
\hline & - Barbecho semillado - Almendro - Viñedo & $(145,89,104)$ \\
\hline Pastizal: & - Pastizal & $(247,205,166)$ \\
\hline & - Pastizal - Matorral & $(224,162,113)$ \\
\hline & - Pastizal - Latizal -Almendro & $(208,139,90)$ \\
\hline Matorral: & - Matorral & $(236,141,143)$ \\
\hline & - Matorral - Sabinar albar & $(222,59,72)$ \\
\hline Pino carrasco: & - Pino carrasco & $(209,231,157)$ \\
\hline & - Pino carrasco - Fustal & $(161,208,105)$ \\
\hline & - Pino carrasco - Latizal & $(115,189,56)$ \\
\hline & - Pino carrasco - Almendro & $(214,207,170)$ \\
\hline & - Pino carrasco - Quercus & $(172,166,136)$ \\
\hline Otros pinos: & - Pino negral - Latizal & $(75,177,91)$ \\
\hline & - Pino laricio - negral - clusiana - Fustal & $(195,204,184)$ \\
\hline & - Pino laricio - negral - clusiana - Latizal & $(110,143,130)$ \\
\hline Prados: & - Prados regados eventualmente - Fustal & $(251,229,176)$ \\
\hline & - Prados regados eventualmente - Latizal & $(248,208,116)$ \\
\hline & - Prados regados eventualmente - Pino carr & $\operatorname{sco}(250,207,0)$ \\
\hline Encina: & - Encina - Chaparra - Carrasca - Pino carras & co $(156,155,144)$ \\
\hline & - Encina - Chaparra - Carrasca & $(177,168,151)$ \\
\hline Viñedo: & - Viñedo & $(202,162,198)$ \\
\hline & - Viñedo - Almendro & $(168,133,178)$ \\
\hline
\end{tabular}


- Viñedo - Almendro - Barbecho semillado

- Viñedo - Almendro - Barbecho blanco

$(130,103,153)$

- Viñedo - Terrenos transf. en regadío

$(59,22,92)$

- Viñedo - Terrenos transf. en olivar

$(216,157,191)$

- Viñedo - Terrenos transf. en olivar y almendro $(178,113,158)$

Otros:

- Sabinar albar

$(188,127,50)$

- Chopo americano - Chopo de Canadá

- Cultivos herbáceos

- Huerta

- Huerta - Matorral - Viñedo

- Latizal

- Latizal - Viñedo - Almendro

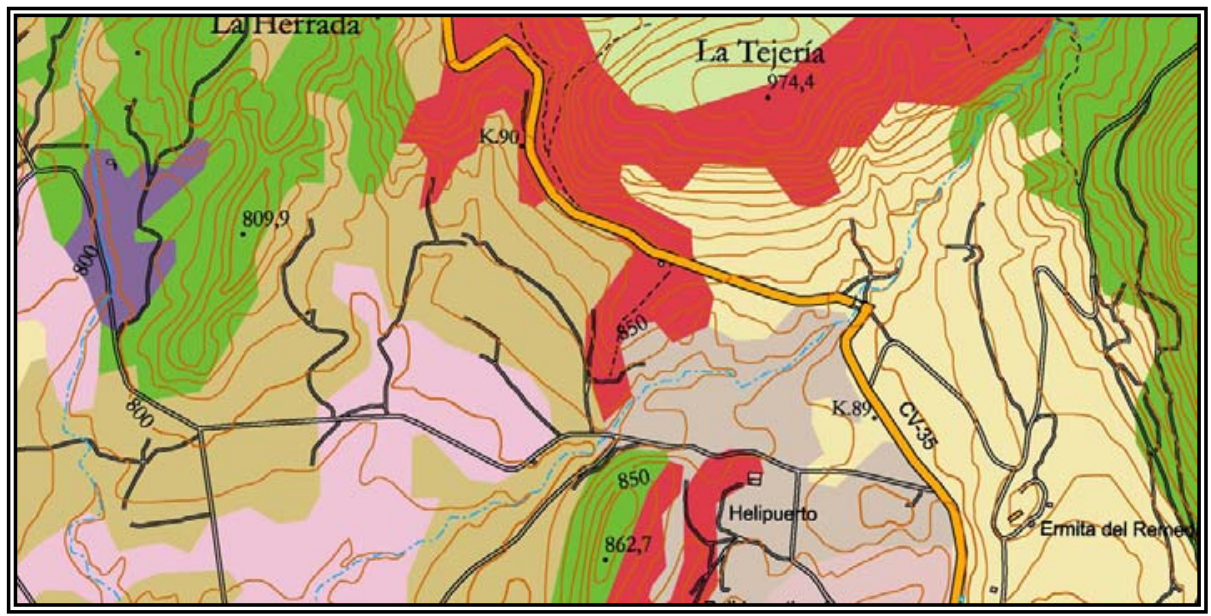

Figura 3.47. Representación de la vegetación

\subsubsection{Clasificación del suelo}

La clasificación del suelo es uno de los datos más relevantes a la hora de ordenar el territorio, aunque generalmente variará con la nueva ordenación, es indispensable conocer la ordenación en vigor.

La información de clasificación del suelo se ha incluido en un mapa al que se ha titulado "Clasificación del suelo y Medio Ambiente", por considerar a aquella la información más relevante y puesto que se trata de información superficial, se ha decidido colocarla como información de fondo, por lo que se utilizará el color para la diferenciación de los diferentes tipos. 


\subsubsection{Estudio del color}

Para la asignación de colores se ha hecho una primera distinción, utilizando en general tonos verdes para las zonas con algún tipo de protección relacionada con vegetación, tonos marrones para zonas urbanas o destinadas a urbanizar y otros colores para el resto. De esta forma los colores utilizados son los que se detallan a continuación.

- Urbano

- Urbanizable

- No urbanizable cesión viales

$(233,125,78)$

- No urbanizable dotacional

$(237,148,130)$

- No urbanizable común

$(188,127,50)$

- No urbanizable protección parque

$(171,158,141)$

- No urbanizable protección forestal

$(208,198,180)$

- No urbanizable protección sabinar

$(196,222,82)$

$(209,231,157)$

- No urbanizable protección paisajística

$(75,177,91)$

- No urbanizable protección de acuífereos

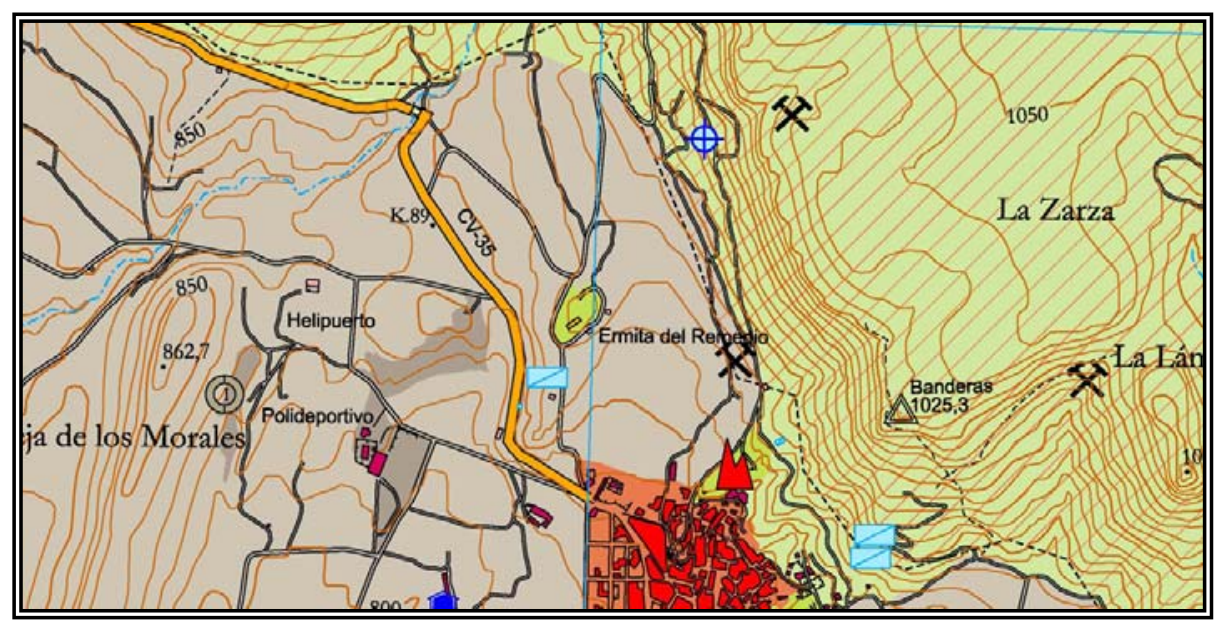

Figura 3.48. Representación de la clasificación del suelo

\subsubsection{Paisaje}

Para la generación de la simbología de paisaje debemos hacer una distinción, por un lado hablaremos de las unidades de paisaje, que dividiremos mediante líneas, por otro lado tendremos el tipo de subunidades paisajísticas que tratamos como elementos superficiales, y por otro tendremos la simbología puntual. 


\subsubsection{Estudio del color}

\subsection{Unidades paisajísticas}

El color utilizado será el negro para todas los líneas que definen las unidades paisajísticas, la distinción se hará por tipo de línea y grosor.

\subsection{Subunidades de paisaje}

Las subunidades de paisaje son zonas con paisajes diferentes que será importante diferenciar, se tratarán entonces como elementos superficiales. Se han tenido en cuenta cinco tipos de subunidades de paisaje, a continuación se listan estos tipos y el color utilizado para su representación:

Urbano

Cultivos de regadío

$(233,125,78)$

Cultivos de secano

Forestal arbolado

Monte bajo - Matorral

$$
\begin{aligned}
& (75,177,91) \\
& (236,141,143)
\end{aligned}
$$

\subsection{Simbología puntual}

Se tratará de que el color de la simbología utilizada sea lo más intuitivo posible y a la vez coincida dentro de lo posible con el de la simbología genérica.

\subsubsection{Elección de la simbología}

\subsection{Simbología puntual}

Se trata del único tipo de simbología paisajística para el que se han definido símbolos puntuales, se tratará de que sean lo más fáciles de interpretar que sea posible.

\subsubsection{Elección del grosor y tipo de línea}

\subsection{Unidades paisajísticas}

Para delimitar las unidades paisajísticas se utilizarán diferentes tipos de línea y grosores; los tipos de línea se pueden apreciar en el siguiente capítulo "Propuesta de normalización", en lo que a grosores se refiere, utilizaremos $0,25 \mathrm{~mm}$ para las unidades paisajísticas, $0,1 \mathrm{~mm}$ para las subunidades y $0,1 \mathrm{~mm}$ para las unidades de especial relevancia.

\subsection{Simbología puntual}

Toda la simbología se generará con grosor $0,1 \mathrm{~mm}$.

\subsubsection{Vías pecuarias}

Las Vías Pecuarias, que se han incluido en el mapa de "Clasificación del suelo y Medio Ambiente" y están señaladas en la leyenda como Veredas, podrían considerarse como un 
elemento superficial, en función de su anchura, pero dado su mayor carácter lineal, las trataremos como elementos lineales.

\subsubsection{Estudio del color}

Al tratarse de una vía de comunicación, utilizaremos el color negro para su representación, color que hemos tomado como base para la simbología de Vías de Comunicación.

\subsubsection{Elección de la simbología}

Debido al hecho de que en muchas ocasiones las Vías Pecuarias coinciden con otras Vías de Comunicación, nos veremos obligados a adoptar una simbología para las Vías Pecuarias que sea compatible con cualquier otra Vías de Comunicación. La solución tomada consiste en trazar dos líneas, una a cada lado del eje de la Vía Pecuaria, con lo que dejaremos el centro libre para la posible inclusión de otro tipo de Vía.

\subsubsection{Elección del grosor y tipo de línea}

También por el motivo reseñado en el punto anterior, deberemos elegir una simbología que no dé lugar a confusión. Es por lo que se ha decidido utilizar un tipo de línea discontinuo y un grosor algo mayor que el mínimo, en este caso $0.25 \mathrm{~mm}$, para que la distinción sea todavía más sencilla.

\subsubsection{EDAR (Estación de depuración de aguas residuales)}

Se trata de un elemento que, si bien ocupa una superficie con representación en la cartografía, puede tratarse como un elemento puntual y se hará así para facilitar su identificación en el mapa. Dentro de este apartado haremos una distinción, y hablaremos tanto de EDAR como de plantas potabilizadoras.

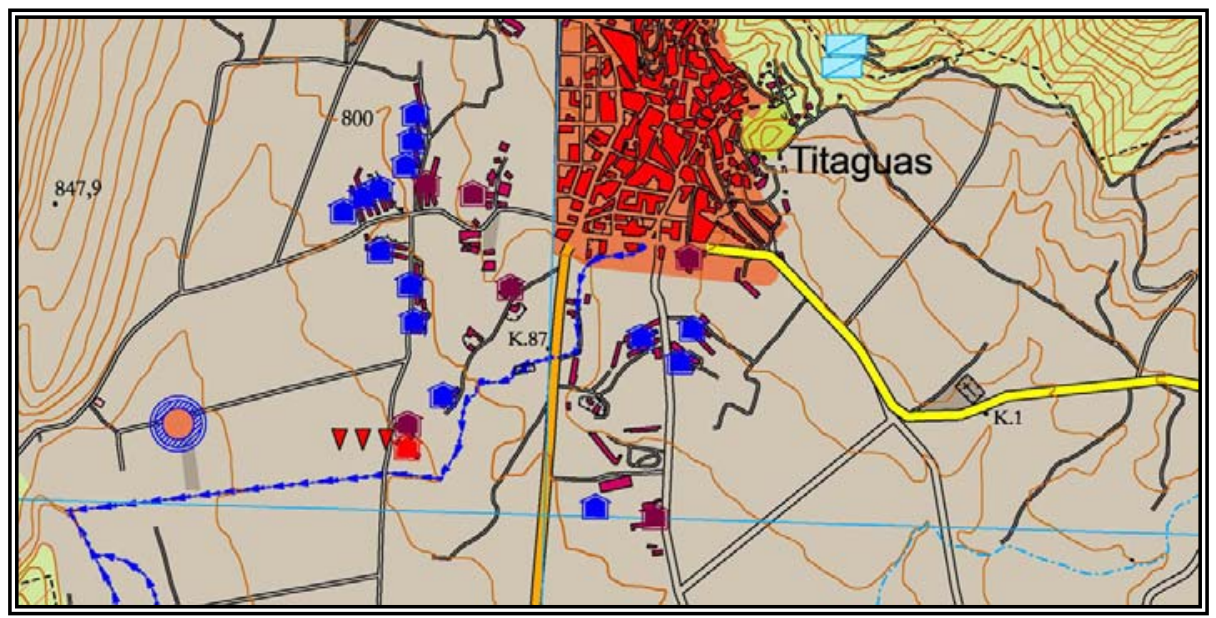

Figura 3.49. Representación de granjas y estación de depuración de aguas residuales. 
Por tratarse de elementos con cierta relación, los símbolos diseñados serán similares.

\subsubsection{Estudio del color}

Apoyándonos en el hecho de que hablamos de instalaciones que tienen relación con el agua, el color utilizado no podía ser otro que el azul. En este caso, se ha elegido un azul diferente al utilizado para los elementos hidrográficos, que será el azul puro $(0,0,255)$. Para que distinguir entre los dos elementos aquí tratados resulte más sencillo, se utilizará además el color rojo $(255,0,0)$ para el símbolo de la depuradora de aguas residuales.

\subsubsection{Elección de la simbología}

El símbolo creado consiste en varios círculos concéntricos, algunos de ellos rellenos de rojo o azul para su mejor diferenciación. El relleno en rojo es sólido, pero no así el azul, para no crear la sensación de que realmente hay una masa de agua, en este caso se ha utilizado un tramado simple, un rallado con inclinación de $45^{\circ}$.

\subsubsection{Granjas}

Se trata de elementos que pueden tener una superficie digna de representación en el mapa, pero para facilitar su localización se ha diseñado una simbología puntual común para todas las granjas consideradas excepto en el color, propiedad que utilizaremos para diferenciar los distintos tipos de granjas.

\subsubsection{Estudio del color}

Como se ha comentado, utilizaremos el color para diferenciar los diferentes tipos de granjas considerados pero, ante la dificultad de asociar un color con un animal, se han tomado tres colores fácilmente diferenciables y se han asignado aleatoriamente a cada uno de los tres tipos de granjas. Estos colores son:

Granja de aves $(255,0,0)$

Granja cunícola $(126,0,65)$

Granja de porcino $(0,0,245)$

\subsubsection{Elección de la simbología}

Se ha tratado de que el símbolo generado sea un símbolo lo más simple posible pero que intente evocar una edificación. En este caso resultará imprescindible la consulta de la leyenda para la correcta identificación de los símbolos del mapa.

\subsubsection{Calificación del suelo}

Como ya se ha comentado, la distinción entre los diferentes edificios de un núcleo urbano la haremos en función de la calificación del suelo. Al tratarse de una propiedad de elementos superficiales, solamente utilizaremos el color para distinguir entre ellos. 


\subsubsection{Estudio del color}

Utilizaremos unos colores que den sensación de armonía, pero a la vez que permitan diferenciar claramente las distintas clases, es decir, buscaremos el contraste entre las clases.

Dentro de lo posible se utilizarán colores que intuitivamente recuerden al elemento que pretenden representar, como el verde para zona verde o el rojo para las edificaciones, aunque esto no será posible en la mayoría de los casos y la elección de colores será en gran medida arbitraria.

Para la elección de los colores se ha tenido en cuenta el criterio adoptado por el Catastro, organismo oficial que elabora la generalidad de la cartografía urbana.

La solución adoptada es la siguiente:

- Urbano residencial $(250,200,50)$

- Viales $(250,225,150)$

- Zona verde $(100,200,50)$

- Equipamiento deportivo $(150,200,125)$

- Equipamiento docente $(245,255,0)$

- Equipamiento cultural $(250,255,100)$

- Equipamiento social (252, 255, 145)

- Religioso $(178,178,178)$

En la figura 3.50 se muestra la leyenda de calificación del suelo donde pueden apreciarse los colores elegidos para la misma, por supuesto también se considera la zona perteneciente a viales.

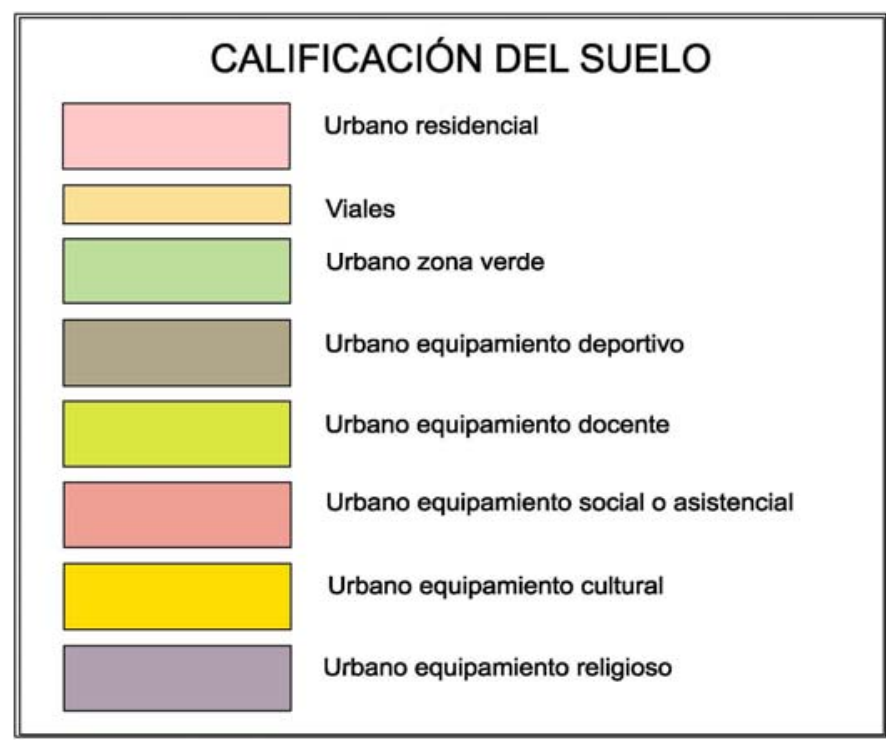

Figura 3.50. Colores asignados a la calificación del suelo 


\subsubsection{Ruido}

El nivel de ruido es un parámetro que afecta a una determinada zona, se trata pues de elementos superficiales, estos datos sónicos los asociaremos a los viales que es donde se toman las mediciones.

Los datos superficiales generalmente los distinguimos mediante el uso de color, pero puesto que ya hemos utilizado el parámetro color para distinguir entre las diferentes clases de calificación del suelo, para diferenciar los niveles de ruido utilizaremos un tramado.

Se trata de un dato meramente cuantitativo, así que no será necesario utilizar además del tramado el color, simplemente variando el espesor del tramado conseguiremos que visualmente se aprecien las diferencias de nivel de ruido sin mayores dificultades.

\subsubsection{Estudio del color}

En principio se puede utilizar cualquier color para el tramado que indique el nivel de ruido; para dar homogeneidad al plano resultante se ha optado por utilizar el mismo color que se utiliza para diferenciar el suelo urbano residencial, y que es el más abundante del plano. Esto no puede generar ningún conflicto, ya que como se ha comentado los niveles de ruido se presentan siempre sobre los viales, que nunca serán por supuesto suelo urbano residencial. El color adoptado será entonces el $(255,0,0)$

\subsubsection{Elección de la simbología}

Para no recargar el plano se ha elegido el tramado más simple posible, un rayado con una inclinación de $45^{\circ}$ a la derecha y con un grosor de línea de $0,1 \mathrm{~mm}$. En el caso que se muestra en el ejemplo sólo contábamos con tres niveles de ruido, pero obviamente podremos incluir más niveles haciendo el rayado más o menos denso según el nivel de ruido sea mayor o menor. Se muestra el resultado final en la figura 3.51.

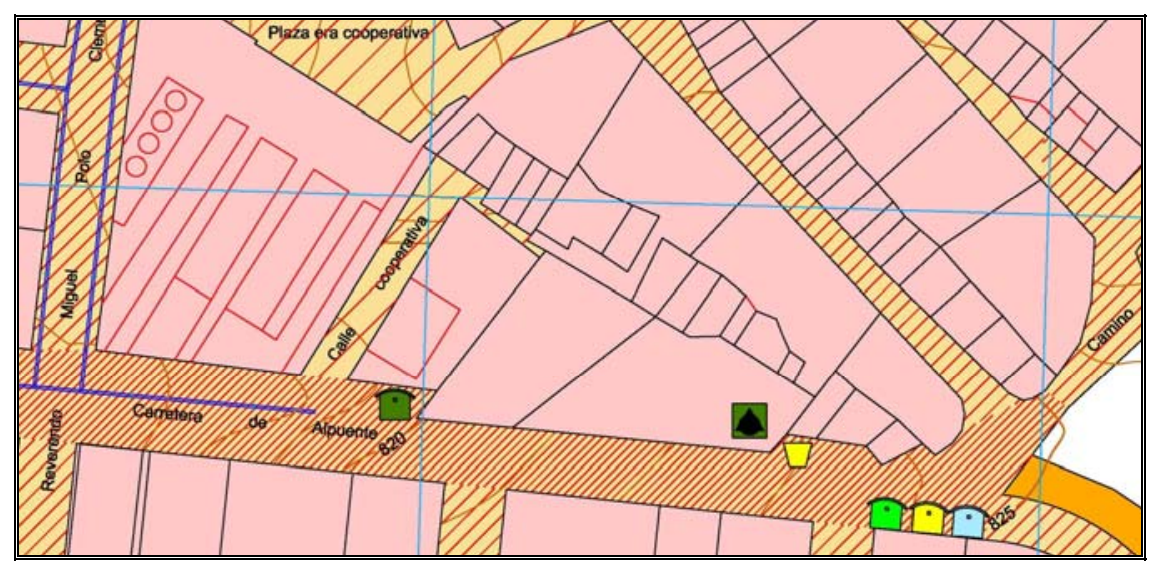

Figura 3.51. Representación de los niveles de ruido 


\subsubsection{Viales}

Los viales serán en general el espacio que quede entre los edificios, se trata pues de elementos superficiales a los que daremos el mismo tratamiento que hemos dado a la calificación del suelo.

\subsubsection{Estudio del color}

Se trata junto con el suelo urbano residencial del elemento que mayor superficie ocupará en nuestro mapa, por esto deberemos elegir un color que no recargue la visión general del mismo y que a su vez esté, como ya se ha comentado, dentro de la gama del color que hemos utilizado para el suelo urbano residencial con el objeto de que nuestro mapa tenga un aspecto más agradable a la vista. El color elegido será, siempre en RGB, (250, 225, 150).

\subsubsection{Conducciones}

Si tenemos la oportunidad de contar con ella, se trata de una información que puede resultar muy útil, ya que deberemos tenerla en cuenta a la hora de realizar cualquier modificación del suelo urbano.

El problema puede radicar en la imposibilidad de disponer de información fiable acerca de todas las conducciones que haya en el municipio.

Vamos a realizar una propuesta de simbología para las conducciones más comunes, aunque en el caso del plano generado sólo contamos con información acerca de las conducciones de aguas.

Se trata de elementos lineales, por lo que nos centraremos en el estudio del color, grosor y tipo de línea.

\subsubsection{Estudio del color}

Como venimos haciendo a lo largo de todo el trabajo, utilizaremos el color azul para las conducciones de agua potable y también siguiendo con el criterio utilizado hasta ahora, el azul usado será el $(0,0,255)$ y no el utilizado para los elementos hidrográficos.

Para las conducciones de aguas residuales (pluviales y fecales), utilizaremos un color marrón $(126,109,0)$, para distinguirlas de las conducciones de agua potable.

Y por último en el caso del gas el color utilizado será el amarillo $(255,255,0)$, por tratarse del color que generalmente se usa para estas conducciones.

\subsubsection{Elección del grosor y tipo de línea}

En cuanto al tipo de línea, se ha adoptado el mismo para las conducciones de agua, que como se ha dicho se distinguirán por el color, y uno diferente para la de gas.

Para las conducciones de agua se utilizará una línea doble, dos líneas paralelas, cruzadas a ciertos intervalos por una pequeña línea perpendicular a ellas.

Para las conducciones de gas se ha diseñado una línea discontinua, cuyos trazos son línea - rombo, de fácil identificación. 
El grosor en todos los casos será el mínimo para evitar la saturación del mapa, aunque aparentemente la conducción de gas tendrá un mayor grosor, efecto que se buscaba dado que el color elegido no resalta demasiado sobre el resto de los colores en general.

\subsubsection{Edificios singulares}

Se trata de edificios con cierta relevancia para la comunidad, señalaremos esta peculiaridad colocando sobre el edificio en cuestión un símbolo que evoque lo mejor posible la característica del edificio. A continuación se enumeran los edificios singulares contemplados y los criterios seguidos a la hora de proponer una simbología para representar a los mismos.

\subsubsection{Estudio del color}

Todos los símbolos estarán incluidos en un cuadrado negro $(0,0,0)$, para que sea mucho más fácil su identificación en el plano.

- Ayuntamiento. Al tratarse de un edificio oficial sin ningún color especialmente representativo, se ha elegido un símbolo en blanco $(255,255,255)$ y negro $(0,0,0)$.

- Colegio. Intentando que el usuario asocie este símbolo con la señal de tráfico que todos conocemos e indica paso de escolares, utilizaremos los colores blanco (255, $255,255)$, negro $(0,0,0)$ y rojo $(255,0,0)$ para el símbolo que nos indicará dónde hay un colegio.

- Museo. Los colores elegidos serán, para que sea fácil su asociación con el suelo de equipamiento cultural, $(250,255,100)$, blanco y negro.

- Parroquia. De la misma forma que en el caso anterior, utilizaremos, además del negro $(0,0,0)$, el color utilizado para el suelo de equipamiento religioso $(178,178,178)$.

- Polideportivo. En este caso utilizaremos un símbolo muy evocador, que será de fácil distinción por cualquier usuario, como serán los aros olímpicos, así que cada uno tendrá el color que tiene tradicionalmente.

- Estación de ferrocarril. Como generalmente estamos acostumbrados a ver la simbología de los ferrocarriles con color rojo $(255,0,0)$, utilizaremos este color para el símbolo que lo indique.

- Biblioteca. Puesto que se trata de equipamiento cultural, utilizaremos el color correspondiente del uso del suelo cultural $(250,255,100)$.

- Teatro. También un edificio cultural, así que también le pondremos el mismo color $(250,255,100)$.

- Parque. Aunque no se trate de un edificio, vamos a incluirlo en este apartado por creer que en general los parques son, al igual que los edificios singulares, lugares emblemáticos de la población. Para el símbolo de parque se utilizará el mismo color que para la zona verde, ya que generalmente parques y zonas verdes suelen coincidir, este color es $(100,200,50)$. 


\subsubsection{Elección de la simbología}

- Ayuntamiento. Se trata de un edificio oficial al que no hay asociada una simbología específica, por lo tanto el símbolo creado para su representación será un edificio conteniendo una letra A.

- Colegio. Como hemos dicho anteriormente, vamos a intentar evocar la señal de tráfico que todos conocemos e indica paso de escolares, por esto, utilizaremos un dibujo parecido para la simbología a aplicar para el colegio.

- Museo. El símbolo diseñado para representar el museo es un edificio que recuerda un museo.

- Parroquia. Se ha intentado que el símbolo creado para la parroquia sea lo más evocador posible, intentando que el usuario llegue a la conclusión, al primer vistazo, de que se trata de un edificio religioso.

- Polideportivo. En este caso, como ya se ha comentado, se utilizarán los aros olímpicos.

- Estación de ferrocarril. No es nada complicada la elección de este símbolo, ya que se ha pensado que lo más conveniente es utilizar el mismo símbolo que se utiliza generalmente para indicar las estaciones de ferrocarril.

- Biblioteca. En este caso se ha creído convenirte utilizar un libro, creyendo que es lo suficientemente alusivo al edificio que se intenta representar.

- Teatro. También intentando que el usuario perciba claramente de qué edificio se trata, se utilizarán las tradicionales máscaras que se vienen empleando para indicar cualquier cosa relacionada con el teatro en la vida cotidiana.

- Parque. Para el parque se ha elegido un símbolo que también nos indique claramente de qué se trata, por esto se ha elegido un elemento que no falta en ningún parque, e tobogán, para representarlo.

\subsubsection{Elección del grosor y tipo de línea}

Los grosores de todos los símbolos serán $0,1 \mathrm{~mm}$., el mínimo que permita distinguir los símbolos, sin restarles nitidez.

\subsubsection{Servicios}

En este grupo introduciremos aquellos edificios en los cuales se desarrollan actividades que prestan un servicio a los ciudadanos. Al igual que ya hemos hecho con los edificios singulares, expondremos a continuación los criterios seguidos para la elección del color, simbología, y grosor y tipo de línea.

\subsubsection{Estudio del color}

De la misma forma que ya hicimos con los edificios singulares, los símbolos estarán incluidos en un cuadrado negro $(0,0,0)$, para que sea mucho más fácil su identificación en el plano. Vemos qué criterio se ha seguido para la elección del color elemento a elemento. 
- Guardia Civil. Los colores que tradicionalmente han representado a este cuerpo son el negro $(0,0,0)$ y el verde $(65,126,0)$, así que serán los elegidos para la simbología correspondiente.

- Policía Local. Dado que la policía suele vestir de azul, y tradicionalmente es el azul el color que más se asocia con ella, utilizaremos el azul $(0,115,255)$ para el símbolo de policía local.

- Centro de salud. En este caso no puede haber ninguna duda, porque todo el mundo asocia la cruz roja con la salud, así que el símbolo elegido será simplemente una cruz roja, por lo que los colores serán blanco $(255,255,255)$ y rojo $(255,0,0)$.

- Farmacia. Estamos acostumbrados cuando buscamos una farmacia a buscar una cruz verde, así que elegiremos este símbolo para las farmacias por creer que resulta ser el más conveniente. Los colores serán entonces blanco $(255,255,255)$ y verde $(0,255$, $0)$

- Correos. Todos asociamos el servicio de correos con el color amarillo, los buzones, los carritos de los carteros, no hay otra elección posible, el color a utilizar será el amarillo $(255,255,0)$.

- Centro social. Como venimos haciendo con el resto de la simbología urbana, utilizaremos para este símbolo el mismo color que utilizamos para el equipamiento social $(152,255,145)$.

- Banco. Se ha utilizado una combinación de los colores blanco y negro.

- Mercado. Se ha utilizado una combinación de los colores blanco y negro.

\subsubsection{Elección de la simbología}

- Guardia Civil. Aunque a los más jóvenes no les resulte demasiado familiar, pensamos que todavía para la mayoría de la gente el tricornio hace pensar el la Guardia Civil, así que utilizaremos este símbolo para indicar su ubicación.

- Policía Local. No hemos encontrado ningún elemento que podamos claramente relacionar con la policía local, por esto crearemos un símbolo arbitrario con las iniciales PL.

- Centro de salud. Ya hemos comentado en el apartado anterior que el símbolo elegido será la cruz roja.

- Farmacia. También se ha comentado anteriormente que elegiremos una cruz verde para reseñar la situación de las farmacias.

- Correos. Siguiendo el mismo criterio utilizado hasta ahora, vamos a crear un símbolo que se parezca lo más posible al utilizado por el servicio de correos, para que se pueda distinguir con facilidad.

- Centro social. La simbología creada es un edificio con las siglas CS en su interior, ya que no se ha encontrado ningún otro símbolo que haga referencia directa a este elemento.

- Banco. De manera similar al caso anterior, se ha creado un símbolo que es el mismo edificio, pero esta vez con un símbolo de $€$ en su interior, haciendo alusión a la función del banco, que es trabajar con dinero.

- Mercado. Exactamente el mismo criterio se ha seguido en esta ocasión, pero dentro del edificio se ha colocado la letra M, en alusión al mercado. 


\subsubsection{Elección del grosor y tipo de línea}

Los grosores de todos los símbolos serán el mínimo que permita distinguir los símbolos, sin restarles nitidez.

\subsubsection{Mobiliario urbano}

Se trata de elementos generalmente demasiado pequeños para que tengan representación en el mapa, así que en este caso se hace necesario el uso de símbolos, vamos a estudiar, de la misma forma que venimos haciendo, los símbolos utilizados uno a uno.

\subsubsection{Estudio del color}

- Parada de autobús. Al no haber un color definitorio del servicio de autobuses, estos colores dependen más bien de la empresa responsable, utilizaremos blanco $(255,255$, 255) y negro $(0,0,0)$.

- Teléfono. Procederemos igual que con las paradas de autobús.

- Contenedor R.S.U.. Según suele ser en la mayoría de los municipios, utilizaremos un verde oscuro $(65,126,0)$ para los contenedores de residuos en general.

- Contenedor vidrio. De la misma forma, los contenedores de vidrio suelen ser verde claro, así que utilizaremos el verde $(0,255,0)$ para la creación de este símbolo.

- Contenedor papel. Usaremos según es usual el color azul (0, 0, 255).

- Contenedor plástico. En este caso el color utilizado será el amarillo (255, 255, 0).

- Papelera. Como también depende del estilo de cada municipio, no hay un color definitorio de las papeleras, así que utilizaremos blanco $(255,255,255)$ y negro $(0,0$, $0)$.

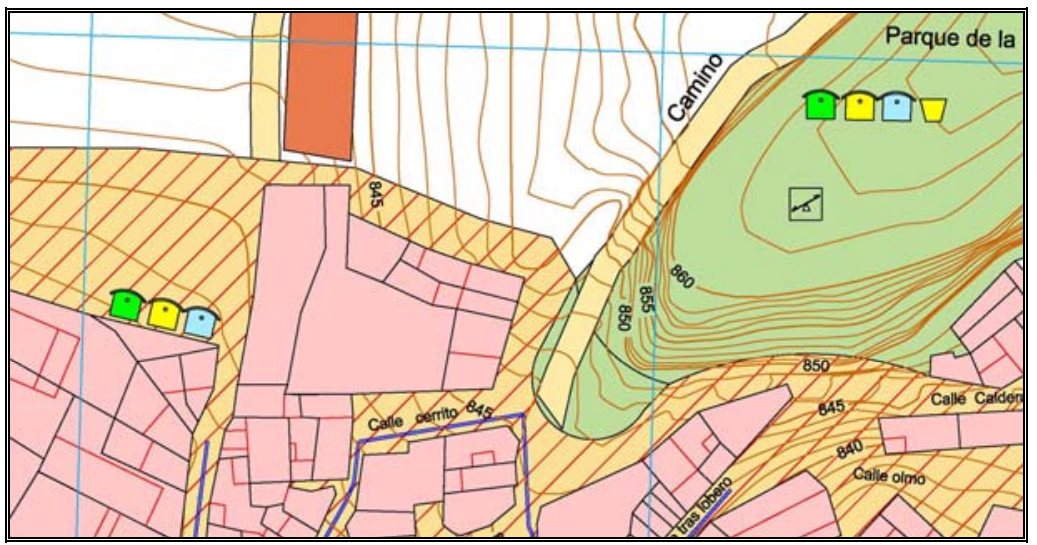

Figura 3.52 Representación del mobiliario urbano 


\subsubsection{Elección de la simbología}

- Parada de autobús. No hemos encontrado un símbolo que intuitivamente nos recuerde a una parada de autobús, así que utilizaremos un símbolo simple, un círculo en el que pondremos la palabra BUS.

- Teléfono. Aunque actualmente ya no es así, se ha intentado crear un símbolo que recuerde a lo que tradicionalmente ha sido un teléfono.

- Contenedor R.S.U.. Se ha intentado que el símbolo creado se parezca lo más posible a un contenedor de los que se utilizan en la mayoría de los municipios.

- Contenedor vidrio. Se usará el mismo símbolo que en el caso anterior, variará el color.

- Contenedor papel. Se usará el mismo símbolo que en el caso anterior, variará el color.

- Contenedor plástico. Se usará el mismo símbolo que en el caso anterior, variará el color.

- Papelera. Utilizaremos, como venimos haciendo, un símbolo que recuerde a una papelera tradicional.

\subsubsection{Elección del grosor y tipo de línea}

Los grosores de todos los símbolos serán 0,1 mm., el mínimo que permita distinguir los símbolos, sin restarles nitidez.

\subsection{Tamaño de letra. Jerarquías}

Cuando hablamos del tamaño de letra, es muy importante establecer una buena jerarquía visual ${ }^{4}$. Debe resultar muy fácil al usuario reconocer cuáles son los topónimos correspondientes a los elementos más importantes.

El color utilizado será en general el negro. Y el tipo de letra utilizado será en general Avant Garde, se trata de una elección arbitraria que responde únicamente a criterios estéticos, manteniendo por supuesto siempre una buena legibilidad.

Se harán dos distinciones, según es usual en la cartografía consultada. Estas serán:

- Se utilizará el el tipo de letra Garamond, el color azul y el tipo cursiva para la hidrografía.

- Se utilizará el tipo de letra Avant Garde para las edificaciones aisladas.

Con todo esto nos queda estudiar el tamaño elegido para la denominación de cada elemento; vamos a adjuntar una tabla con todas las tipografía utilizadas para aportar claridad a la explicación dada.

\begin{tabular}{|l|l|l|l|}
\hline \multicolumn{1}{|c|}{ ELEMENTO } & \multicolumn{1}{c|}{ FUENTE } & \multicolumn{1}{c|}{ TAMAÑO } & \multicolumn{1}{c|}{ COLOR } \\
\hline Río permanente & Garamond & $3,4 \mathrm{~mm}$. & Azul $(0,0,255)$ \\
\hline Río intermitente & Garamond & $2,2 \mathrm{~mm}$. & Azul $(0,0,255)$ \\
\hline Manantial o fuente & AvantGarde & $2,2 \mathrm{~mm}$. & Azul $(0,0,255)$ \\
\hline
\end{tabular}

${ }^{4}$ Palomar Vázquez, J.M., "Desarrollo de estrategias, métodos y herramientas para la automatización y mejora de los procesos de producción cartográfica. Aplicación a la generación de mapas excursionistas”(Tesis Doctoral), 2003. 


\begin{tabular}{|l|l|l|l|}
\hline Autovía o autopista & AvantGarde & $2,5 \mathrm{~mm}$. & Negro \\
\hline Carretera nacional & AvantGarde & $2,2 \mathrm{~mm}$. & Negro \\
\hline Carretera autonómica $1^{\circ}$ orden & AvantGarde & $2,0 \mathrm{~mm}$. & Negro \\
\hline Carretera autonómica $2^{\circ}$ orden & AvantGarde & $2,0 \mathrm{~mm}$. & Negro \\
\hline Pista o camino & AvantGarde & $1,8 \mathrm{~mm}$. & Negro \\
\hline Punto kilométrico & Garamond & $1,8 \mathrm{~mm}$. & Negro \\
\hline Edificación singular & AvantGarde & $1,5 \mathrm{~mm}$. & Negro \\
\hline Vértice geodésico & AvantGarde & $1,5 \mathrm{~mm}$. & Negro \\
\hline Paraje & Garamond & $2,1 \mathrm{~mm}$. & Negro \\
\hline Acotación curva nivel & Garamond & $1,5 \mathrm{~mm}$. & Negro \\
\hline Punto acotado & Garamond & $1,5 \mathrm{~mm}$. & Negro \\
\hline
\end{tabular}

\subsection{Evaluación de la simbología}

Una vez elaborada la propuesta de simbología, deberemos evaluar los resultados para comprobar que realmente se ajustan a nuestras expectativas, esta evaluación la podremos hacer contestando a una serie de preguntas, como pueden ser $^{5}$ :

- Ofrece el mapa resultado una primera impresión favorable

- Es adecuada la escala del mapa para la representación de los datos temáticos

- Destaca la información temática de la cartografía base

- Tiene la simbología la definición suficiente

- Es correcto el diseño de la leyenda

- Se han aplicado correctamente las asociaciones subjetivas y convencionales

- Aparecen en el mapa "interacciones del color" como el contraste simultáneo, la inducción y el contraste sucesivo

- Se perciben claramente las diferencias de tonos

- Existen zonas coloreadas que por su gran tamaño tienen una saturación aparente exagerada

- Los tonos para mostrar diferencias de grupo son los adecuados

- Los tonos para mostrar diferencias dentro de un mismo grupo son los adecuados

- Los colores son los adecuados

- Existe un número de tonos excesivo

- Se han aplicado colores más saturados para áreas menores y viceversa

- La información que debe aportar el mapa que da clara tras un estudio somero del mismo

5 Pérez, R. Propuesta de Normalización para la representación cartográfica en Internet. Tesis Doctoral. Madrid, 2003. 



\section{PROPUESTA DE NORMALIZACIÓN}

\begin{tabular}{|l|l|}
\hline ELEMENTO & SIMBOLOGÍA \\
\hline Río & \\
\hline Cauce de río & \\
\hline Barranco & \\
\hline Acequia & \\
\hline Estanque & \\
\hline
\end{tabular}




\begin{tabular}{|l|l|}
\hline Piscina & \\
\hline Depósito de abastecimiento agua & \\
\hline Pozo & \\
\hline Manantial & \\
\hline Fuente & \\
\hline Curretera nacional & \\
\hline Curva de nivel normal & \\
\hline
\end{tabular}




\begin{tabular}{|c|c|}
\hline Autonómica $2^{\circ}$ orden & \\
\hline Pista & \\
\hline Camino & \\
\hline Límite municipal & +- \\
\hline Límite provincial & \begin{tabular}{l|l|l}
-1 & - \\
\end{tabular} \\
\hline Edificación urbana & \\
\hline Edificación aislada & \\
\hline Nave agroindustrial & \\
\hline Edificio singular & \\
\hline Red alta tensión & 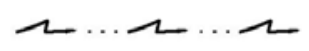 \\
\hline Red media tensión & $-0--0--0--$ \\
\hline
\end{tabular}




\begin{tabular}{|l|l|}
\hline Red baja tensión & \\
\hline Microreservas & \\
\hline Espacios de especial relevancia & \\
\hline Riesgos geológicos & \\
\hline Almendro & \\
\hline Almendro - Viñedo & \\
\hline Almendro - Barbecho Blanco & \\
\hline Olivar - Almendro & \\
\hline
\end{tabular}




\begin{tabular}{|l|c|}
\hline Barbecho Semillado & \\
\hline Barbecho Semillado - Almendro & \\
\hline Barbecho Semillado - Viña & \\
\hline Barbecho Semillado - Viña - Almendro & \\
\hline Pastizal & \\
\hline Pino Carrasco & \\
\hline Pastizal - Matorral & \\
\hline & \\
\hline
\end{tabular}




\begin{tabular}{|l|c|}
\hline Pino Carrasco - Latizal & \\
\hline Pino Carrasco - Almendro & \\
\hline Pino Carrasco - Quercus & \\
\hline Pino Laricio - Negral - Fustal & \\
\hline Viña - Almendro - Barbecho Semillado & \\
\hline Priña - Almendro & \\
\hline Prados Regados - Fustal & \\
\hline
\end{tabular}




\begin{tabular}{|l|l|}
\hline Viña - Almendro - Barbecho Blanco & \\
\hline Viña transformándose en Regadío & \\
\hline Viña transformándose en Olivar & \\
\hline Viña transformándose en Olivar y Alm. & \\
\hline Eluvial Barbecho Semillado - Viña & \\
\hline Lncina Chaparra - Carrasca - Pino Car. & \\
\hline Sabinar Albar & \\
\hline
\end{tabular}




\begin{tabular}{|l|c|}
\hline Cultivos Herbáceos & \\
\hline Huerta & \\
\hline Huerta - Matorral - Viñedo & \\
\hline Suelo Urbano & \\
\hline Suelo Urbanizable & \\
\hline S. no Urbanizable Viales & \\
\hline S. no Urbanizable Dotacional & \\
\hline S. no Urbanizable Protegido Forestal & \\
\hline Suelo no Urbanizable Común & \\
\hline
\end{tabular}




\begin{tabular}{|l|l|}
\hline S. no Urbanizable Protegido Paisaje & \\
\hline S. no Urbanizable Protegido Acuíferos & \\
\hline Zona de paisaje negativo & \\
\hline Zona de paisaje positivo & \\
\hline Vías Pecuarias & \\
\hline Vertederos sólidos urbanos & \\
\hline Cortafuegos & \\
\hline
\end{tabular}




\begin{tabular}{|l|l|}
\hline Urbano residencial & \\
\hline Viales & \\
\hline Zona verde & \\
\hline Equipamiento deportivo & \\
\hline Equipamiento docente & \\
\hline Equido $65-67 \mathrm{~dB}$ & \\
\hline Equipamiento cultural & \\
\hline & \\
\hline & \\
\hline
\end{tabular}




\begin{tabular}{|l|l|}
\hline Conducción gas natural & \\
\hline Conducción agua potable & \\
\hline Conducción saneamiento & \\
\hline Ayuntamiento & \\
\hline Colegio & \\
\hline Purroquia & \\
\hline
\end{tabular}




\begin{tabular}{|l|c|}
\hline Parque & \\
\hline Guardia Civil & \\
\hline Policía Local & \\
\hline Centro de salud & \\
\hline Farmacia & \\
\hline Contenedor R.S.U. & \\
\hline Contro social & \\
\hline
\end{tabular}




\begin{tabular}{|l|l|}
\hline Contenedor vidrio & \\
\hline Contenedor papel & \\
\hline Contenedor plástico & \\
\hline Papelera & \\
\hline Cantera abandonada & \\
\hline Eranjad paisajística & \\
\hline Granja avícola & \\
\hline
\end{tabular}




\begin{tabular}{|l|l|}
\hline Subunidad paisajística & \\
\hline Paisaje de cultivos de regadío & \\
\hline Paisaje de cultivos de secano & \\
\hline Paisaje forestal arbolado & \\
\hline Paisaje forestal monte bajo - matorral & \\
\hline Paisaje urbano & \\
\hline
\end{tabular}




\section{APLICACIÓN DE ESTA NORMALIZACIÓN AL MUNICIPIO DE TITAGUAS}

Como ya se explicó en el primer punto de este trabajo, donde se definieron los objetivos del mismo, una vez realizada la propuesta de normalización se aplicará al municipio de Titaguas. Esta tarea está basada en un proyecto para la integración del citado municipio en la Agenda 21, en colaboración con la Diputación de Valencia. El citado proyecto se introdujo además en un Sistema de Información Geográfica (SIG), que debería ser el siguiente paso a dar con los resultados de esta tesis.

\subsection{Realización de la cartografía en formato digital}

La primera tarea a abordar para al aplicación de la normalización propuesta a la cartografía del municipio de Titaguas consistió obviamente en la elaboración de una correcta cartografía base a partir de los datos con que contábamos.

Parte de estos datos se nos proporcionaron en formato digital, pero hubo que llevar a cabo también un proceso de digitalización con parte de aquellos, como fue por ejemplo la información referente a los cultivos, tomada del Mapa de Cultivos y Aprovechamientos de España del Ministerio de Agricultura Pesca y Alimentación.

Una vez contamos con toda la cartografía disponible en formato digital, procedimos a la depuración de la misma y su integración en un único archivo con el motivo de evitar la duplicidad de información, tanto para conseguir una total coherencia del resultado como para disminuir el volumen de datos a tratar. 
Para la depuración de los datos hubo de tenerse en cuenta la escala de representación a la que se iban a generar los mapas y planos finales en formato papel. El proceso anteriormente expuesto dio lugar a dos archivos, uno con la cartografía de todo el término municipal, que como ya se comentó en el apartado correspondiente estará correctamente tratada para la producción de mapas a escala 1:20.000 según se recoge en la Ley de Ordenación del Territorio y Conservación del Paisaje de la Comunidad Valenciana; y un segundo archivo con la cartografía urbana preparado para la generación de planos cuya representación en formato papel se llevará a cabo a escala 1:1.500.

Una vez contábamos con los archivos (en formato dgn de Microstation) que contenían toda la información a tratar, se llevó a cabo la clasificación de los datos y su disposición por niveles con el objeto de facilitar el tratamiento de aquellos.

A partir de los archivos depurados y ordenados se procedió a la aplicación de la normalización adoptada en la tesis y que se explica en el punto anterior.

\subsection{Cartografía en formato papel}

Aunque todo el tratamiento de la cartografía se realiza en formato digital, hay que tener en cuenta que la tecnología necesaria para utilizar la información únicamente en formato digital no está disponible para todos los usuarios, por lo que será preceptivo generar planos y mapas en formato papel.

Como se ha comentado en el apartado anterior, ya se tuvo en cuenta la escala a la que se iba a general la cartografía a la hora de preparar los datos, así que llegados a este punto la tarea se simplifica enormemente.

La siguiente decisión a tomar fue el número de mapas o planos a generar, teniendo en cuenta que se generarían la mínima cantidad necesaria para poder representar toda la información sin que hubiese lugar a confusión entre los datos.

En nuestro caso, se consideró que en un único plano se podía representar toda la información urbana. Sin embargo, se consideró necesaria la utilización de tres mapas a escala 1:20.000 para poder incluir todos los datos territoriales sin que hubiese lugar para la confusión de los mismos. Esto se debió sobre todo a la cantidad de datos de tipo espacial, que no es posible solapar en un mismo mapa. 


\section{LÍNEAS FUTURAS}

Con la realización de esta tesis se han sentado las bases para la consecución de una normalización cartográfica en materia de Ordenación del Territorio y Protección del Paisaje, pero son las administraciones públicas las que deben regular dicha normalización.

La propuesta aportada ha sido realizada pensando en la generación de cartografía en formato papel y a las escalas estudiadas; lo deseable sería que esta normalización pudiese hacerse extensiva al uso de cartografía digital, así como a la integración de la misma en Sistemas de Información Geográfica, con el consiguiente cambio de escalas requerido. 



\section{CARTOGRAFÍA RESULTANTE}



Cartografía urbana

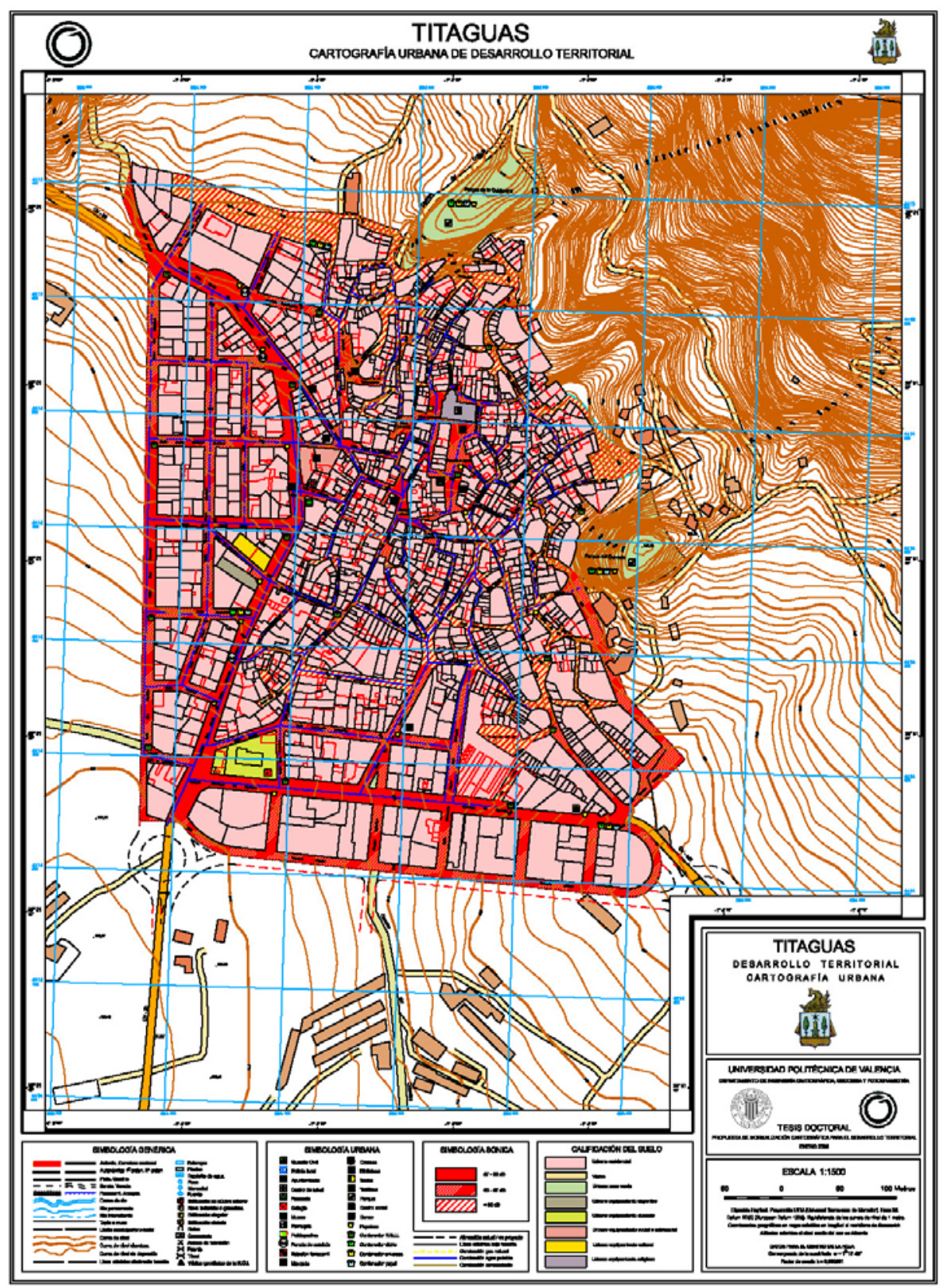



Clasificación del suelo y Medio Ambiente

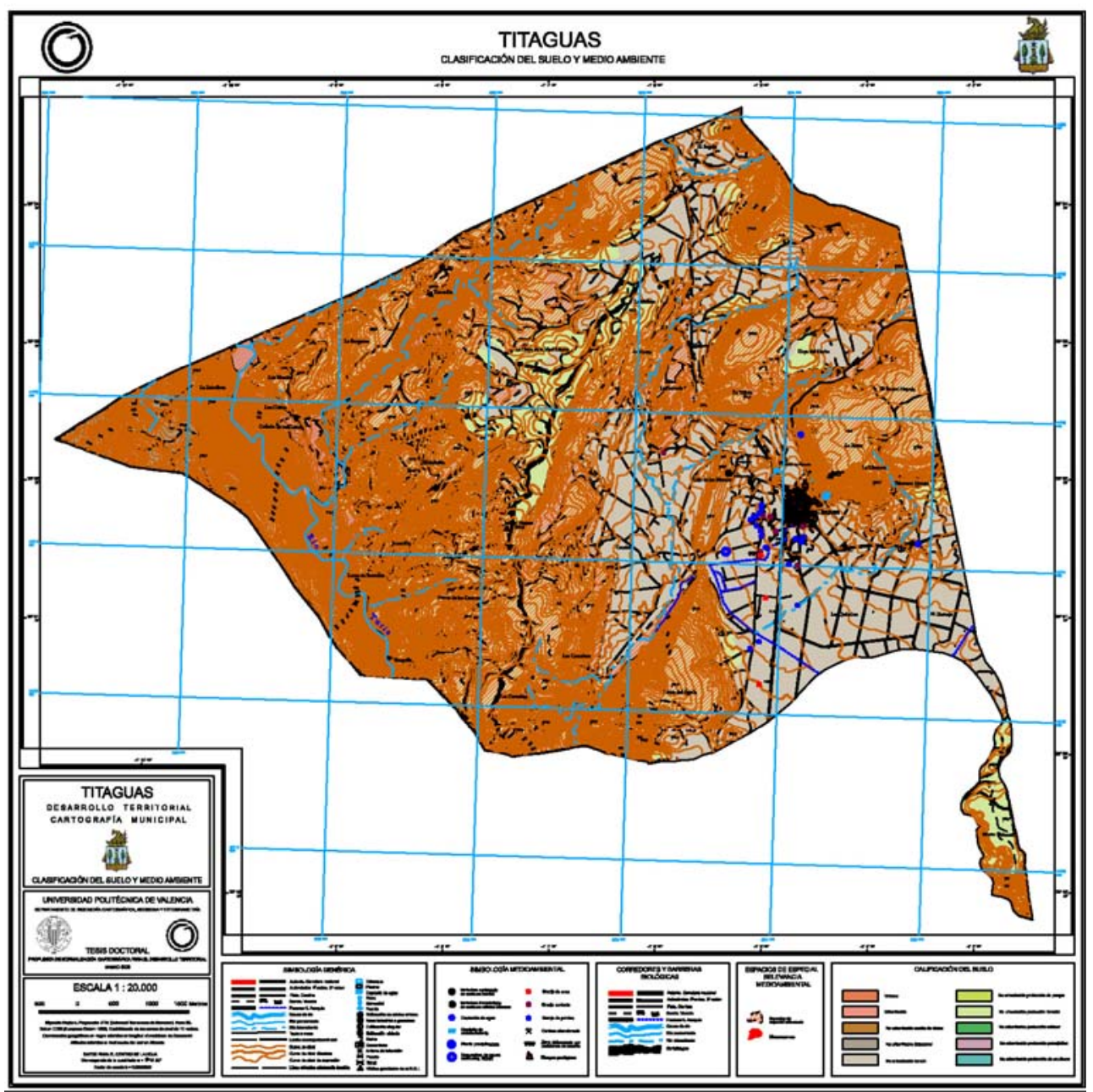



Paisaje

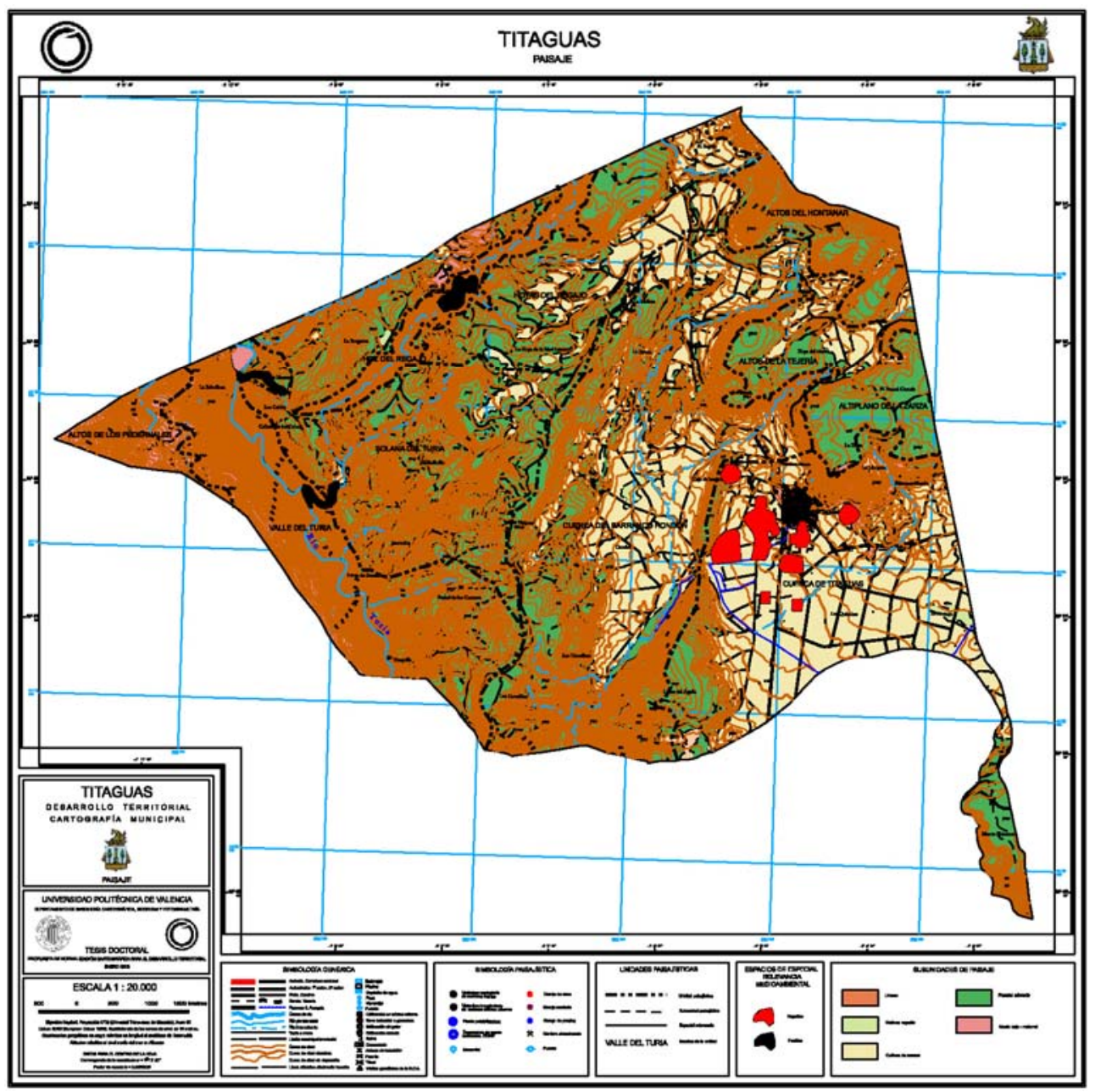



Vegetación

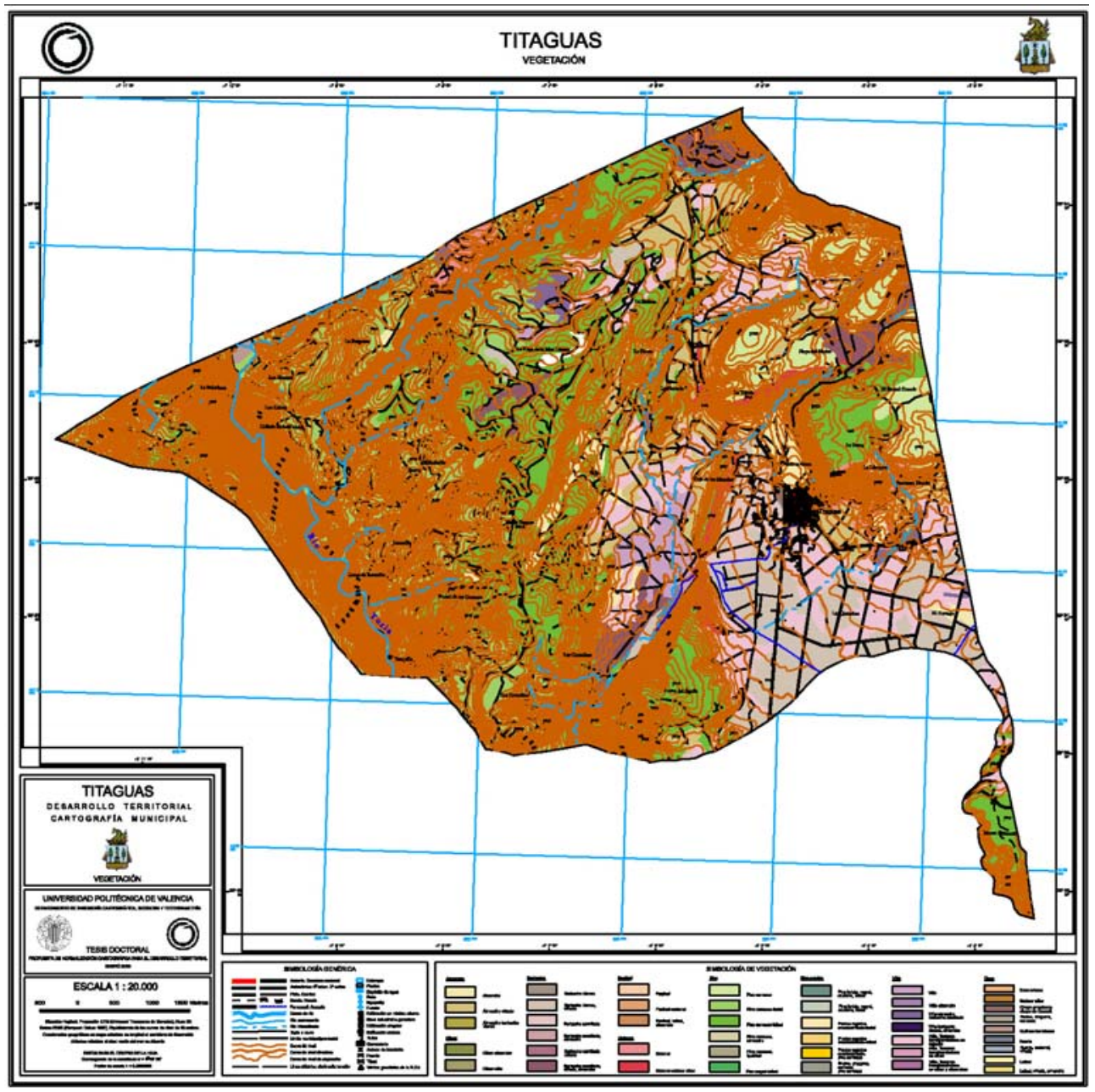





\section{BIBLIOGRAFÍA}

\section{PUBLICACIONES}

AYUGA TÉLLEZ, F. et al. (2001). Gestión sostenible de paisajes rurales.

BENLLIURE MORENO, J.M. (2000). Grandes Retos para la ordenación del litoral valenciano.

BERTIN, J. (1967). Sémmiologie Graphique. Gauthier-Villars. París.

BERTIN, J. (1977). La graphique et le traitement graphique de l'information. Flammarion. París.

BUREL, F. et al. (2002). Ecología del Paisaje.

CANCER POMAR, L. (1999). La degradación y la protección del paisaje. Cátedra. Madrid.

CONSEJO ECONÓMICO Y SOCIAL. (2002). Informe sobre el Documento de consulta para la Estrategia Española de Desarrollo Sostenible. Consejo Económico y Social. Madrid.

DE BOLÓS, M. (1992). Manual de ciencia del paisaje. Masson. Barcelona. 
DENT, D.B. (1990). Thematic map design. Wm C. Brown Publishers. Duburque (EE.UU.)

DIPUTACIÓ PROVINCIAL DE VALÈNCIA et al. (1986), Mapa Geocientífico de la provincia de Valencia.

ESPAÑOL ECHÁNIZ, I. (1998). Las obras públicas en el paisaje. Ministerio de Fomento. Madrid.

Estrategia Española de Desarrollo Sostenible.

FUNDACIÓN ALFONSO MARTÍN ESCUDERO (2001). Gestión sostenible de paisajes rurales. Madrid.

GAJA I DÍAZ, F. (2005). Revolución Informacional, Crisis Ecológica y Urbanismo. Editorial U.P.V. Valencia.

GARCÍA CAMARERO, Julio. (2001). Programa de acción contra la desertificación. Revista ecosistemas. Año X, No3.

GENERALITAT VALENCIANA (2000). Modelos Territoriales sostenibles en espacios litorales mediterráneos. Valencia.

GÓMEZ, D. (1994). Ordenación del Territorio. Agrícola Española. Madrid.

GONZÁLEZ DE VALLEJO, L. I. (2002). Ingeniería Geológica. Pearson educación. Madrid.

HARTSHORNE, R.(2003). The Nature of Geography.

HIGUERAS, A. (2003). Teoría y método de la Geografía. Prensas Universitarias de Zaragoza. Zaragoza.

MACEACHREN et al (1993). Geographic visualization. IEEE Computer Society. Washington D.C. USA.

MARTÍN DÍAZ, J. et al. (2003). Agenda Local 21. ¿Qué es? ¿Cómo se hace?. Fundación de iniciativas locales. Madrid.

MARTÍN LÓPEZ, J. (1999). Cartografía. C.O.I.T.T. Madrid.

MARTÍNEZ-ÁLVAREZ, J. A. (1989). Cartografía geológica. Paraninfo. Madrid.

ORTEGA CANTERO, N. (2002). Estudios sobre historia del paisaje español. Catarata. Madrid 
ORTEGA CANTERO, N. (2004). Naturaleza y cultura del paisaje. UAM. Madrid

PALOMAR VÁZQUEZ, J.M., (2003). Desarrollo de estrategias, métodos y herramientas para la automatización y mejora de los procesos de producción cartográfica. Aplicación a la generación de mapas excursionistas. Tesis Doctoral. Valencia.

PEÑA MONNÉ, J. L. (1997). Cartografía geomorfológico básica y aplicada. Geoforma ediciones. Logroño.

PÉREZ, R. (2003). Propuesta de normalización para la representación cartográfica en Internet. Tesis Doctoral. Madrid.

PUJADAS, R. et al. (1998). Ordenación y planificación territorial. Síntesis. Madrid.

ROBINSON, A. et al. (1987). Elementos de Cartografía. Omega. Barcelona

VÁZQUEZ MAURE, F. (1995). Lectura de mapas. Fundación General de la U.P.M. Madrid. 


\section{PÁGINAS WEB}

http://eris.unalmed.edu.co/ jiramirez/ $\quad$ 04-2005

http://nivel.euitto.upm.es/ mab $\quad$ 04-2005

http://nivel.topografia.upm.es/ mab $\quad$ 01-2006

http://noticias.juridicas.com/base datos/Admin/cnudesierto.html 03-2005

$\begin{array}{ll}\text { http://www.artesvisuales.com } & \text { 07-2007 }\end{array}$

http://www.catpaisatge.net/cat/index.php $11-2007$

http://www.cma.gva.es $\quad$ 03-2005

$\begin{array}{ll}\text { http://www.desarrolloweb.com } & \text { 07-2007 }\end{array}$

$\begin{array}{ll}\text { http://www.femp.es/life/ } & \text { 02-2005 }\end{array}$

http://www.fundaciocaixacatalunya.org/osocial/redirect.html?link=http 11-2007

://www.fundaciocaixacatalunya.org/CDA/ObraSocial/Home/0,3423,1

$\underline{\mathrm{x} 1 \mathrm{y}, 00 . \mathrm{html}}$

http://www.fundacionglobalnature.org/proyectos/gestion_agroambient

al/life erosion.htm

http://www.gm-unccd.org/Spanish/Docs/text.htm

03-2005

http://www.ingurumena.ejgv.euskadi.net

03-2006

http://www.juntadeandalucia.es/medioambiente/clima atmosfera/infge

$11-2004$

n/sicam1 2.html\#01.

http://www.landscape-forum-ireland.com

$11-2007$

http://www.larioja.org/ma/prevencion ambiental/diagnostico/introdu

$11-2004$

ccion.htm

http://www.medioambiente.gov.ar/acuerdos/convenciones/Unccd/cda

03-2005

ge21.htm

http://www.mma.es/conserv nat/acciones/desertificacion/html/lucde

me.htm

03-2005

http://www.oecd.org.

$11-2004$

http://www.paysage.qc.ca

$11-2007$

http://www.ramsar.org/key_ccd_moc_s.htm

03-2005

http://www.ucm.es/info/ec/jec7/pdf/com1-6.pdf.

11-2004

http://www.un.org/esa/sustdev/documents/agenda21/spanish/agenda

03-2005

21spchapter12.htm

http://www.unccd.int/cop/officialdocs/cric3/pdf/inf4spa.pdf

03-2005 

